\title{
Natural products from Myxococcales and Bacillales \& Description of a new myxobacterial taxon
}

\section{Dissertation}

\author{
for the award of the degree \\ "Doctor of Philosophy (Ph.D.)" \\ Division of Mathematics and Natural Sciences \\ of the Georg-August-Universität Göttingen
}

\begin{abstract}
within the Doctoral program Biology
of the Georg-August University School of Science (GAUSS)
\end{abstract}

submitted by

Sakshi Sood

born in

Jubbal, India

Göttingen 2014 


\section{Thesis committee}

Prof. Dr. Rolf Daniel, Department of Genomic and Applied Microbiology and Genomics Laboratory, Institute of Microbiology and Genetics

Prof. Dr. Rolf Müller, Department of Microbial Drugs and Microbial Natural Products, Helmholtz Centre for Infection Research and Helmholtz Institute for Pharmaceutical Research Saarland

\section{Members of the Examination Board}

Reviewer

Prof. Dr. Rolf Daniel, Department of Genomic and Applied Microbiology and Genomics Laboratory, Institute of Microbiology and Genetics

Second Reviewer

Prof. Dr. Rolf Müller, Department of Microbial Drugs and Microbial Natural Products, Helmholtz Centre for Infection Research and Helmholtz Institute for Pharmaceutical Research Saarland

\section{Further members of the Examination Board:}

Prof. Dr. Stefanie Pöggeler, Department of Genetics of Eukaryotic Microorganisms, Institute of Microbiology and Genetics

PD Dr. Michael Hoppert, Department of General Microbiology, Institute of Microbiology and Genetics

PD Dr. Wilfried Kramer, Department of Molecular Genetics, Institute of Microbiology and Genetics

Jun.-Prof. Dr. Kai Heimel, Department of General Microbiology, Institute of Microbiology and Genetics

Date of Oral Examination: March 14, 2014

Time: 12:30-14:00 


\section{List of publications}

\section{Journal publications}

Paenilarvins, iturin family lipopeptides from the honey bee pathogen Paenibacillus larvae

Sakshi Sood, Heinrich Steinmetz, Kathrin I. Mohr, Marc Stadler, Marvin Djukic, Rolf Daniel and Rolf Müller. (Manuscript in preparation for resubmission)

Aggregicoccus edonensis gen. nov., sp. nov., an unusually aggregating myxobacterium isolated from a soil sample

Sakshi Sood, Ram Prasad Awal, Joachim Wink, Kathrin I. Mohr, Manfred Rohde, Marc Stadler, Peter Kämpfer, Stefanie P. Glaeser, Peter Schumann, Ronald Garcia and Rolf Müller.

Submitted to International Journal of Systematics and Evolutionary Microbiology on December $13^{\text {th }}, 2013$

Revised on February $5^{\text {th }}, 2014$

Pyrronazols, metabolites from the myxobacteria Nannocystis pusilla and $\mathbf{N}$. exedens are unique chlorinated pyrrole-oxazole-pyrones.

Rolf Jansen, Sakshi Sood, Volker Huch, Brigitte Kunze, Marc Stadler and Rolf Müller. Journal of Natural Products, 2014. DOI: 10.1021/np400877r

\section{Poster presentations}

Antimicrobial compounds from Paenibacillus larvae and their role in pathogenesis

Sakshi Sood, Heinrich Steinmetz, Elzbieta Brzuszkiewicz, Kathrin Mohr, Rolf Daniel and Rolf Müller.

VAAM International Workshop on Drug Producing microorganisms, Braunschweig, Germany (2012)

Antimicrobial compounds from Paenibacillus larvae and their role in pathogenesis

Sakshi Sood, Heinrich Steinmetz, Elzbieta Brzuszkiewicz, Kathrin Mohr, Rolf Daniel and Rolf Müller.

Central European Symposium on Antimicrobials and Antimicrobial Resistance, Primosten, Croatia (2012) 


\section{Table of Contents}

\section{Abbreviations IV}

Chapter A Introduction 1

A.1 Natural products 1

A.1.1 Beginning of the era of Wonder Drugs 1

A.1.2 Natural products - much more than just antibiotics 2

A.1.3 Requisite for new natural products in future 3

A.1.4 Microbes as a source of novel natural products 3

A.2. Paenibacillus as a source of natural products 4

A.2.1 Paenibacillus larvae and its secondary metabolite potential 6

A.3 Myxobacteria: a promising source of natural products 8

A.3.1 Taxonomy of myxobacteria 9

A.3.2 Treasure from myxobacterial metabolome 10

A.3.3 Quest for novel myxobacteria and their metabolites 13

A.4 Process of drug development from microbial natural products 15

A.5 Challenges and benefits of microbial drug discovery program 16

A.6 Aim of this thesis 17

References 19

Chapter B Paenilarvins, iturin family lipopeptides from the honey bee Pathogen Paenibacillus larvae $\quad 26$

$\begin{array}{ll}\text { B.1 Abstract } & 27\end{array}$

B.2 Introduction $\quad 27$

B.3 Results and Discussion 29

B.3.1. Bioactivity screening of P. larvae DSM 25719 and DSM $25430 \quad 29$

B.3.2 Structural analysis of paenilarvins 30

B.3.3 Mass spectrometric analysis $\quad 32$

B.3.4 Antimicrobial and cytotoxic activity of paenilarvins 36

B.4 Conclusion $\quad 37$

B.5 Experimental Section $\quad 40$

B.5.1 General Experimental Procedures 40

B.5.2 Bacterial strain and growth conditions 41 
B.5.3 Extraction and isolation of active compounds 41

B.5.4 Assignment of absolute stereochemistry of amino acid residues 42

B.5.5 Structural characteristics of paenilarvins 42

B.5.6 Antimicrobial assay 43

B.5.7 Cytotoxicity assay $\quad 43$

Acknowledgements 44

References $\quad 45$

$\begin{array}{ll}\text { Supplemental information } & 48\end{array}$

Chapter C Aggregicoccus edonensis gen. nov., sp. nov., an unusually aggregating myxobacterium isolated from a soil sample $\quad 69$

$\begin{array}{ll}\text { C.1 Abstract } & 70\end{array}$

$\begin{array}{ll}\text { C.2 Introduction } & 70\end{array}$

C.3 Results and Discussion $\quad 71$

C.4 Description of Aggregicoccus gen. nov. 83

C.5 Description of Aggregicoccus edonensis sp. nov. 84

Acknowledgements $\quad 84$

References $\quad 85$

$\begin{array}{ll}\text { Supplemental information } & 87\end{array}$

Chapter D Pyrronazols, Metabolites from the Myxobacteria Nannocystis pusilla and $\mathbf{N}$. exedens are Unusual Chlorinated PyroneOxazole-Pyrroles $\quad 96$

$\begin{array}{ll}\text { D.1 Abstract } & 97\end{array}$

D.2 Introduction $\quad 97$

D.3 Results and Discussion 98

D.4 Experimental Section $\quad 107$

$\begin{array}{ll}\text { D.4.1 General Experimental Procedures } & 107\end{array}$

D.4.2 Isolation of Pyrronazols A, A2 and B from N. pusilla, strain Ari $7 \quad 107$

D.4.3 Isolation of Pyrronazol C1 and C2 from N. pusilla, strain Na a174 109

D.4.4 X-Ray Structure Determination of Pyrronazol A (1) 109

D.4.5 Structural characteristics of compounds isolated 110

D.4.6 Antimicrobial Testing 111

D.4.7 Cytotoxicity assay 112

Acknowledgements 112 
References 113

$\begin{array}{ll}\text { Supplemental information } & 114\end{array}$

$\begin{array}{ll}\text { Chapter E Discussion } & 127\end{array}$

E.1 Paenilarvins, antifungal peptides from honey bee pathogen, Paenibacillus larvae

E.2 Aggregicoccus edonensis gen. nov., sp. nov., a soil myxobacterium with characteristic aggregation

E.3 Pyrronazols and phenazines from Nannocystis pusilla 132

References

Summary

List of Figures

List of Tables 


\section{Abbreviations}

\begin{tabular}{|c|c|}
\hline$[\mathrm{M}+\mathrm{H}]^{+}$ & Protonated molecular ions \\
\hline$[\mathrm{M}+\mathrm{Na}]^{+}$ & Molecular ions with sodium \\
\hline$[\mathrm{M}-\mathrm{H}]^{+}$ & Deprotonated molecular ions \\
\hline$\left[\mathrm{M}-\mathrm{H}_{2} \mathrm{O}\right]^{+}$ & Dehydrated molecular ions \\
\hline${ }^{13} \mathrm{C} \mathrm{HMQC}$ & Carbon Heteronuclear Multiple Quantum Coherence \\
\hline 1D NMR & One dimensional Nuclear magnetic resonance \\
\hline${ }^{1} \mathrm{H} \mathrm{HMQC}$ & Proton Heteronuclear Multiple Quantum Coherence \\
\hline ACCs & Acetyl-CoA-carboxylase \\
\hline adj. & adjective \\
\hline AFB & American foulbrood \\
\hline Asn & Asparagine \\
\hline BCFAs & Branched chain fatty acids \\
\hline BD & Becton Dickinson \\
\hline BLAST & Basic Local Alignment Search Tool \\
\hline Calcd. & Calculated \\
\hline $\mathrm{CD}_{3} \mathrm{OH}$ & Deuterated methanol \\
\hline $\mathrm{CDCl}_{3}$ & Deuterated Chloroform \\
\hline CoA & Coenzyme A \\
\hline cosy & Correlated Spectroscopy \\
\hline CTAB & Cetyl trimethylammonium bromide \\
\hline $\mathrm{dd} \mathrm{H}_{2} \mathrm{O}$ & Double distilled water \\
\hline DMSO & Dimethyl sulfoxide \\
\hline
\end{tabular}

EDTA Ethylenediaminetetraacetic acid

ERIC Enterobacterial repetitive intergenic consensus

f. sp. Formae specialis

FAs Fatty acids

FASTA DNA and protein sequence alignment software package

fem. feminine

Fig. $\quad$ Figure

FISH Fluorescence in situ hybridization 


\begin{tabular}{|c|c|}
\hline FTMS & Fourier Transform Mass Spectrometry \\
\hline GBF & Gesellschaft für Biotechnologische Forschung \\
\hline GC-MS & Gas chromatography-mass spectrometry \\
\hline gen. nov. & Genus novel \\
\hline Gln & Glutamine \\
\hline Gr. & Greek \\
\hline HEPES & Buffering agent \\
\hline HIV-1 & Human immunodeficiency virus -1 \\
\hline HMBC & Heteronuclear Multiple-Bond Correlation \\
\hline HRESIMS & High Resolution Electron Spray Ionization Mass spectrometry \\
\hline $\mathrm{IC}_{50}$ & Half maximal inhibitory concentration \\
\hline IMG/ER & Integrated Microbial Genomes/Expert Review \\
\hline IR & Infrared \\
\hline Lat. & Latin \\
\hline $\mathrm{LD}_{50}$ & Lethal dose, $50 \%$ \\
\hline $\mathrm{LT}_{100}$ & Lethal time, $100 \%$ \\
\hline$m / z$ & Mass-to-charge ratio \\
\hline MALDI-TOF & Matrix Assisted Laser Desorption Ionization-Time of Flight Mass Spectrometry \\
\hline masc. & masculine \\
\hline Mbp & Megabasepairs \\
\hline $\mathrm{MeOH}$ & Methanol \\
\hline MIC & Minimum inhibitory concentration \\
\hline $\mathrm{mp}$. & Melting point \\
\hline n.i. & No inhibition \\
\hline $\mathrm{NCBI}$ & National Center for Biotechnology Information \\
\hline NCCB & The Netherlands Culture Collection of Bacteria \\
\hline NMR & Nuclear Magnetic Resonance \\
\hline NOE & Nuclear Overhauser effect \\
\hline NOESY & Nuclear Overhauser effect spectroscopy \\
\hline NRP & Nonribosomal peptides \\
\hline NRPSs & Nonribosomal peptide synthetase \\
\hline OAG & O-alkylglycerol \\
\hline PK & Polyketides \\
\hline
\end{tabular}


PKSs Polyketide synthetase

Pro Proline

rDNA Ribosomal DNA

ROESY Rotating-frame nuclear Overhauser effect correlation spectroscopy

RP-HPLC Reverse phase-High pressure liquid chromatography

rpm Revolutions per minute

RP-MPLC Reverse phase-Medium pressure liquid chromatography

rRNA Ribosomal RNA

$R_{\mathrm{t}} \quad$ Retention time

SCFAs Straight chain fatty acids

SDS Sodium dodecyl sulfate

Ser Serine

SHELX Program for structure determination

Si Silica

sp. nov. Species novel

B-Aa B-Amino acid

SSH Suppression subtractive hybridization

Subsp. Subspecies

Tab. Table

TE buffer Tris-EDTA buffer

TLC Thin Layer chromatography

TOCSY Total Correlation Spectroscopy

Tyr Tyrosine

UV/Vis Ultraviolet visible

$\mathrm{v} / \mathrm{v} \quad$ Volume by volume

Ver. Version

vvm Volume gas per reaction volume per minute

$\mathrm{w} / \mathrm{v} \quad$ Weight by volume

XAD Adsorbent resins (Amberlite)

$\varepsilon \quad$ Molar extinction coefficient

$\lambda_{\max } \quad$ Wavelength of the most intense UV/Vis absorption 


\section{Chapter A}

\section{Introduction}

\section{A.1. Natural products}

Chemical compounds isolated from natural origins are called natural products. These compounds may be products of primary or secondary metabolism of diverse living organisms. While primary metabolites like polysaccharides, proteins, nucleic and fatty acids are similar in all biological systems, the chemical and taxonomic diversity of secondary metabolites is enormous. Additionally, the bioactivities of secondary metabolites are versatile in contrast to primary metabolites (Berdy, 2005). Hence, in most cases the term, "natural products" refers to secondary metabolites, small molecules produced by an organism that are not essential for the survival of the organism. Secondary metabolites can include products of overflow metabolism as a result of nutrient limitation, shunt metabolism products during stationary phase, defense mechanism regulator molecules, etc. (Sarker et al., 2005).

Natural products have been used to treat human diseases since the dawn of medicine through the use of traditional medicines predominantly derived from plants. Most early therapeutic drugs such as aspirin, digitoxin, morphine, quinine, and pilocarpine were results of clinical, pharmacological, and chemical studies on these traditional medicines (Butler, 2004).

Natural products have been reestablished as potential source of new medicines in scientific community in recent years. In spite of competition from other drug discovery methods, natural products still continue to provide novel therapeutic molecules. $40 \%$ of the modern drugs in use have been developed from natural products (Sarker et al., 2005).

\section{A.1.1. Beginning of the era of Wonder Drugs}

Antibiotics are compounds of natural, semi-synthetic or synthetic origin which kill or inhibit the growth of microorganisms without significant toxicity to the human or 
animal hosts. The search for antibiotics began in the late 1800s, with the growing acceptance of the 'germ theory of diseases', a theory given by Louis Pasteur which linked microbes to various infectious diseases. As a result, scientists began to devote time to search for drugs that would kill these infection causing agents. The goal of such research was to find compounds that would hamper microbial growth without toxicity to the patient. Sir Alexander Fleming discovered the production of penicillin by Penicillium notatum in 1929 as a substance killing cells of Staphylococcus aureus (Fleming, 1929). However, it was Florey, Chain and Heatley who were later successful in developing a stable form of penicillin which showed significant in vivo activity against many Gram positive bacterial pathogens. With the conjoined efforts between several universities and pharmaceutical companies, the commercial production of first chemotherapeutic agent, penicillin from a microbe became a reality, thus marking the beginning of the golden age of antibiotics i.e. the "wonder drugs" (Demain, 2006). The advent of penicillin was followed by discovery of many new antibiotics from actinomycetes by Selman Waksman. Streptomycin became one of the most famous amongst them. The tide began to change thereafter with the discovery of numerous antimicrobial drugs like cephalosporins, tetracyclines, aminoglycosides, chloramphenicol, macrolides and many others. All these compounds, or derivatives thereof, are still in use as drugs today.

\section{A.1.2. Natural products - much more than just antibiotics}

Natural products are widely recognized in the pharmaceutical industry for their broad structural diversity as well as their wide range of pharmacological activities. The activity may be highly specific or can be unspecific or even toxic in action. Although natural product discovery was mainly devoted to antibiotics in the early phase, but between the seventies and the nineties the exploration and the wide utilization of natural products began e.g. as enzyme inhibitors (lovastatin, pravastatin), immunosuppressants (cyclosporin, sirolimus, tacrolimus and mycophenolic acid), antiparasitic agents (avermectins, narasin, lasalocid) bioherbicides (bialaphos), plant growth regulators (gibberellins), biopesticides (kasugamycin, polyoxins), bioinsecticides (spinosins and nikkomycin) and antitumor agents (doxorubicin, daunorubicin, mitomycin, bleomycin, etc.) (Demain, 2006). However, at subinhibitory concentrations these compounds can exhibit pleiotropic effects at different 
concentrations (Romero et al., 2011). They can act as signaling molecules that regulate gene expression in microbial population, or physiological functions such as motility, sporulation, pigmentation, quorum sensing, biofilm formation and virulence (Romero et al., 2011).

\section{A.1.3. Requisite for new natural products in future}

New and reemerging infectious diseases for which an effective therapy is still unavailable are a matter of concern in modern times. In addition to this, emergence and rise of pathogens resistant to currently used drugs present a great threat to disease management. Development of multidrug resistance is now gathering pace and contributing more substantially to the problem. This conveys an overt message that a continual supply of structurally novel antibiotics with multiple modes of action needs to be part of the antimicrobial armamentarium. A similar situation exists with the need to develop new cancer chemotherapeutic agents. This has given rise to an urgent need for identification of novel molecular scaffolds which can serve as new leads for effective drug development. Natural products can contribute to the process of drug development by their application in unmodified state in as isolated from nature, by providing basic chemical scaffolds that can be used to derive new molecules, or by signifying novel modes of pharmacological action or targets that allow synthesis of entirely novel analogs (Sarker et al., 2005).

With an insight into new molecular targets, it is essential to look and screen for natural molecular diversity against these targets. Products from natural origin can play a crucial role in meeting such demand since a lot of world's biodiversity such as marine environments and extreme environments still remain unexplored (Xiong et al., 2013). Advances in technology can open access to untapped reservoir of genetic and metabolic diversity within the eukaryotic as well as microbial world.

\section{A.1.4. Microbes as a source of novel natural products}

Due to technical improvements in screening programs and chromatographic techniques, biological activity is observed for $\sim 20-25 \%$ of the reported natural products, and $10 \%$ of these active natural products are obtained from microbes (Demain and Sanchez, 2009). The versatility of microbial drugs is gigantic. Microbes keep on producing novel metabolites as they move into the diverse ecological units. 
From the microbes that have been used so far to obtain the biologically active compounds, filamentous actinomycetes and fungi in particular, are the source for the majority of commercially exploited natural products while unicellular bacteria like Bacillus sp. on the other hand, more commonly, but not exclusively, produce peptide antibiotics like gramicidin, surfactin and subtilin.

The fact that the secondary metabolite producing ability is not evenly distributed in the microbial world is indicated by the number of bioactive compounds obtained from fungi (Keller et al., 2005) (61\%) followed by actinobacteria (Watve et al., 2001) (28\%) both of which represent the largest groups of producers (Berdy, 2012). Mycobacteria, Mycoplasmatales and Spirochaetes are occasional producers unlike Bacillus (Fickers, 2012) and Pseudomonas species (Gross and Loper, 2009) which are most frequent producers amongst the prokaryotic, unicellular bacteria. Myxobacteria and Cyanobacteria species seem to join these distinguished organisms as recognizedprolific species producing chemically diverse compounds (Weissmann and Müller, 2010; Singh et al., 2011) However, the bias observed in production of bioactive compounds can also be attributed to the amount of work done on each of these groups of microorganisms over the years.

\section{A.2. Paenibacillus spp. as a source of natural products}

Paenibacillus is a group of endospore forming, aerobic or facultative anaerobic, rod shaped bacteria which belonged to the genus Bacillus until 1993 when Ash et al. reassigned some of the bacilli to a new genus Paenibacillus using a battery of phenotypic characters and a highly specific gene probe based on 16S rRNA. At present a total of 152 species (including subspecies) belong to this genus according to the Leibniz Institute DSMZ (German Collection of Microorganisms and Cell Cultures). Diverse ecological niches like soil, rhizospheres, diseased insect larvae, food, animal faeces etc. have been used as a source for isolation of novel Paenibacillus sp. (Saha et al., 2005).

Paenibacillus species are notable for their ability to produce secondary metabolites such as antibacterial and antifungal compounds, pigments, toxins, along with inductors of competition and symbiosis, enzyme inhibitors, pheromones and promoters of vegetable and animal growth (Li-jing et al., 2011). Production of such 
secondary metabolites can confer special benefits to the producing organisms such as biocontrol of the competitors by scavenging minerals and nutrients and inhabiting the colonization sites in their natural environment (Lorentz et al., 2006). Therefore, a number of Paenibacillus species have been studied as a source of biologically active novel natural compounds and for their potential application as biocontrol agents in the recent past.

The type species of genus Paenibacillus, Paenibacillus polymyxa produces peptide antibiotics like polymyxins, polypeptins, jolipeptin, gavaserin, saltavalin and fusaricidins active against bacteria, actinomycetes and fungi (Raza et al., 2009). Polymyxins (Stansly et al., 1947) were found to be produced by Paenibacillus polymyxa (formerly known as Bacillus polymyxa) and selectively active against Gram negative bacteria by disruption of bacterial cell membrane lipopolysaccharides. Polymyxins $B$ and $E$ (colisitin) have been regularly used in clinical practice against a number of pathogenic bacteria (Falagas and Kasiakou, 2006). In recent years, polymyxins have been shown to be effective in treatment of patients infected with multidrug-resistant Gram negative bacteria (Falagas et al., 2008). Martin et al. described another cyclic peptide antibiotic belonging to polymyxins, mattacin (polymyxin $\mathrm{M}$ ) produced by $P$. kobensis and active against a wide variety of Gram positive and negative bacteria including several human and plant pathogens.

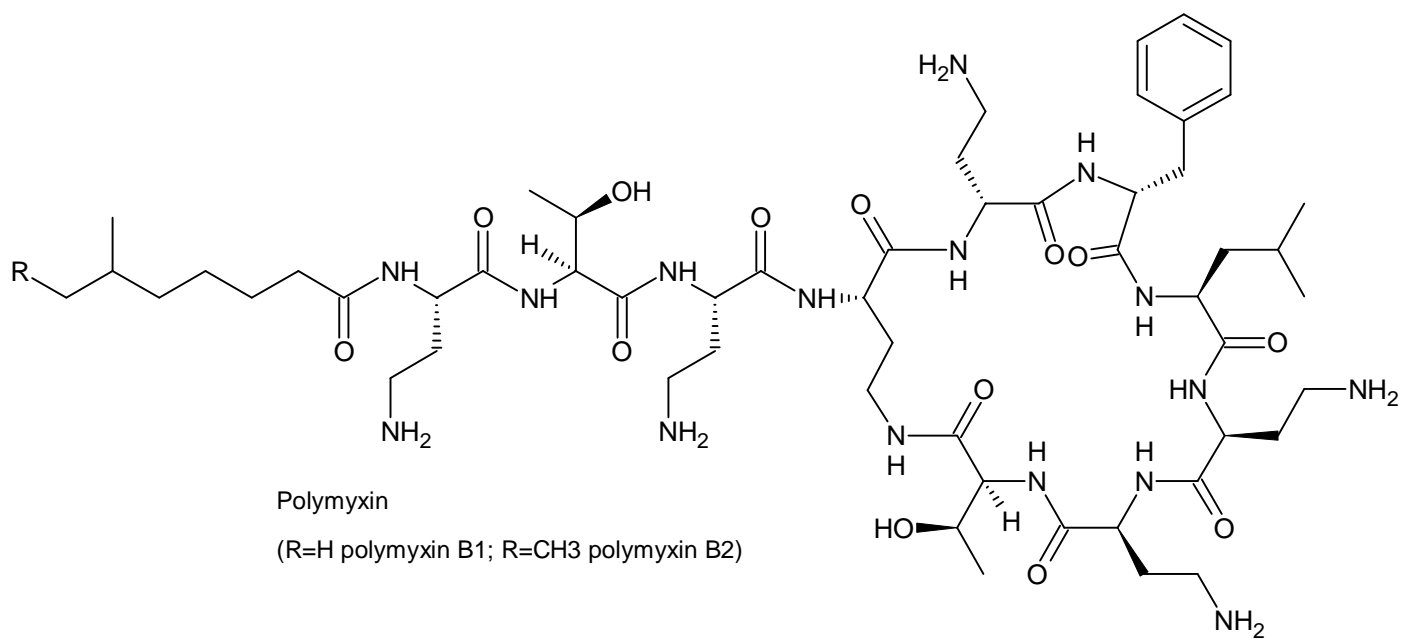

Fig. A1. Structure of Polymyxin B isolated from B. subtilis

P. alvei, strain NP75 has been reported to coproduce two new peptide antibiotics, paenibacillin $P$ and paenibacillin $N$ active against Gram positive and negative 
bacteria, respectively (Anandraj et al., 2009). A soil isolate of $P$. tianmuensis produces battacin, a cationic lipopeptide antibiotic active against some critical multi drug-resistant Gram negative bacterial strains of Pseudomonas aeruginosa and $E$. coli (Qian et al., 2011). In 2010, paenimacrolidin, a polyunsaturated macrolactone showing bacteriostatic activity against methicillin-resistant Staphylococcus aureus was discovered from Paenibacillus sp. (Wu et al., 2011). Additionally, P. peoriae (Weid et al., 2003), P. brasiliensis (Fortes et al., 2008), P. koreensis (Chung et al., 2000) and many other species have been described to demonstrate antimicrobial activity though their active components have not yet been isolated.

In conclusion, a number of Paenibacillus species continue to be studied as a source of biologically active novel natural compounds for their potential application in therapeutics and as biocontrol agents against phytopathogens like Fusarium oxysporum f. sp. nevium, the causative agent of fusarium wilt of watermelons (Raza et al., 2009).

\section{A.2.1. Paenibacillus larvae and its secondary metabolite potential}

Paenibacillus larvae is the etiological agent of a disastrous honey bee epidemic, American Foulbrood (AFB). AFB is an economically significant and a very contagious disease which can lead to the collapse of entire bee colonies. It is a notifiable disease in many countries and the effective measures for control usually involve burning of infected colonies to prevent the spread to other healthy colonies. Efforts to study the complete pathogenesis of $P$. larvae have thrown light on many aspects of the infectious disease in last few decades but a comprehensive understanding of disease progression and virulence factors employed by the pathogen is still lacking.

Bacillus larvae was first described as the causative agent of AFB in honey bees (Apis mellifera) by Whites in 1906. Another organism named Bacillus pulvifaciens was later accounted for causing powdery scale disease in honey bee larvae. But both these species along with many others were correctly classified into genus Paenibacillus in 1993 based on comparative 16S rRNA sequence analysis (Ash et al., 1993). However, strains belonging to species Paenibacillus larvae were reclassified into two subspecies as $P$. larvae subsp. larvae and $P$. larvae subsp. pulvifaciens based on possible phenotypic and genotypic differentiation and distinguished pathologies 
(Heyndrickx et al., 1996). It was in 2006 that conclusive evidence based on polyphasic taxonomic study on strains from both the subspecies was presented that justified bringing the two subspecies together into a single species, Paenibacillus larvae.

Four different genotypes of $P$. larvae (ERIC I - IV) have been described on the basis of repetitive-element PCR using enterobacterial repetitive intergenic consensus (ERIC) primers (Genersch and Otten, 2003). The four genotypes show phenotypic differences in metabolism as well as in colony and spore morphology. But most importantly, they show differences in their level of virulence on larval and colonial level (Genersch et al., 2005; Ashiralieva and Genersch, 2006; Rauch et al., 2009). Strains of the genotype ERIC I and ERIC II are the most common field isolates from AFB diseased colonies while genotypes ERIC III and ERIC IV are rarely isolated. Experimental bioassays accomplished on honey bee larvae infected with $P$. larvae spores have revealed that $P$. larvae ERIC I strains have $\mathrm{LT}_{100}$ of around 13 days while the other three genotypes ERIC II-IV have $\mathrm{LT}_{100}$ of 5-7 days (Genersch et al., 2005). Owing to their higher virulence and the frequency with which genotype ERIC I and ERIC II are encountered in diseased colony samples in nature, they are mostly used for in depth study of the disease.

Paenibacillus larvae infects the honey bee larvae in their first instar stage through the ingestion of food contaminated with spores (Yue et al., 2008). The spores germinate inside the midgut lumen followed by proliferation of the vegetative cells. The vegetative cells then breach the epithelial barrier and colonize haemocoel. The cells of bacteria degrade the larvae body after its death into a thick ropy mass which later dry to form hard scales containing a huge number of infectious bacterial spores which can spread to other healthy bee colonies through various means.

Many virulence factors like toxins (Fünfhaus et al., 2013), S-layer protein (Poppinga et al., 2012) and proteases (Antunez et al., 2010; Antunez et al., 2011) have been described in the recent years for their potential involvement in pathogenesis. Four fragments showing homology to the various nonribosomal peptide synthetases from Bacillus sp. were identified in the genome of $P$. larvae ERIC I and ERIC II. Precisely, partial sequences showing homology to the mycosubtilin synthetase subunit, iturin $A$ synthetase subunit and bacitracin synthetase subunit were identified during the 
comparative genome analysis (Fünfhaus et al., 2009). The products of these gene clusters have been suggested to be putative virulence factors of the pathogen but have not yet been recognized and purified.

\section{A.3. Myxobacteria: a promising source of natural products}

Myxobacteria were discovered by Roland Thaxter in 1892. They are a fascinating group of gram negative, aerobic, $\delta$-proteobacteria with noteworthy features like social behavior, gliding on solid surfaces and formation of fruiting bodies under starvation. The cells within the fruiting bodies become metabolically dormant and environmentally resistant exhibiting an impressive morphological complexity. Myxobacteria are found in various habitats including soil, bark of trees, decomposing insects and lichens, decaying plant material, dung of herbivores and marine environments since they can utilize a diverse array of natural macromolecules as food sources by secretion of exo-enzymes. In addition, they can also utilize living or dead bacterial, fungal or yeast cells as food in their natural surroundings. They are known to possess one of the largest genomes amongst bacteria (9-13 Mbp) with a DNA of high GC content of 66-72 mol\% (Reichenbach, 1999; Goldman et al., 2006).

However, in the last three decades the myxobacteria attracted much attention as promising producers of compounds with both, unique structures and bioactivities owing to their rich secondary metabolome. Sorangium cellulosum So ce56 which has one of the largest bacterial genomes is known to have around 20 secondary metabolite gene clusters (Schneiker et al., 2007). Secondary metabolite gene clusters account for $9 \%$ of genome of Myxococcus xanthus which is comparatively higher than many species of actinomycetes (Bode and Müller, 2005).

The biosynthetic potential of these microbes is remarkable and has an immense room for exploration and exploitation. They have hitherto yielded at least 100 different core structures and 500 different derivatives (Garcia et al., 2009a). The majority of the secondary metabolites produced by myxobacteria are polyketides, nonribosomal peptides, or their hybrids while other structural metabolite types comprise terpenoids, phenylpropanoids, and alkaloids (Nett and König, 2007). Distinctive modes of action against a broad range of both prokaryotic and eukaryotic cells can often be observed by compounds isolated from myxobacteria (Weissmann and Müller, 2010). 


\section{A.3.1. Taxonomy of myxobacteria}

All known myxobacteria are included in the order Myxococcales, which is further divided into three suborders, Sorangiineae, Cystobacterineae and Nannocystineae (Reichenbach, 2005). Novel myxobacterial taxa continue to be discovered from strains isolated in varied locations worldwide signifying that the myxobacterial diversity is yet unexplored. Availability of the 16S rRNA sequences of cultured strains of halophilic (lizuka et al., 2003a,b), halotolerant (lizuka et al., 2006) and anaerobic (Coates et al., 2002; Sanford et al., 2002) myxobacteria suggest the wide-ranging physiological and ecological niches which can be inhabited by myxobacteria. Dawid and colleagues isolated some psychrophilic myxobacterial species from Antarctic soil samples with optimal growth temperatures ranging from $4^{\circ} \mathrm{C}$ to $9^{\circ} \mathrm{C}$ (Dawid et al., 1988). $16 \mathrm{~S}$ rDNAs of many myxobacteria is also detected during the metagenomic studies but these bacteria are often termed as viable but not cultivable (VBNC) environmental strains (Garcia et al., 2010). Such strains are not significantly represented and described currently due to their unfamiliar and slightly complex physiological and nutritional growth requirements. A combination of new sophisticated isolation techniques, selective culture media, and other methods may make culturing such bacteria possible under laboratory conditions in future.

With the continuous discovery of new and reclassification of some known myxobacterial taxa, it is immensely important to revise and update the current phylogeny of this group. The unique morphological traits of myxobacteria are the primary basis for isolation and characterization of families, genera and species and to identify the taxonomic status of novel strains within the order Myxococcales. However, such characteristics are often lost or become aberrant when the strains are repeatedly subcultured under laboratory conditions and so, are unreliable for taxonomic classification (Garcia et al., 2010). Exploration and application of some new molecular taxonomic approaches along with the traditional ones is necessary to alleviate some of these problems and to clearly delineate a potential new taxon from its closest relatives (Shimkets and Woese, 1992). The novel tools available for systematics include the complete 16S rRNA gene sequencing and its comparative analysis by phylogenetic trees, DNA-DNA hybridization studies with related organisms, analyses of molecular markers and signature pattern(s), biochemical 
assays, physiological and morphological tests. All these genotypic, chemotaxonomic and phenotypic tools in combination with each other or all together can furnish substantial information for elucidating the reliable taxonomic position of a microbe and constitute a polyphasic approach for taxonomic studies.

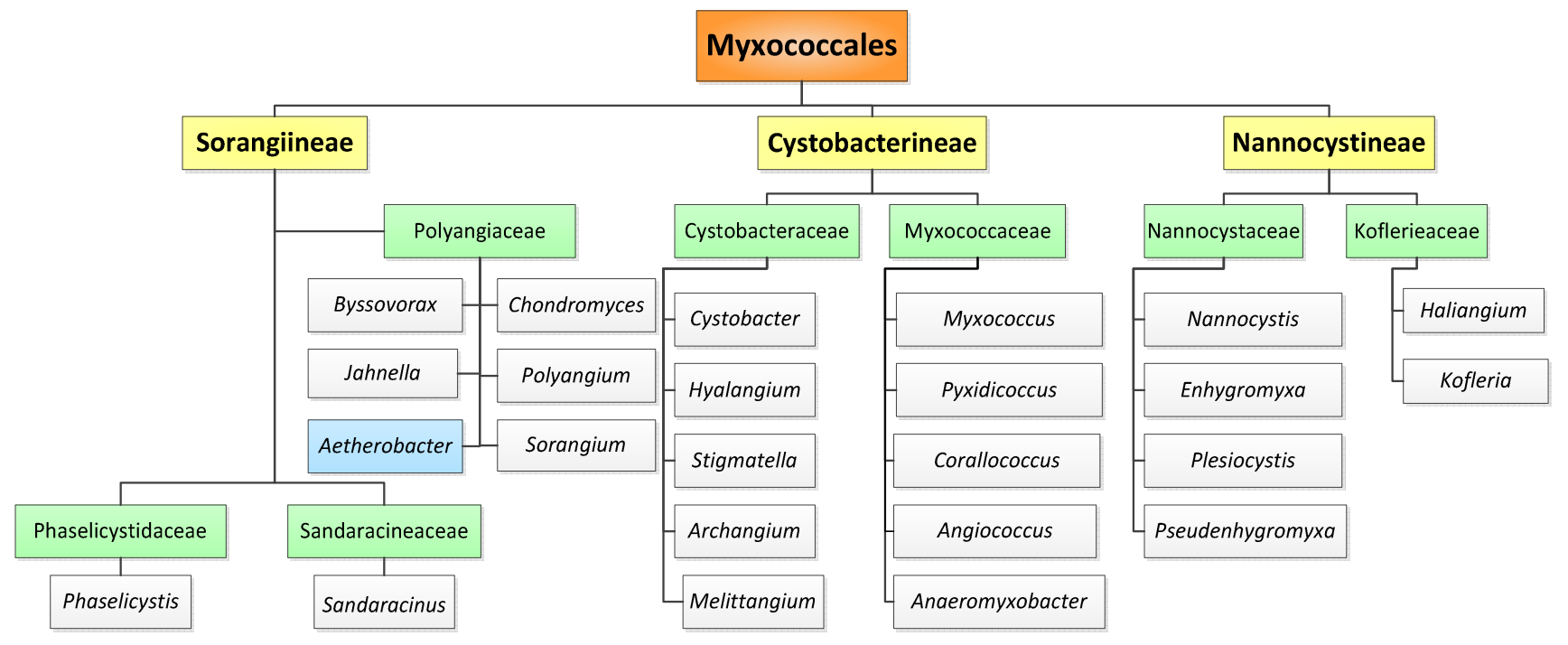

Fig.A2. Systematic description of myxobacteria within order Myxococcales (orange). Three suborder (yellow) and seven families (green) are also indicated. Aetherobacter (blue) is a novel unpublished genus. (Garcia et al., 2009b; Mohr et al., 2011; lizuka et al., 2003; lizuka et al., 2013)

Progress in polyphasic approach has become an important tool in bacterial systematics and should be applied more effectively for myxobacteria to classify newly isolated strains as well as reclassification of strains placed under invalid taxa. Recently, cellular fatty acid analysis has been used for chemo-taxonomic classification of myxobacteria and it has been proven to be a valid tool to verify the rDNA based phylogeny (Garcia et al., 2011). More such molecular markers or methods need to be determined for deciphering accurate phylogenetic relationships between the closely related taxa. Following a polyphasic approach will progressively pave the way for modern myxobacterial systematics rooted in the genetic lineages of the organisms.

\section{A.3.2. Treasure from myxobacterial metabolome}

The myxobacterial metabolome is unique both in structural diversity and biological activities. About $40 \%$ of the myxobacterial compounds that have been described 
represent novel chemical scaffolds while others comprise structural elements already known from other organisms like streptomycetes and cyanobacteria but modified by myxobacteria into new compounds (Reichenbach, 2001). Only in very rare events, structures exactly identical to compounds known from other sources were identified from myxobacteria suggesting the diverse chemical space of the myxobacterial metabolome.

These findings have motivated more research efforts to identify lead compounds amongst the myxobacterial secondary metabolites for clinical application. One of the most celebrated compounds from myxobacteria is epothilone B which was isolated from Sorangium cellulosum. It was found to possess cytotoxic activity against mouse fibroblast cell line L929 and human T-24 bladder carcinoma cell line (Gerth et al., 1996a). It was hence further investigated and exhibited selective activity against breast and colon tumor cell lines in the in vitro antitumor screening program of the National Cancer Institute (Höfle et al., 1996). A semi-synthetic analogue of epothilone $B$, ixabepilone (Ixempra ${ }^{\circledR}$ ) was the first natural product of myxobacterial origin approved for clinical use in 2007 for treatment of breast cancer (Hunt, 2009). Disorazols, (Elnakady et al., 2004), tubulysins (Sasse et al., 2000), rhizopodin (Jansen et al., 2008), chivosazols (Diestel et al., 2009) and chondramides (Sasse et al., 1998) all act on cytoskeletal elements and need to be evaluated for development to potential anticancer drugs (Kaur et al., 2006; Elnakady et al., 2004; Khalil et al., 2006). In addition to affecting the cytoskeletal elements, myxobacterial compounds can also act on a number of other target sites inside the eukaryotic cells. Argyrins (Nickeleit et al., 2008) and gephyronic acid (Sasse et al., 1994), for example, both isolated from the myxobacterium Archangium gephyra exhibit cytotoxic activities by inhibition of proteasome activity and inhibition of protein synthesis, respectively.

Approximately $54 \%$ of the bioactive myxobacterial metabolites exhibit antifungal activity (Gerth et al., 2003) following varied mechanism of actions. The main target of such compounds like stigmatellin (Thierbach et al., 1984), myxothiazol (Thierbach and Reichenbach, 1981), haliangicin (Fudou et al., 2001) and myxalamid (Gerth et al., 1983) is the mitochondrial respiratory chain. Soraphen, a polyketide metabolite produced by Sorangium cellulosum came into limelight upon revelation of its unique mode of action which targeted the fungal Acetyl-CoA-carboxylase (Gerth et al., 
1994). Its mechanism of action became a model for novel test systems, e.g. showing small-molecule inhibitors of human ACCs have potential in the treatment of metabolic syndromes like obesity (Schreurs et al., 2009) and cancer (Beckers et al., 2007).
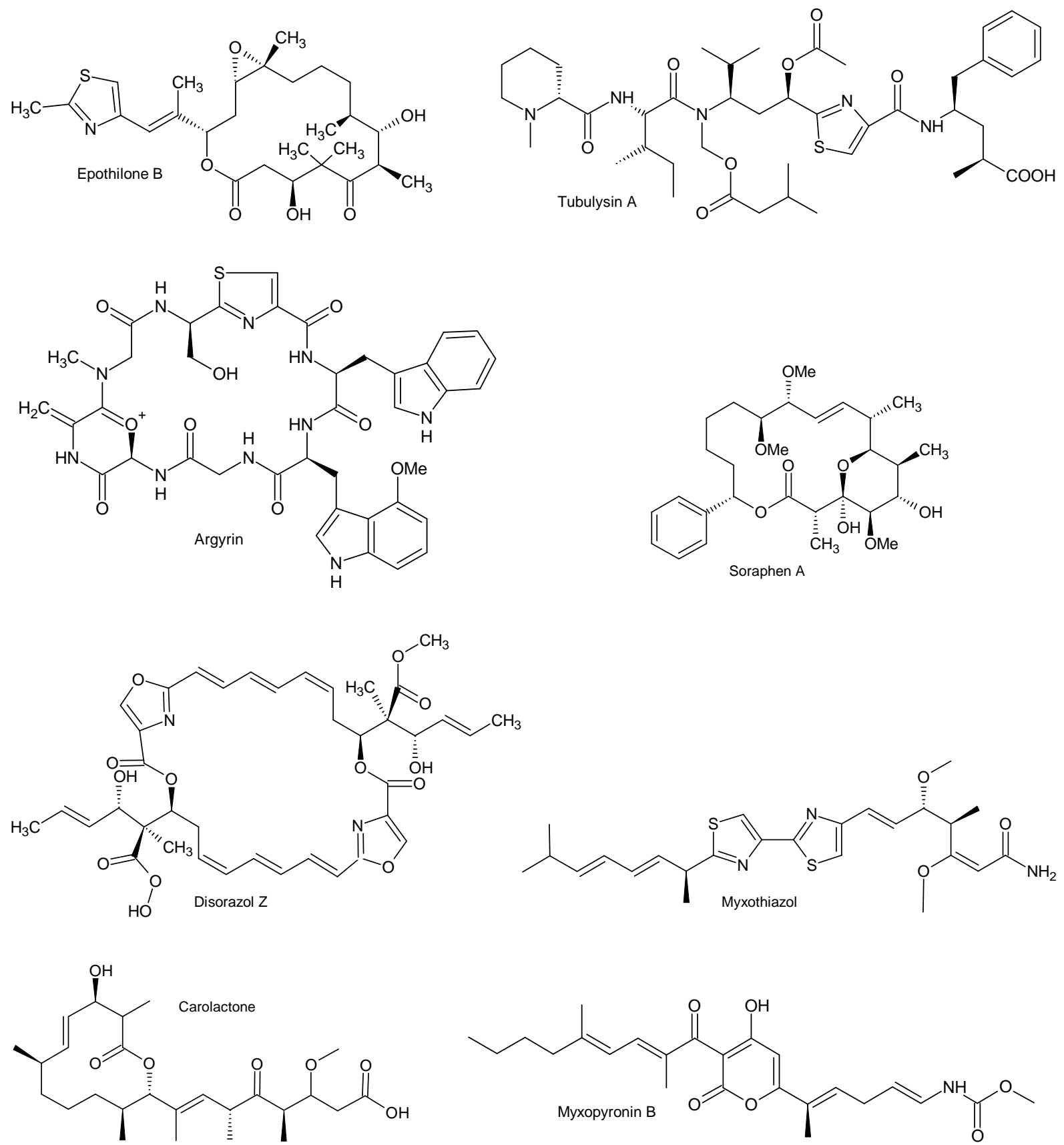

Fig.A3. Natural compounds from myxobacteria with cytotoxic, antifungal and antibacterial activity (Weissman and Müller, 2010)

Out of the huge repertoire of myxobacterial metabolites, around $29 \%$ show activities against various bacteria (Gerth et al., 2003) and these antibacterial compounds use varied mode of actions. DNA-dependent RNA polymerase is the key enzyme of 
transcription in all living organisms, and hence, also a crucial target for antibacterial therapy. Myxobacterial compounds like corallopyronin (Irschik et al., 1985), myxopyronin (Irschik et al., 1983a), ripostatins (Irschik et al., 1995) and sorangicins (Irschik et al., 1987) can serve as lead structures for development to effective drugs specifically targeting the eubacterial RNA polymerase. Etnangien (Irschik et al., 2007a) has the ability to inhibit bacterial RNA polymerase as well as DNA polymerase, making it an interesting lead molecule for further investigation.

Thuggacins (Irschik et al., 2007b) show activity against selective Gram positive bacteria by inhibition of the cellular electron-transport chain (Steinmetz et al., 2007). Protein synthesis is inhibited by angiolam (Kunze et al., 1985), althiomycin (Kunze et al., 1982) and myxovalargin (Irschik et al., 1983b). Myxovirescins (Gerth et al., 1982) specifically inhibit incorporation of $\mathrm{N}$-acetyl-glucosamine during murein synthesis leading to disruption of the cell wall synthesis.

In the continuing efforts to exploit the myxobacterial secondary metabolism, many new compounds have been identified and described recently including roimatacenes produced by Cystobacter ferrugineus (Zander et al., 2011), hyaladione isolated from Hyalangium minutum (Okanya et al., 2012) and icumazoles (Barbier et al., 2012) which were described as a new class of antifungals from Sorangium cellulosum. Another highly potent compound, carolactone (Jansen et al., 2010) which inhibits biofilm formation by Streptococcus mutans was isolated from Sorangium cellulosum (Müller and Wink, 2013).

\section{A.3.3. Quest for novel myxobacteria and their metabolites}

The strain collection at the Helmholtz Centre for Infection Research has continued to expand over the last few decades and currently comprises more than 8000 isolates of myxobacteria and other gliding bacteria. Our ongoing screening of this huge strain collection for bioactive molecules, which can serve as potential drug candidates or leads in future, has revealed the remarkable ability of myxobacteria to synthesize novel natural products with unique structures. A bulk of the compounds isolated from myxobacteria come from selected genera, such as Sorangium, Myxococcus and Chondromyces sp., reflecting the non-uniform potential to produce secondary metabolite within the myxobacterial species (Garcia et al., 2009). However, this 
conclusion is based upon the production under laboratory conditions and may vary in their natural environments. Another striking feature is the commonly observed similarity in the secondary metabolite profiles of strains belonging to the same suborder (Gerth et al., 2007). This aspect can be exploited for chemotaxonomy of myxobacteria using selected secondary metabolites as biomarkers.

Additionally, production of a family of closely related metabolites with varied biological activity rather than a single natural product with unique structure is often observed for myxobacteria (Gerth et al., 2007). For example, Sorangium cellulosum can produce at least 30 different variants of epothilone upon fermentation (Gerth et al., 2007). In contrast, a single myxobacterial strain can also produce a huge repertoire of structurally unrelated secondary metabolites based on their genetic potential.

Sampling from biologically complex or extreme environments increases the likelihood of isolation of novel myxobacterial taxa (Dawid, 2000). Forest soil samples which are usually enriched with decaying plant matter and animal dung can serve as an excellent source for isolation of novel strains (Garcia et al., 2009). Such extremely intricate environments seem to be ideal for fostering new myxobacteria and their interaction and competition for limited common resources act as important factors for the development of bioactive secondary metabolites. Recently, 58 halotolerant strains were isolated using conventional isolation methods from saline-alkaline soil samples collected in Xinjiang, China (Zhang et al., 2013). Some of these strains could grow at salt concentration as high as $2 \%$ while others formed fruiting bodies at $1 \%$ salt concentration displaying their osmotolerance, which is quite unusual in terrestrial myxobacteria.

Additionally, refined isolation and baiting techniques, selective culture media, and other methods could possibly lead to discovery of novel taxa (Garcia et al., 2010). For example, Anaeromyxobacter dehalogenans was isolated on the basis of its ability to grow using acetate as an electron donor and 2-chlorophenol as an electron acceptor (Sanford et al., 2002). It was described as first myxobacteria taxon with the ability to grow under facultative anaerobic conditions. Isolation methods involving different prey strains as bait for myxobacteria and imitating natural predatory environment are also often helpful in myxobacterial isolation (Li et al., 2013). 
Identification, isolation and screening of new myxobacteria over the last three decades have led to the discovery of many new compounds. This implies that the probability of finding uncharacterized metabolites increases with isolation and screening of novel families, genera or species of myxobacteria. Isolation of aetheramides, potent HIV inhibitory molecules isolated from the novel myxobacterial genus, Aetherobacter (not validly published) clearly exemplifies the potential of new taxa in production of new molecules (Plaza et al., 2012). Aetheramides were found to be active against fungi and human colon tumor cell line (HCT-116) but most importantly against the virus, HIV-1. Indiacens were also isolated and purified as compounds with antibiotic activity against certain bacteria and filamentous fungi from another novel myxobacterial genus, Sandaracinus amylolyticus, (Steinmetz et al., 2012).

Bioassay-based screening and fractionation, and HPLC-coupled mass spectrometry of the crude extracts from selected strains form a part of conventional methods in drug discovery. Apart from these commonly used screening and de-replication processes for identification of novel myxobacterial products, new approaches need to be implemented in order to discover yet unidentified metabolites. Co-cultivation with other soil bacteria and mimicking the natural environment during cultivation could be employed as new strategies for screening for potential new bioactive compounds from already known taxa as well as novel taxa.

\section{A.4. Process of drug development from microbial natural}

\section{products}

In a classic microbe-based natural product program, microbiologists isolate pure cultures of microorganism from environmental samples collected from the biosphere. Environmental samples can vary from the traditional soil samples to leaf litter, tree barks, animal dung and beetle carcasses but each kind of environmental sample has its own characteristic microbial spectrum (Borris, 1996).

Extracts from small scale fermentations of the isolated pure cultures are then screened on a panel of preliminary assays. Cultures that are found to be active in one or more assays are again grown under similar conditions to check the reproducibility of the original activity before the culture extract is subjected to some 
form of dereplication.

Dereplication, the process of determining whether the active compound is novel is a vital part of any natural product program. A finely designed and executed dereplication process helps to avoid wasting resources and allows focusing on unique molecules and activities. Isolation and identification of the active constituent follows the dereplication process for the positive extracts. Optimization of media and growth conditions is also often crucial to obtain higher yields of compounds. Isolation of the active compounds is performed by various subsequent chemical processes guided at each step by bioassay data. The molecular structure of the compound is determined using various spectroscopic and chemical techniques like NMR spectroscopy and X-Ray crystallography. Isolation of the pure compound at larger scale is then carried out after optimization of all the biological as well as chemical procedures.

After the isolation and identification of the compound, it must be evaluated against the entire spectrum of specific assays to identify its molecular targets and potential toxicity or side effects to normal eukaryotic cells. Eventually, the potential lead compound has to undergo a rigorous safety assessment program which involves tests on several species of animal and with high doses of compound. Any significant toxicity in any species of test animals even at very high doses of compound can lead to termination of active interest in a compound by a pharmaceutical company. In case the compound passes through safety assessment, it has to undergo clinical trials before it reaches the market.

\section{A.5. Challenges and benefits of microbial drug discovery program}

High-throughput screening from all natural sources presents a number of challenges. The problem of reliable access and supply is of utmost concern. Even slight variations in growth conditions of the microbes can sometimes cause difficulties with production and initial detection of active compounds as well as subsequent repetition of assays or purification. Loss of production of the anticipated compound is also possible upon repeated sub-culturing under laboratory conditions. Even if supply is consistent, the initial raw extract usually consists of a complex mixture of various compounds including media components which need to be separated from the 
desired compound using successive separation techniques. The raw extract might also contain only very small quantities of a bioactive substance and often as a mixture with structurally related molecules or its own derivatives and the initial concentration might be too low to be effectively detected by high-throughput screening. Additionally, the primary screening assays may be disguised by poor solubility of the compound or by fluorescent or colored false positives. Furthermore, the activity observed from a raw extract during the primary screening could be due to the synergistic activity of two constituents that may then diminish or disappear upon separation. The key compound can also be unstable making isolation a challenging task. Finally, extensive study is often required for complete structural elucidation of the compound to be absolutely sure that the molecule is novel.

Microorganisms also implicate a number of advantages in a natural products discovery program compared to other sources of natural products. Firstly, the diversity of the microbes taxonomically as well as biochemically is enormous. The accessibility of a wide range of microbes makes a high screening throughput both practical and lucrative. One of the major advantages of working with microorganisms is the ability to screen vast numbers of cultures on a small scale and production of large quantities of microbial products by fermentation. It is unlikely that continuous supply becomes a hurdle in the development of a microbial product. The innumerable antibiotics derived from microbial natural products currently in use imply the real potential of microbes as source of lead drugs in future.

\section{A.6. Aim of this thesis}

The main goals embedded in this thesis include identification of novel microbial natural products and myxobacterial taxa. In this framework, one of the first objectives was to screen two Paenibacillus larvae and 50 myxobacterial strains using a comprehensive reactivation-process with up-to-date methods. After the screening was accomplished, the focus was set on P. larvae ERIC II (DSM 25430) and Nannocystis pusilla, Ari7 for purification of uncharacterized secondary metabolites. Large scale fermentations were carried out for P. larvae ERIC II (DSM 25430) and N. pusilla, Ari7 followed by bioassay guided separation for purification of compounds. Structure elucidation of the pure compounds was done using NMR spectroscopy and mass spectrometry. Furthermore, amino acid composition, sequence and 
stereochemistry were analyzed for the compounds obtained from $P$. larvae. Finally, the biological activities of the pure compounds which were isolated in sufficient amounts were tested against a panel of bacteria, fungi and yeasts along with various cell lines.

Additionally, 16S rRNA gene sequences of the same set of 50 myxobacterial strains were analyzed. Strain MCy $1366^{\top}$ (Ar1733) was found to be branching out from rest of the known strains in the family Myxococcaceae and was selected for further investigation. MCy $1366^{\top}$ along with the 9 type strains from family Myxococcaceae was also studied and compared for antibiotic resistance, fatty acid composition using GC-MS and cytoplasmic proteome using MALDI-TOF analysis. In addition, strain MCy $1366^{\top}$ was subjected to many physiological tests to ascertain its position as a new genus. 


\section{References}

Anandaraj, B., Vellaichamy, A., Kachman, M., Selvamanikandan, A., Pegu, S., and Murugan, V. (2009) Co-production of two new peptide antibiotics by a bacterial isolate Paenibacillus alvei NP75. Biochemical and Biophysical Research Communications 379,179-185

Antunez, K., Anido, M., Arredondo, D., Evans, J. D., and Zunino, P.(2010) Paenibacillus larvae enolase as a virulence factor in honey bee larvae infection. Veterinary microbiology, 147, 83-89

Antunez, K., Arredondo, D., Anido, M., and Zunino, P. (2011) Metalloprotease production by Paenibacillus larvae during the infection of honeybee larvae. Microbiology, 157, 1474-1480

Ash, C., Priest, F. G., and Collins, M. D. (1993) Molecular identification of rRNA group 3 bacilli (Ash, Farrow, Wallbanks and Collins) using a PCR probe test. Proposal for the creation of a new genus Paenibacillus. Antonie van Leeuwenhoek 64, 253-260

Ashiralieva, A., and Genersch, E. (2006) Reclassification, genotypes and virulence of Paenibacillus larvae, the etiological agent of American foulbrood in honeybees - a review. Apidologie, 37, 411-420

Barbier, J., Jansen, R., Irschik, H., Benson, S., Gerth, K., Böhlendorf, B., Höfle, G., Reichenbach, H., Wegner, J., Zeilinger, C., Kirschning, A., and Müller, R., (2012) Isolation and structure elucidation (by total synthesis) of icumazoles and noricumazoles - new antifungal antibiotics and cation channel blockers from Sorangium cellulosum. Angew. Chem. Int. Ed. 51, 1256-1260

Beckers, A., Organe, S., Tinunermans, L., Scheys, K., Peters, A., Brusselmans, K., Verhoeven, G., and Swinnen, J.V., (2007) Chemical inhibition of Acetyl-CoA Carboxylase induces growth arrest and cytotoxicity selectively in cancer cells. Cancer Res. 67, $8180-8187$

Berdy, J. (2012) Thoughts and facts about antibiotics: Where we are now and where we are heading. J. Antibiot. 65, 385-395

Berdy, J., (2005) Bioactive Microbial Metabolites. J. Antibiot. 58(1): 1-26

Bode, H.B. and Muller, R. (2005) The impact of bacterial genomics on natural product research. Angew. Chem. Int. Ed.,44(42):6828-6846

Borris, R. P. (1996) Natural products research: perspectives from a major pharmaceutical company. Journal of Ethnopharmacology 51, 29-38

Butler, M. S., (2004). The Role of Natural Product Chemistry in Drug Discovery. J. Nat. Prod. 67, 2141 2153

Chung, Y.R., Kim, C. H., Hwang, I., and Chun, J. (2000) Paenibacillus koreensis sp. nov., a new species that produces an iturin-like antifungal compound. Intern. J. Syst. Evol. Microb. 50, 1495-1500

Coates, J.D., Kimberly, A., Chakraborty, C.R., O' Connor, S.M., and Achenbach, L.A. (2002) Diversity and ubiquity of bacteria capable of utilizing humic substances as electron donors for anaerobic respiration. Appl. Environ. Microbiol. 68, 2445-2452

Dawid, W. (2000) Biology and global distribution of myxobacteria in soils. FEMS Microbiol. Rev. $24,403-427$

Dawid, W., Gallikowski, C.A., and Hirsch, P. (1988) Psychrophilic myxobacteria from Antarctic soils. Polarforschung. 58, 271-278

Demain, A. L. (2006) From natural products discovery to commercialization: a success story J. Ind. Microbiol. Biotechnol. 33, 486-495 
Demain, A. L. and Sanchez, S. (2009) Microbial drug discovery: 80 years of progress. J. Antibiot. 62, $5-16$

Diestel, R., Irschik, H., Jansen, R., Khalil, M. W., Reichenbach, H., and Sasse, F., (2009) Chivosazoles A and F, Cytostatic Macrolides from Myxobacteria, Interfere with Actin. ChemBioChem 10, 2900 2903

Elnakady, Y. A., Sasse, F., Lünsdorf, H., and Reichenbach, H., (2004) Disorazol A1, a highly effective antimitotic agent acting on tubulin polymerization and inducing apoptosis in mammalian cells. Biochemical Pharmacology 67, 927-935

Falagas, M. E., and Kasiakou, K. S., (2006) Toxicity of polymyxins: a systematic review of the evidence from old and recent studies. Critical Care 10, 1-13

Falagas, M.E., Grammatikos, A. P., and Michalopoulos, A., (2008) Potential of old-generation antibiotics to address current need for new antibiotics. Expert Rev. Anti- Infect. Ther. 6(5), 593-600

Fickers, P. (2012) Antibiotic compounds from Bacillus: why are they so amazing? Am. J. Biochem. Biotechnol. 8, 40-46

Fleming, A. (1929) On the antibacterial action of cultures of a penicillium, with special reference to their use in the isolation of B. influenzæ. Br. J. Exp. Pathol. 10 (3), 226-36

Fortes, T.O., Alviano, D.S., Tupinamba, G., Padron, T.S., Antoniolli, A. R., Alviano, C.R., and Seldin, L. (2008) Production of an antimicrobial substance against Cryptococcus neoformans by Paenibacillus brasilensis Sa3 isolated from the rhizosphere of Kalanchoe brasiliensis. Microbiological Research 163, 200-207

Fudou, R., lizuka, T., and Yamanaka, S., (2001) Haliangicin, a novel antifungal metabolite produced by a marine myxobacterium- Fermentation and biological characteristics. J. Antibiotics 54(2), 149-152

Fünfhaus, A., Ashiralieva, A., Borriss, R. and Genersch, E. (2009) Use of suppression subtractive hybridization to identify genetic differences between differentially virulent genotypes of Paenibacillus larvae, the etiological agent of American Foulbrood of honeybees. Environ. Microbiol. Rep.,1, 240-250

Fünfhaus, A., Poppinga, L., and Genersch, E. (2013) Identification and characterization of two novel toxins expressed by the lethal honey bee pathogen Paenibacillus larvae, the causative agent of American foulbrood. Environ. Microbiology. doi:10.1111/1462-2920.12229

Garcia, R. O., Reichenbach, H., Ring, M. W., and Müller, R. (2009b) Phaselicystis flava gen. nov., sp. nov., an arachidonic acid-containing soil myxobacterium, and the description of Phaselicystidaceae fam. nov. Int. J. Syst. Bacteriol. 59, 1524-1530

Garcia, R., Gerth, K., Stadler, M., Dogma, I. J., Jr. \& Müller, R., (2010) Expanded phylogeny of myxobacteria and evidence for cultivation of the 'unculturables'. Mol. Phylogenet. Evol. 57, 878-887

Garcia, R., Gerth, K., Stadler, M., Dogma, I. J., Jr. and Müller, R., (2010) Expanded phylogeny of myxobacteria and evidence for cultivation of the 'unculturables'. Mol. Phylogenet. Evol. 57, 878-887

Garcia, R., Pistorius, D., Stadler, M., and Müller, R. (2011) Fatty acid related phylogeny of myxobacteria as an approach to discover polyunsaturated omega-3/6 fatty acids. J. Bacteriol. 193, 1930-1942

Garcia, R.O., Krug, D., and Müller, R. (2009a) Discovering natural products from Myxobacteria with emphasis on rare producer strains in combination with improved analytical methods. Methods Enzymol. 458, 59-91 
Garcia, R.O., Krug, D., and Müller, R. (2009a) Discovering natural products from Myxobacteria with emphasis on rare producer strains in combination with improved analytical methods. Methods Enzymol. 458, 59-91

Genersch, E., A. Ashiralieva, and I. Fries. (2005) Strain- and genotype-specific differences in virulence of Paenibacillus larvae subsp. larvae, a bacterial pathogen causing American foulbrood disease in honeybees. Appl. Environ. Microbiol. 71:7551-7555.

Genersch, E., and Otten, C. (2003) The use of repetitive element PCR fingerprinting (rep-PCR) for genetic subtyping of German field isolates of Paenibacillus larvae subsp. larvae. Apidologie 34: 195206

Genersch, E., Forsgren, E., Pentikäinen, J., Ashiralieva, A.., Rauch, S. ,Kilwinski, J., and Fries, I. (2006) Reclassification of Paenibacillus larvae subsp. pulvifaciens and Paenibacillus larvae subsp. larvae as Paenibacillus larvae without subspecies differentiation. Int. J. Syst. Evol. Microbiol. 56:501511.

Gerth K., Irschik H., Jansen R., Kunze B., Müller R., Sasse F. (2007). Myxobakterien, vom Aussenseiter zum Geheimfavoriten, in Vorbild Natur, G. Kreysa, D. Sell (Eds.) Dechema e.V., Frankfurt am Main, $64-71$

Gerth, K., Bedorf, N., Höfle, G., Irschik, H., and Reichenbach, H., (1996a) Epothilons A and B: Antifungal and cytotoxic compounds from Sorangium cellulosum (Myxobacteria). Production, physicochemical and biological properties. J. Antibiotics, 49, 560-3

Gerth, K., Bedorf, N., Irschik, H., Höfle, G., and Reichenbach, H., (1994) The Soraphens: A family of novel antifungal compounds Sorangium cellulosum (Myxobacteria). J. Antibiot. 47(1), 23-31

Gerth, K., Irschik, H., Reichenbach, H., and Trowitsch, W., (1982) The Myxovirescins, a family of antibiotics from Myxococcus virescens (Myxobacterales). J. Antibiot. 35, 1454-1459

Gerth, K., Jansen, R., Reifenstahl, G., Höfle, G., Irschik, H., Kunze, B., Reichenbach, H., and Thierbach, G., (1983) The Myxalamides, new antibiotics from Myxococcus Xanthus (Myxobacterales). J. Antibiotics 36(9), 1150-1156

Gerth, K., Pradella, S., Perlova, O., Beyer, S., and Müller, R., (2003) Myxobacteria: proficient producers of novel natural products with various biological activities-past and future biotechnological aspects with the focus on the genus Sorangium. J. Biotechnol. 106, 233-253

Goldman, B. S., Nierman, W. C., Kaiser, D., Slater, S.C., Durkin, A. S., Eisen, J. A., Ronning, C. M., Barbazuk, W. B., Blanchard, M., Field, C., Halling, C., Hinkle, G., lartchuk, O., Kim, H. S., Mackenzier, C., Madupu, R., Miller, N., Shvartsbeyn, A., Sullivan, S. A., Vaudin, M., Wiegand, R., Kaplan, H. B., (2006) Evolution of sensory complexity recorded in a myxobacterial genome. Proc. Nat. Acad. Sci. 103, 15200-15205

Gross, H., Loper, J. E. (2009) Genomics of secondary metabolite production by Pseudomonas spp. Nat. Prod. Rep. 26, 1408-1446

Heyndrickx, M., Vandemeulebroecke, K., Hoste, B., Janssen, P., Kersters, K., De Vos, P., Logan, N. A., Ali, N. \& Berkeley, R. (1996). Reclassification of Paenibacillus (formerly Bacillus) pulvifaciens (Nakamura 1984) Ash et al. 1994, a later subjective synonym of Paenibacillus (formerly Bacillus) larvae (White 1906) Ash et al. 1994, as a subspecies of $P$. larvae, with emended descriptions of $P$. larvae as P. larvae subsp. larvae and P. larvae subsp. pulvifaciens. Int. J. Syst. Bacterio.I 46, 270-279

Höfle, G., Bedorf, N., Steinmetz, H., Schomburg, D., Gerth, K., and Reichenbach, H., (1996) Epothilone A and B-Novel 16-Membered Macrolides with Cytotoxic Activity: Isolation, Crystal Structure, and Conformation in Solution. Angew. Chem. Int. Ed. Engl. 35, 13-14

Hunt, J. T. (2009) Discovery of Ixabepilone. Mol. Cancer Ther. 8,275-281 
lizuka, T., Fudou, R., Jojima, Y., Ogawa, S., Yamanaka, S., Inukai, Y., and Ojika, M. (2006) Miuraenamides $\mathrm{A}$ and $\mathrm{B}$, novel antimicrobial cyclic depsipeptides from a new slightly halophilic myxobacterium: taxonomy, production, and biological properties. J. Antibiot. 59, 385-391

lizuka, T., Jojima, Y., Fudou, R., Hiraishi, A., Ahn, J.W. and Yamanaka, S. (2003a) Plesiocystis pacifica gen. nov., sp. nov., a marine myxobacterium that contains dihydrogenated menaquinone, isolated from the pacific coasts of Japan. Int. J. Syst. Evol. Microbiol. 53, 189-195

lizuka, T., Jojima, Y., Fudou, R., Tokura, M., Hiraishi, A. and Yamanaka, S. (2003b) Enhygromyxa salina gen. nov., sp. nov., a slightly halophilic myxobacterium isolated from the coastal areas of Japan. Syst. Appl. Microbiol. 26, 189-196

lizuka, T., Jojima, Y., Fudou, R., Tokura, M., Hiraishi, A., and Yamanaka, S. (2003) Enhygromyxa salina gen. nov., sp. nov., a slightly halophilic myxobacterium isolated from the coastal areas of Japan. System. Appl. Microbiol. 26, 189-196

lizuka, T., Jojima, Y., Hayakawa, A., Fujii, T., Yamanaka, S., and Fudou, R. (2013) Pseudenhygromyxa salsuginis gen. nov., sp. nov., a myxobacterium isolated from an estuarine marsh. Int. J. Syst. Bacteriol. 63, 1360-1369

Irschik, H., Augustiniak, H., Gerth, K., Höfle, G., and Reichenbach, H., (1995) Ripostatins, novel inhibitors of eubacterial RNA polymerase isolated from Myxobacteria. J. Antibiot. 48, 787-792

Irschik, H., Gerth, K., Höfle, G., Kohl, W., and Reichenbach, H., (1983a) The myxopyronins, new inhibitors of bacterial RNA synthesis from Myxococcus fulvus (Myxobacterales). J. Antibiot. 36, 1651-8

Irschik, H., Gerth, K., Kemmer, T., Steinmetz, H., and Reichenbach, H., (1983b) The myxovalargins, new peptide antibiotics from Myxococcus fulvus (Myxobacterales). J. Antibiot. 36, 6-12

Irschik, H., Jansen, R., Gerth, K., Höfle, G., and Reichenbach, H., (1987) Sorangicins, novel and powerful inhibitors of eubacterial RNA polymerase isolated from myxobacteria. J. Antibiot. 40, 7-13

Irschik, H., Jansen, R., Hofle, G., Gerth, K., and Reichenbach, H., (1985) The corallopyronins, new inhibitors of bacterial RNA synthesis from Myxobacteria. J. Antibiot. 38, 145-52

Irschik, H., Reichenbach, H., Höfle, G., and Jansen, R., (2007b) The Thuggacins, novel antibacterial macrolides from Sorangium cellulosum acting against selected Gram positive bacteria. J. Antibiot. 60, 733-738

Irschik, H., Schummer, D., Höfle, G., Reichenbach, H., Steinmetz, H., and Jansen, R., (2007a) Etnangien, a macrolide-polyene antibiotic from Sorangium cellulosum that inhibits nucleic acid polymerases. J. Nat. Prod. 70, 1060-1063

Jansen, R., Irschik, H., Huch, V., Schummer, D., Steinmetz, H., Bock, M., Schmidt, T., Kirschning, A., and Müller, R., (2010) Carolacton - a macrolide ketocarbonic acid reducing biofilm formation by the caries- and endocarditis-associated bacterium Streptococcus mutans. European J. Org. Chem. 7, $1284-1289$

Jansen, R., Steinmetz, H., Sasse, F., Schubert, W. D., Hagelüken, G., Albrecht, S. C., and Müller, R., (2008) Isolation and structure revision of the actin-binding macrolide rhizopodin from Myxococcus stipitatus (Myxobacteria). Tetrahedron Letters 49, 5796-5799

Katznelson, H. (1950). Bacillus pulvifaciens (n. sp.), an organism associated with powdery scale of honeybee larvae. J. Bacteriol. 59, 153-155

Kaur, G., Hollingshead, M., Holbeck, S., Schauer-Vukasinovic, V., Camalier, R. F., Domling, A., and Agarwal, S., (2006) Biological evaluation of tubulysin A: a potential anticancer and antiangiogenic natural product. Biochem. J. 396, 235-242 
Keller, N. P., Turner, G., and Bennett, J. W. (2005) Fungal secondary metabolism—from biochemistry to genomics. Nat. Rev. Microbiol. 3, 937-947

Khalil, M. W., Sasse, F., Lünsdorf, H., Elnakady, Y. A., and Reichenbach, H., (2006) Mechanism of action of tubulysin, an antimitotic peptide from myxobacteria. Chembiochem. 7, 678-683

Kunze, B., Kohl, W., Höfle, G., and Reichenbach, H., (1985) Production, isolation, physic-chemical and biological properties of Angiolam A, a new antibiotic from Angiococcus Disciformis (Myxobacterales). J. antibiot. 38, 1649-1654

Kunze, B., Reichenbach, H., Augustiniak, H., and Höfle, G., (1982) Isolation and identification of althiomycin from Cystobacter fuscus (myxobacterales). J. antibiot. 35, 635-636

Li, B., Xie, X., Zhang, X., Cai, Z., and Zhu, H. (2013) Influence of different prey strains on isolation myxobacteria in saline-alkaline soils of Xinjiang. Wei Sheng Wu Xue Bao. 53(4), 379-89

Li-jing, Z., Xiao-nan, Y., Xiang-ying, L., Wei, M. and Feng, L. (2011) Antifungal, Insecticidal and Herbicidal Properties of Volatile Components from Paenibacillus polymyxa Strain BMP-11. Agricultural Sciences in China, 10(5): 728-736

Lorentz, R.H., Artico, S., Silveira, A.B., Einsfeld, A., and Corcao, G. (2006) Evaluation of antimicrobial activity in Paenibacillus spp. strains isolated from natural environment. Lett. Appl. Microbiol. 43, 541547

Martin, N.I., Hu, H., Moake, M.M., Churey, J. J., Whittal, R., Worobo, R. R., and Vederas, J. C. (2003) Isolation, structural characterization, and properties of mattacin (polymyxin M), a cyclic peptide antibiotic produced by Paenibacillus kobensis M. J. Biol. Chem. 278 (15), 13124-13132

Mohr, K. I.; Garcia, R. O.; Gerth, K.; Irschik, H.; Müller, R. (2011) Sandaracinus amylolyticus gen. nov., sp. nov., a starch degrading soil myxobacterium, and description of Sandaracinaceae fam. nov. Int. J. Syst. Bacterial. 62, 1191-1198

Müller, R., and Wink, J., (2013) Future potential for anti-infectives from bacteria - How to exploit biodiversity and genomic potential. Int. J. Med. Microb.

Nett, M. and König, G. M. (2007) The chemistry of gliding bacteria. Nat. Prod. Rep., 24, 1245-1261

Nickeleit, I., Zender, S., Sasse, F., Geffers, R., Brandes, G., Sörensen, I.,Steinmetz, H., Kubicka, S., Carlomagno, T., Menche, D., Gütgemann, I., Buer, J., Gossler, A., Manns, M. P., Kalesse, M., Frank, R., and Malek, N. P., (2008) Argyrin A reveals a critical role for the tumor suppressor protein p2 $7^{\text {kip } 1}$ in mediating mntitumor activities in response to proteasome inhibition. Cancer Res. 14, 23-35

Okanya, P.W., Mohr, K.I., Gerth, K., Steinmetz, H., Huch, V., Jansen, R., and Müller, R., (2012) Hyaladione, an S-methyl cyclohexadiene-dione from Hylangium minutum. J. Nat.Prod. 75, 768-770

Plaza, A., Garcia, R., Bifulco, G., Martinez, J.P., Hüttel, S., Sasse, F., Meyerhans, A., Stadler, M., and Müller, R., (2012) Aetheramides A and B, potent HIV-inhibitory depsipeptides from a myxobacterium of the new genus "Aetherobacter". Org. Lett.14, 2854-2857

Poppinga L, Janesch B, Fünfhaus A, Sekot G, Garcia-Gonzalez E, et al. (2012) Identification and Functional Analysis of the S-Layer Protein SplA of Paenibacillus larvae, the Causative Agent of American Foulbrood of Honey Bees. PLoS Pathog. 8(5): e1002716. doi:10.1371/journal.ppat.1002716

Qian, C. D., Wu, X. C., Teng, Y., Zhao, W. P., Li, O., Fang, S. G., Huang, Z. H. and Gao, H. C. (2011) Battacin (Octapeptin B5), a new cyclic lipopeptide antibiotic from Paenibacillus tianmuensis active against multidrug-resistant gram-negative bacteria. Antimicro. Agents and Chemother. 56(3), 14581465

Rauch, S., Ashiralieva, A., Hedtke, K., and Genersch, E., (2009) Negative Correlation between 
Individual-Insect-Level Virulence and Colony-Level Virulence of Paenibacillus larvae, the Etiological Agent of American Foulbrood of Honeybees. Applied and Environmental Microbiology, 75, 3344-3347

Raza, W., Yang, X., Wu, H., Wang, Y., Xu, Y., and Shen, Q., (2009) Isolation and characterisation of fusaricidin-type compound-producing strain of Paenibacillus polymyxa SQR-21 active against Fusarium oxysporum f.sp. nevium. Eur J Plant Pathol 125, 471-483

Reichenbach, H. (1999) The ecology of the myxobacteria. Environmental Microbiology 1: 15-21

Reichenbach, H. (2001) Myxobacteria, producers of novel bioactive substances. J. Ind. Microbiol. Biotechnol. 27(3), 149-156

Reichenbach, H. (2005) In Bergey's Manual of Systematic Bacteriology, Eds, Brenner, D. J.; Krieg, N. R.; Staley, J. T. Springer, 2, $1059-114$

Romero, D., Traxler, M. F., López, D. and Kolter, R. (2011) Antibiotics as Signal Molecules. Chem. Rev., 111(9), 5492-5505

Saha, P., Mondal, A.K., Mayilraj, S., Krishnamurthi, S., Bhattacharya, A., and Chakrabarti, T. (2005) Paenibacillus assamensis sp. nov., a novel bacterium isolated from a warm spring in Assam, India. Int. J. Syst. Evol. Microbiol 55, 2577-2581

Sanford, R., Cole, J. and Tiedje, J. (2002) Characterization and description of Anaeromyxobacter dehalogenans gen. nov., sp. nov., an aryl-halorespiring facultative anaerobic myxobacterium. Appl. Environ. Microbiol. 68, 893-900

Sanford, R., Cole, J. and Tiedje, J. (2002) Characterization and description of Anaeromyxobacter dehalogenans gen. nov., sp. nov., an aryl-halorespiring facultative anaerobic myxobacterium. Appl. Environ. Microbiol. 68, 893-900

Sarker, S.D., Latif, Z., and Gray, A. I. (2005) Natural Product isolation- An overview. In Natural Products Isolation: Methods in Biotechnol. 2nd ed. Humana Press Inc., Totowa, NJ. 20, 1-25

Sasse, F., Kunze, B., Gronewold, T. M. A., and Reichenbach, H., (1998)The Chondramides: Cytostatic agents from myxobacteria acting on the actin cytoskeleton. Journal of the National Cancer Institute 90, 20

Sasse, F., Steinmetz, H., Heil, J., Höfle, G., and Reichenbach, H., (2000) Tubulysins, new cytostatic peptides from myxobacteria acting on microtubule. J. Antibiot. 53, 879-885

Sasse, F., Steinmetz, H., Höfle, G., and Reichenbach, H., (1994) Gephyronic Acid, a Novel Inhibitor of Eukaryotic Protein Synthesis from Archangium gephyra (Myxobacteria) J. Antibiotics 48, 26-30

Schneiker, S., Perlova, O., Kaiser, O., Gerth, K., Alici, A., Altmeyer, M. O., Bartels, D., Bekel, T., Beyer, S., Bode, E., et. al. (2007) Complete genome sequence of the myxobacterium Sorangium cellulosum. Nat. Biotechnol. 25(11):1281-1289

Schreurs, M., van Dijk, T. H., Gerding, A., Havinga, R., Reijngoud, D. J., and Kuipers, F., (2009) Soraphen, an inhibitor of the acetyl-CoA carboxylase system, improves peripheral insulin sensitivity in mice fed a high-fat diet. Diabetes, Obes. and Metab. 11, 987-991

Shimkets, L., and Woese, C. S., (1992) A phylogenetic analysis of the myxobacteria: Basis for their classification. Proc. Nati. Acad. Sci. USA. 89, 9459-9463

Singh, R. K., Tiwari, S. K., Rai, A. K., and Mohapatra, T. M. (2011) Cyanobacteria: an emerging source for drug discovery, The Journal of Antibiotics, 64, 401-412

Stansly, P. G., Shepard, R. G., and White, H. J., (1947) Polymyxin: a new chemotherapeutic agent. Bull. Johns Hopkins Hosp. 81, 43-54 
Steinmetz, H., Irschik, H., Kunze, B., Reichenbach, H., Höfle, G., and Jansen, R., (2007) Thuggacins, macrolide antibiotics active against Mycobacterium tuberculosis: isolation from myxobacteria, structure elucidation, conformation analysis and biosynthesis. Chemistry 13(20), 5822-5832

Steinmetz, H., Mohr, K. I., Zander, W., Jansen, R.,Gerth, K., and Müller, R. (2012) Indiacens A and B: Prenyl Indoles from the Myxobacterium Sandaracinus amylolyticus. J. Nat. prod. 75, 1803-1805

Thierbach, G., and Reichenbach, H., (1981) Myxothiazol, a new antibiotic interfering with respiration. Antimicrobial agents and chemotherapy 19(4), 504-507

Thierbach, G., Kunze, B., Reichenbach, H., and Hofle, G., (1984) The mode of action of stigmatellin, a new inhibitor of the cytochrome b-c1 segment of the respiratory chain. Biochim. Biophys. Acta. $765,227-235$

Watve, M. G., Tickoo, R., Jog, M. M. and Bhole, B. D. (2001) How many antibiotics are produced by the genus Streptomyces? Arch. Microbiol. 176, 386-390

Weid, I., Alviano, D. S., Santos, A. L. S., Soares, R.M.A., Alviano, C.S., and Seldin, L. (2003) Antimicrobial activity of Paenibacillus peoriae strain NRRL BD-62 against a broad spectrum of phytopathogenic bacteria and fungi. Journal of Applied Microbiology 95, 1143-1151

Weissmann, K. J. and Müller, R. (2010) Myxobacterial secondary metabolites: bioactivities and modes-of-action, Nat. Prod. Rep., 27, 1276-1295

White, G. F. (1906) The bacteria of the apiary with special reference to bee disease. In Bureau of Entomology, Technical Series no. 14, pp. 1-50. Washington, DC: US Department of Agriculture

Wu, X. C., Qian, C. D., Fang, H. H., Wen, Y. P., Zhou, J. Y., Zhan, Z. J., Ding, R., Li, O., and Gao, H. (2011) Paenimacrolidin, a novel macrolide antibiotic from Paenibacillus sp. F6-B70 active against methicillin-resistant Staphylococcus aureus. Microb. Biotech. 4(4), 491-502

Xiong, Z. Q., Wang, J. F., Hao, Y. Y. and Wang, Y. (2013) Recent Advances in the discovery and development of marine microbial natural products. Mar. Drugs 11, 700-717

Yue, D., Nordhoff, M., Wieler L. H. and Genersch, E. (2008) Fluorescence in situ hybridization (FISH) analysis of the interactions between honeybee larvae and Paenibacillus larvae, the causative agent of American foulbrood of honeybees (Apis mellifera). Environmental Microbiology, 10, 1612-1620

Zander, W., Gerth, K., Mohr, K.I., Kessler, W., Jansen, R., and Müller, R., (2011) Roimatacene: an antibiotic against gram-negative bacteria isolated from Cystobacter ferrugineus $\mathrm{Cb}$ G35 (myxobacteria). Chemistry 17, 7875-7881

Zhang, X., Yao, Q., Cai, Z., Xie, X., and Zhu, H. (2013) Isolation and Identification of Myxobacteria from Saline-Alkaline Soils in Xinjiang, China. PLOS ONE 8(8):e70466. doi:10.1371/journal.pone.0070466 


\title{
Chapter B
}

\section{Paenilarvins, iturin family lipopeptides from the honey bee pathogen Paenibacillus larvae}

\author{
Sakshi Sood, Heinrich Steinmetz, Kathrin I. Mohr, Marc Stadler, Marvin Djukic, Rolf \\ Daniel and Rolf Müller
}

(Current Status - Published online in ChemBioChem on July $28^{\text {th }}, 2014$ )

\section{Author's contribution to this work}

Performed and analyzed genomic data: MD

Purified compounds: SS, HS

Performed and analyzed biological assay data: SS

Analyzed chemical and NMR data: HS

Wrote the paper: SS, HS

Provided research facilities and supervised the project: MS, RD, RM

Conceived and designed the experiments: HS (chemical), KM (biological) 


\section{B.1. Abstract}

Paenibacillus larvae has been extensively studied in past few decades as an appalling honey bee pathogen. In the present work, we screened $P$. larvae genotype ERIC I and II crude methanol extracts for antimicrobial activity based on the detection of 4 secondary metabolite gene clusters showing homology to various known antibiotic clusters during complete genome sequencing project. Paenilarvins, iturinic lipopeptides exhibiting strong antifungal activity were identified and purified guided by bioactivity assays from cultures of $P$. larvae ERIC II. The molecular structures were determined using 1D, 2D NMR spectroscopy and mass spectrometry. Nonribosomally synthesized peptides can yield a plethora of advantages to the producing organisms from survival benefits to regulation of metabolism and virulence, apart from some being pharmaceutically significant, e.g. in the form of antibiotics. Paenilarvins represent the first secondary metabolites isolated and characterized from $P$. larvae. These lipopeptides may play a role in $P$. larvae survival and pathogenesis but further studies are needed to investigate their function in detail.

\section{B.2. Introduction}

American foulbrood (AFB), one of the most catastrophic honey bee (Apis mellifera) epidemics, is a notifiable disease in many countries and strict laws are enforced for its regulation. Burning of infected or diseased colonies is considered the most effective control measure against AFB in most countries bringing huge losses. Despite being a deleterious and economically significant disease for honey bees, the complete molecular pathogenesis of AFB remains obscure.

Paenibacillus larvae, a Gram positive, rod shaped and spore forming bacterium which only infects the larvae in first instar stage through its spores, is the etiological agent of AFB. Genotyping of $P$. larvae isolates on the basis of repetitive-element PCR using enterobacterial repetitive intergenic consensus (ERIC) primers identified four genotypes of $P$. larvae (P. larvae ERIC I - IV) (Genersch et al., 2006) which vary in varied aspects 
but most importantly, in their level of virulence (Genersch, 2010; Genersch et al., 2005; Rauch et al., 2009). Strains of the genotypes ERIC I and ERIC II are the most common field isolates and account for most of the AFB outbreaks worldwide, making them most significant genotypes for study.

Fluorescence in situ hybridization (FISH) using $P$. larvae-specific, 16S rRNA targeted oligonucleotide probes was used to study the interaction between the host and the pathogen (genotype ERIC I and II) in detail (Yue et al., 2008). This study gave a deep insight of the disease progression starting from the ingestion of spores of $P$. larvae by the honey bee larvae through contaminated food to the formation of hard scales from dead larval remains. These hard scales are the source for millions of bacterial spores, which can further be transmitted by use of contaminated equipment or by adult honey bees feeding on contaminated honey within a colony as well as between colonies.

A number of potential virulence factors have been described to be instrumental in $P$. larvae pathogenesis in recent years. The $P$. larvae secretome was studied in detail and established as a source of some of these factors (Antunez et al., 2010). Enolase, produced by $P$. larvae was identified as a highly toxic and immunogenic protein to Apis mellifera larvae (Antunez et al., 2011a). P. larvae was also detected to produce metalloprotease in vivo during bee larvae infection (Antunez et al., 2011b). Both aforementioned enzymes have been reported to be possibly involved in larval degradation during and after infection. Poppinga et al. (2012) recently established the functional S-layer protein, SpIA of $P$. larvae ERIC II as an important virulence factor. The latest report on the subject has affirmed that $P$. larvae ERIC I strains produce $A B$ binary toxins, Plx1 and PIx2 as virulence factors (Fünfhaus et al., 2013).

Lately in an attempt to identify all the putative virulence genes in $P$. larvae, suppression subtractive hybridization (SSH) was applied for comparative genomics of $P$. larvae genotypes (Fünfhaus et al., 2009) and several fragments showing homology to nonribosomal peptide synthetases (NRPSs) and polyketide synthetases (PKSs) subunits belonging to the iturin family lipopeptides, bacitracin and bacillomycin were 
identified in different genotypes. Open reading frames showing close homology to NRPSs of the antibiotic plipastatin and surfactin were also observed in another study on $P$. larvae genome using a combination of bioinformatics and proteomics (Chan et al., 2011). NRPS and PKS are giant multifunctional enzyme systems with numerous domains bundled together into functional modules responsible for nonribosomal assembly of secondary metabolites. The end products of such complex multistep biosynthetic process are nonribosomal peptides (NRP) or polyketides (PK) or their hybrids with broad structural diversity and biological activities like enzyme inhibitors, immunosuppressants, antiparasitic agents, bioherbicides, plant growth regulators, biopesticides, bioinsecticides, antitumor agents as well as in microbial survival and pathogenesis (Demain, 2006; Romero et al., 2011).

Our interest in natural products from bacterial and fungal sources and confirmation of the presence of NRPSs and NRPS/PKS hybrid clusters in P. larvae DSM 25719 (ERIC I) and DSM 25430 (ERIC II) genome (Djukic et al., 2014), allured us to examine $P$. larvae for the production of novel secondary metabolites which could be of significance to the pathogen and possibly as pharmaceuticals or agrochemicals. In this study we identified and isolated a group of related lipopeptides, paenilarvins from $P$. larvae DSM 25430 (ERIC II), elucidated the molecular structure of the major products and determined their biological activity. All the isolated paenilarvins belong to the iturin family of lipopeptides and are closely related to mojavensin $A$, an iturinic lipopeptide produced by marine-derived bacterium Bacillus mojavensis B0621 A (Ma et al., 2012).

\section{B.3. Results and Discussion}

\section{B.3.1. Bioactivity screening of P. larvae DSM 25719 and DSM 25430}

The potential of $P$. larvae for the production of bioactive secondary metabolites was confirmed following complete genome sequencing of $P$. larvae DSM 25719 (ERIC I) and DSM 25430 (ERIC II) which has been recently reported by Djukic et al. Four different NRPS or NRPS/PKS hybrid clusters were identified during this study based on genome analysis and comparison with variations in domain organization and size of clusters 
between the two genotypes. The two strains were grown in the presence of an absorber resin (Amberlite XAD 16) and the crude methanol extracts were tested for their antimicrobial activity against a panel of microorganisms including gram positive and gram negative bacteria, yeast and filamentous fungi in 96 well plate diffusion assay.

Crude extracts of DSM 25719 (ERIC I) and DSM 25430 (ERIC II) showed activity against Nocardia flava, Staphylococcus aureus, Chromobacterium violaceum and Mucor hiemalis. However, while the antibacterial activity was not reproducible, the antifungal activity against $M$. hiemalis was persistent in extracts from various batches of shake flasks. Also, crude extracts from DSM 25430 strain were much more bioactive in comparison to DSM 25719 extracts against $M$. hiemalis with MIC value of $2.1 \mu \mathrm{g} / \mathrm{ml}$ for the former strain. These results prompted us to follow the observed antifungal activity and investigate the production of these antifungal compounds by P. Iarvae DSM 25430 (ERIC II).

Paenibacillus spp. have been described as an accomplished source of biologically active secondary metabolites in a number of previous studies (Li-jing et al., 2011; Raza et al., 2009; Stansly et al., 1947; Anandraj et al., 2009; Qian et al., 2011; Wu et al., 2011). Therefore, bioassay guided HPLC fractionation and MS spectrometry was implemented to $P$. larvae DSM 25430 extract to detect the antifungal compounds. This displayed the presence of a group of closely related peptides ranging in their molecular masses from $1069 \mathrm{Da}$ to $1112.7 \mathrm{Da}$. The mass range of the identified compounds was closely related to iturin family compounds like mycosubtilin, mojavensin produced by Bacillus spp. (Peypoux et al., 1986; Ma et al., 2012) but a detailed structural analysis was essential for complete characterization.

\section{B.3.2. Structural analysis of paenilarvins}

P. larvae DSM 25430 strain (ERIC II) was fermented in 5L scale with XAD-16 amberlite adsorber resin which was collected and eluted with methanol to give a crude extract at the end of fermentation. Successive chromatography of the crude methanol extract on silica gel and reverse phase column guided by antifungal activity against $M$. hiemalis, 
yielded 7 compounds belonging to the paenilarvin group. The most active compounds, paenilarvins $A$ and $B$ were used for further structure elucidation and biological assays. The complete molecular structures of paenilarvins $A$ and $B$ were determined by mass and nuclear magnetic resonance (NMR) (1D and 2D) spectral analysis.

Paenilarvin A (1) was obtained by RP-HPLC as colorless amorphous powder. The positive HRESIMS spectra presented a molecular ion cluster at $m / z 1112.6108[\mathrm{M}+\mathrm{H}]^{+}$ consistent with the molecular formula $\mathrm{C}_{52} \mathrm{H}_{82} \mathrm{~N}_{13} \mathrm{O}_{14}$ (calcd. 1112.6099), which was supported by the ${ }^{13} \mathrm{C}$ NMR spectrum. The intense IR absorptions between 1600 and $1700 \mathrm{~cm}^{-1}$ and between 3100 and $3400 \mathrm{~cm}^{-1}$ showed the presence of amide $\mathrm{C}=\mathrm{O}$ and $\mathrm{NH}$ groups, respectively. The weak UV band at $277 \mathrm{~nm}$ and $223 \mathrm{~nm}$ was in good agreement with a peptide containing aromatic amino acids. Among all 52 carbon in signals the ${ }^{13} \mathrm{C}$ NMR spectrum of 1 displayed 13 amide carbonyl signals between 172.7 and $177.9 \mathrm{ppm}$ and 8 methine carbons in the range between 48.5 and $63.2 \mathrm{ppm}$ as it could be expected for a small peptide. Correspondingly, the complex ${ }^{1} \mathrm{H}$ NMR spectrum of 1 furnished $17 \mathrm{H} / \mathrm{D}$ exchangeable protons between $6.75 \mathrm{ppm}$ and $8.75 \mathrm{ppm}$ and at least 8 methine protons in the range 4.05 to $5.0 \mathrm{ppm}$. A detailed analysis of COSY, TOCSY, HSQC and HMBC data for paenilarvin A (1) (Fig.B1) in $\mathrm{CD}_{3} \mathrm{OH}$ solution revealed the presence of four asparagine, one tyrosine, one glutamine, and one proline residues (Table B1). Furthermore, the methylene group $\left(\delta_{\mathrm{C}} 44.2, \delta_{\mathrm{H}} 2.49,2.41\right)$ and the methine $\left(\delta_{\mathrm{C}} 48.5, \delta_{\mathrm{H}} 4.15\right)$ adjacent to the doublet of $23 \mathrm{NH}\left(\delta_{\mathrm{H}} 7.49,9.5 \mathrm{~Hz}\right)$ were recognized as parts of a long B-amino-acid. The methyl doublet $\left(\delta_{C} 19.7, \delta_{H} 0.86\right)$ and a methyl triplet $\left(\delta_{\mathrm{C}} 11.8, \delta_{\mathrm{H}} 0.87\right)$ signals and the combination of the remaining methine $\left(\delta_{\mathrm{C}}\right.$ $\left.35.7, \delta_{H} 1.29\right)$ and methylene signals $\left(\delta_{C} 30.6,, \delta_{H} 1.32,1.13\right)$ by ${ }^{1} H,{ }^{1} \mathrm{H}$ COSY and ${ }^{1} \mathrm{H},{ }^{13} \mathrm{C}$ HMBC correlations completed the structure of this part as 3-amino-14-methylhexadecanoic acid (B-Aa). The sequence of the amino acid residues in 1 was established by analysis of HMBC and ROESY correlations showing connections of the a-methine protons of amino acid residues to carbonyl carbons of the neighboring residues as comprised in Fig.B2 and Table B1. 


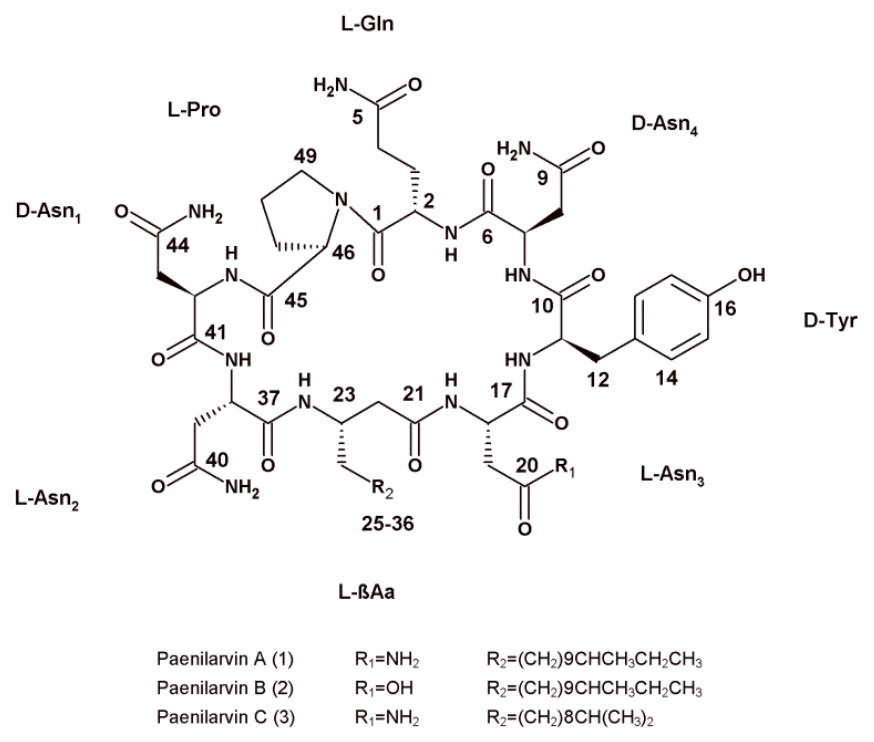

Fig. B1. Structures of paenilarvins A (1), B (2), and C (3).

\section{B.3.3. Mass spectrometric analysis}

The sequence of the amino acid residues was analyzed by ESI TOF MSMS and on Orbitrap FTMS mass spectrometer analyzer. The full scan spectrum of (1) showed a single and a doubly-charged molecular ions at $\mathrm{m} / \mathrm{z} 1112.6108[\mathrm{M}+\mathrm{H}]^{+}$and $\mathrm{m} / \mathrm{z} 556.8098$ $[\mathrm{M}+2 \mathrm{H}]^{2+}$ (Fig.BS12) while the MS1 spectrum of Paenilarvin B (2) showed similar single and doubly-charged ions at $\mathrm{m} / \mathrm{z} 1113.5963[\mathrm{M}+\mathrm{H}]^{+}$and $\mathrm{m} / \mathrm{z} 557.3026[\mathrm{M}+2 \mathrm{H}]^{2+}$ (Fig.BS25). Equally the MS1 spectrum of (3) showed values at $\mathrm{m} / \mathrm{z} 1084.5804[\mathrm{M}+\mathrm{H}]^{+}$ and $m / z 542.7948[\mathrm{M}+2 \mathrm{H}]^{2+}$ (Fig.BS39). For further investigations the MS2 spectra of (1) were analyzed. Based on the $m / z[\mathrm{M}+\mathrm{H}]^{+} 1112.610$ two fragments at $m / z 707.44$ and $\mathrm{m} / \mathrm{z} 406.17$ were observed. These two fragments are in conclusion with the partial amino acid sequence: Pro, Asn, Asn, B-Aa, Asn and additionally the sequence Gln, Asn, Tyr, both in good agreement with the HMBC- and ROESY-NMR data. The compounds $\mathbf{1}$ and $\mathbf{3}$ showing the same amino acid sequence of Gln, Asn, Tyr, Asn, BAa, Asn, Asn, Pro but different B-amino-acid side chains. MS3 spectra showed the immonium ion for the side chains: $\left(\mathrm{NH}_{2}{ }^{+}=\mathrm{CH}-\mathrm{CH}_{14} \mathrm{H}_{29}\right)$ that could also be identified for compound 1 and 2 at $m / z=226.167$, as well as for compound $3\left(\mathrm{NH}_{2}{ }^{+}=\mathrm{CH}-\mathrm{C}_{12} \mathrm{H}_{25}\right)$ at $m / z=198.220$. 
Table B1. ${ }^{1} \mathrm{H}(700 \mathrm{MHZ})$ and ${ }^{13} \mathrm{C}(175 \mathrm{MHz})$ NMR data of paenilarvin $\mathrm{A}(1)$ in $\mathrm{CD}_{3} \mathrm{OH}$

\begin{tabular}{|c|c|c|c|c|c|c|}
\hline $\begin{array}{l}\text { Amino } \\
\text { acid }\end{array}$ & Position & $\delta_{\mathrm{C}}$ & $\delta_{\mathrm{H}}(J$ in $\mathrm{Hz})$ & COSY & HMBC & $\begin{array}{l}\text { ROESY } \\
\text { Selected signals }\end{array}$ \\
\hline \multirow[t]{9}{*}{ Gln } & 1 & 172.8 & & & $2,2 \mathrm{NH}, 46$ & \\
\hline & 2 & 51.7 & $4.65(\mathrm{~m})$ & $3 \mathrm{ab}, \mathrm{NH}$ & $3 a b, 4 a b$ & $49 a b$ \\
\hline & $3 a$ & 27.9 & $2.11(\mathrm{~m})$ & $2,3 \mathrm{~b}, 4 \mathrm{ab}$ & $2,4 \mathrm{ab}$ & $2,49 b$ \\
\hline & $3 b$ & & $2.06(\mathrm{~m})$ & $2,3 a, 4 a b$ & & $2,4 \mathrm{a}$ \\
\hline & $4 a$ & 31.9 & $2.33(\mathrm{~m})$ & $3 a b$ & $2,5 \mathrm{NH}_{2}$ & \\
\hline & $4 b$ & & $2.32(\mathrm{~m})$ & $3 a b$ & & \\
\hline & 5 & 177.8 & & & $3,4 \mathrm{ab}, 5 \mathrm{NH}$ & \\
\hline & $2 \mathrm{NH}$ & & $7.46(\mathrm{~d}, 8.0)$ & 2 & & $2,3 a b$ \\
\hline & $5 \mathrm{NH}_{2}$ & & $7.53(\mathrm{~s}), 6.81(\mathrm{~s})$ & & & $3 a b, 4 a b$ \\
\hline \multirow[t]{7}{*}{ Asn 4} & 6 & 173.1 & & & $2,2 \mathrm{NH}, 7,8 \mathrm{ab}$ & \\
\hline & 7 & 52.5 & $4.64(\mathrm{~m})$ & $7 \mathrm{NH}, 8 \mathrm{ab}$ & $8 \mathrm{ab}$ & \\
\hline & $8 \mathrm{a}$ & 36.9 & $2.73(\mathrm{~m})$ & $7,8 b$ & 7 & 7 \\
\hline & $8 b$ & & $2.70(\mathrm{~m})$ & $7,8 \mathrm{a}$ & & 7 \\
\hline & 9 & 175.0 & & & $7,8 \mathrm{ab}, 9 \mathrm{NH}_{2}$ & \\
\hline & $7 \mathrm{NH}$ & & $8.28(\mathrm{~d}, 6.7)$ & 7 & 11 & $8 \mathrm{ab}, 11$ \\
\hline & $9 \mathrm{NH}_{2}$ & & $7.54(\mathrm{~s}), 6.85(\mathrm{~s})$ & & & $8 \mathrm{ab}$ \\
\hline \multirow[t]{9}{*}{ Tyr } & 10 & 174.3 & & & $7,11 \mathrm{NH}, 12 \mathrm{ab}$ & \\
\hline & 11 & 58.4 & $4.28(\mathrm{~m})$ & $11 \mathrm{NH}, 12 \mathrm{ab}$ & $12 \mathrm{ab}$ & $12 \mathrm{ab}, 14$ \\
\hline & $12 \mathrm{a}$ & 36.8 & $3.09(\mathrm{dd}, 14.4,5)$ & $11,12 b$ & 11,14 & $11,12 b, 14$ \\
\hline & $12 b$ & & $2.91(\mathrm{~m})$ & $11,12 \mathrm{a}$ & & \\
\hline & 13 & 128.6 & & & $11,12 \mathrm{ab}, 15$ & \\
\hline & $14^{*}$ & 131.3 & $7.06(\mathrm{~d}, 8.4)$ & 15 & $12 \mathrm{ab}$ & $11,12 \mathrm{ab}$ \\
\hline & $15^{*}$ & 116.5 & $6.72(\mathrm{~d}, 8.4)$ & 14 & & \\
\hline & 16 & 157.4 & & & 14,15 & \\
\hline & $11 \mathrm{NH}$ & & $8.49(\mathrm{~d}, 8.0)$ & 11 & & $12 \mathrm{ab}, 18$ \\
\hline \multirow[t]{7}{*}{ Asn 3} & 17 & 175.0 & & & $\begin{array}{l}11,11 \mathrm{NH}, 18, \\
19\end{array}$ & \\
\hline & 18 & 52.7 & $4.61(\mathrm{dd}, 13.5,7)$ & $18 \mathrm{NH}, 19 \mathrm{ab}$ & $19 \mathrm{ab}$ & \\
\hline & $19 \mathrm{a}$ & 38.2 & $2.56(\mathrm{dd}, 15.3,7.5)$ & $18,19 b$ & $18,20 \mathrm{NH}_{2}$ & 18 \\
\hline & $19 b$ & & $2.48(\mathrm{~m})$ & $18,19 \mathrm{a}$ & & $18,23,24 b$ \\
\hline & 20 & 174.6 & & & $18,19,20 \mathrm{NH}_{2}$ & \\
\hline & $18 \mathrm{NH}$ & & $8.01(\mathrm{~d}, 4.7)$ & 18 & & $22 \mathrm{ab}, 23$ \\
\hline & $20 \mathrm{NH}_{2}$ & & $7.58(\mathrm{~s}) 6.81(\mathrm{~s})$ & & & $19 \mathrm{ab}$ \\
\hline \multirow{5}{*}{$\begin{array}{l}\text { B-amino- } \\
\text { acid } \\
(\text { ß-Aa) }\end{array}$} & 21 & 174.2 & & & $18 \mathrm{NH}$ & \\
\hline & $22 \mathrm{a}$ & 44.2 & $2.49(\mathrm{~m})$ & 23 & $23 \mathrm{NH}, 24 \mathrm{a}$ & $23 \mathrm{NH}, 24 \mathrm{a}$ \\
\hline & $22 b$ & & $2.41(\mathrm{~d}, 14.0)$ & 23 & & $23,24 b$ \\
\hline & 23 & 48.5 & $4.15(\mathrm{~m})$ & $\begin{array}{l}22 \mathrm{ab}, \quad 23 \mathrm{NH}, \\
24 \mathrm{ab}\end{array}$ & $21,22 \mathrm{ab}$ & $22 b, 24 b, 25-33$ \\
\hline & $\begin{array}{l}24 a \\
24 b\end{array}$ & 36.2 & $\begin{array}{l}1.65(\mathrm{~m}) \\
1.50(\mathrm{~m})\end{array}$ & $\begin{array}{l}23,25 \mathrm{ab} \\
23,25 \mathrm{ab}\end{array}$ & $22 b$ & $\begin{array}{l}22 \mathrm{a}, 23,23 \mathrm{NH}, 25- \\
33\end{array}$ \\
\hline
\end{tabular}




$\begin{array}{llllll}25-33 & 27.1-31.2 & 1.33-1.09(\mathrm{~m}) & & & 22 \mathrm{ab}, 23 \\ 34 & 35.7 & 1.29(\mathrm{~m}) & 34 \mathrm{Me}, 35 & 34 \mathrm{Me}, 36 \mathrm{Me} & \\ 34 \mathrm{Me} & 19.7 & 0.86(\mathrm{~d}, 6.2) & 34 & 33,35 & \\ 35 \mathrm{a} & 30.6 & 1.32(\mathrm{~m}) & 34,36 \mathrm{Me} & 34 \mathrm{Me}, 36 \mathrm{Me} & \\ 35 \mathrm{~b} & & 1.13(\mathrm{~m}) & 34,36 \mathrm{Me} & & \\ 36 \mathrm{Me} & 11.8 & 0.87(\mathrm{t}, 7.3) & 35 \mathrm{ab} & 34 & \\ 23 \mathrm{NH} & & 7.49(\mathrm{~d}, 9.5) & 23 & & 23,38\end{array}$

\begin{tabular}{|c|c|c|c|c|c|c|c|}
\hline \multirow[t]{8}{*}{ Asn2 } & 37 & 173.6 & \multirow[b]{2}{*}{$492(\mathrm{~m})$} & \multirow{2}{*}{\multicolumn{2}{|c|}{$38 \mathrm{NH} 39 \mathrm{ab}$}} & \multicolumn{2}{|l|}{ 23NH, 39ab } \\
\hline & 38 & 51.7 & & & & \multicolumn{2}{|l|}{$39 \mathrm{ab}$} \\
\hline & $39 a$ & 38.8 & $2.97(\mathrm{dd}, \quad 15.7$ & \multicolumn{2}{|c|}{$38,39 \mathrm{~b}$} & \multirow[t]{3}{*}{$40 \mathrm{NH}_{2}$} & $40 \mathrm{NH}_{2}$ \\
\hline & $39 b$ & & $5.1)$ & \multirow{2}{*}{\multicolumn{2}{|c|}{$38,39 a$}} & & \multirow[t]{2}{*}{$39 \mathrm{a}$} \\
\hline & & & $\begin{array}{l}2.61 \\
8.6)\end{array}(\mathrm{dd}, \quad 15.7$, & & & & \\
\hline & 40 & \multirow[t]{3}{*}{174.9} & & & & \multirow{3}{*}{$39 \mathrm{ab}, 40 \mathrm{NH}_{2}$} & \\
\hline & $38 \mathrm{NH}$ & & $7.73(\mathrm{~d}, 7.5)$ & \multirow{2}{*}{\multicolumn{2}{|c|}{38}} & & $38,39 b$ \\
\hline & $40 \mathrm{NH}_{2}$ & & $7.44(\mathrm{~s}), 6.85(\mathrm{~s})$ & & & & $39 \mathrm{ab}$ \\
\hline \multirow{7}{*}{ Asn1 } & 41 & 172.9 & & & & \multicolumn{2}{|l|}{38,43} \\
\hline & 42 & 52.0 & $4.48(\mathrm{~m})$ & \multicolumn{2}{|c|}{$42 \mathrm{NH}, 43 \mathrm{ab}$} & \multicolumn{2}{|l|}{$43 \mathrm{ab}$} \\
\hline & $43 a$ & 36.7 & \multirow{2}{*}{$\begin{array}{l}2.92(\mathrm{~m}) \\
2.84(\mathrm{dd}, 16,4.5)\end{array}$} & $42,43 b$ & & \multirow[t]{2}{*}{$42,44 \mathrm{NH}_{2}$} & $42,44 \mathrm{NH}_{2}$ \\
\hline & $43 b$ & & & $42,43 a$ & & & 42 \\
\hline & 44 & \multirow[t]{3}{*}{175.4} & & & & \multirow[t]{3}{*}{$42,44 \mathrm{NH}_{2}$} & \\
\hline & $42 \mathrm{NH}$ & & $8.55(\mathrm{~d}, 6.9)$ & 42 & & & 46,47 \\
\hline & $44 \mathrm{NH}_{2}$ & & $7.61(\mathrm{~s}), 6.85(\mathrm{~s})$ & & & & $43 \mathrm{ab}$ \\
\hline \multirow[t]{9}{*}{ Pro } & 45 & 175.4 & \multirow[b]{2}{*}{$4.23(\mathrm{dd}, 7.5,7.5)$} & & & \multicolumn{2}{|l|}{$46,47 a b$} \\
\hline & 46 & 63.3 & & $47 \mathrm{ab}$ & & $47,48,49 \mathrm{ab}$ & $47 \mathrm{a}, 48 \mathrm{~b}$ \\
\hline & $47 \mathrm{a}$ & 30.6 & $2.25(\mathrm{~m})$ & $46,48 \mathrm{ab}$ & & \multirow[t]{2}{*}{46} & \multirow[t]{2}{*}{$46,48 b$} \\
\hline & $47 b$ & & $1.91(\mathrm{~m})$ & $46,48 \mathrm{ab}$ & & & \\
\hline & $48 \mathrm{a}$ & 26.2 & $2.10(\mathrm{~m})$ & $47 \mathrm{ab}$ & $48 b$ & \multirow[t]{3}{*}{$46,47 a, 49 b$} & \multirow[t]{3}{*}{$47 \mathrm{a}$} \\
\hline & $48 b$ & & \multirow[t]{2}{*}{$1.96(\mathrm{~m})$} & $49 \mathrm{ab}$ & & & \\
\hline & & & & $\begin{array}{l}47 a b \\
49 a b\end{array}$ & $48 \mathrm{a}$ & & \\
\hline & $49 a$ & 49.1 & \multirow{2}{*}{$\begin{array}{l}4.01(\mathrm{~m}) \\
3.75(\mathrm{ddd}, 17,7, \\
6)\end{array}$} & $48 \mathrm{ab}, 49 \mathrm{~b}$ & & \multirow[t]{2}{*}{$2,47 a, 48 b$} & $2,48 b, 49 b$ \\
\hline & $49 b$ & & & $48 \mathrm{ab}, 49 \mathrm{a}$ & & & $2,48 \mathrm{a}, 49 \mathrm{a}$ \\
\hline
\end{tabular}




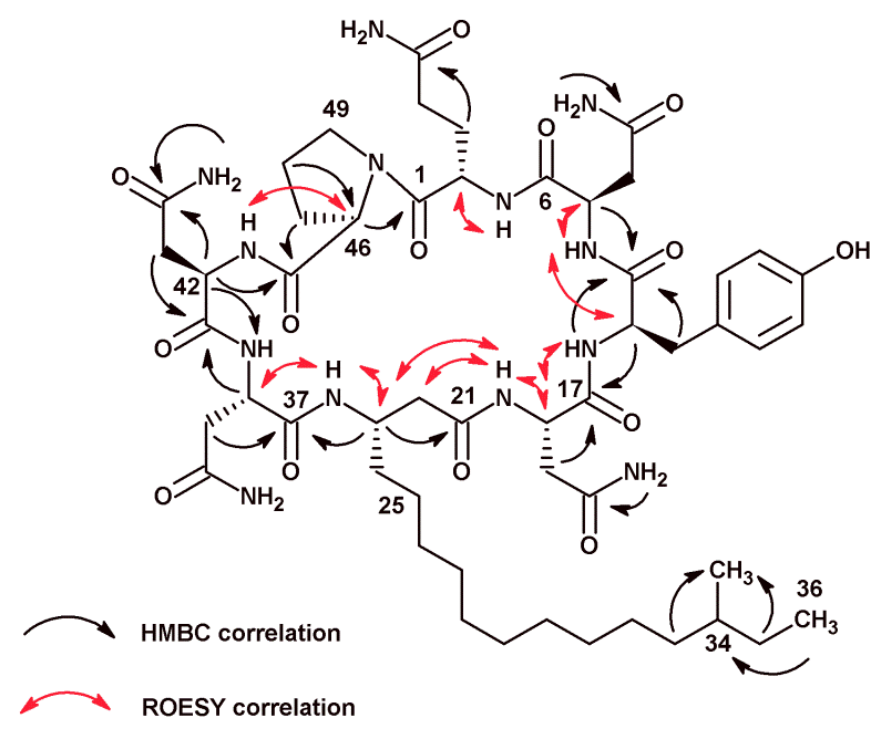

Fig. B2. Key HMBC and ROESY correlations of paenilarvin A (1)

The stereochemistry of paenilarvin A (1) was determined by Marfey's method (Marfey, 1984; Bhushan and Bruckner, 2004). After final hydrolysis the solution was compared with standard L- and D-amino acids and authentic amino acid derivatives by coinjection. Thus, paenilarvin A (1) was found to contain 1 (L)-Pro, 2 (L)-Asn, 2 (D)-Asn, 1 (L)-Gln, and 1 (D)-Tyr. The positions of the $\mathbf{D}$ - and L-Asn residues were assigned by analysis of the 2D ROESY spectrum analogously to the cyclic lipopeptides maribasins $A$ and $B$, which similary comprise seven amino acid residues and the same type of side chain (Zhang et al., 2010). Accordingly, the stereochemistry was deduced by mapping the 2D ROESY correlations between the a-proton and the amide proton of amino acid 1 (AS1) and between the amide proton of AS1 and the a-proton of AS2, that both have the same configuration. The strong ROESY correlation from the Asn $n_{1}$ amide proton $\left(\delta_{H}\right.$ 8.55) with the L-Pro $\alpha$-proton $\left(\delta_{H} 4.23\right)$ and the absence of a correlation with the Asn ${ }_{1} \alpha-$ proton $\left(\delta_{H} 4.48\right)$ indicated that the amino acid side chain is on the opposite side of the main plain of the molecule. Thus, Asn $n_{1}$ was assigned to have $\mathbf{D}$ configuration. The Asn ${ }_{2}$ amide proton $\left(\delta_{H}\right.$ 7.73) neither showed a correlation with the Asn ${ }_{1} \alpha$-proton $\left(\delta_{H} 4.48\right)$ nor with the $A s n_{2}$ a-proton $\left(\delta_{H}\right.$ 4.92), which implied $\mathbf{L}$ configuration for $A s n_{2}$. ROESY correlations of the amide protons and a-protons of $A s n_{2}, B$-proton of $B-A a$ and $A_{s n_{3}}$ showed that they were on the same side, respectively. Thus, $B-A a$ and $A_{3} n_{3}$ had $\mathbf{L}$ 
configurations (Fig.B1). Corresponding to the $\mathbf{D}$ configuration of Tyr derived by Marfey's method, a ROESY correlation of the Tyr amide proton $\left(\delta_{H} 8.49\right)$ with the $A s n_{3}$ a-proton $\left(\delta_{H}\right.$ 4.61) was found but no correlation with the Tyr $\alpha$-proton $\left(\delta_{H} 4.28\right)$. The ROESY correlation of the amide proton $\left(\delta_{H} 8.28\right)$ of $A_{s n_{4}}$ with the $\alpha$-proton $\left(\delta_{H} 4.28\right)$ of Tyr and with the a-proton $\left(\delta_{H} 4.64\right)$ of $A_{s n_{4}}$ suggested $\mathbf{D}$ configuration for $A_{s n_{4}}$. In contrast, no correlation of amide proton $\left(\delta_{H}\right.$ 7.46) of the $L$ Gln with the a-proton of $A_{s n_{4}}$ was observed. Consequently, the structure of paenilarvin A (1) was finally established as cyclo L-Pro-D-Asn ${ }_{1}$-L-Asn 2 -L-B-amino-14-methylhexadecanoic acid-L-Asn ${ }_{3}$-D-Tyr-D$\mathrm{Asn}_{4}$-L-GIn.

\section{B.3.4. Antimicrobial and cytotoxic activity of paenilarvins}

Screening of pure paenilarvins, A (1) and B (2) obtained from P. larvae DSM 25430 (ERIC II) for antimicrobial activities against a broad panel of bacteria, fungi and yeasts showed no activity against the group of Gram positive and negative bacteria tested. However, both lipopeptides showed activity against most of the fungi and yeasts but 1 showed much better activity compared to $\mathbf{2}$ with minimum inhibitory concentration (MIC) as low as $2.1 \mu \mathrm{g} / \mathrm{ml}$ against Trichosporon oleaginous, Aspergillus clavatus, Botryotinia fuckeliana and Hormoconis resinae (Table B2). Compound $\mathbf{2}$ was not significantly active against all the fungi and yeast tested with a lowest MIC value observed as $16.6 \mu \mathrm{g} / \mathrm{ml}$. When $\mathbf{1}$ and $\mathbf{2}$ were tested for their cytotoxicity against mouse fibroblast cell line L929, 1 was again found to be much more active $\left(\operatorname{LD}_{50} 4 \mu \mathrm{g} / \mathrm{ml}\right)$ than 2 which showed no significant cytotoxic activity $\left(\mathrm{LD}_{50}>10 \mu \mathrm{g} / \mathrm{ml}\right)$.

Lipopeptides belonging to the iturin family (iturin, mycosubtilin, bacillomycin and bacillopeptin) have long been known to possess strong antifungal and haemolytic activity, but show only restricted antibacterial effects (Maget-Dana and Peypoux, 1994). Thus, the strong antifungal activities of iturins producing organisms make them promising candidates as biocontrol agents. Mojavensin A was also found to be active against soil borne phytopathogens like Fusarium oxysporum f. sp. cucumerinum and Valsa mali and weakly inhibitory to Staphylococcus aureus (Ma et al., 2012). However, 
anteiso - C15 mojavensin A is not as active against fungi as other iturins. Hence, the strong antifungal activity and no antibacterial activity of compounds $\mathbf{1}$ and $\mathbf{2}$ against our test organisms correspond to the biological activity data available for other iturins.

Table B2. Minimum inhibitory concentration (MIC) in $\mu \mathrm{g} / \mathrm{mL}$ of paenilarvin $\mathrm{A}$ (1) and B (2)

\begin{tabular}{|c|c|c|c|c|}
\hline & Test organisms & Paenilarvin A (1) & Paenilarvin B (2) & Control $^{[\mathrm{a}, \mathrm{b}, \mathrm{b} 2, \mathrm{c}]}$ \\
\hline \multirow{8}{*}{ 离 } & Saccharomyces cerevisiae (DSM 70449) & 4.2 & 33.3 & $4.2^{[\mathrm{b}]}$ \\
\hline & Rhodotorula glutinis (DSM 10134) & 4.2 & 16.6 & $<0.52^{[\mathrm{b}]}$ \\
\hline & Candida albicans (DSM 1665) & 4.2 & n.i. & $8.3^{[\mathrm{b} 2]}$ \\
\hline & Wickerhamomyces anomalus (DSM 6766) & 4.2 & 16.6 & $2.1^{[\mathrm{b}]}$ \\
\hline & Nematospora coryli (DSM 6981) & 4.2 & 33.3 & $3.3^{[\mathrm{b}]}$ \\
\hline & Trichosporon oleaginous (DSM 11815) & 2.1 & 16.6 & $0.52^{[\mathrm{b}]}$ \\
\hline & Debaryomyces hansenii (DSM 3428) & 4.2 & n.i. & $8.3^{[\mathrm{b}]}$ \\
\hline & Pichia membranifaciens (DSM 21959) & 4.2 & 33.3 & $0.052^{[\mathrm{b}]}$ \\
\hline \multirow{5}{*}{ 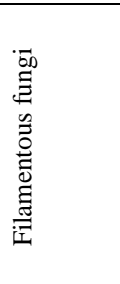 } & Mucor hiemalis (DSM 2656) & 4.2 & 33.3 & $2.1^{[\mathrm{b}]}$ \\
\hline & Aspergillus clavatus (DSM 816) & 2.1 & 8.3 & $2.1^{[\mathrm{b}]}$ \\
\hline & Botryotinia fuckeliana (DSM 877) & 2.1 & 16.6 & $2.1^{[\mathrm{b}]}$ \\
\hline & Hormoconis resinae (DSM 1203) & 2.1 & 16.6 & $<0.25^{[\mathrm{b}]}$ \\
\hline & Penicillium capsulatum (DSM 2210) & 4.2 & 33.3 & $16.6^{[\mathrm{b}]}$ \\
\hline \multirow{5}{*}{ 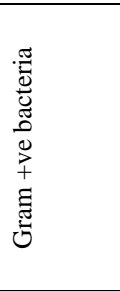 } & Nocardioides simplex (DSM 20130) & n.i. & n.i. & $16.6^{[\mathrm{a}]}$ \\
\hline & Nocardia sp. (DSM 43069) & n.i. & n.i. & $<0.52^{[\mathrm{a}]}$ \\
\hline & Staphylococcus aureus (DSM 346) & n.i. & n.i. & $0.1^{[\mathrm{a}]}$ \\
\hline & Micrococcus luteus (DSM 20030) & n.i. & n.i. & $3.3^{[\mathrm{a}]}$ \\
\hline & Paenibacillus polymyxa (DSM 36) & n.i. & n.i. & $6.7^{[\mathrm{a}]}$ \\
\hline \multirow{2}{*}{ हี } & Pseudomonas aeruginosa (DSM 50071) & n.i. & n.i. & $0.13^{[\mathrm{c}]}$ \\
\hline & Chromobacterium violaceum (DSM 30191) & n.i. & n.i. & $1.0^{[\mathrm{a}]}$ \\
\hline
\end{tabular}

${ }^{[a]}$ Oxytetracyclin hydrochloride, $(1 \mathrm{mg} / \mathrm{ml}) ;{ }^{[b]}$ Nystatin, $(1 \mathrm{mg} / \mathrm{ml}$ in $\mathrm{MeOH}) ;{ }^{[b 2]}$ Nystatin, $\left(1 \mathrm{mg} / \mathrm{ml}\right.$ in DMSO); ${ }^{[c]}$ Gentamycin $(1 \mathrm{mg} / \mathrm{ml})$; Paenilarvin A and B (1mg/ml in $\mathrm{MeOH})$; n.i. - no inhibition

\section{B.4. Conclusion}

$P$. larvae is pathogen of great economic as well as environmental concern because of its ability to cause one of the most serious and contagious diseases of honey bees, American foulbrood. We have come a far way in understanding $P$. larvae and its 
pathogenicity in the last century but several aspects of the biology of the pathogen still remain elusive. In our study, we explored the secondary metabolite potential of $P$. larvae owing to the identification of genome segments homologous to putative NRPSs and PKSs clusters of closely related organisms like Bacillus subtilis (Fünfhaus et al., 2009; Chan et al., 2011).

Out of the four NRPS or NRPS/PKS hybrid clusters identified during complete genome sequencing and annotation of $P$. larvae DSM 25719 (ERIC I) and DSM 25430 (ERIC II), one of the clusters was found to show significant similarity to the NRPS/PKS hybrid clusters encoding for iturin family synthetases present in Bacillus subtilis (Djukic et al., 2014). Iturin family compounds have been characterized as lipopeptides with a $\beta$-amino fatty acid chain linked to a circular heptapeptide produced by Bacillus sp. (Maget-Dana and Peypoux, 1994). The first report of production of an iturin like compound by a Paenibacillus $s p$. came in 2000 from a chitinolytic bacterial strain, Paenibacillus koreensis $\mathrm{YC} 00^{\top}$, isolated from a compost sample collected from Chinju, Republic of Korea (Chung et al., 2000) but the complete molecular structure of the compound was not described.

In the course of this study, we were able to identify a group of antifungal compounds within the mass range from 1069.7 $\mathrm{Da}$ to $1112.7 \mathrm{Da}$ in our bioactivity guided assays with crude extracts of $P$. larvae DSM 25430 (ERIC II). Purification and molecular characterization of the compounds using mass spectrometry and NMR spectroscopy clarified that the compounds belong to iturin family and the complete structure elucidation of the purified compounds revealed two major cyclic compounds produced by the strain, paenilarvins $A$ and $B$. Paenilarvin $A$ has the same amino acid sequence as mojavensin A ( $\mathrm{Ma}$ et al., 2012) except that the B- Aa side chain is extended by two methylene units. Paenilarvin $B$ has the same side chain as paenilarvin $A$ but contains an aspartic acid instead of asparagine in position $\mathrm{Asn}_{2}$.

Paenilarvins $A$ and $B$ showed no antibacterial activity but strong antifungal activity against rare human pathogenic species like Aspergillus clavatus and Penicillium 
capsulatum and phytopathogens like Nematospora coryli and Botryotinia fuckeliana. Paenilarvins also exhibited significant activity against a commercially important fuel contaminant fungus, Hormoconis resinae (Haggett and Morchat, 1992). Cytotoxic activity against mouse fibroblast cell line L929 was also observed during the study.

Production of paenilarvins by the pathogen in vitro raises the question of their potential involvement and function in the pathogenicity of $P$. larvae. Production of secondary metabolites usually serves survival functions in the producing organisms in their ecological niche (Demain and Fang, 2000) as these compounds can generate competitive advantage in nature but may also be employed by a producing microorganism for an entirely different purpose. Considering the fact that honey bees are exposed to a lot of pathogens like parasitic mites, small hive beetle, microsporidian parasites, viruses and fungi, (Campano et al., 1999; Murray and Aronstein, 2008) it can be speculated that $P$. larvae produces paenilarvins to be dominant amongst these potential pathogens. Certain microbes also show entomopathogenic activity, infecting and killing insects by production of secondary metabolites (Kanoaka et al., 1977). However, these hypothesis can only be ascertained by examining the inhibitory effects of these compounds against prospective honey bee pathogens and honey been larvae.

It is also known that antibiotics can exert diverse effects at subinhibitory concentrations and their response depends upon the concentration used, a concept called as hormensis (Calabrese and Baldwin, 2002; Davies et al., 2006). The analysis of effect of subinhibitory antibiotic concentrations have demonstrated regulation of key biological processes including transcription, translation, transport of exoproteins, stress response, quorum sensing, and biofilm formation (Romero et al., 2011). This has also been studied in regard to virulence and pathogenic properties of a number of bacteria (Aminov, 2009). In 2011, aureusimine A and aureusimine B were determined to be regulators of virulence factor expression for exotoxins, $Y$ hemolysin, regulatory, redox associated superantigen like genes in $S$. aureus (Wyatt et al., 2011). Paenilarvins $A$ and $B$ could also be involved in regulation of physiological processes in $P$. larvae which can only be confirmed upon a deep investigation on molecular level. 
It is noteworthy that production of paenilarvins was only detected in P. larvae ERIC II (DSM 25430, DSM 16116) and none at all in ERIC I (DSM 25719, DSM 7030). This observation is supported by the genome sequencing and annotation data revealing the presence of an incomplete NRPS/PKS cluster in the DSM 25719 (ERIC I) genome. However, we still observed some antibacterial and antifungal activity in crude extracts of P. larvae DSM 25719 strains during our preliminary experiments indicating that they have the potential to produce some other biologically active secondary metabolites which still need to be discovered.

In this study, we could purify and characterize one group of secondary metabolites produced by P. larvae DSM 25430 (ERIC II), which possibly plays an important role for the pathogen. However, their precise function in pathogenesis needs still to be determined. The presence of other biosynthetic clusters is obvious from the genomic data obtained for the pathogen suggesting that other important secondary metabolites remain undiscovered (Djukic et al., 2014; Fünfhaus et al., 2009). Further studies are needed to unravel the products of these biosynthetic clusters and to investigate their exact role in pathogenesis. A comprehensive understanding of $P$. larvae pathogenesis combined with molecular evidence on virulence factors can pave the way for effectively dealing with this devastating honey bee disease in the future.

\section{B.5. Experimental Section}

\section{B.5.1. General Experimental Procedures}

Spectral and physico-chemical data were obtained with the following instruments: NMR spectra were recorded on a Bruker Ascend $700 \mathrm{TCl}$ cryo probe spectrometer $\left({ }^{1} \mathrm{H} 700\right.$ $\mathrm{MHZ},{ }^{13} \mathrm{C} 176 \mathrm{MHz}$ ) using $\mathrm{CD}_{3} \mathrm{OH}$ as solvent. All 2D NMR spectra were analyzed using ACD NMR Spectrus software. IR spectra were recorded on a Perkin-Elmer FT-IR spectrometer. UV spectra were measured on a Shimadzu UV/Vis-2102 spectrometer with methanol as solvent. Optical rotation: Perkin Elmer $241 \mathrm{MC}$ spectrometer, solvent methanol. Mass spectra were obtained on a Bruker maXis UHRTOF using electrospray 
ionization (ESI) in positive mode, molecular formulae were calculated including the isotope pattern (Smart Formula algorithm) and in addition ESI TOF MSMS on Finnigan LTQ Orbitrap Mass spectrometer. Analytical HPLC: Gradient in 25 min. Solvent A: 5\% acetonitrile $95 \%$ water $+5 \mathrm{mM} \mathrm{NH}_{4} \mathrm{CH}_{3} \mathrm{COO}$, pH $5.5\left(40 \mu \mathrm{L} \mathrm{CH}_{3} \mathrm{COOH} / \mathrm{L}\right)$; Solvent B: $95 \%$ acetonitrile $5 \%$ water $+5 \mathrm{mM} \mathrm{NH}_{4} \mathrm{CH}_{3} \mathrm{COO}$, pH $5.5\left(40 \mu \mathrm{L} \mathrm{CH}_{3} \mathrm{COOH} / \mathrm{L}\right)$; flow: $600 \mu \mathrm{L} / \mathrm{min}$.; Temperature $40^{\circ} \mathrm{C}$; column: Waters Acquit y BEH C18, $50 \times 2.1 \mathrm{~mm}, 1.7 \mu \mathrm{m}$ equipped with the corresponding pre-column.

\section{B.5.2. Bacterial strain and growth conditions}

Four P. larvae isolates representing genotypes ERIC I (DSM 25719, DSM 7030) and ERIC II (DSM 25430, DSM 16116) were used for the study. The strains had been cryopreserved at $-80^{\circ}$ C. DSM 25430 was reactivated in $20 \mathrm{~mL}$ of modified MYPGP broth (Nordström and Fries, 1995) with beef infusion replaced by $2 \%$ meat extract and $0.2 \%$ vitamin solution at neutral $\mathrm{pH}$. The strain was then sub-cultured to $600 \mathrm{~mL}$ in the same medium in Erlenmeyer's flasks and used as a seed culture. Scale-up fermentation (5.2L) of the strain was performed in $1 \mathrm{~L}$ Erlenmeyer's flasks each containing $350 \mathrm{ml}$ of the modified MYPGP media supplemented with $2 \%$ Amberlite XAD-16 resin and incubated at $30^{\circ} \mathrm{C}, 160 \mathrm{rpm}$ for 6 days. The XAD resin was separated and collected from the culture at the end of fermentation by sieving.

\section{B.5.3. Extraction and isolation of active compounds}

$1 \mathrm{~L}$ of methanol was used for elution from the adsorber XAD resin packed in a glass column. Methanol was evaporated from the extract to give a dry crude material of $6.14 \mathrm{~g}$. This extract was separated on $120 \mathrm{~g}$ of silica gel in an open column equilibrated with ethyl acetate. Elution from the silica gel was made using ethyl acetate and increasing percentage of methanol from $100 \%$ ethyl acetate to $100 \%$ methanol to obtain mainly 4 fractions. The organic solvent from each fraction was evaporated.

Fractions $3(1.19 \mathrm{~g})$ which was eluted with $2 \mathrm{~L}$ of $50 / 50(\mathrm{v} / \mathrm{v})$ ethyacetate and methanol from silica gel was dissolved in methanol and passed through RP cartridge [Strata ${ }^{\mathrm{TM}}-\mathrm{X}$ $33 \mu \mathrm{m}$, Polymeric Reversed Phase, $200 \mathrm{mg} / 6 \mathrm{~mL}$ ] and concentrated to $6 \mathrm{~mL}$. Processed 
sample was further purified by four runs of preparative RP-HPLC [column $250 \times$

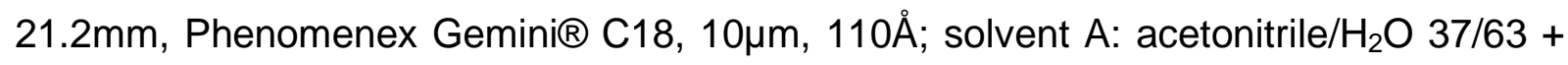
$0.1 \%$ formic acid; solvent $\mathrm{B}$ : acetonitrile $/ \mathrm{H}_{2} \mathrm{O} 40 / 60+0.1 \%$ formic acid; gradient: $0 \% \mathrm{~B}$ for $35 \mathrm{~min}$ and $100 \%$ B from 35 to $80 \mathrm{~min}$; flow rate $20 \mathrm{~mL} / \mathrm{min}$; UV detection at $210 \mathrm{~nm}$ ]. The fractions contained pure paenilarvin A (1) $6.8 \mathrm{mg}$, paenilarvin $B(2) 3.9 \mathrm{mg}$, and paenilarvin C (3) $12.8 \mathrm{mg}$ along with other related peptides.

\section{B.5.4. Assignment of absolute stereochemistry of amino acid residues}

Marfey's method was used for determining the stereochemistry of amino acid residues in paenilarvins. $1.1 \mathrm{mg}$ of the lipopeptide was hydrolysed in $0.5 \mathrm{~mL}$ of $6 \mathrm{~N} \mathrm{HCL}$ at $110^{\circ} \mathrm{C}$ overnight. Then, the sample was dried in vacuum. $50 \mu \mathrm{L}$ Water, FDAA (Marfey's reagent, $100 \mu \mathrm{L})$ in acetone and $1 \mathrm{M}$ sodium-hydrogen carbonate $(20 \mu \mathrm{L})$ were added to the hydrolyzed products and the mixture heated at $41^{\circ} \mathrm{C}$ for one hour. $10 \mu \mathrm{L} 2 \mathrm{M} \mathrm{HCL}$ was added later to stop the reaction and the mixture was evaporated to dryness. The residue was dissolved in $0.5 \mathrm{~mL}$ Water/ DMSO $1: 1$ and analyzed with reversed-phase

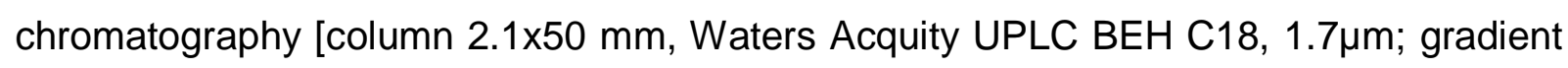
acetonitrile/water $5 / 95+0.1 \%$ formic acid to acetonitrilie/water $40 / 60+0.1 \%$ formic acid in $30 \mathrm{~min}$; flow rate $0.6 \mathrm{~mL} / \mathrm{min}$; UV detection: DAD, MS-spectrometer Amazon ${ }^{\mathrm{TM}}$ Bruker ESI mode.

\section{B.5.5. Structural characteristics of paenilarvins}

Paenilarvin A (1) white, solid; UV (methanol) $\lambda_{\max }(\log \varepsilon) 223$ (4.27 sh), 277 (3.35) nm; $[\alpha]_{\mathrm{D}}+15.4^{\circ}\left(c=0.039\right.$, DMSO); $R_{\mathrm{t}}: 10.9 \mathrm{~min} ; v=3383,2927,2855,1668,1541,1517$, $1384 \mathrm{~cm}^{-1} ;{ }^{1} \mathrm{H}$ and ${ }^{13} \mathrm{C}$ NMR (see Table B1); HRESIMS: $\mathrm{m} / z$ 1112.6108 $\left[\mathrm{M}+\mathrm{H}^{+}\right]$(calcd. for $\left.\mathrm{C}_{52} \mathrm{H}_{82} \mathrm{~N}_{13} \mathrm{O}_{14}, 1112.6099\right)$.

Paenilarvin B (2) white, solid; UV (methanol) $\lambda_{\max }(\log \varepsilon) 223$ (4.23), $277(3.35) \mathrm{nm}$; [ $\left.\alpha\right]_{\mathrm{D}}$ $+6.4^{\circ}\left(c=0.075\right.$, methanol); $R_{\mathrm{t}}: 11.1 \mathrm{~min} ;{ }^{1} \mathrm{H} \mathrm{NMR}\left(\mathrm{CD}_{3} \mathrm{OH}+5 \mu \mathrm{L} \mathrm{HCOOH}, 700 \mathrm{MHz}\right)$ selected signals: for Asp: $\delta_{\mathrm{C}} 173.0 \mathrm{ppm}$ (C37), n.o. (C38), 37.6 (C39), 175.4ppm (C40), $\delta_{\mathrm{H}} 4.87$ (m, H38), 3 and 2.84 ( $\left.\mathrm{m}, \mathrm{H} 39 \mathrm{a}, \mathrm{b}\right), 7.78$ (38NH); HRESIMS: $\mathrm{m} / z$ 1113.5953 [M $+\mathrm{H}^{+}$] (calcd. for $\left.\mathrm{C}_{52} \mathrm{H}_{81} \mathrm{~N}_{12} \mathrm{O}_{15}, 1113.5939\right)$. 
Paenilarvin C (3) white, solid; UV (methanol) $\lambda_{\max }(\log \varepsilon) 223$ (4.80), $277(3.35) \mathrm{nm}$; $[\alpha]_{\mathrm{D}}$ $+11.8^{\circ}\left(c=0.221\right.$, DMSO); $R_{\mathrm{t}}: 9.6 \mathrm{~min} ;{ }^{1} \mathrm{H}$ NMR (DMSO- $\left.\mathrm{d}_{6}, 700 \mathrm{MHz}\right)$ selected signals: end of the side chain: $-\mathrm{CH}_{2}\left(\delta_{\mathrm{C}} 38.5, \delta_{\mathrm{H}} 1.24,1.13\right),-\mathrm{CH}\left(\delta_{\mathrm{C}} 27.4, \delta_{\mathrm{H}} 1.49, \mathrm{~m}\right),-\left(\mathrm{CH}_{3}\right)_{2}$ $\left(\delta_{\mathrm{C}} 22.5, \delta_{\mathrm{H}}\right.$ 0.84, d, 6.7, $\mathrm{Hz}$ ); HRESIMS: $\mathrm{m} / \mathrm{z} 1084.5790\left[\mathrm{M}+\mathrm{H}^{+}\right]$(calcd. for $\left.\mathrm{C}_{50} \mathrm{H}_{78} \mathrm{~N}_{13} \mathrm{O}_{14}, 1084.5785\right)$.

\section{B.5.6. Antimicrobial assay}

The MIC of compounds $\mathbf{1}$ and $\mathbf{2}$ was determined against the Gram-positive bacteria (Staphylococcus aureus, Nocardia flava, Micrococcus luteus, Nocardioides simplex and Paenibacillus polymyxa), Gram-negative bacteria (Chromobacterium violaceum, Pseudomonas aeruginosa), filamentous fungi (Mucor hiemalis, Aspergillus clavatus, Hormoconis resinae, Penicillium capsulatum, Botryotinia fuckeliana) and yeasts (Saccharomyces cerevisiae, Candida albicans, Rhodotorula glutinis, Nematospora coryli, Trichosporon oleaginous, Debaryomyces hansenii, Pichia membranifaciens and Wickerhamomyces anomalus). Bacterial test strains were cultivated in EBS medium ( $0.5 \%$ casein peptone, $0.5 \%$ protease peptone, $0.1 \%$ meat extract, $0.1 \%$ yeast extract, $\mathrm{pH} 7.0$ ) and fungi in MYC medium (1.0\% phytone peptone, $1.0 \%$ glucose, $50 \mathrm{mM}$ HEPES [11.9g/L] pH 7.0 ) at $30-37^{\circ} \mathrm{C}, 160 \mathrm{rpm}$ for $24-48 \mathrm{hrs}$ and the cell concentration adjusted to $\mathrm{OD}_{600} 0.01$ for bacteria and $\mathrm{OD}_{548} 0.1$ for yeasts. $10 \mu \mathrm{L}$ aliquots (conc. $1 \mathrm{mg} / \mathrm{mL}$ in $\mathrm{MeOH}$ ) of $\mathbf{1}, 2$ and $5 \mu \mathrm{l}$ aliquots of reference drugs (oxytetracycline hydrochloride (Sigma), $1 \mathrm{mg} / \mathrm{mL}$ in water; nystatin dihydrate (Sigma), $1 \mathrm{mg} / \mathrm{mL}$ in $\mathrm{MeOH}$ or DMSO and gentamycin (Serva), $1 \mathrm{mg} / \mathrm{ml}$ in water) were used. The MIC values were determined in 96 well microtitre plates by 1:1 serial dilution, as previously described (Okanya et al., 2011). The lowest concentration of the drug preventing visible growth of the test strains was taken as the MIC.

\section{B.5.7. Cytotoxicity assay}

Compounds $\mathbf{1}$ and $\mathbf{2}$ were also tested for their cytotoxic activity against mouse fibroblast cell line L929. The $\mathrm{IC}_{50}$ value was determined using MTT assay as previously described (Okanya et al., 2011). 


\section{Acknowledgements}

S.S. is highly indebted to Erasmus Mundus External Cooperation Window for a PhD scholarship and all their support. We acknowledge Christel Kakoschke for recording the NMR spectra and Silke Reineke, Aileen Teichmann, Diana Telkemeyer and Wera Collisi for their technical assistance. We are grateful to Dr. Alberto Plaza for proofreading of this manuscript. 


\section{References}

Aminov, R. I. (2009) The role of antibiotics and antibiotic resistance in nature. Environ. Microbiol. 11(12), 2970-2988

Antunez, K., Anido, M., Evans, J. D., and Zunino, P. (2010) Secreted and immunogenic proteins produced by the honeybee bacterial pathogen, Paenibacillus larvae. Vet. Microbial. 141, 385-389

Antunez, K., Anido, M., Arredondo, D., Evans, J. D., and Zunino, P. (2011a) Paenibacillus larvae enolase as a virulence factor in honey bee larvae infection. Vet. Microbial. 147, 83-89

Antunez, K., Arredondo, D., Anido, M., and Zunino, P. (2011b) Metalloprotease production by Paenibacillus larvae during the infection of honeybee larvae. Microbiol. 157, 1474-1480

Bhushan, R., and Bruckner, H. (2004) Marfey's reagent for chiral amino acid analysis: A review. Amino Acids 27, 231-247

Calabrese, E. J., and Baldwin, L. A. (2002) Defining hormesis. Hum. Exp. Toxicol. 21, 91-97

Campano, F., Flores, J. M., Puerta, F., Ruiz, J. A., and Ruz, J. M. (1999) Fungal diseases of the honeybee (Apis mellifera L.). In: Colin M. E., Ball B. V., Kilani M. (eds.). Bee disease diagnosis. Zaragoza: CIHEAM, 61-68. (Options Méditerranéennes: Série B. Etudes et Recherches; n. 25)

Chan, Q. W., Cornman, R. S., Birol, I., Liao, N.Y., Chan, S. K., Docking, T. R., et al. (2011) Updated genome assembly and annotation of Paenibacillus larvae, the agent of American foulbrood disease of honey bees. BMC Genomics 12, 450

Chung, Y. R., Kim, C. H., Hwang, I., and Chun, J. (2000) Paenibacillus koreensis sp. nov., a new species that produces an iturin-like antifungal compound. Int. J. Syst. Evol. Micro. 50, 1495-1500

Davies, J., Spiegelman, G. B., and Yim, G. (2006) The world of subinhibitory antibiotic concentrations. Curr. Opin. Microbiol. 9, 445-453

Demain, A. L. (2006) From natural products discovery to commercialization: a success story. J Ind Microbiol. Biotechnol. 33, 486-495

Demain, A. L., and Fang, A. (2000) The Natural Functions of Secondary Metabolites. Advances in Biochemical Engineering/ Biotechnology, Vol. 69 Managing Editor: Th. Scheper

Djukic, M., Brzuszkiewicz, E., Fünfhaus, A., Voss, J., Gollnow, K., Poppinga, L., Liesegang, H., GarciaGonzalez, E., Genersch, E., and Daniel, R. (2014) How to Kill the Honey Bee Larva: Genomic Potential and Virulence Mechanisms of Paenibacillus larvae. PLos Pathogens (In Press)

Fünfhaus, A., Ashiralieva, A., Borriss, R., and Genersch, E. (2009) Use of suppression subtractive hybridization to identify genetic differences between differentially virulent genotypes of Paenibacillus larvae, the etiological agent of American Foulbrood of honeybees. Environ. Microbiol. Rep 1, 240-250

Fünfhaus, A., Poppinga, L., and Genersch, E. (2013) Identification and characterization of two novel toxins expressed by the lethal honey bee pathogen Paenibacillus larvae, the causative agent of American foulbrood. Environ. Microbiol. 15(11), 2951-2965

Genersch, E. (2010) American Foulbrood in honeybees and its causative agent, Paenibacillus larvae. $J$ Invert. Path. 103 (2010) S10-S19 
Genersch, E., Forsgren, E., Pentikainen, J., Ashiralieva, A., Rauch, S., Kilwinski, J., and Fries, I. (2006) Reclassification of Paenibacillus larvae subsp. pulvifaciens and Paenibacillus larvae subsp. larvae as Paenibacillus larvae without subspecies differentiation Intern. J. Sys. Evol. Microb. 56, 501-511

Genersch, E., Ashiralieva, A., and Fries, I. (2005) Strain- and genotype-specific differences in virulence of Paenibacillus larvae subsp. larvae, a bacterial pathogen causing American foulbrood disease in honeybees. App. Environ. Microbiol. 71, 7551-7555

Haggett, R. D. and Morchat, R. M. (1992) Microbiological contamination: Biocide treatment in naval distillate fuel. Int. Biodeterior. Biodegrad. 29(1), 87-99

Kanoaka, M., Isogai, A., Murakoshi, S., Ichjnoe, M., Suzuki, A., and Tamura, S. (1977) Bassianolide, a new insecticidal cyclodepsipeptide from Beauveria bassiana and Verticillium lecanii. Agric. Biol. Chem. 42(3), 629-635

Ma, Z., Wang, N., Hu, J., and Wang, S. (2012) Isolation and characterization of a new iturinic lipopeptide, mojavensin A produced by a marine-derived bacterium Bacillus mojavensis B0621A. J. antib. 65, 317322

Maget-Dana, R., and Peypoux, F. (1994) Iturins, a special class of pore forming lipopeptides: biological and physicochemical properties. Toxicology $87,151-174$

Marfey, P. (1984) Determination of D-amino acids. II. Use of a bifunctional reagent, 1,5-difluoro-2,4dinitrobenzene. Carlsberg Res. Commun. 49, 591-596

Murray, K. D., and Aronstein, K. A. (2008) Transformation of the Gram-positive honey bee pathogen, Paenibacillus larvae, by electroporation. J. Microbiol. Meth. 75, 325-328

Nordström, S., and Fries, I. (1995) A comparison of media and cultural conditions for identification of Bacillus larvae in honey. J. Apic. Res. 34, 97-103

Okanya, P. W., Mohr, K. I., Gerth, K., Jansen, R., and Müller, R. (2011) Marinoquinolines A-F, pyrroloquinolines from Ohtaekwangia kribbensis (Bacteroidetes) J. Nat. Prod. 74, 603-608

Poppinga, L., Janesch, B., Fünfhaus, A., Sekot, G., Garcia-Gonzalez, E., Hertlein, G., et al. (2012) Identification and Functional Analysis of the S-Layer Protein SplA of Paenibacillus larvae, the Causative Agent of American Foulbrood of Honey Bees. PLoS Pathog. 8(5): e1002716. doi:10.1371/journal.ppat.1002716

Romero, D., Traxler, M. F., López, D., and Kolter, R. (2011) Antibiotics as Signal Molecules. Chem. Rev. 111(9), 5492-5505

Rauch, S., Ashiralieva, A., Hedtke, K., and Genersch, E. (2009) Negative correlation between individualinsect-level virulence and colony-level virulence of Paenibacillus larvae, the etiological agent of American Foulbrood of honeybees. Appl. Environ. Microbiol. 75, 3344-3347

Wyatt, M. A., Wang, W., Roux, C. M., Beasley, F. C., Heinrichs, D. E., Dunman, P. M. and Magarvey, N. A. (2010) Clarification of "Staphylococcus aureus Nonribosomal Peptide Secondary Metabolites Regulate Virulence". Science 329, 294 (Corrected 2011) 
Yue, D., Nordhoff, M., Wieler L. H. and Genersch, E. (2008) Fluorescence in situ hybridization (FISH) analysis of the interactions between honeybee larvae and Paenibacillus larvae, the causative agent of American foulbrood of honeybees (Apis mellifera). Environ. Microbiol. 10, 1612-1620

Zhang, D. J., Liu, R. F., Li, Y. G., Tao, L. M., and Tian, L. L. (2010) Two New Antifungal Cyclic Lipopeptides from Bacillus marinus B-9987. Chem. Pharm. Bull. 58(12), 1630-1634 


\section{Supplemental information}

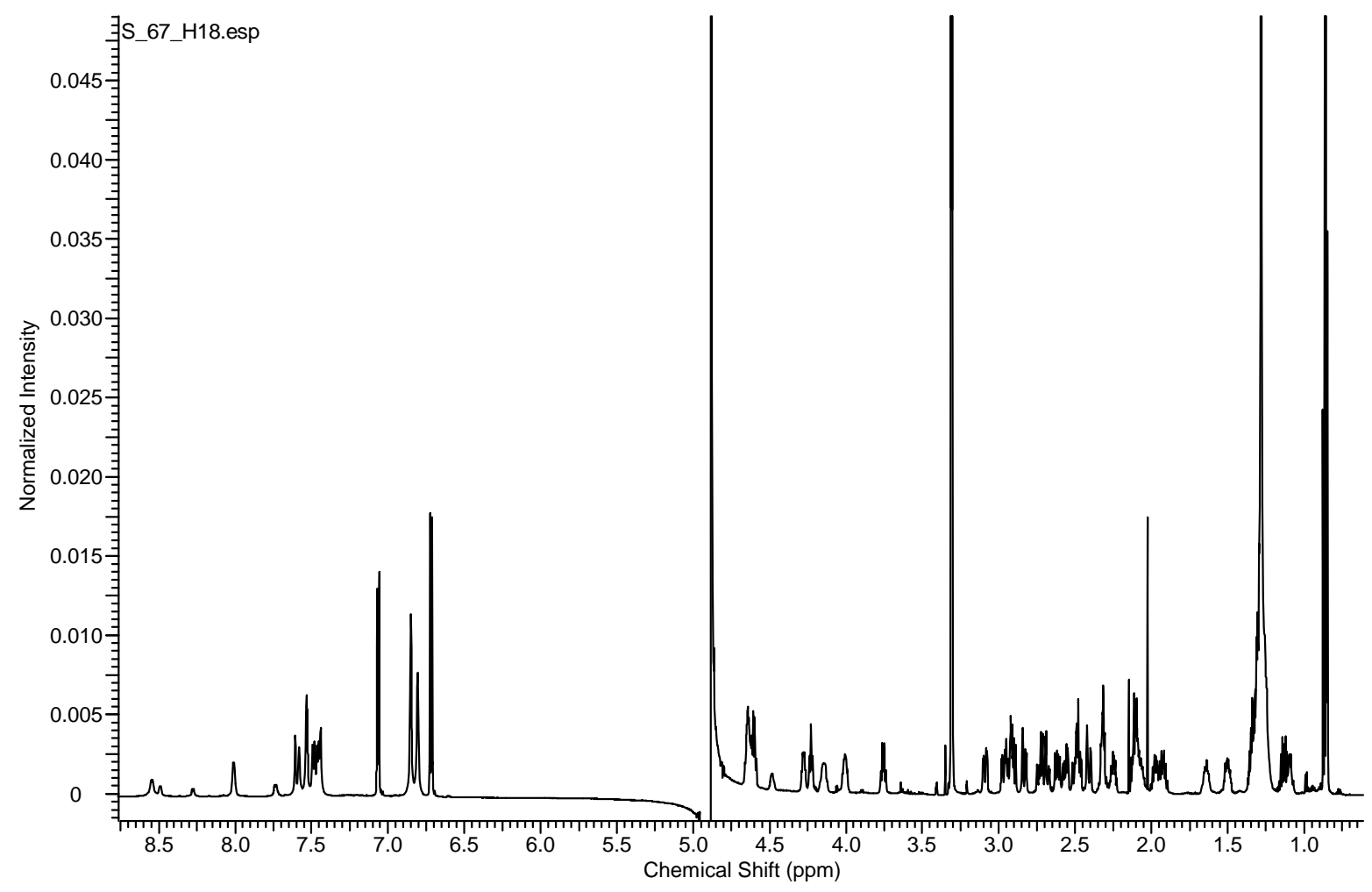

Figure BS1. ${ }^{1} \mathrm{H}$ NMR of 1 in $\mathrm{CD}_{3} \mathrm{OH}, 700 \mathrm{MHz}$ 


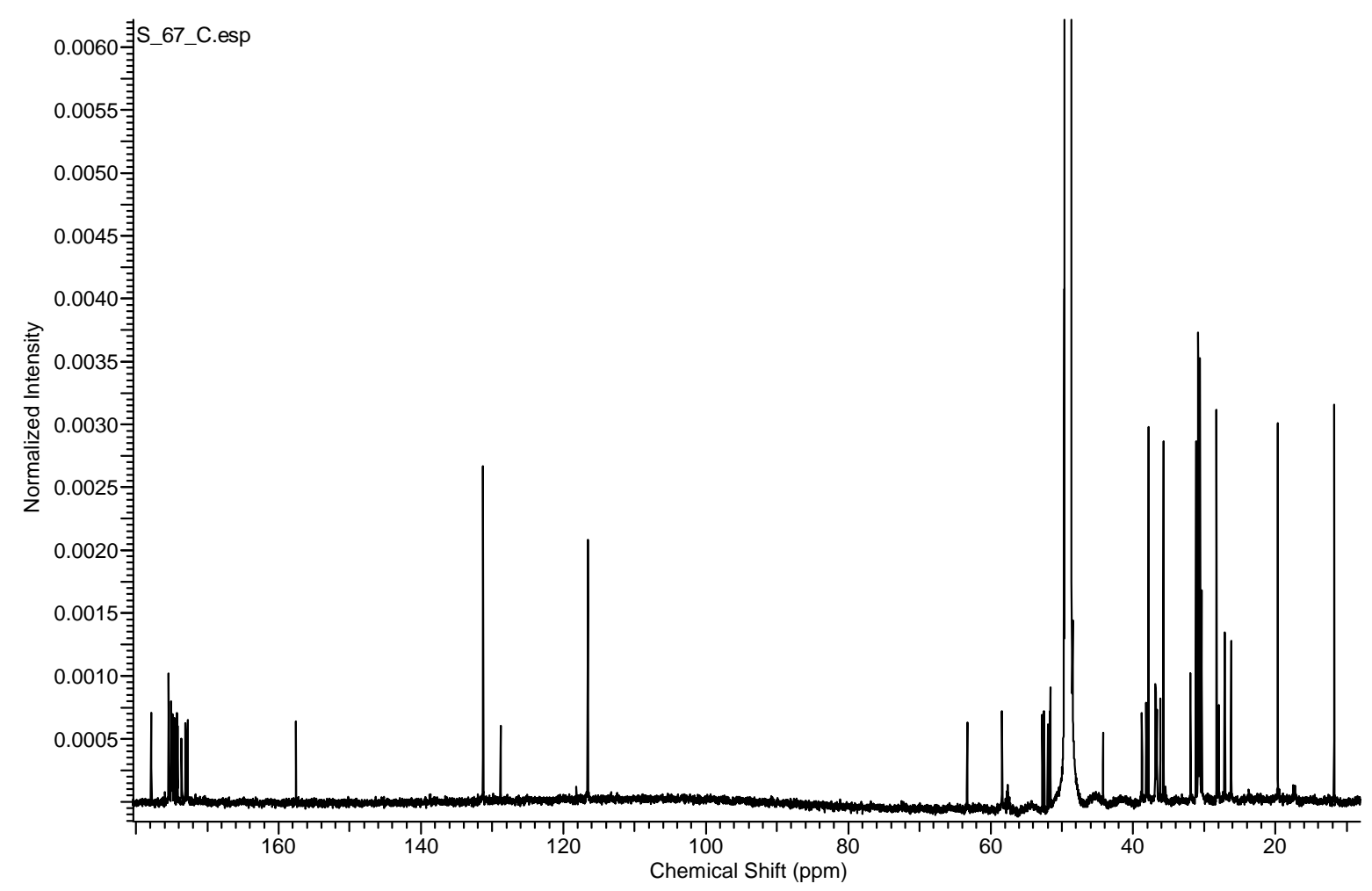

Figure BS2. ${ }^{13} \mathrm{C}$ NMR of 1 in $\mathrm{CD}_{3} \mathrm{OH}, 176 \mathrm{MHz}$

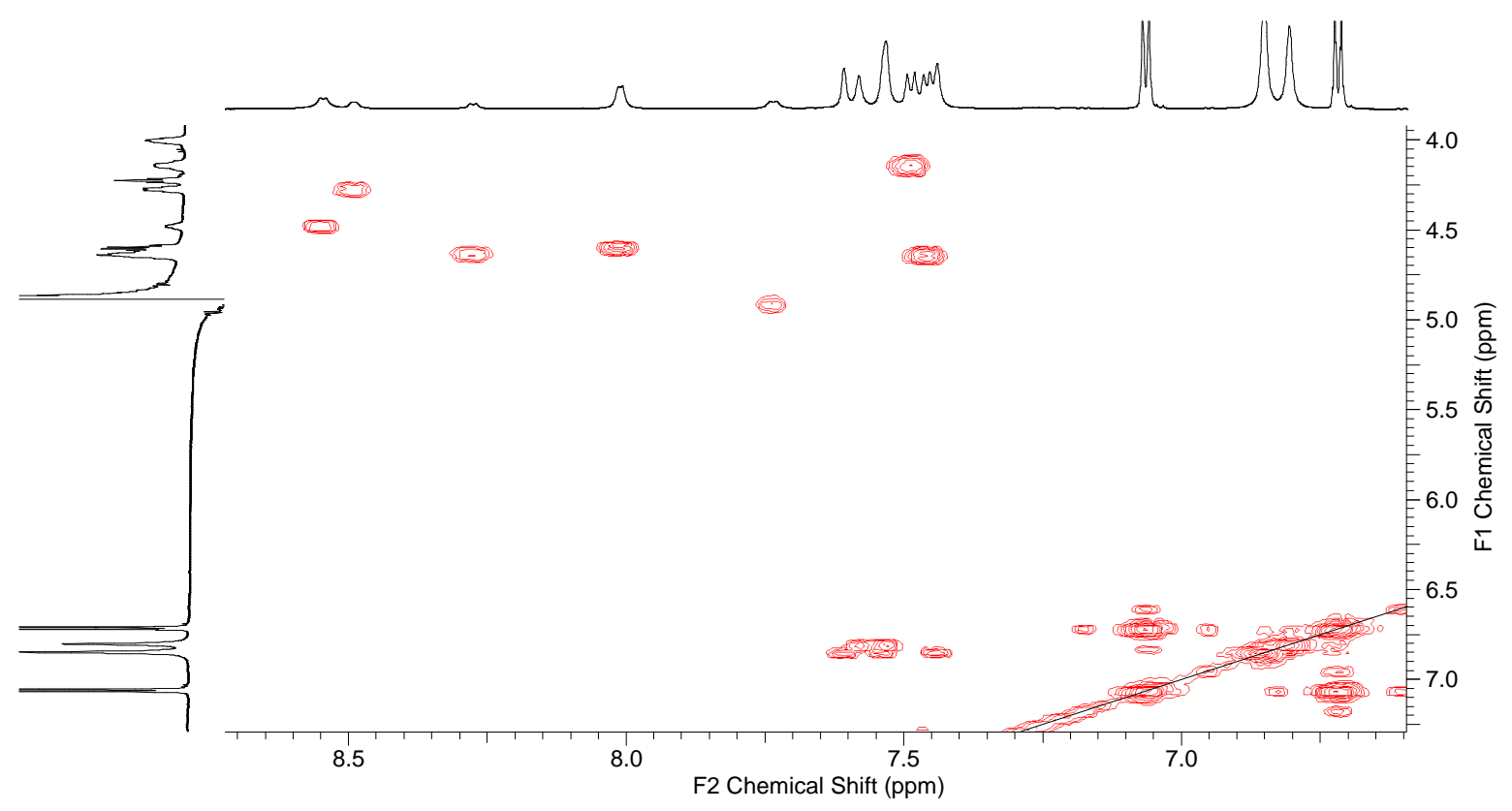

Figure BS3. ${ }^{1} \mathrm{H}-{ }^{1} \mathrm{H}$ COSY NMR of 1 in $\mathrm{CD}_{3} \mathrm{OH}$, selected area 


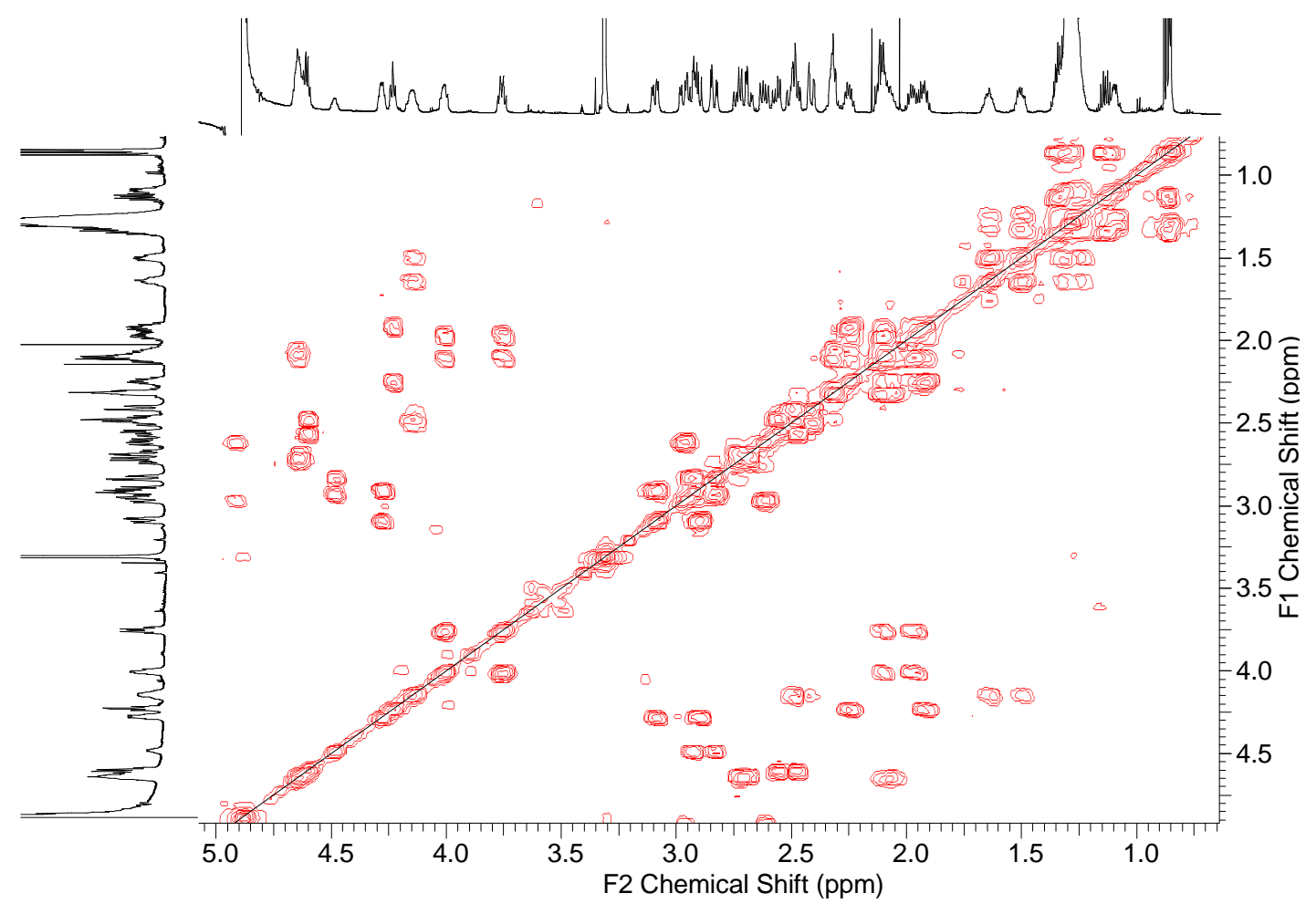

Figure BS4. ${ }^{1} \mathrm{H}-{ }^{1} \mathrm{H}$ COSY NMR of 1 in $\mathrm{CD}_{3} \mathrm{OH}$, selected area

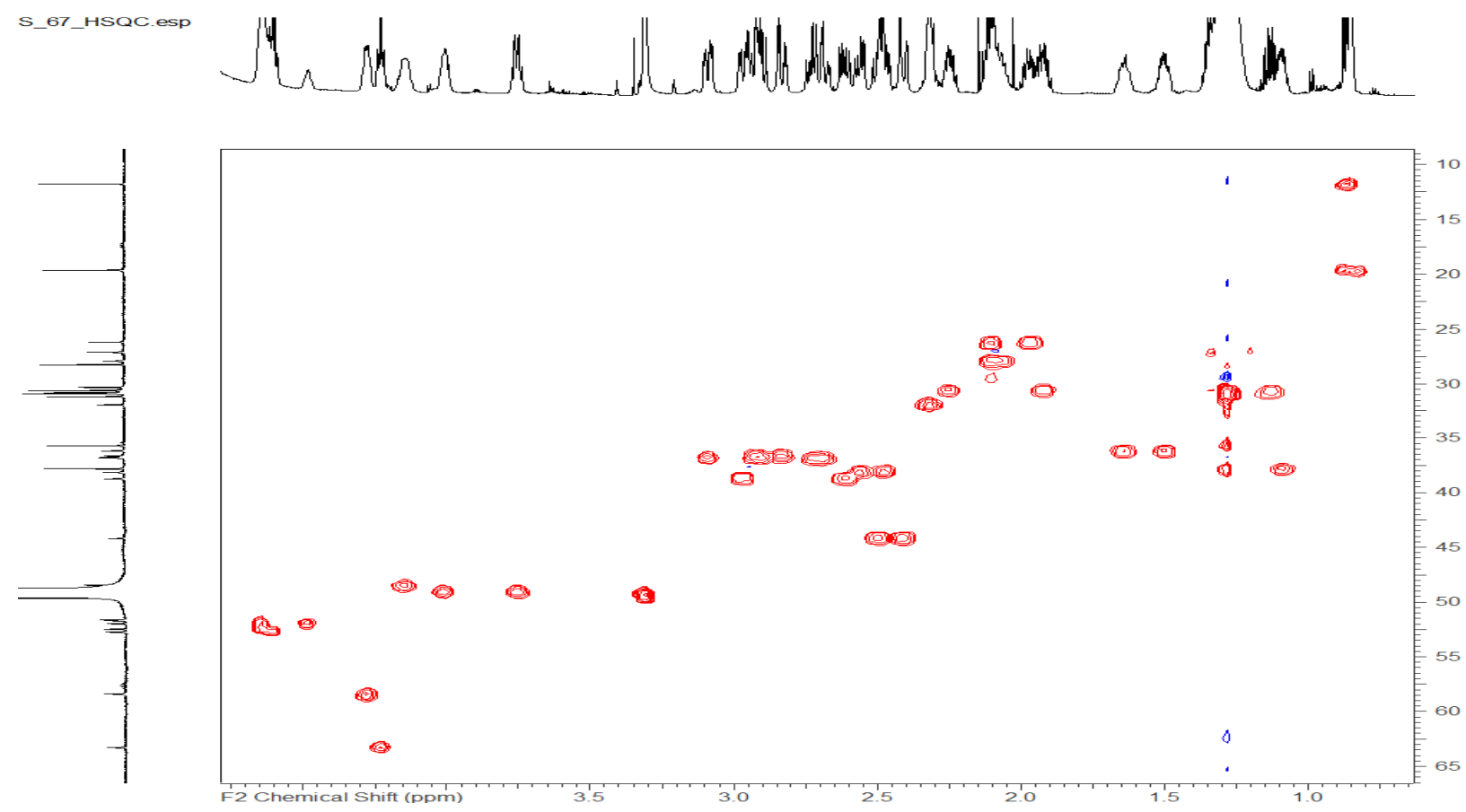

Figure BS5. HSQC NMR of 1 in $\mathrm{CD}_{3} \mathrm{OH}$, selected area 


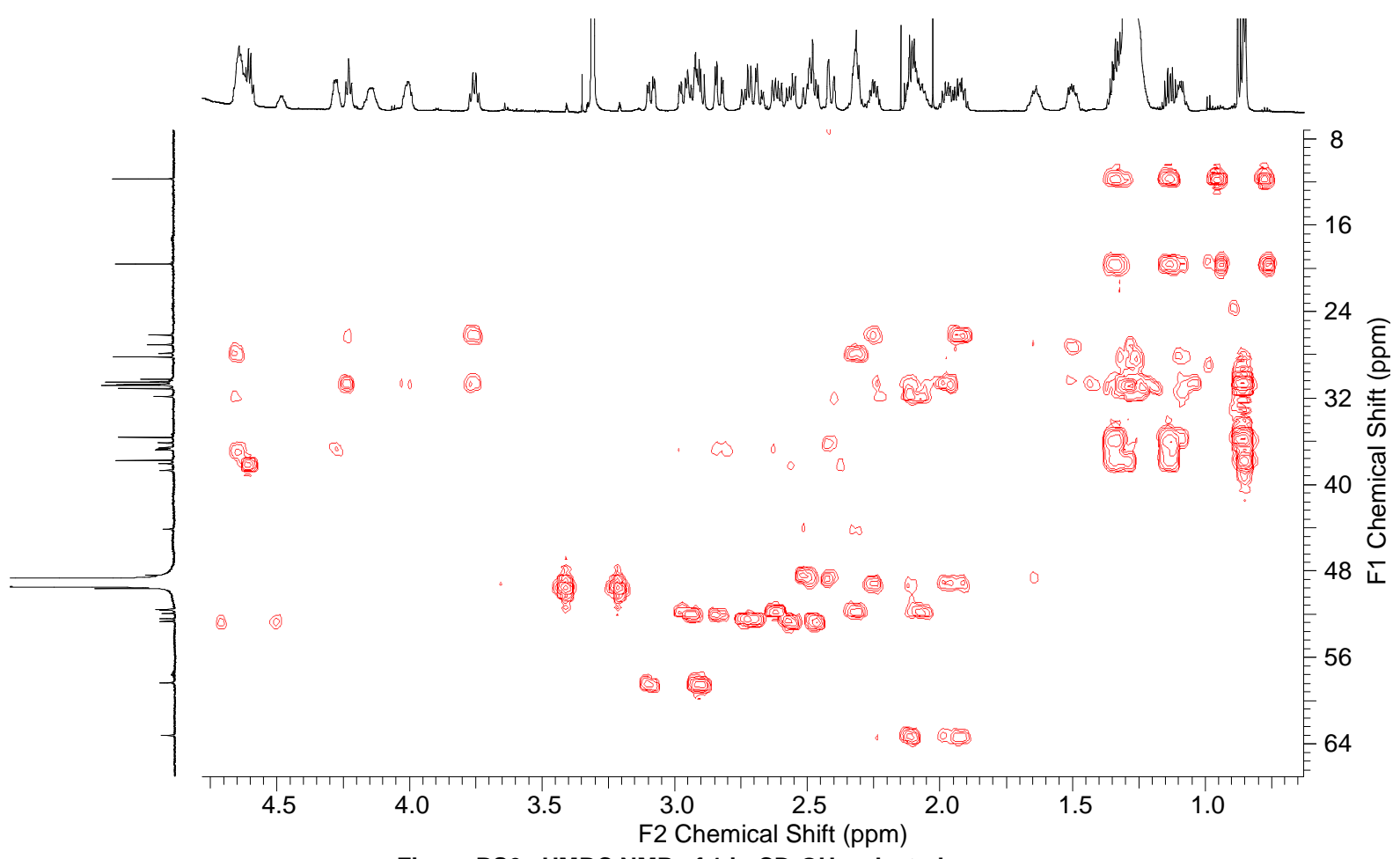

Figure BS6. HMBC NMR of 1 in $\mathrm{CD}_{3} \mathrm{OH}$, selected area

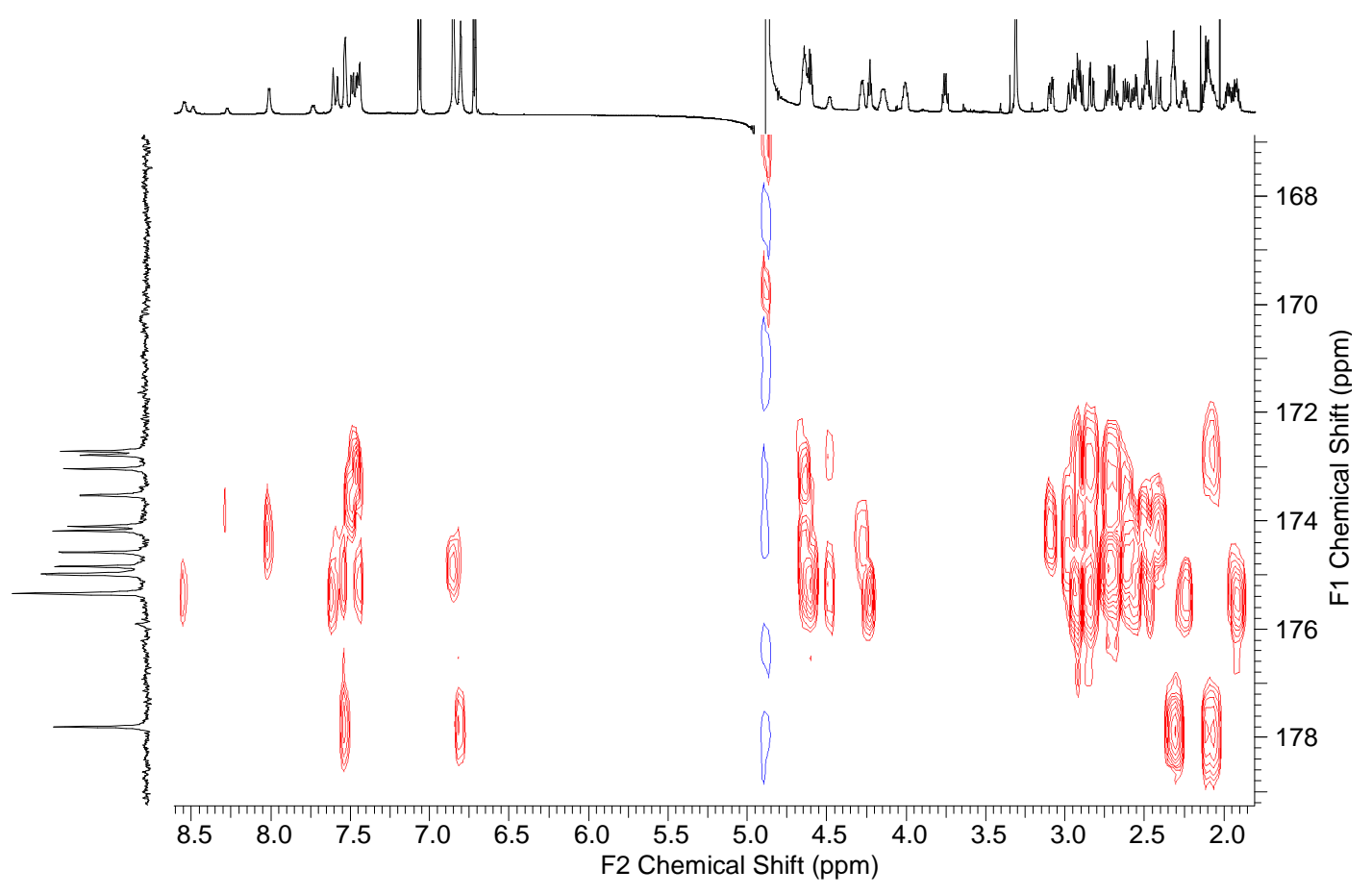

Figure BS7. HMBC NMR of 1 in $\mathrm{CD}_{3} \mathrm{OH}$, selected area 


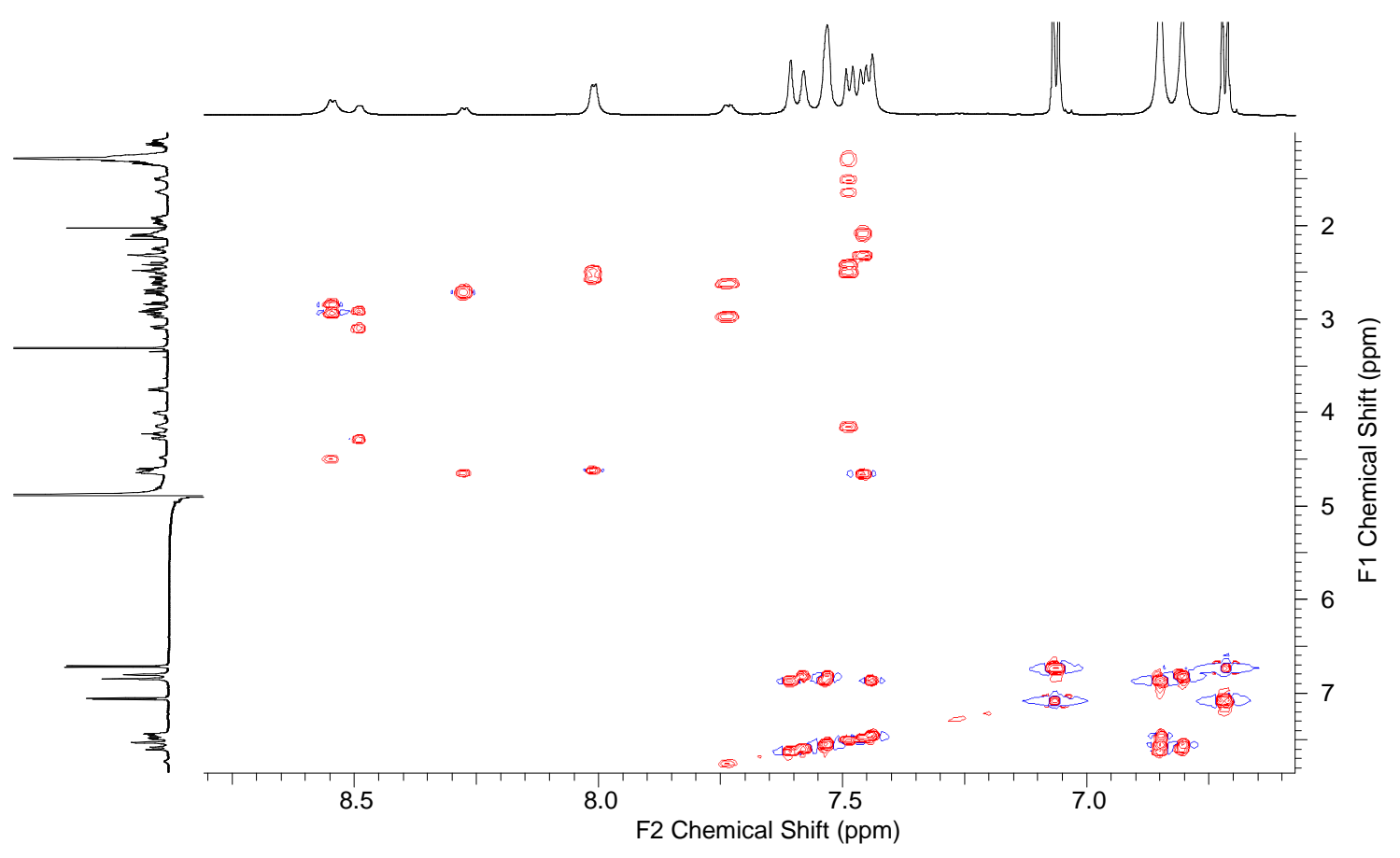

Figure BS8. TOCSY NMR of 1 in $\mathrm{CD}_{3} \mathrm{OH}$, selected area

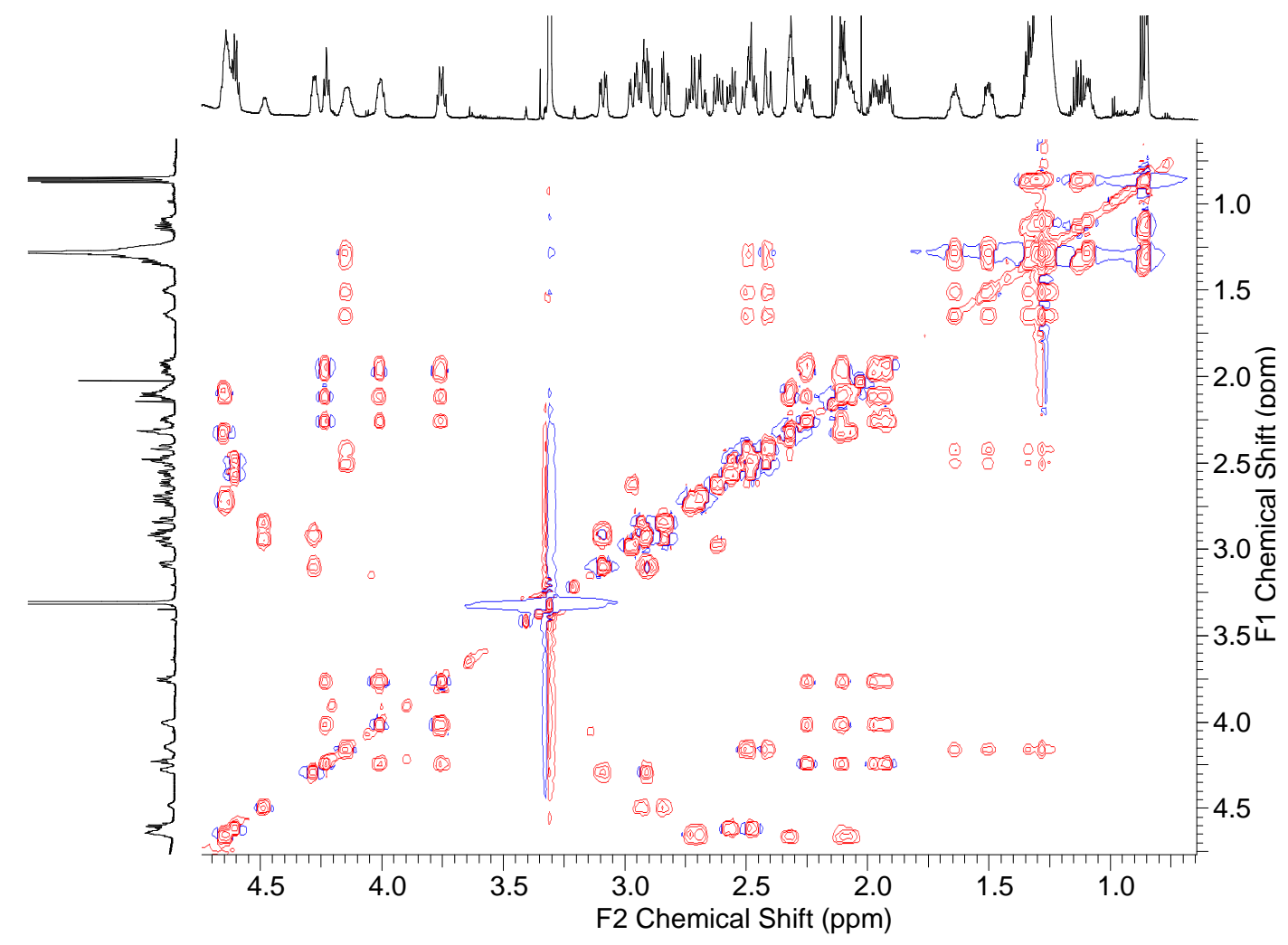

Figure BS9. TOCSY NMR of 1 in $\mathrm{CD}_{3} \mathrm{OH}$, selected area 


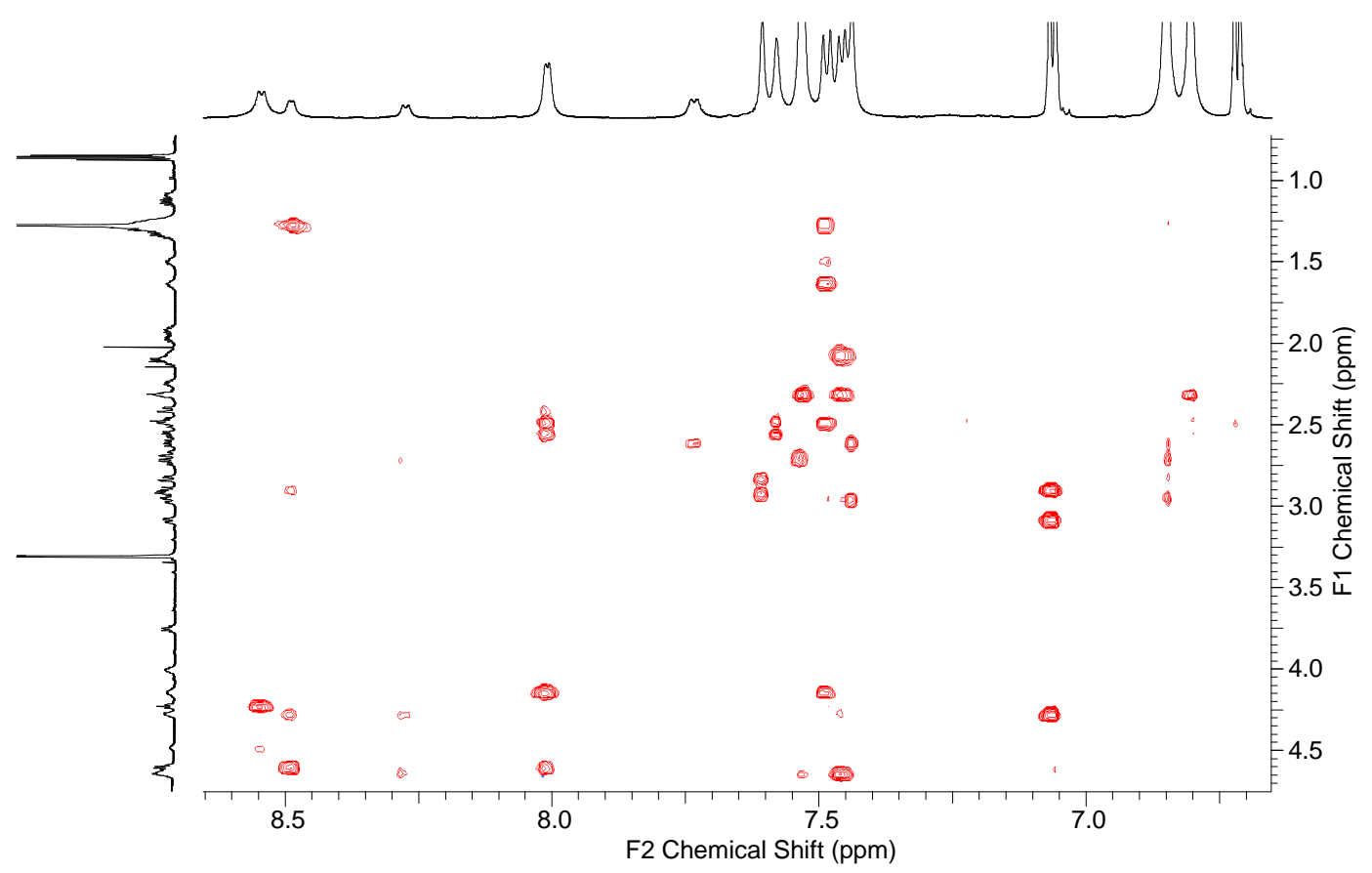

Figure BS10. ROESY NMR of 1 in $\mathrm{CD}_{3} \mathrm{OH}$, selected area

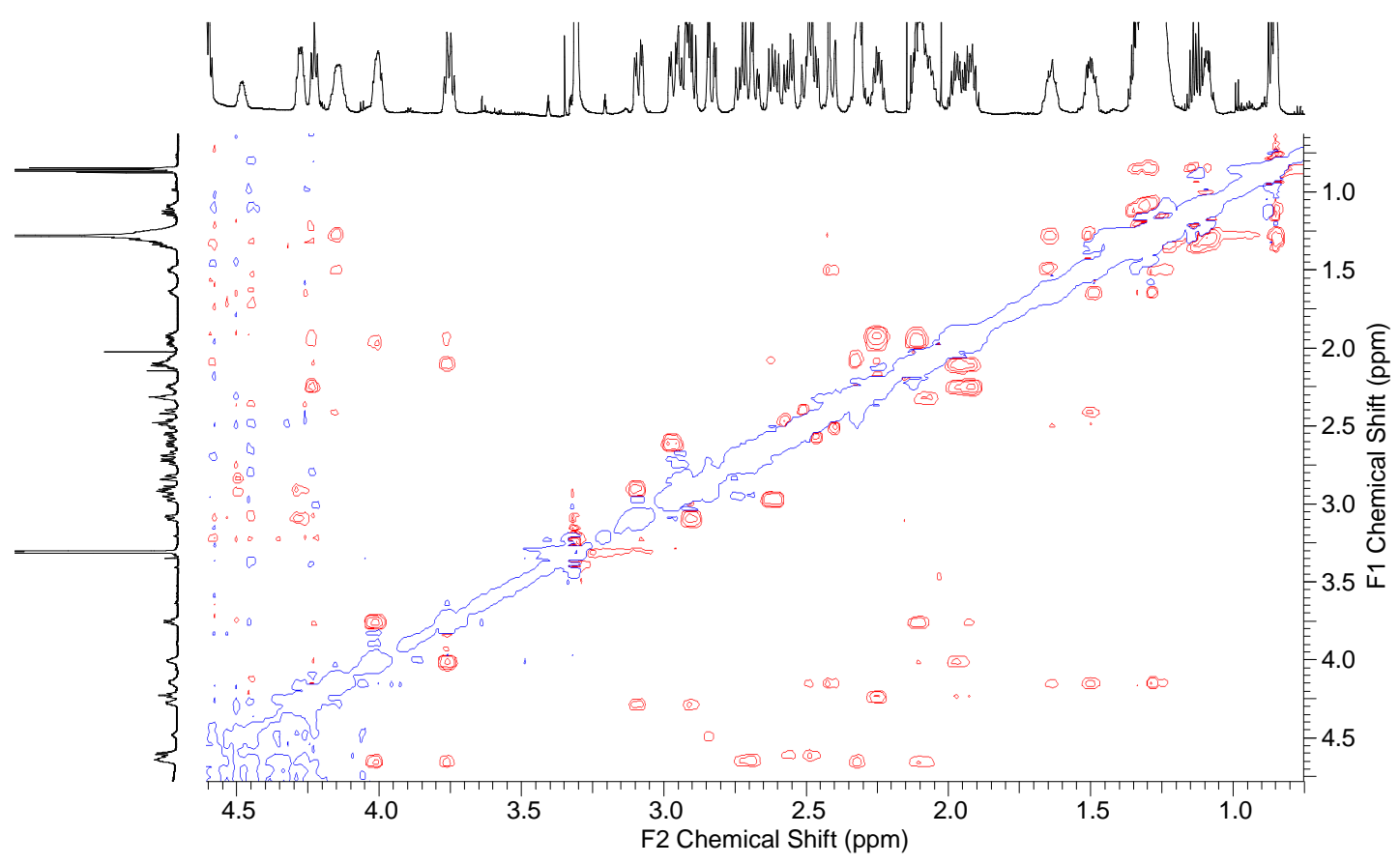

Figure BS11. ROESY NMR of 1 in $\mathrm{CD}_{3} \mathrm{OH}$, selected area 


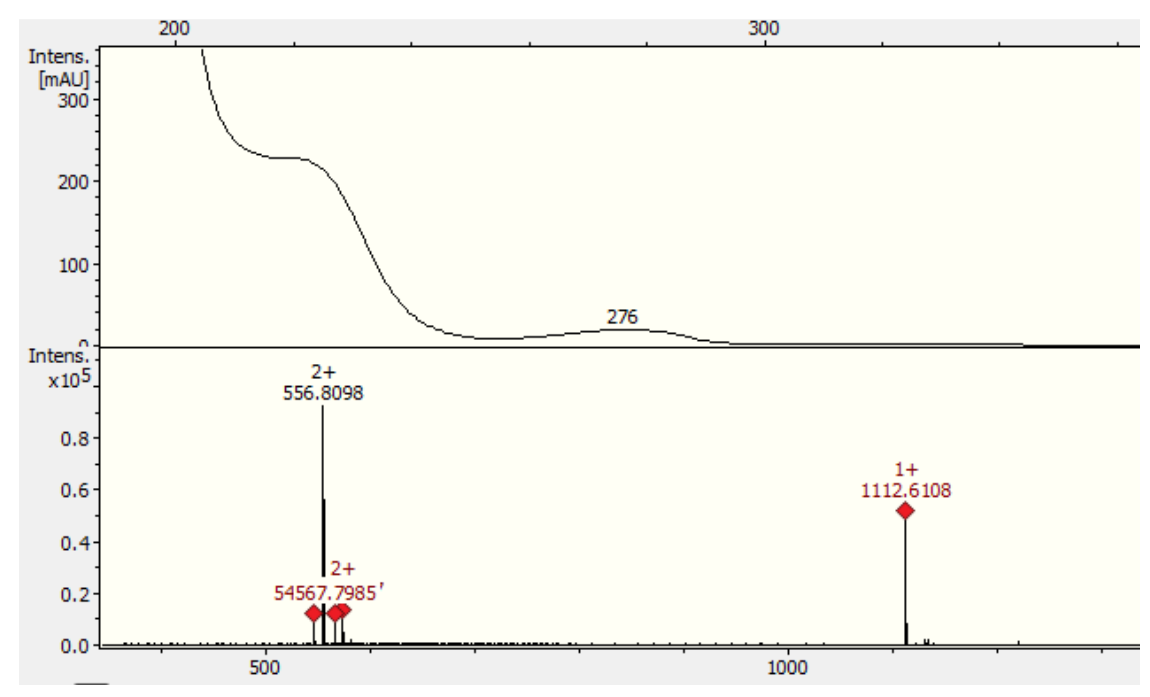

Figure BS12: ESI HRMS of paenilarvin A (1)

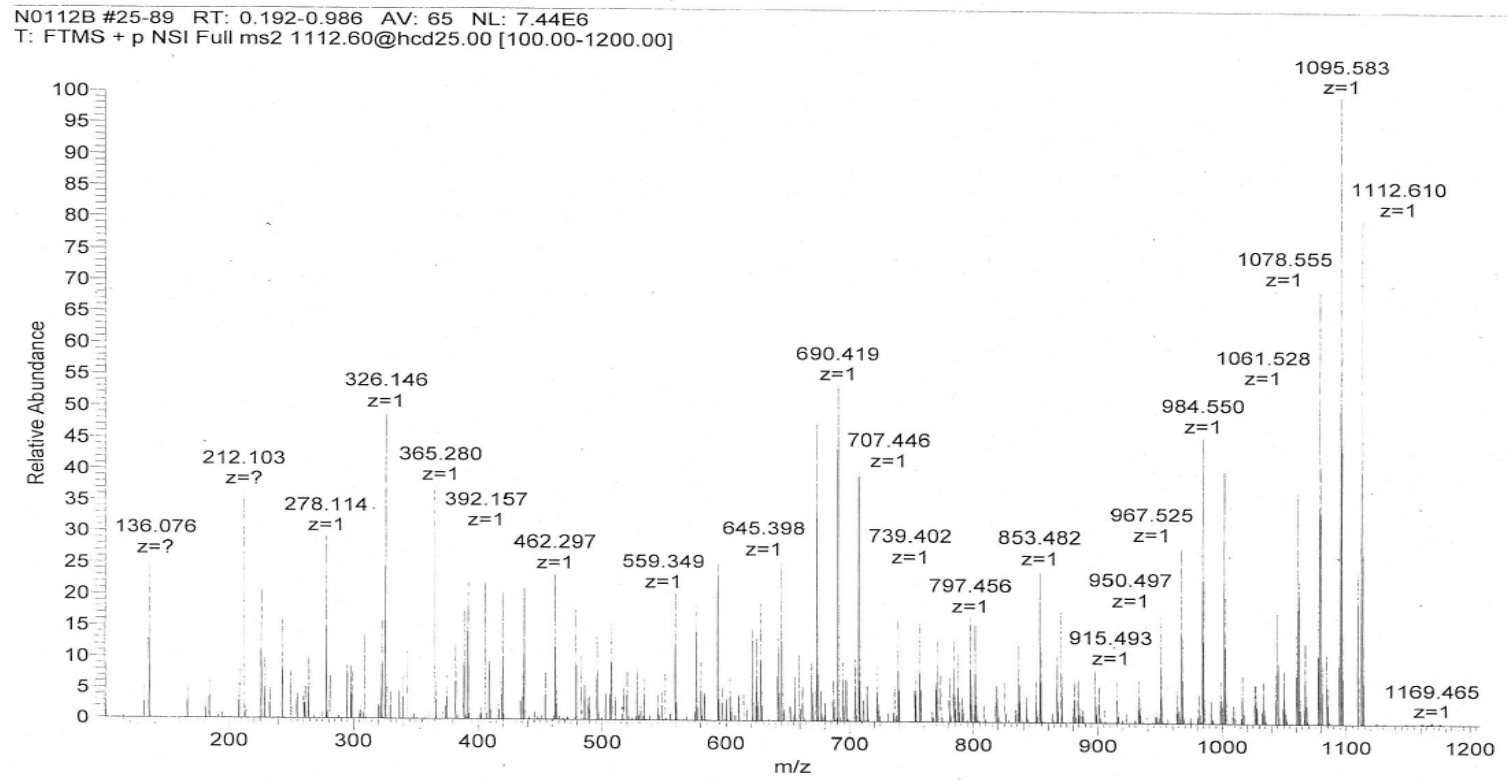


No112K \#3-65 RT: 0.044-1.599 AV: 63 NL: 2.41E3
T: ITMS + p NSI w Full ms3 556.80@cid28.00 707.40@cid32.00 [190.00-800.00]

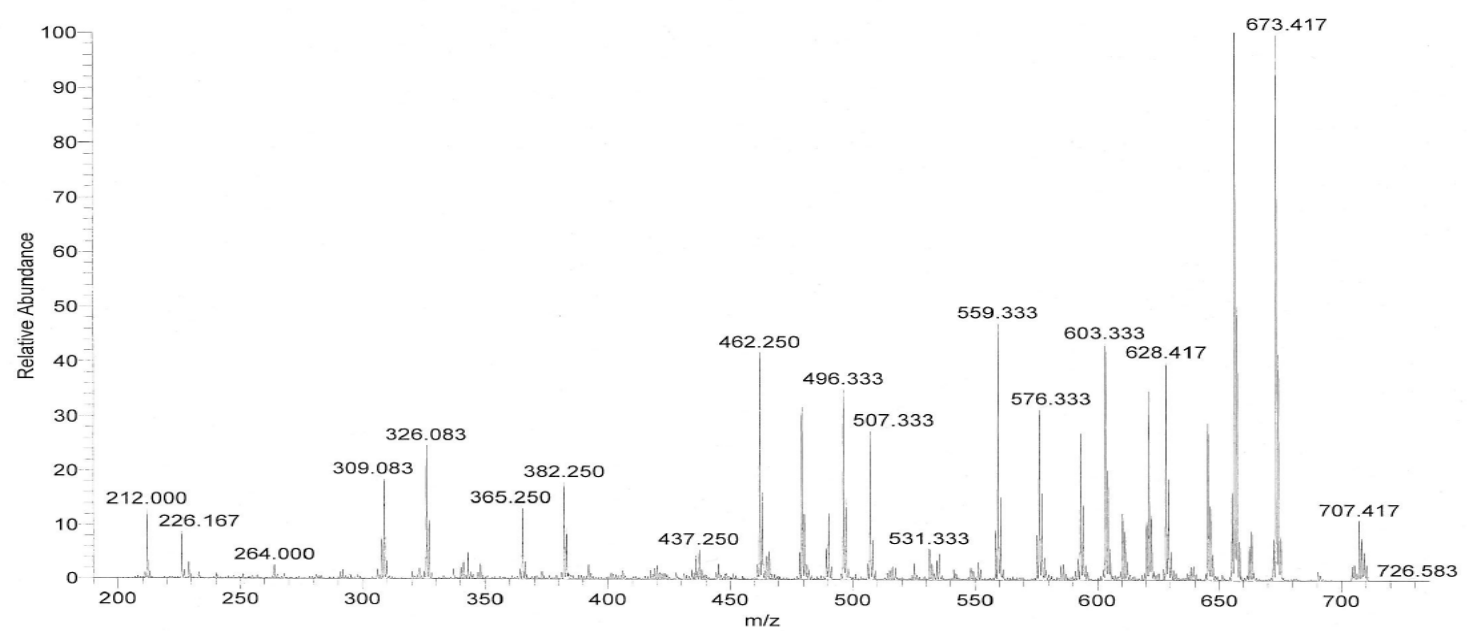

N0112G \#4-13 RT: $0.279-1.076$ AV: 10 NL: 1.03E5
T: FTMS + p NSI w Full ms3 556.80@cid28.00 406.20@cid25.00 [110.00-500.00]

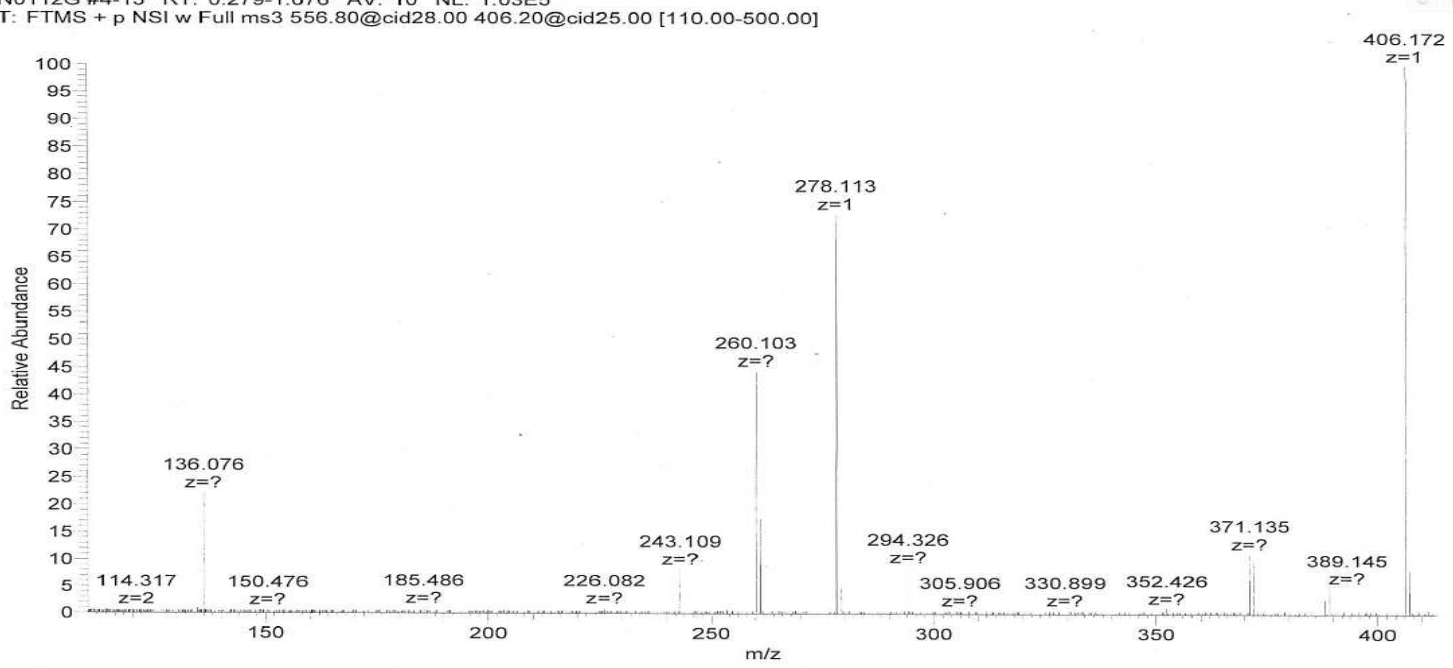

Figure BS13. MS/MS spectra of (1) 


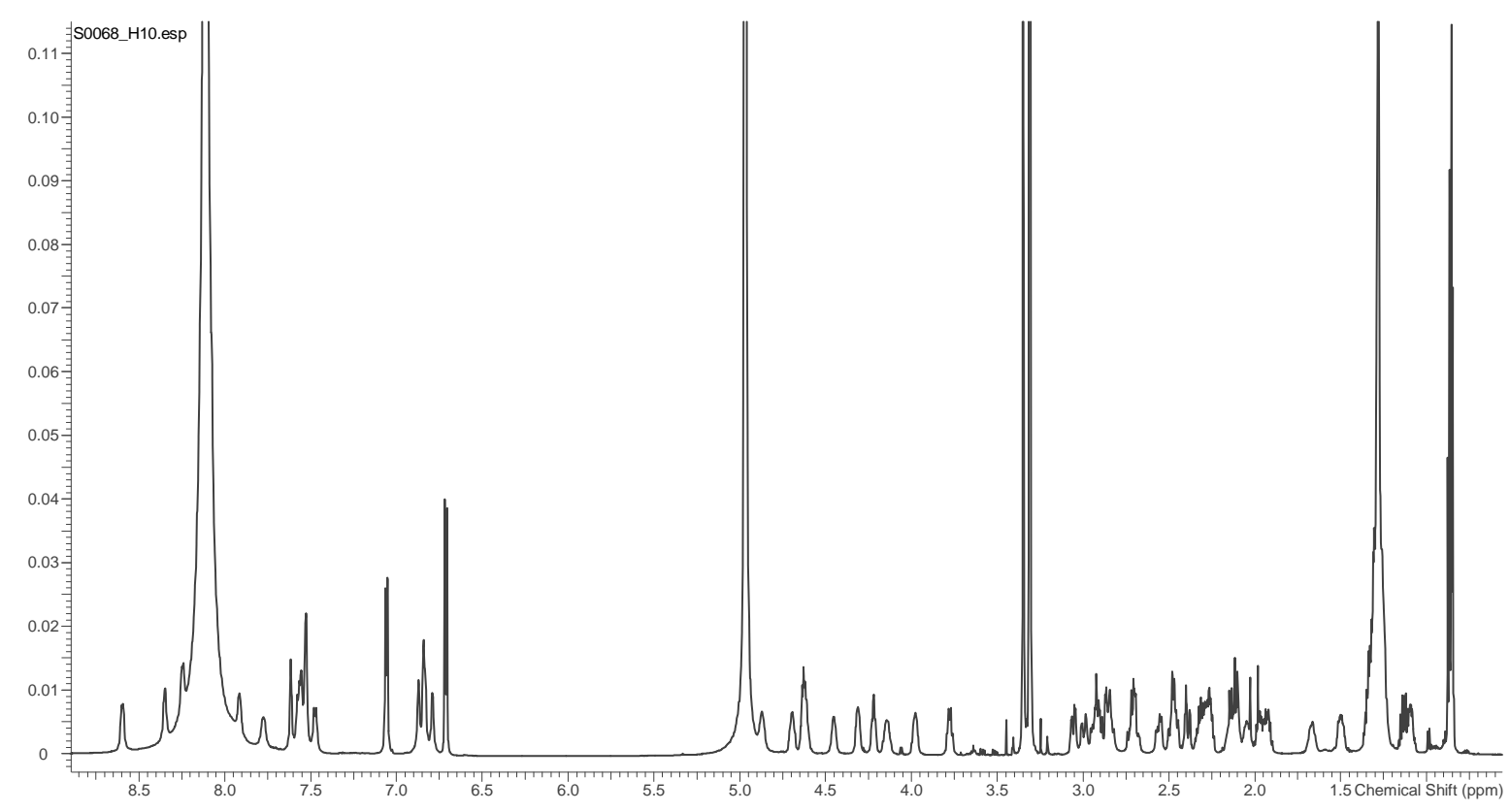

Figure BS14. ${ }^{1} \mathrm{H} \mathrm{NMR}$ of 2 in $\mathrm{CD}_{3} \mathrm{OH}+5 \mu \mathrm{LCOOH}, 700 \mathrm{MHz}$

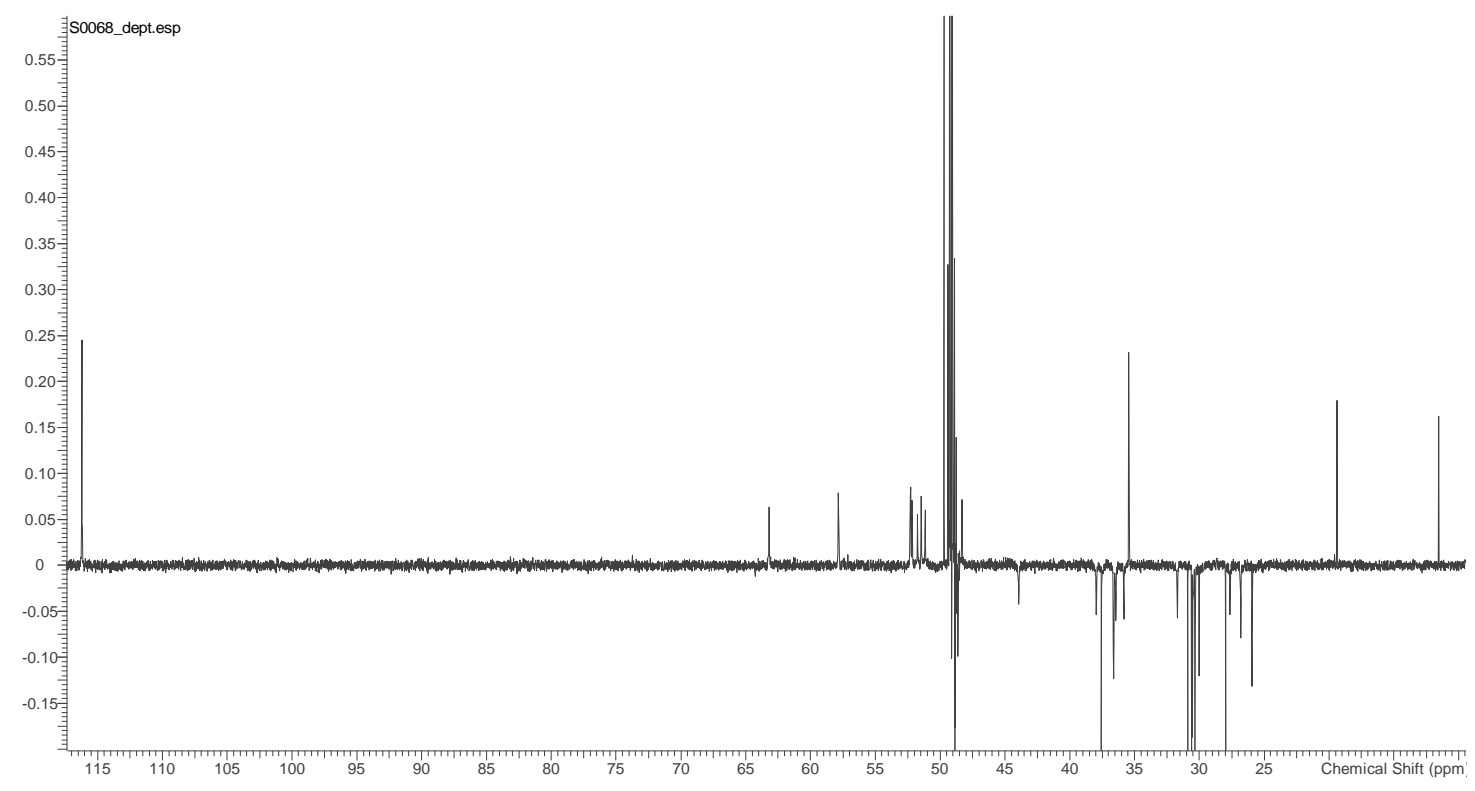

Figure BS15. ${ }^{13} \mathrm{C}$ NMR DEPT of 2 in $\mathrm{CD}_{3} \mathrm{OH}+5 \mu \mathrm{L} \mathrm{HCOOH}, 176 \mathrm{MHz}$, selected area 


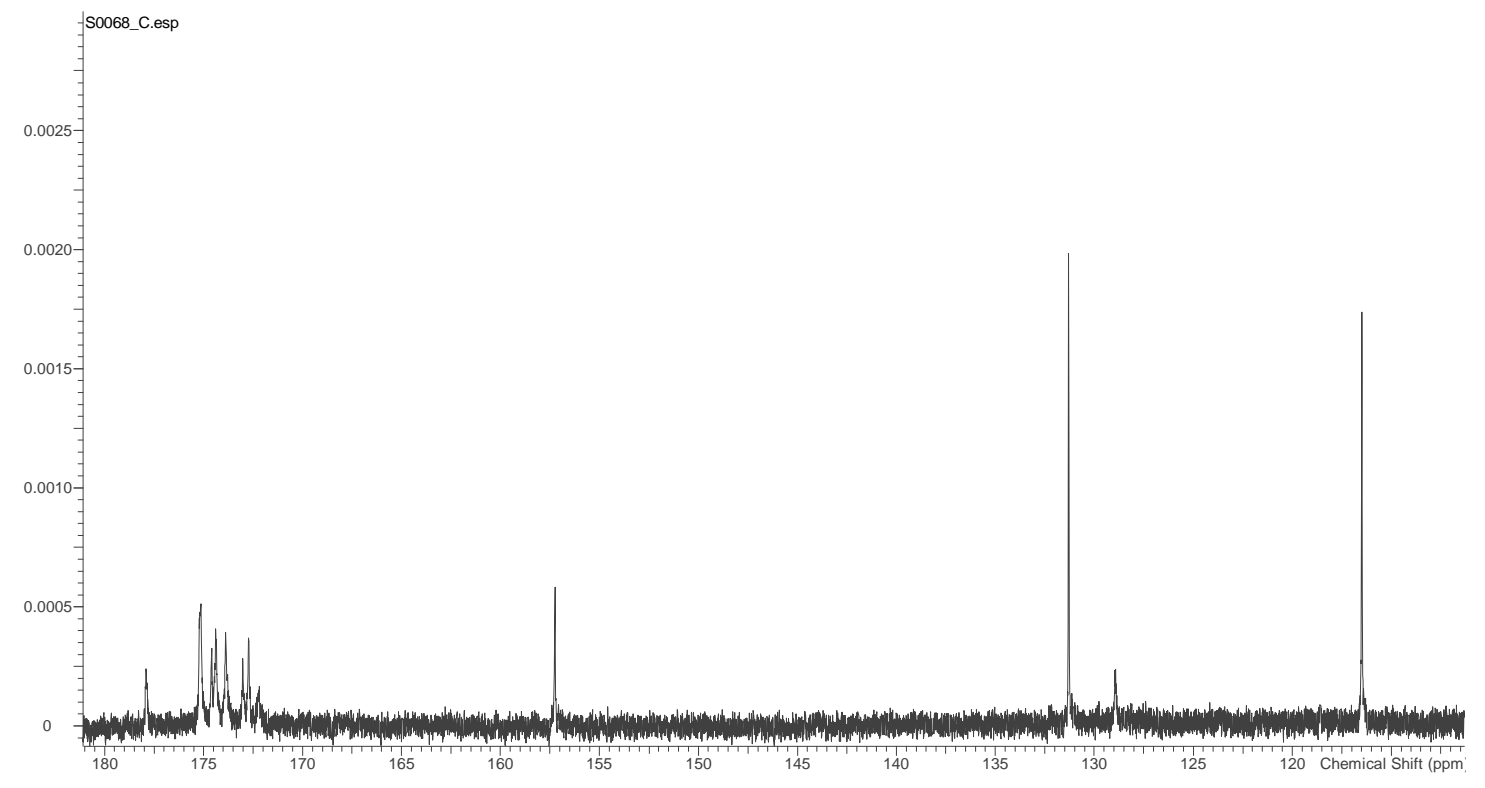

Figure BS16. ${ }^{13} \mathrm{C}$ NMR of 2 in $\mathrm{CD}_{3} \mathrm{OH}+5 \mu \mathrm{L} \mathrm{HCOOH,} 176 \mathrm{MHz}$, selected area

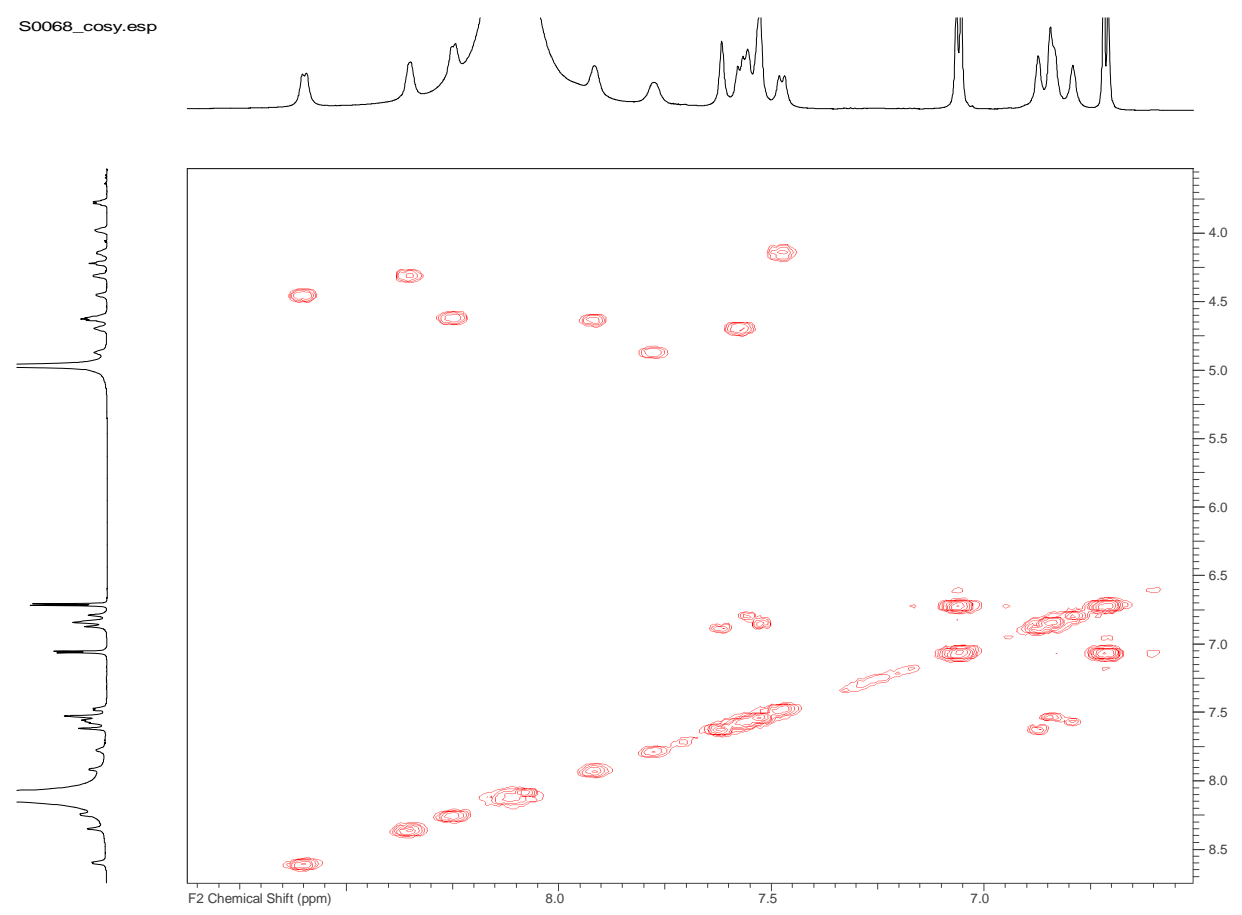

Figure BS17. ${ }^{1} \mathrm{H}-{ }^{1} \mathrm{H}$ COSY NMR of 2 in $\mathrm{CD}_{3} \mathrm{OH}+5 \mu \mathrm{L} \mathrm{HCOOH}, 700 \mathrm{MHz}$, selected area 


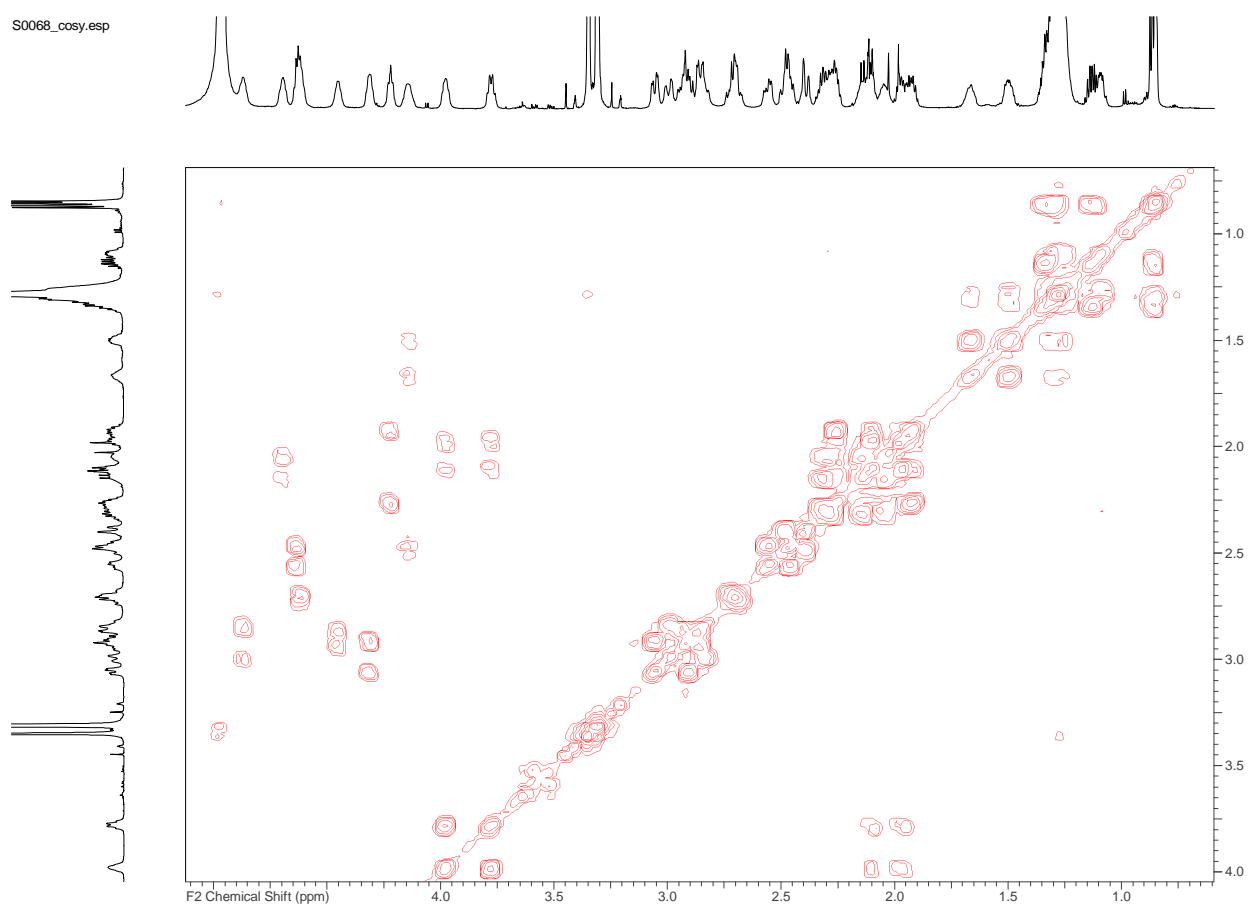

Figure BS18. ${ }^{1} \mathrm{H}-{ }^{1} \mathrm{H}$ COSY NMR of 2 in $\mathrm{CD}_{3} \mathrm{OH}+5 \mu \mathrm{L} \mathrm{HCOOH}, 700 \mathrm{MHz}$, selected area

S0068_hsqc.esp
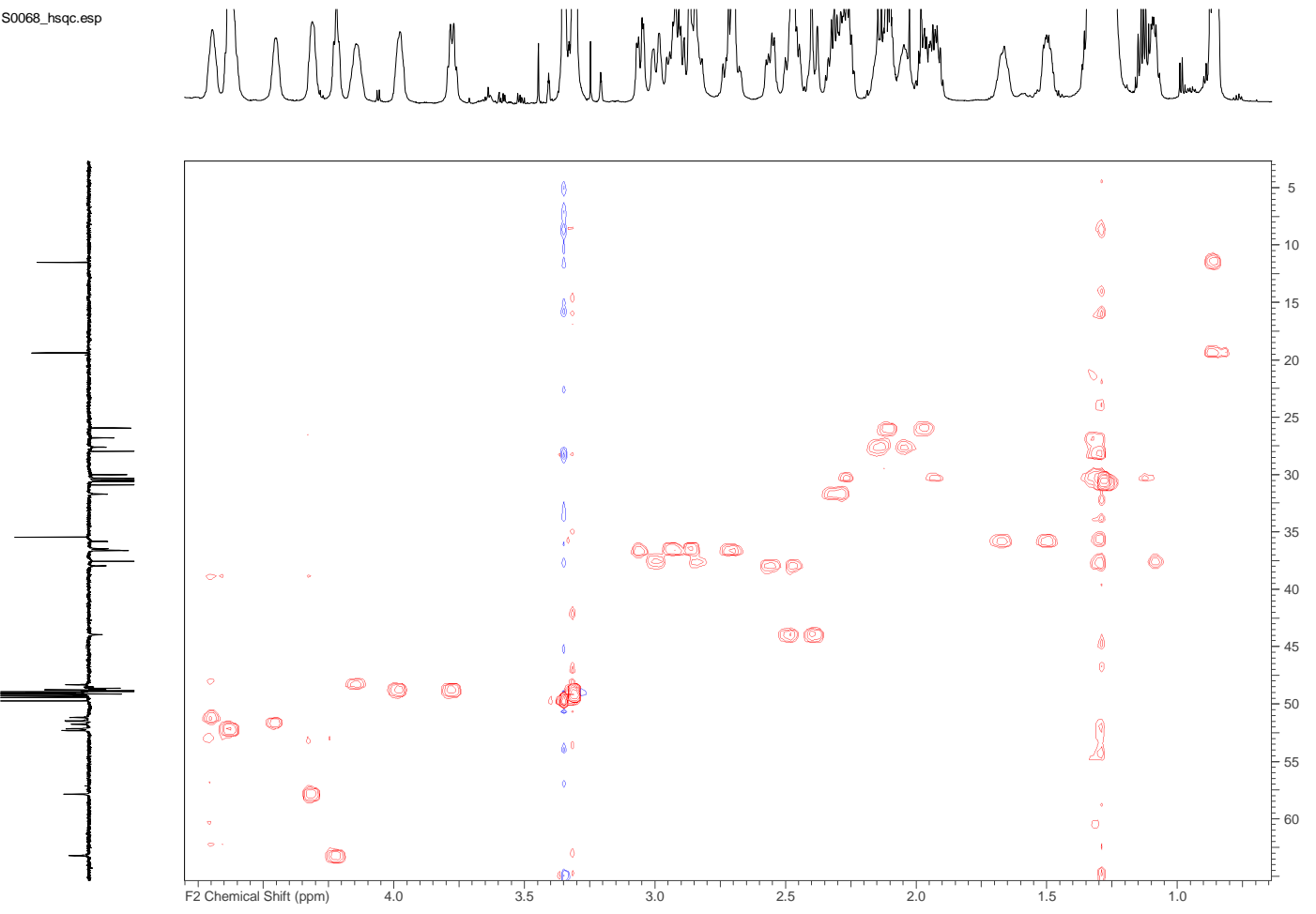

Figure BS19. HSQC NMR of 2 in $\mathrm{CD}_{3} \mathrm{OH}+5 \mu \mathrm{L} \mathrm{HCOOH,} 700 \mathrm{MHz}$, selected area 

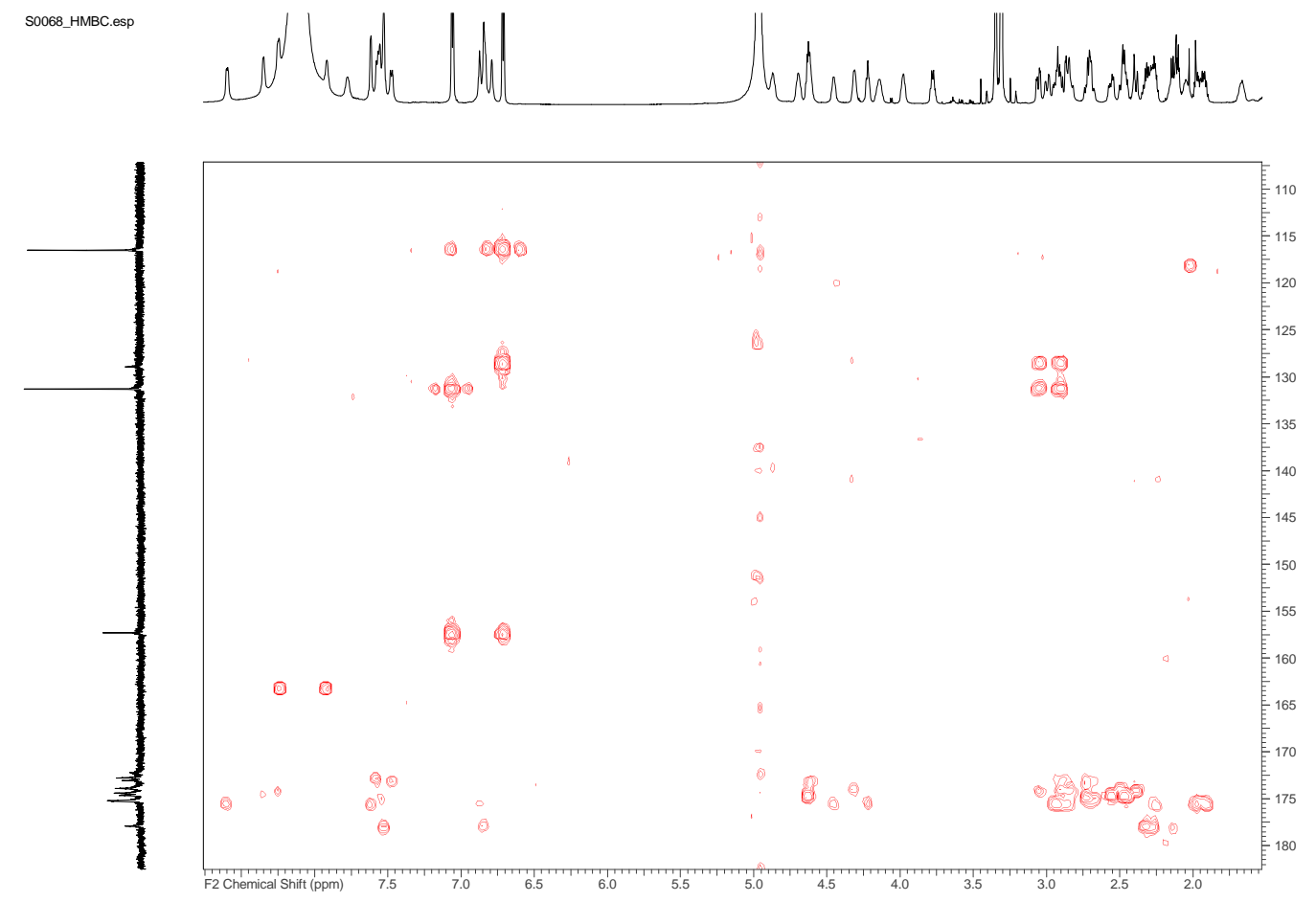

Figure BS20. $\mathrm{HMBC}$ NMR of 2 in $\mathrm{CD}_{3} \mathrm{OH}+5 \mu \mathrm{L} \mathrm{HCOOH}, 700 \mathrm{MHz}$, selected area
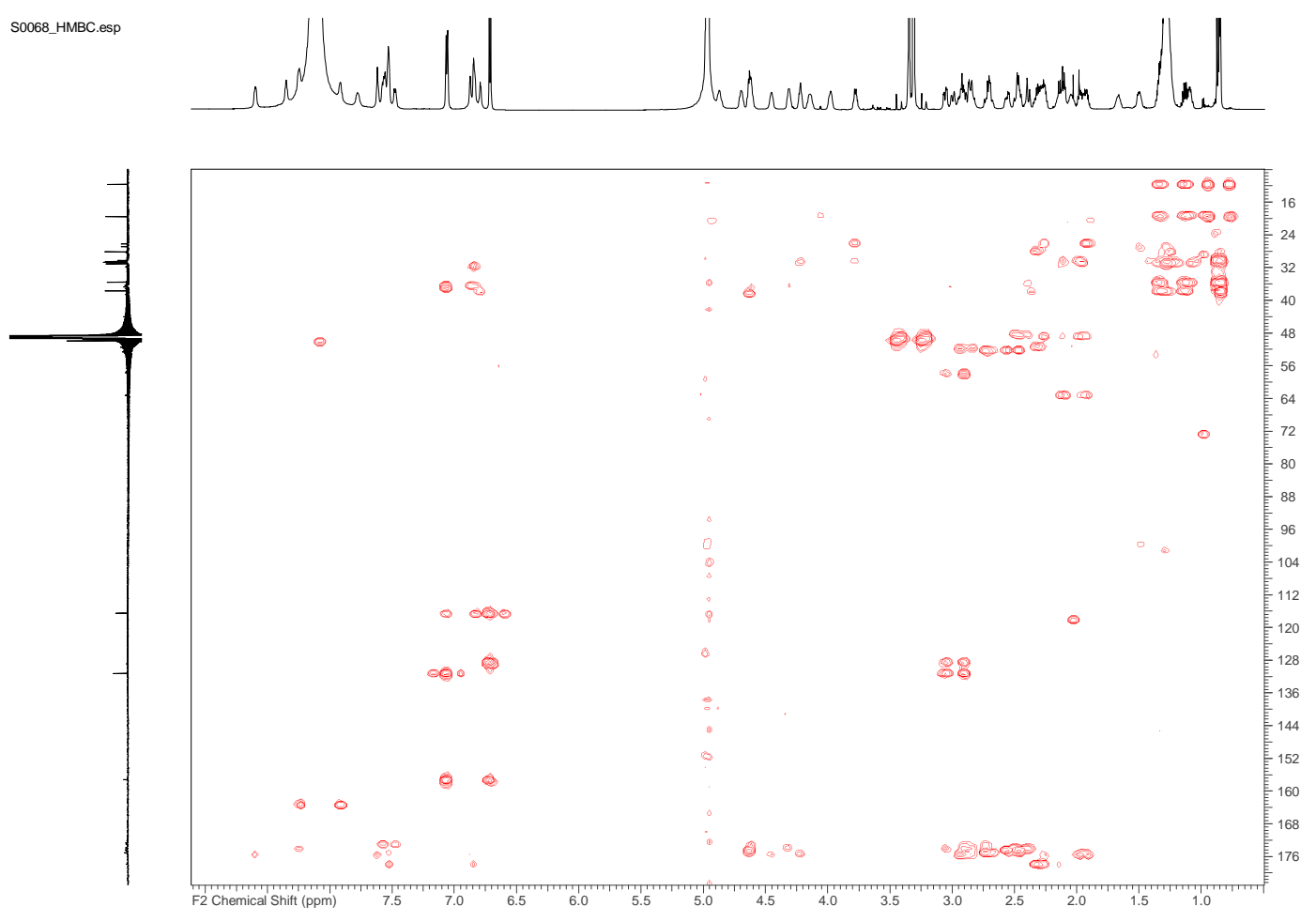

Figure BS21. HMBC NMR of 2 in $\mathrm{CD}_{3} \mathrm{OH}+5 \mu \mathrm{LCOOH}, 700 \mathrm{MHz}$, selected area 

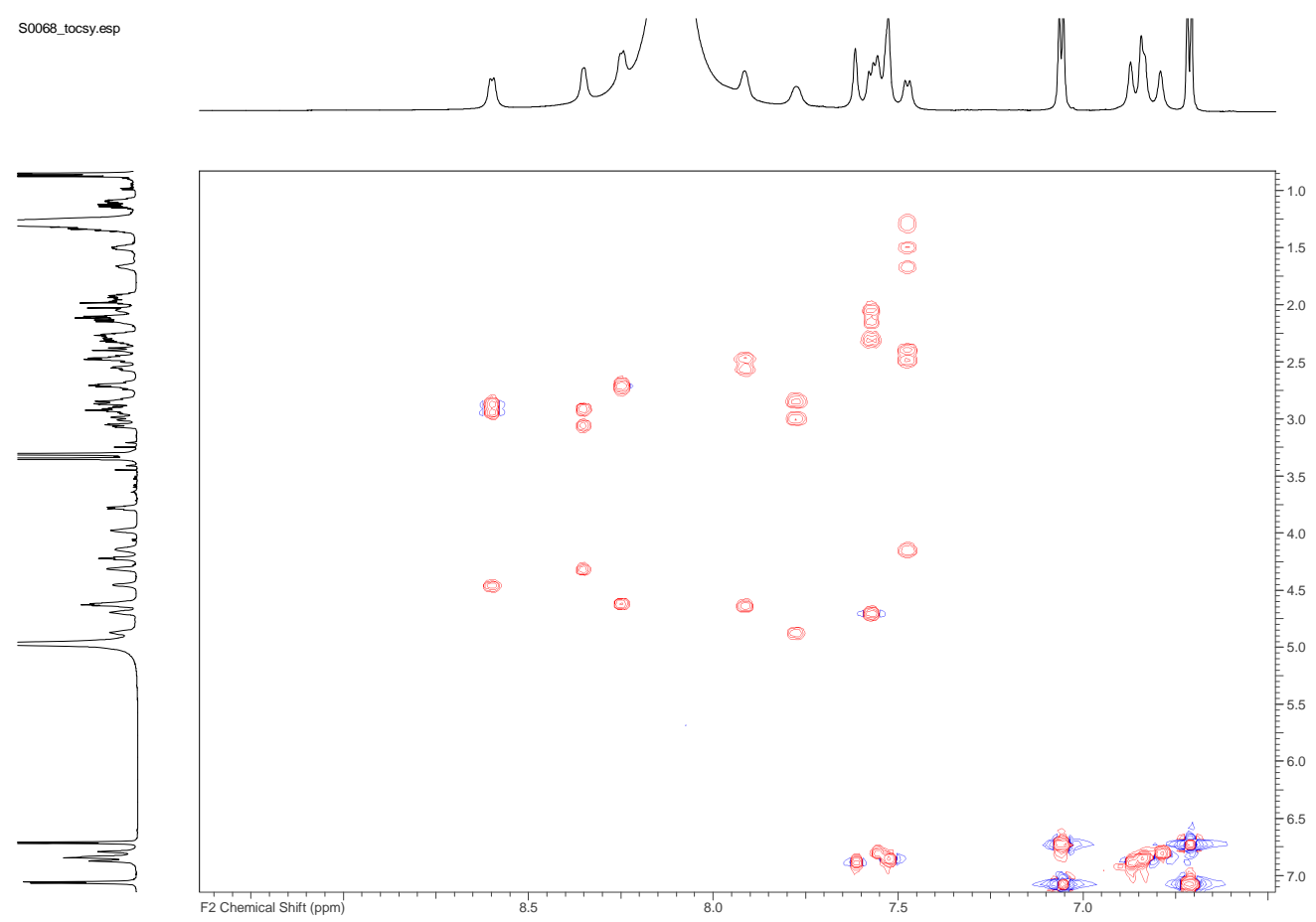

Figure BS22. TOCSY NMR of 2 in $\mathrm{CD}_{3} \mathrm{OH}+5 \mu \mathrm{L} \mathrm{HCOOH,} 700 \mathrm{MHz}$, selected area

S0068_tocsy.esp
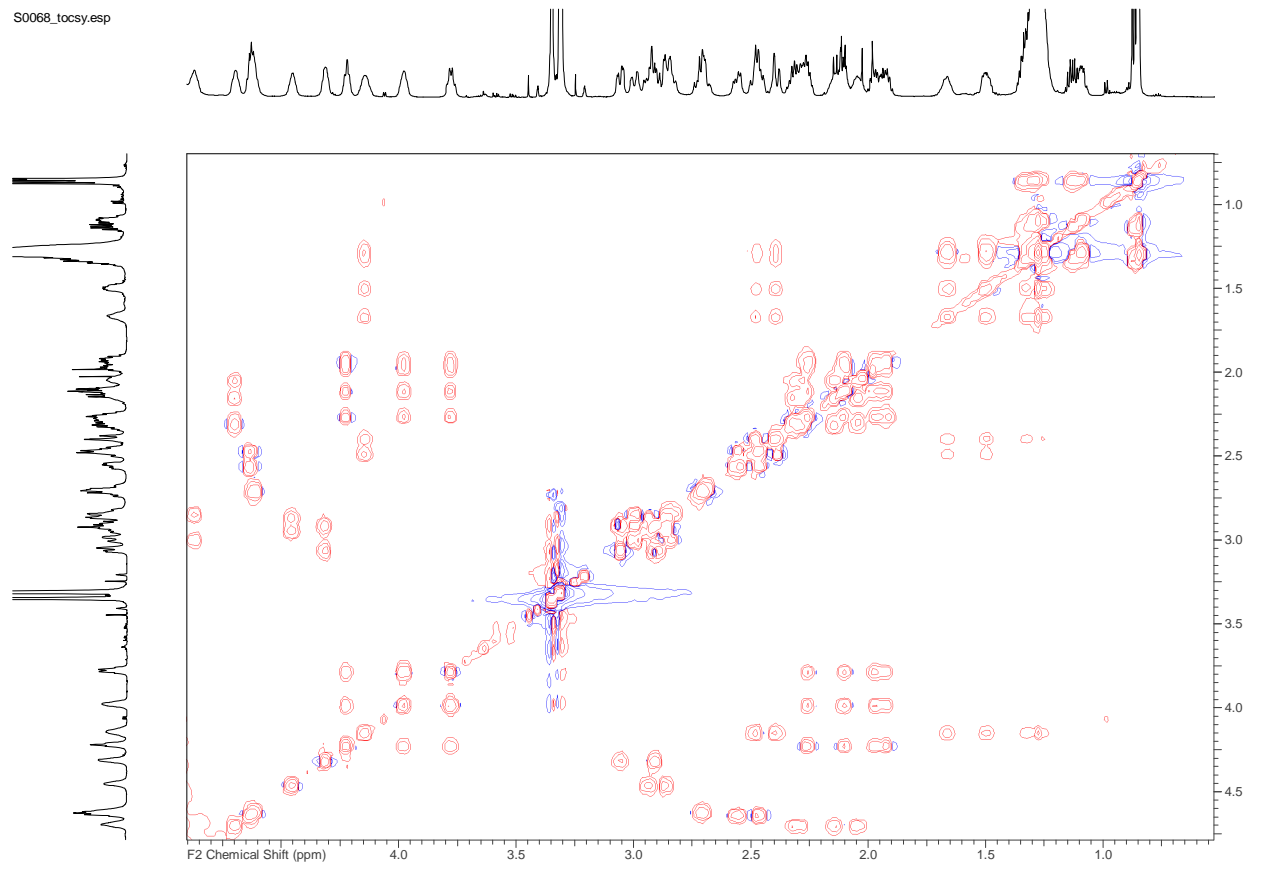

Figure BS23. TOCSY NMR of 2 in $\mathrm{CD}_{3} \mathrm{OH}+5 \mu \mathrm{L} \mathrm{HCOOH}, 700 \mathrm{MHz}$, selected area 


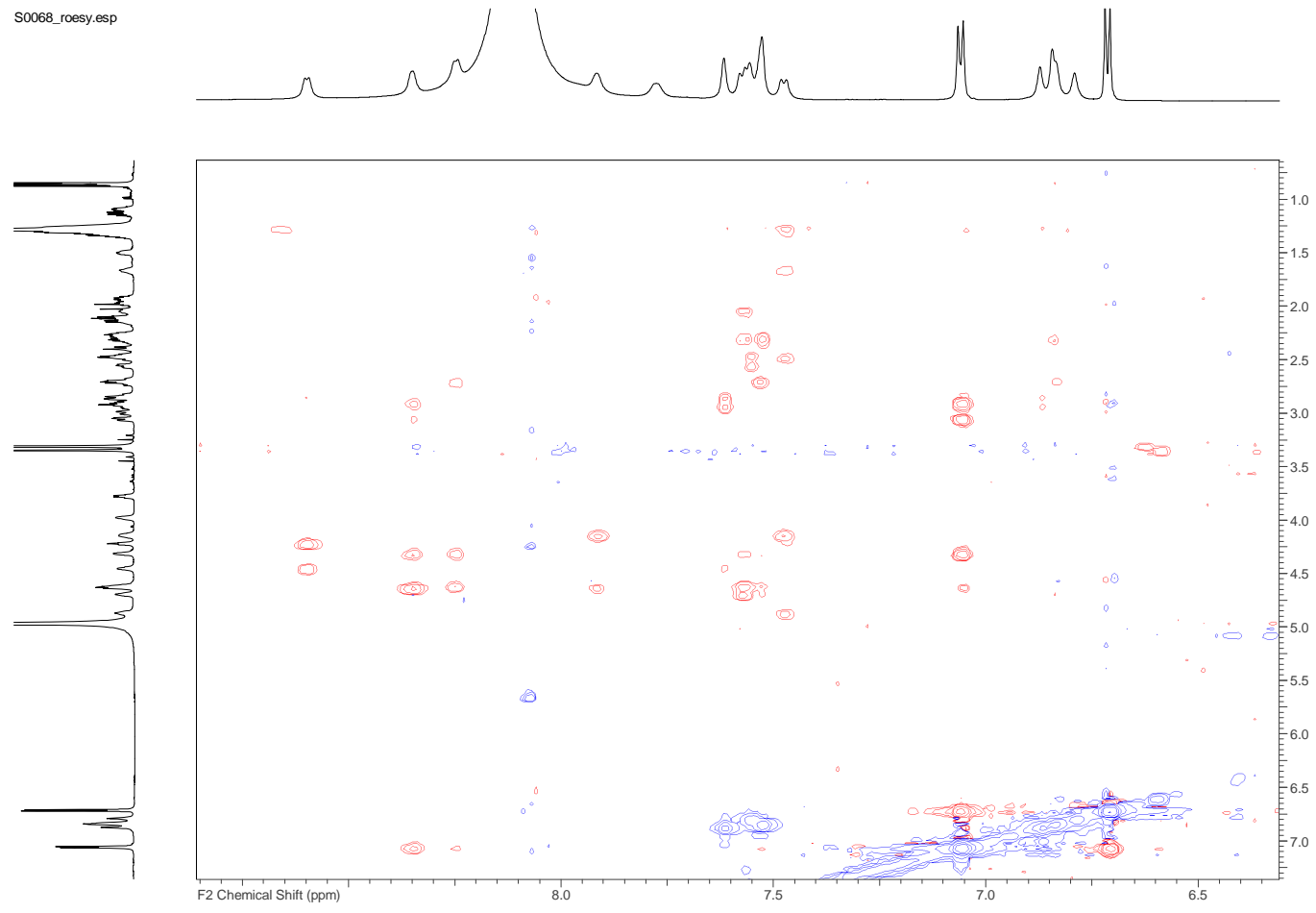

Figure BS24. ROESY NMR of 2 in $\mathrm{CD}_{3} \mathrm{OH}+5 \mu \mathrm{L} \mathrm{HCOOH,} 700 \mathrm{MHz}$, selected area

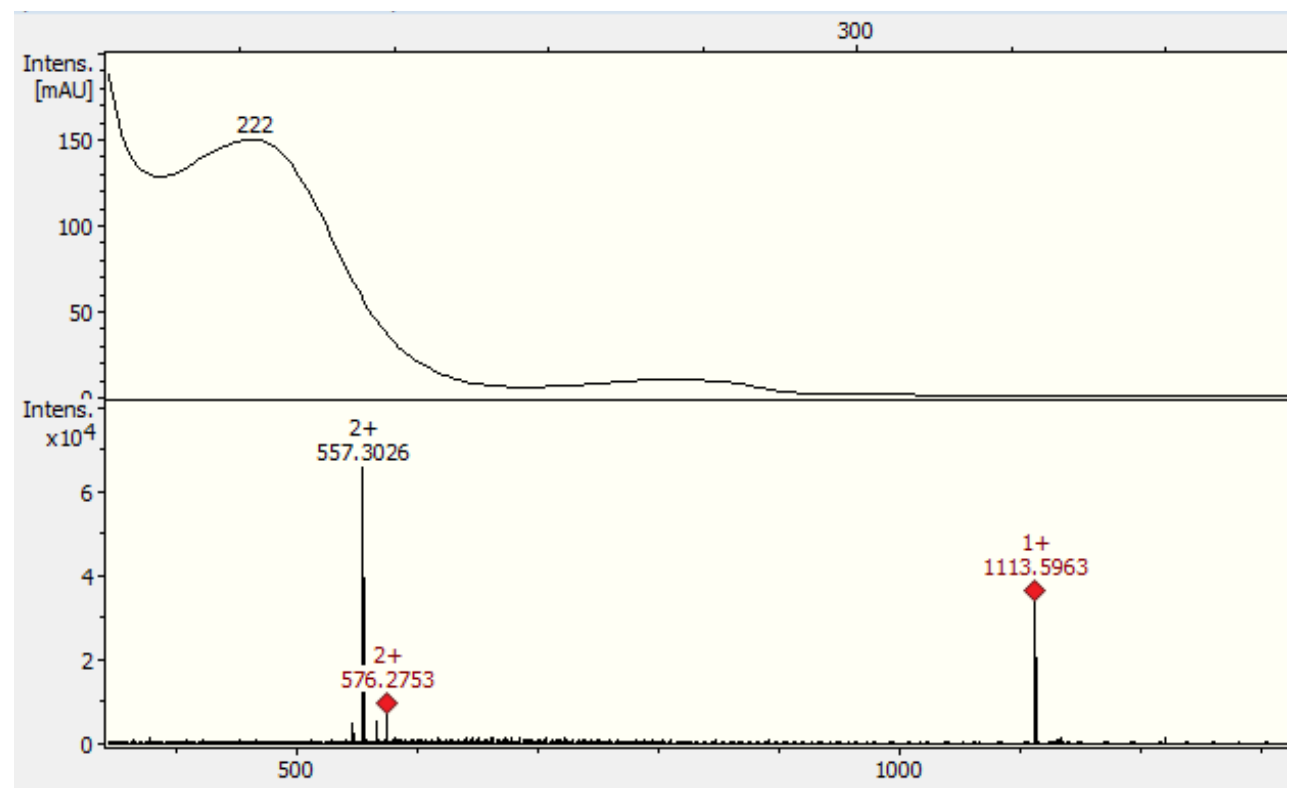

Figure BS25. ESI HRMS of paenilarvin B (2) 


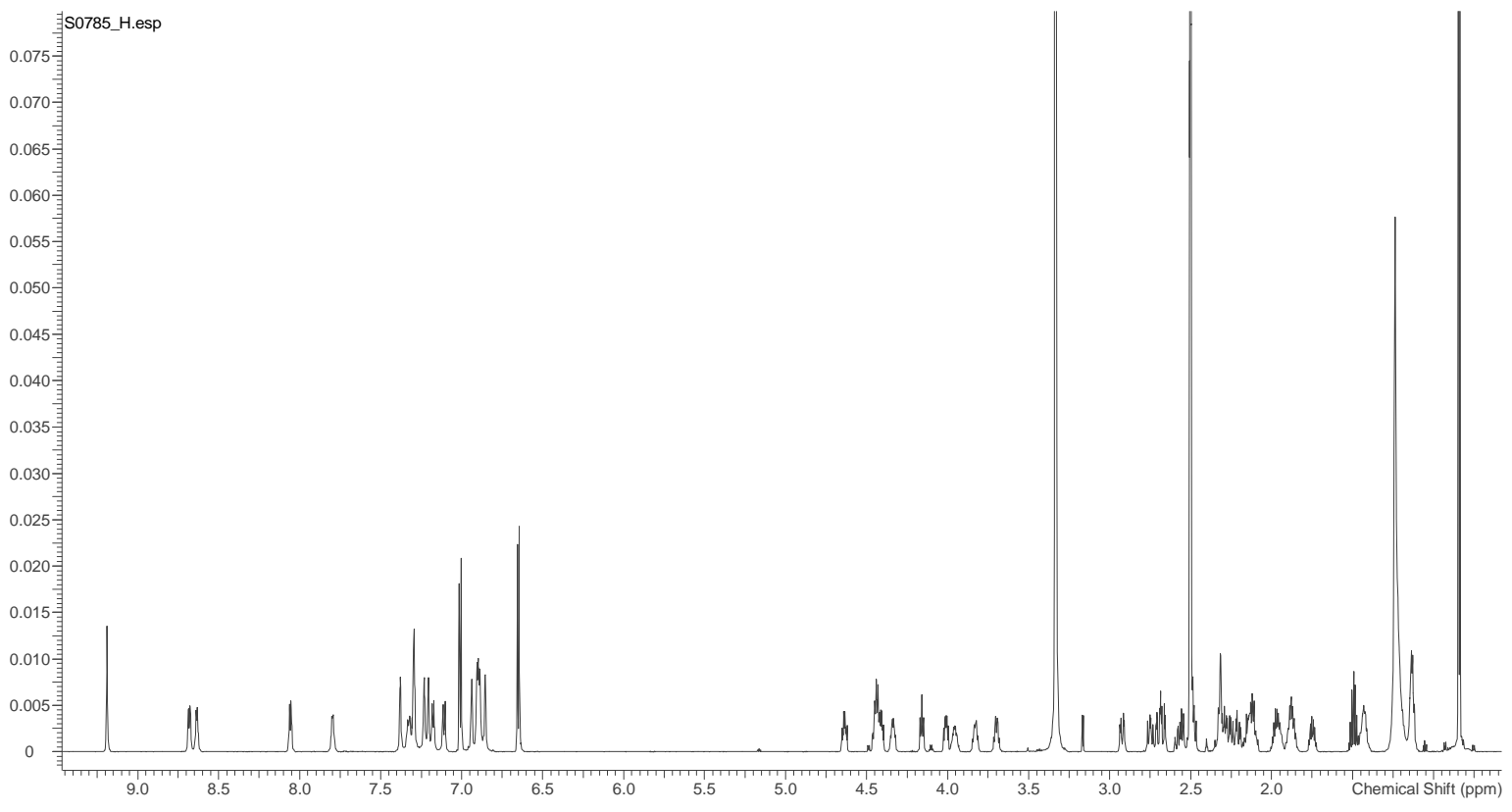

Figure BS26: ${ }^{1} \mathrm{H}$ NMR of 3 in DMSO-d $6,700 \mathrm{MHz}$

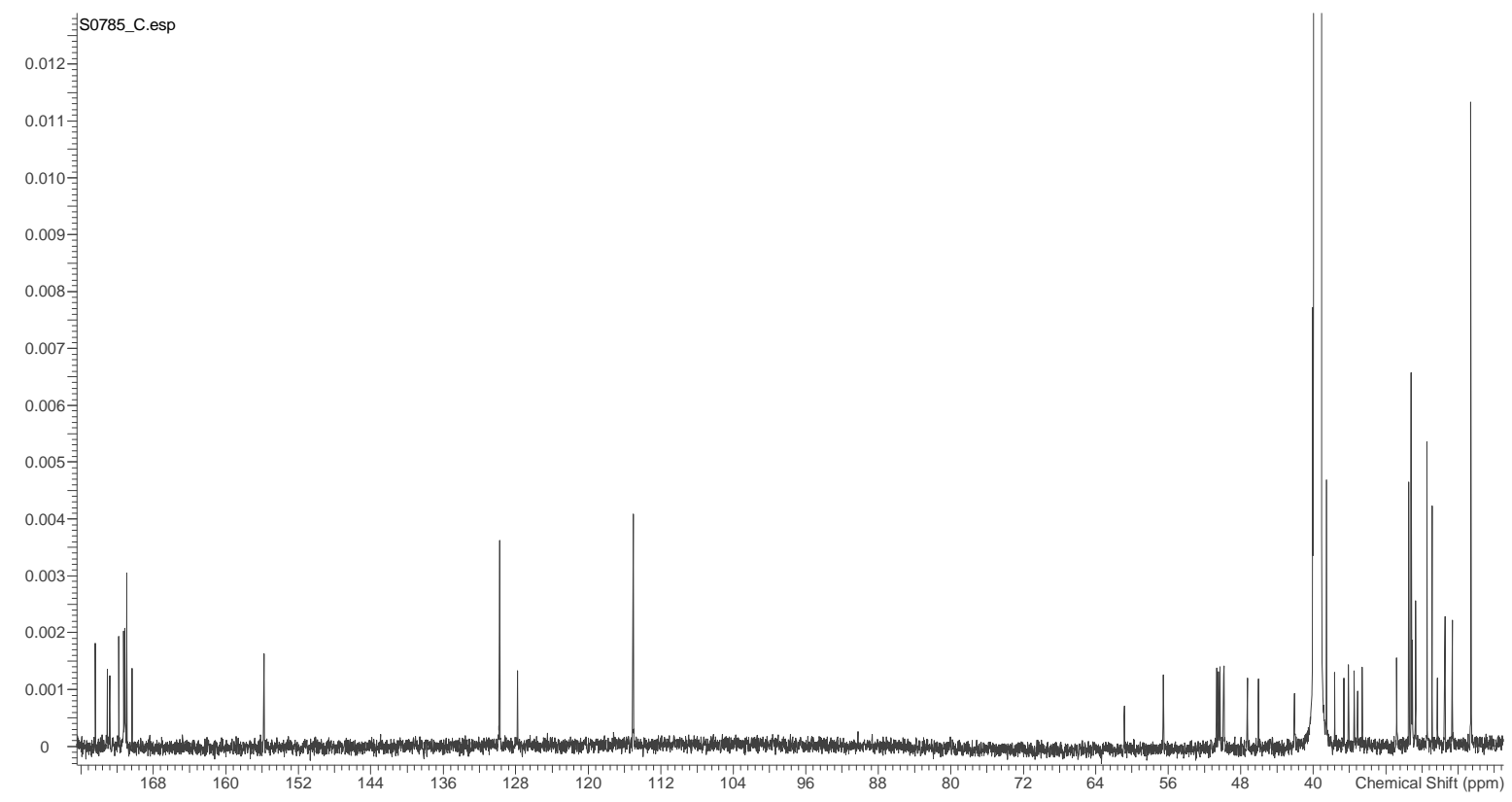

Figure BS27. ${ }^{13} \mathrm{C}$ NMR of 3 in DMSO-d $6,176 \mathrm{MHz}$ 


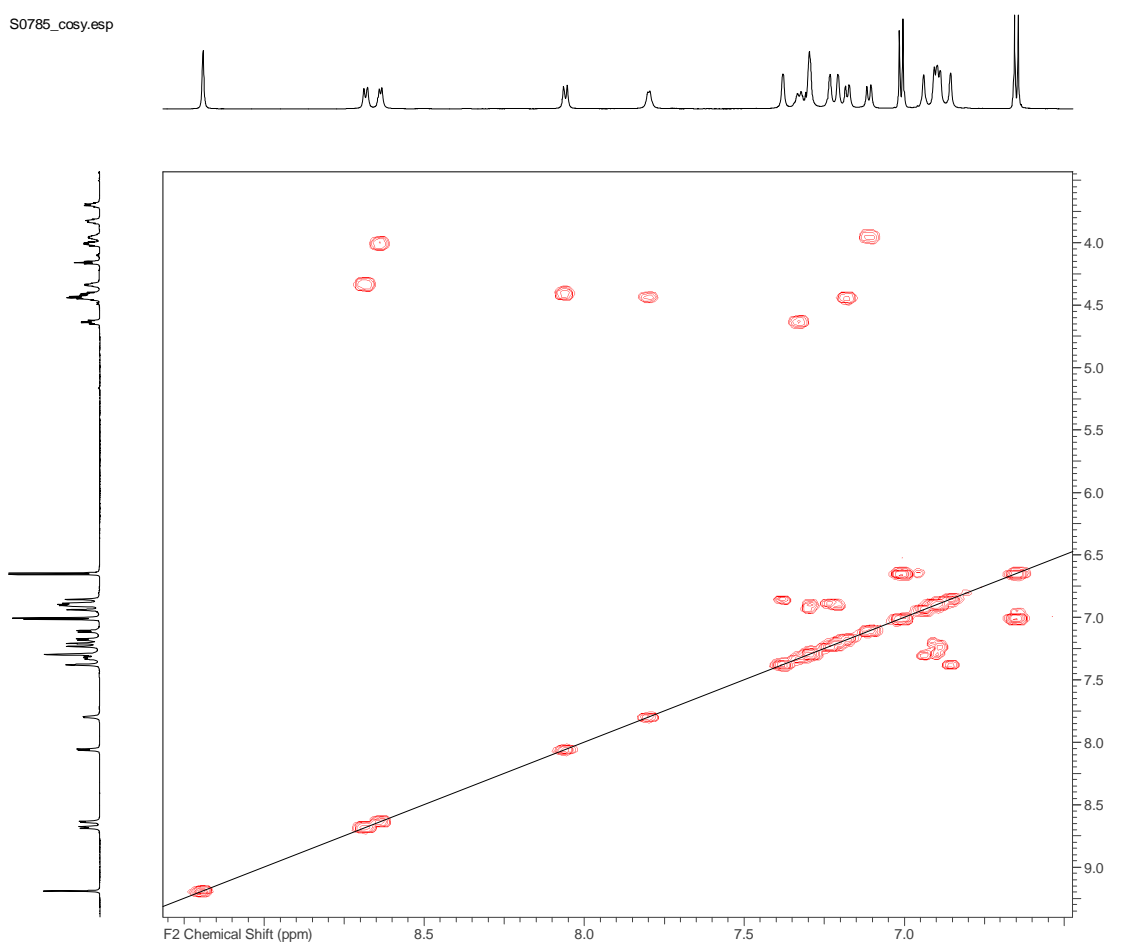

Figure BS28. ${ }^{1} \mathrm{H}-{ }^{-1} \mathrm{H}$ COSY NMR of 3 in DMSO- $\mathrm{d}_{6}$, selected area

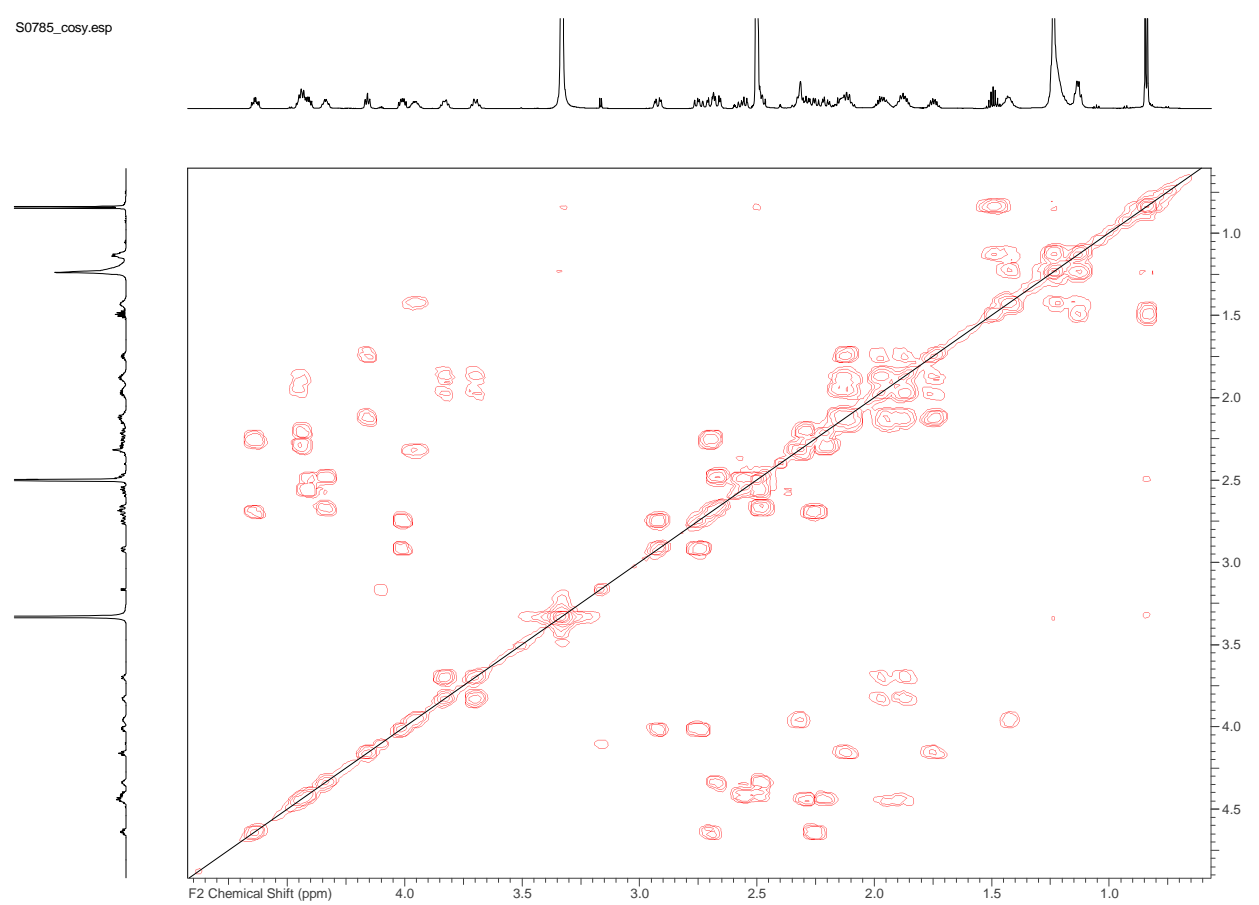

Figure BS29. ${ }^{1} \mathrm{H}-{ }^{1} \mathrm{H}$ COSY NMR of 3 in DMSO- $\mathrm{d}_{6}$, selected area 
S0785_HSQC.esp
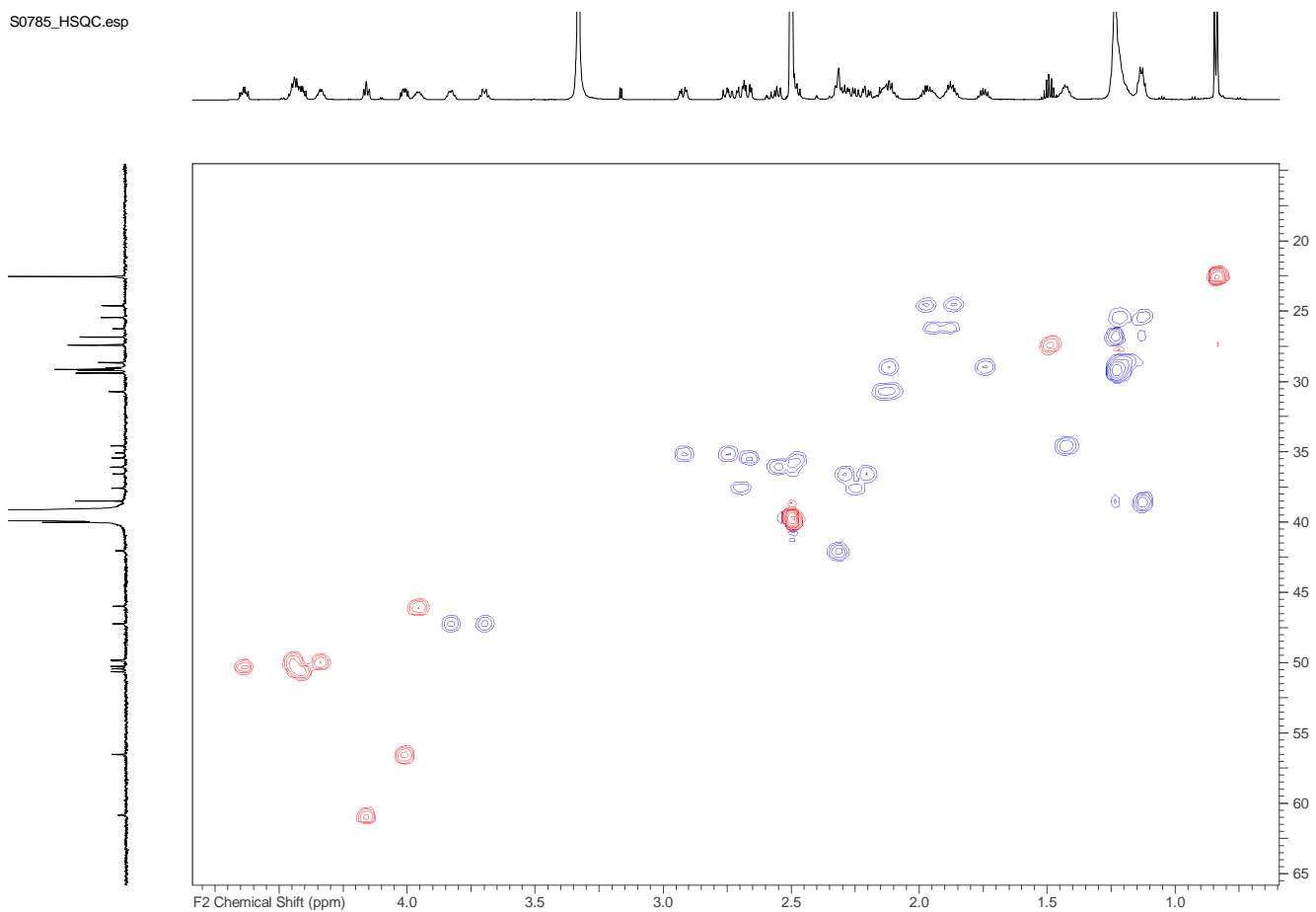

Figure BS30. HSQC NMR of 3 in DMSO-d $\mathrm{d}_{6}+5 \mu \mathrm{L} \mathrm{HCOOH,} 700 \mathrm{MHz}$, selected area

S0785 HMBC.esp
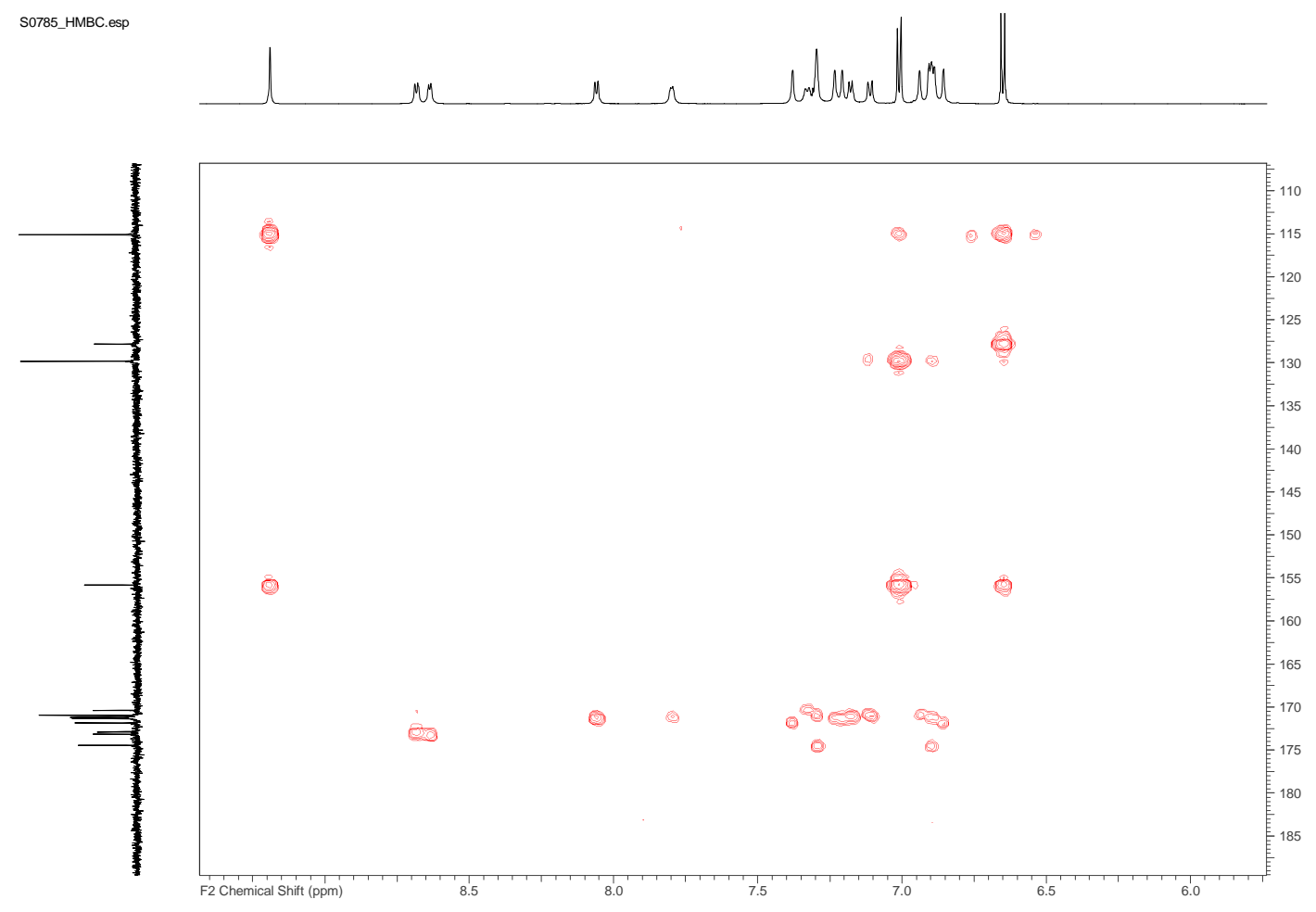

Figure BS31. HMBC NMR of 3 in DMSO-d $d_{6}, 700 \mathrm{MHz}$, selected area 

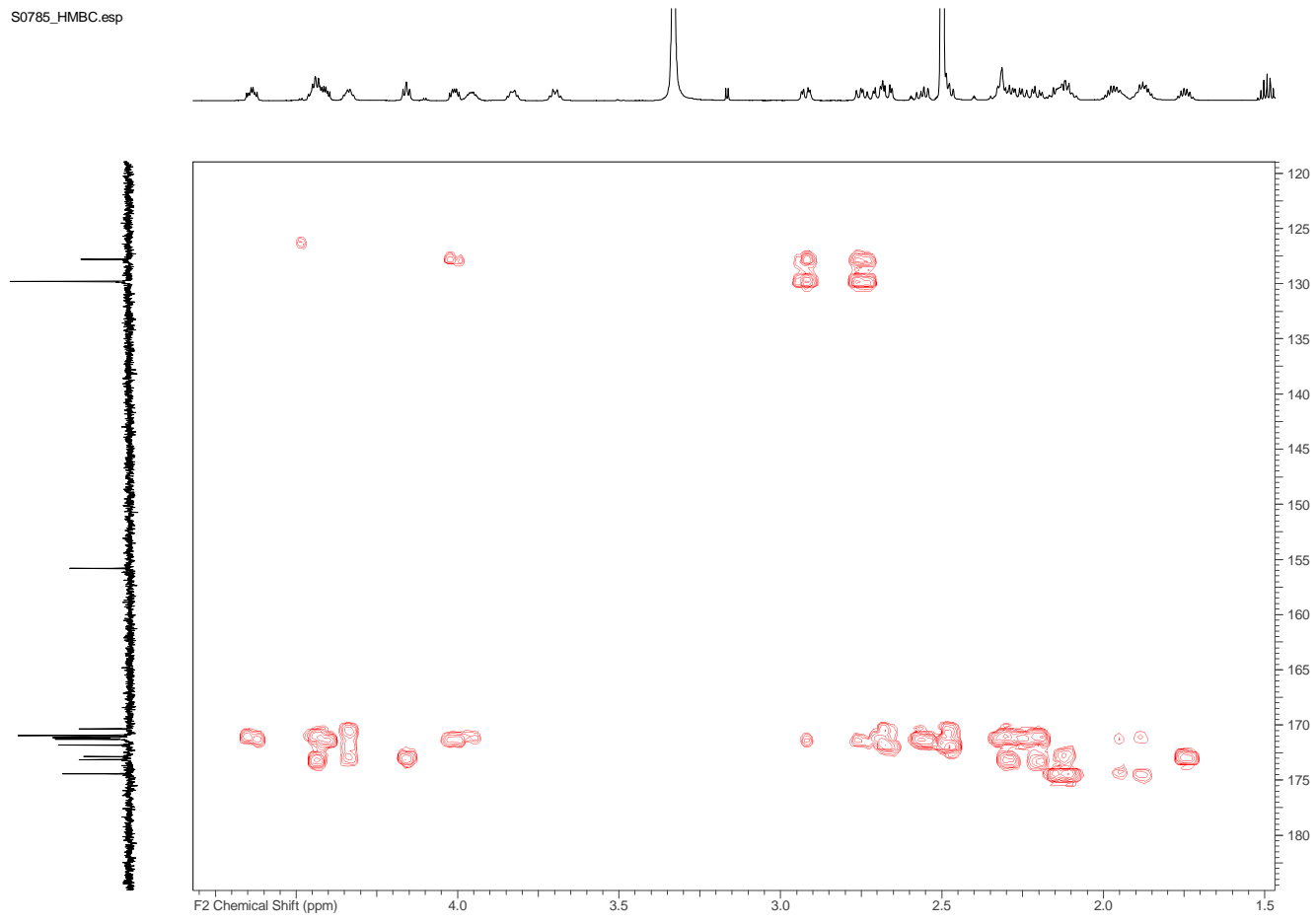

Figure BS32. HMBC NMR of 3 in DMSO- $d_{6}, 700$ MHz, selected area

S0785_HMBC.esp
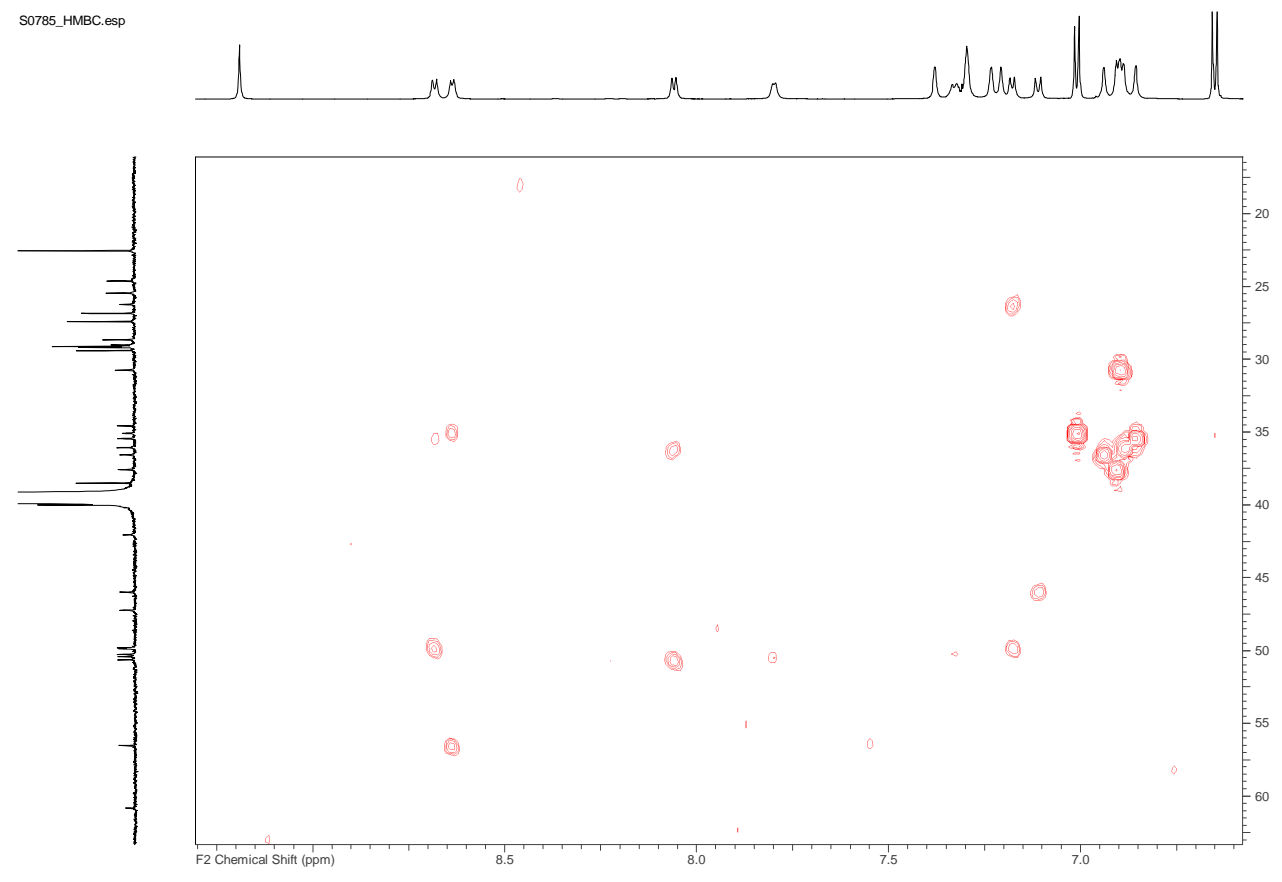

Figure BS33. HMBC NMR of 3 in DMSO-d ${ }_{6}, 700 \mathrm{MHz}$, selected area 


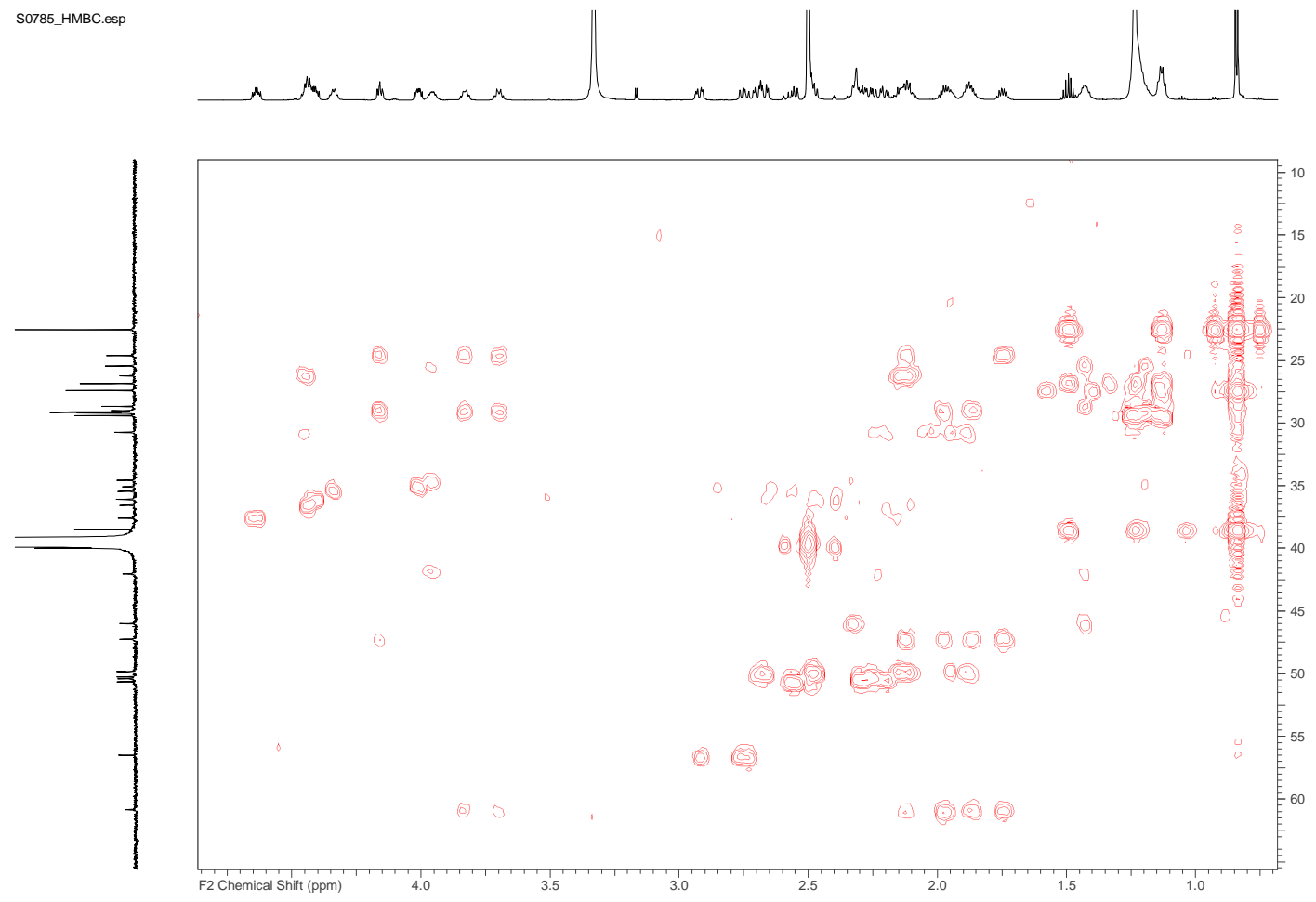

Figure BS34. HMBC NMR of 3 in DMSO- $d_{6}, 700 \mathrm{MHz}$, selected area

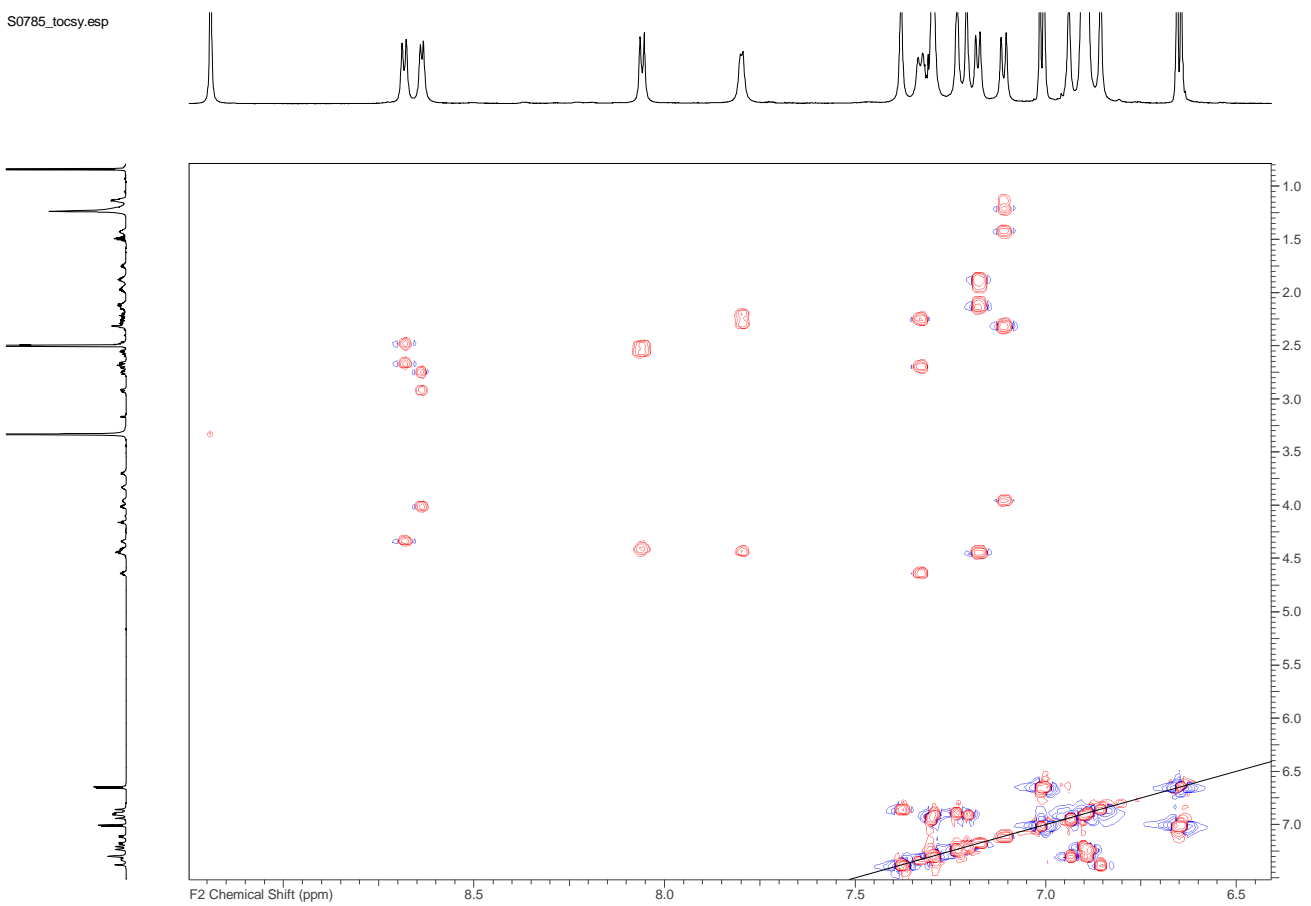

Figure BS35. TOCSY NMR of 3 in DMSO-d, 700 MHz, selected area 

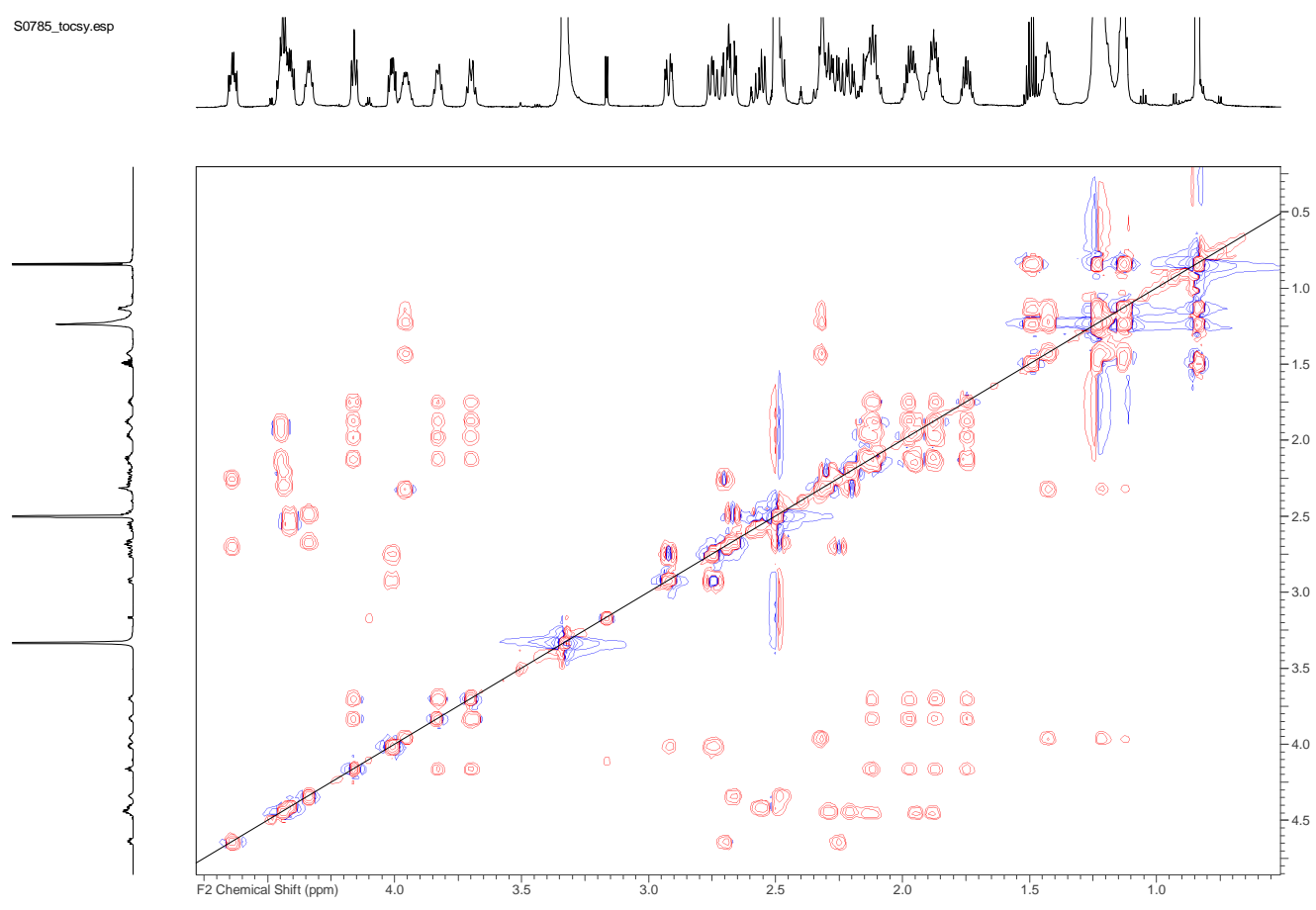

Figure BS36. TOCSY NMR of 3 in DMSO- $\mathrm{d}_{6}, 700 \mathrm{MHz}$, selected area
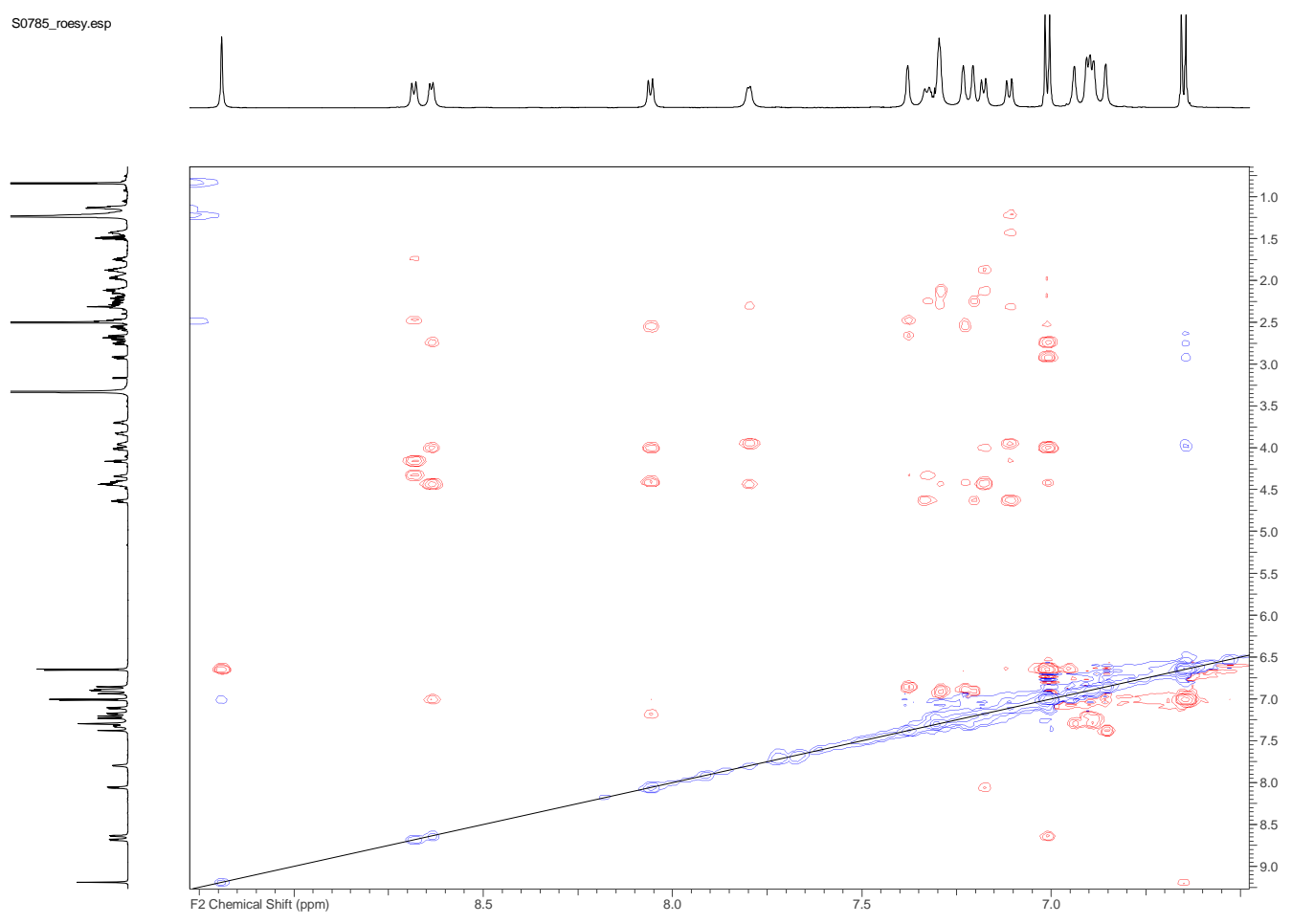

Figure BS37. ROESY NMR of 3 in DMSO- $\mathrm{d}_{6}, 700 \mathrm{MHz}$, selected area 


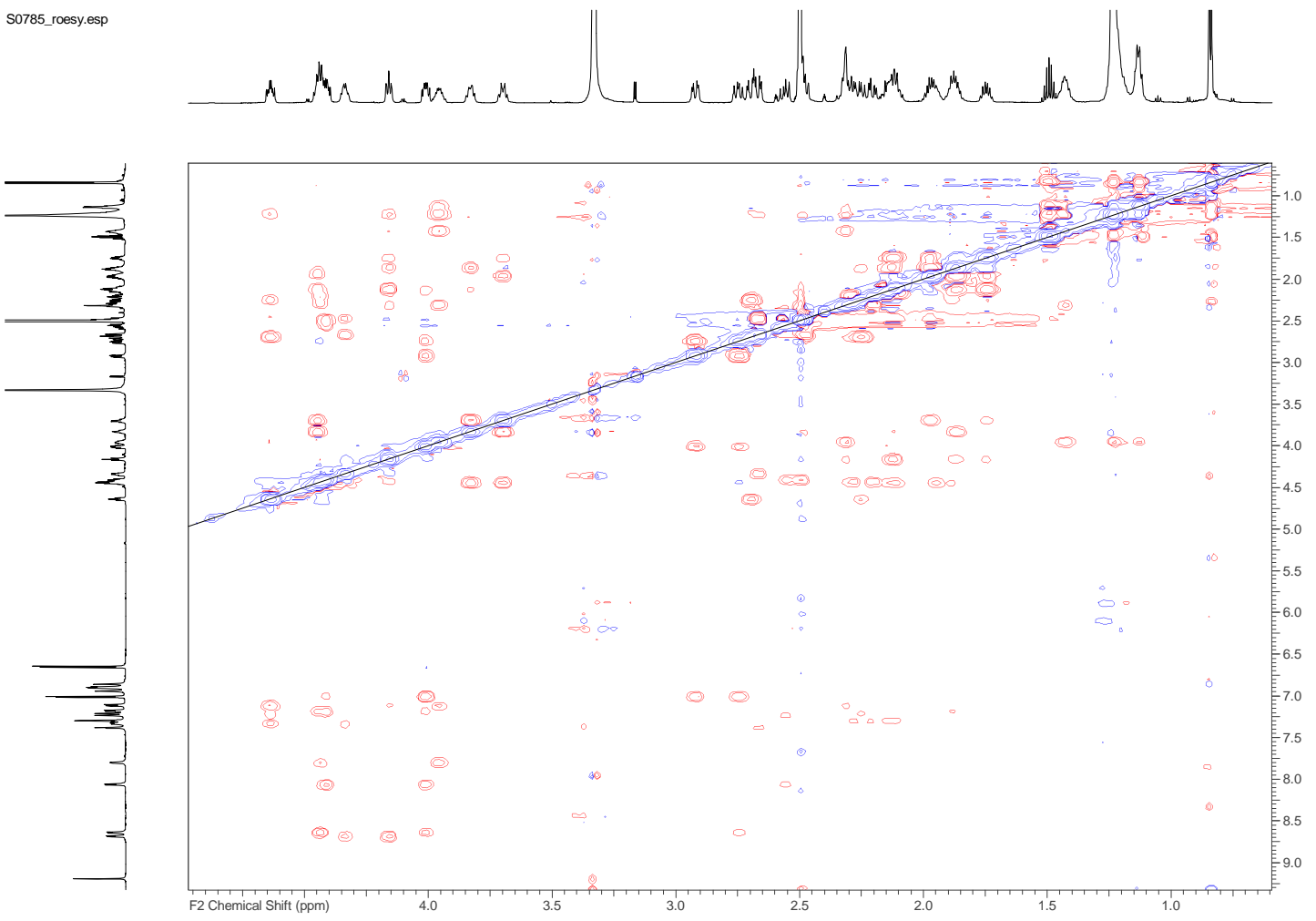

Figure BS38. ROESY NMR of 3 in DMSO- $\mathrm{d}_{6}, 700 \mathrm{MHz}$, selected area

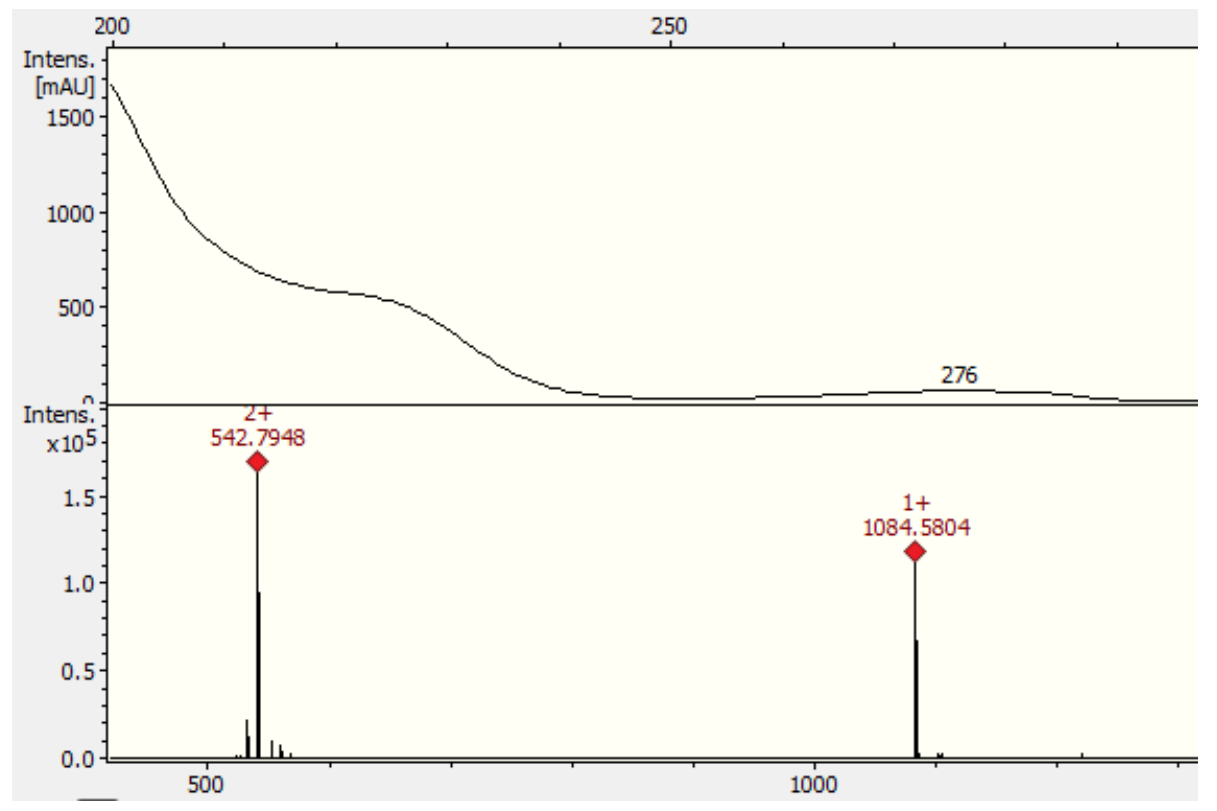

Figure BS39. ESI HRMS of paenilarvin C (3) 


\section{Chapter C}

\section{Aggregicoccus edonensis gen. nov., sp. nov., an unusually aggregating myxobacterium isolated from a soil sample}

Sakshi Sood*, Ram Prasad Awal*, Joachim Wink, Kathrin I. Mohr, Manfred Rohde, Marc Stadler, Peter Kämpfer, Stefanie P. Glaeser, Peter Schumann, Ronald Garcia and Rolf Müller

Submitted to International Journal of Systematic and Evolutionary Microbiology on December $13^{\text {th }}, 2013$

Last revised on February $5^{\text {th }}, 2014$

(Current status - Published online on March $3^{\text {rd }}, 2014$ )

\section{Author's contribution to this work}

${ }^{*}$ Contributed equally

Morphological, physiological and sequencing experiments and analysis: SS, RA

SEM Images: MR

DNA-DNA hybridization experiments and analysis: PK, SG

MALDI-TOF experiments and analysis: HB

Fatty acid profile experiments: RG

Wrote the paper: SS, RPA

Provided research facilities: JW, MS, RM

Conceived and designed the experiments: JW, KM 


\section{C.1. Abstract}

A novel myxobacterium MCy $1366^{\top}$ (Ar1733) was isolated in 1981 from a soil sample collected from a region near Tokyo, Japan. It displayed general myxobacterial features like Gram negative staining, rod shaped vegetative cells, gliding on solid surfaces, microbial lytic activity, fruiting body-like aggregates and myxospore-like structures. The strain was mesophilic, aerobic and showed chemoheterotrophic mode of nutrition. It was resistant to many antibiotics like cephalosporin $\mathrm{C}$, kanamycin, gentamycin, hygromycin $\mathrm{B}$, polymyxin and bacitracin and the key fatty acids of whole cell hydrolysates were iso- $\mathrm{C}_{15: 0}$, iso- $\mathrm{C}_{17: 0}$, and iso- $\mathrm{C}_{17: 0}$ 2-OH. The genomic $\mathrm{G}+\mathrm{C}$ content of the novel strain is $65.6 \mathrm{~mol} \%$. The $16 \mathrm{~S}$ rRNA gene sequence showed highest similarity $(97.60 \%)$ to "Stigmatella koreensis" strain KYC1019 (not validly described taxon, GenBank accession no. EF112185). The phylogenetic analysis based on 16S rRNA gene sequences and MALDI-TOF data revealed a novel branch in the family Myxococcaceae. DNA-DNA hybridization showed only $28 \%$ similarity between the novel strain and the closest species, Corallococcus exiguus DSM $14696^{\top}$ ( $97 \%$ 16S rRNA gene sequence similarity). A recent isolate from a Switzerland soil sample and designated reference strain, MCy10622 displayed 99.9\% 16S rRNA gene similarity and showed almost the same characteristics with $\mathrm{MCy} 1366^{\top}$. Since some morphological features like fruiting body like aggregates were barely reproducible in the type strain, the newly isolated strain MCy 10622 was also intensively studied. On the basis of a comprehensive taxonomic study, we propose a novel genus and species, Aggregicoccus edonensis gen. nov., sp. nov., for strain MCy $1366^{\top}$ and MCy10622. The type strain for the genus Aggregicoccus is MCy $1366^{\top}\left(=\mathrm{DSM} 27872^{\top}=\right.$ NCCB $\left.100468^{\top}\right)$.

\section{C.2. Introduction}

Myxobacteria are known for their unique life cycle and the ability to produce natural products with unique structures and bioactivities (Weissman and Müller, 2010). They form a phylogenetically coherent group within the class $\delta$-proteobacteria based on 16S rRNA gene sequence analysis (Garcia et al., 2010). Three suborders, 7 families, 23 genera and 55 species with valid names have been published within the order 
Myxococcales until today (Approved List of Bacterial Names). Myxobacterial systematics is mainly based on morphological characteristics like shape and size of vegetative cells and myxospores, swarming colonies and fruiting bodies. However, their morphological characteristics are often unstable and may vary or be lost on repeated subculturing under laboratory conditions (Garcia et al., 2010). 16S rRNA gene sequences are also quite conservative for fine discrimination between closely related taxa (Fox et al., 1992). Hence, a polyphasic approach should be followed in order to clearly delineate a potential new taxon from its closest relatives. Recently, fatty acid analysis with respect to different taxonomic clades within myxobacteria helped to establish chemotaxonomic-phylogenetic correlations (Garcia et al., 2011). In the future, other molecular markers and approaches also need to be identified and applied to establish a modern myxobacterial systematics.

Using divergent approaches based on genotypic, phenotypic and chemotaxonomic analysis performed together with the reference strain MCy10622 and selected type strains belonging to the genera Myxococcus, Corallococcus, Pyxidicoccus, and Melittangium, we propose a new genus for a soil bacterium from Japan, MCy1366 ${ }^{\top}$.

\section{C.3. Results and Discussion}

Two strains described here were isolated from different geographical locations in different time and place. MCy $1366^{\top}$ was isolated at the Helmholtz Centre for Infection Research ( $\mathrm{HZl}$; formerly GBF, Gesellschaft für Biotechnologische Forschung, Braunschweig, Germany) in 1981 from a soil sample, collected in 1980 near Tokyo, Japan. The reference strain MCy10622 was isolated in July 2013 at the Helmholtz Institute for Pharmaceutical Research Saarland (HIPS, Saarbrücken, Germany) from a soil sample collected from Zürich, Switzerland. Standard isolation and purification protocols were used for both strains (Reichenbach and Dworkin, 1992). The type and neotype strains used in this study are listed in Table $\mathrm{S} 1$ in the supplementary information. All strains were continuously maintained on $\mathrm{CY} / \mathrm{H}$ medium supplemented with $1 \mathrm{ml} \mathrm{l}^{-1}, 500$ fold diluted vitamin solution after autoclaving (Mohr et al., 2011; Schlegel, 1992) and VY/2 agar. All cultures were incubated at $30^{\circ} \mathrm{C}$, liquid cultures at $160-200$ rpm unless specified otherwise. 
Morphology of vegetative cells and myxospores was studied with phase-contrast microscopy (Olympus BX51). Fruiting body like aggregates (for MCy $1366^{\top}$ ), fruiting bodies (for MCy10622) and swarming colonies were observed under an Olympus SZX12 stereomicroscope and Zeiss Discovery.V20 stereomicroscope on P (Garcia et al., 2009), VY/2 and CY agar (Shimkets et al., 2006). All photographs were taken using the image analysis software "AxioVision LE" and AxioCam MRc camera (Carl Zeiss). Fruiting body aggregate morphology of MCy $1366^{\top}$ was also studied by field emission scanning electron microscopy using a Zeiss Merlin, aldehyde fixed, criticalpoint dried and gold palladium sputtered samples. Images were taken with the Everhart-Thornley SE-detector and Inlens-SE detector in a 25:75\% ratio applying the SEMSmart software version 5.05. Formation of myxospore-like structures by strain MCy $1366^{\top}$ was observed in myxo media broth (10 g casein peptone, $1 \mathrm{mg} \mathrm{CoCl}$, $0.05 \mathrm{~g} \mathrm{CaCl}_{2} \cdot 2 \mathrm{H}_{2} \mathrm{O}, 0.25 \mathrm{~g} \mathrm{MgSO}_{4} \cdot 7 \mathrm{H}_{2} \mathrm{O}, 23.6 \mathrm{~g} \mathrm{HEPES}, 1$ litre distilled water, $\mathrm{pH}$ 7.0) after incubation for at least 3 days.

The swarm colony of both isolates on VY/2 agar was transparent, soft, thin, and surrounded by a clear halo, owing to the lysis of yeast cells as often described for most members of Myxococcaceae (Reichenbach, 2005) but the salmon orange color of the MCy $1366^{\top}$ cells was evident upon scraping the swarm with the loop. Swarm colony on $\mathrm{P}$ agar was yellow to orange colored with large flame-like outward extensions at the periphery (Fig.C1d) and surrounded by a clear halo suggesting starch hydrolysis. Swarm on $\mathrm{CY}$ agar was with shades of orange to brown color (Fig.C1b), ripples and flat ridges like structures in the center and intricate wavy veins at the edges (Fig.C1c). Such an undulating vein structure is typical for Myxococcaceae swarms on peptone containing agar (Reichenbach, 2005). Radiating veins in the swarm or corrosion of agar, typical for Cystobacteraceae and Nannocystaceae, respectively, were not observed on any medium.

Vegetative cells were slender rods with slight tapering ends, mostly measuring 0.72 $0.82 \mu \mathrm{m} \times 5.71-10.73 \mu \mathrm{m}$ except few which were as long as $20 \mu \mathrm{m}$ upon cultivation in myxo media for 2 days (Fig.CS1b). Numerous optically refractile, irregular spherical to ellipsoidal myxospore-like structures (1.3-1.7 $\mu \mathrm{m}$ in size) surrounded by a conspicuous dark capsule were observed in the same media after longer (10-20 
days) incubation period (Fig.C1h). Cultivation in $\mathrm{CY} / \mathrm{H}$ and myxo media broth displayed salmon orange and beige color of the vegetative cells of $\mathrm{MCy} 1366^{\top}$ and MCy10622, respectively, which often gathered into a huge aggregate of cells. Such a massive aggregation of cells often into a single clump with a branching morphology pattern is a peculiar characteristic of both isolates in liquid media (Fig.C1a).

Fruiting bodies like aggregates of MCy $1366^{\top}$ could only be observed on $\mathrm{P}$ and $\mathrm{CY}$ agar after prolonged incubation (8-10 weeks) (Fig.C1e). They mostly appeared solitary as yellowish orange spherical heads and lacked sporangioles and stalk. Immature fruiting bodies had the appearance of humps or knobs on the agar, as in Myxococcus spp. (Reichenbach, 2005). Cell aggregation on the agar, presumably in an attempt to form the fruiting bodies was clearly visible under stereomicroscope as well as by scanning electron microscopic imaging (Fig.C1g). No fruiting bodies were observed on buffered VY/2 agar, while the new isolate MCy10622 could form reproducible fruiting bodies on the same agar within one week of incubation (Fig.C1f). However, the fruiting bodies of MCy10622 were irregularly shaped, cushion like cell mounds formed in groups clearly distinguishing themselves from MCy $1366^{\top}$ fruiting bodies (Fig.C1f). Myxospores similar to spherical structures observed in liquid myxo media were also observed upon teasing of fruiting bodies and fruiting body like aggregates on a glass slide.

Reaction of 3 week old swarm colonies of MCy $1366^{\top}$ and MCy10622 on VY/2 agar to Congo Red stain was determined using the method of McCurdy (McCurdy, 1969). Enzyme activity was determined using APIZym strips (BioMérieux) inoculated with the cells grown in $\mathrm{CY} / \mathrm{H}$ broth and further diluted with sterile water (1:10) and incubated aerobically at $30^{\circ} \mathrm{C}$ overnight. Starch hydrolysis, cellulose and agar degradation was studied as described by Mohr et al. (2011). The chitin degradation assay was performed using CT-6 (Reichenbach, 2006) and synthetic $S$ agar (0.5 g $\mathrm{CaCl}_{2} .2 \mathrm{H}_{2} \mathrm{O}, 0.5 \mathrm{~g} \mathrm{MgSO}_{4} .7 \mathrm{H}_{2} \mathrm{O}, 0.06 \mathrm{~g} \mathrm{~K}_{2} \mathrm{HPO}_{4}, 8 \mathrm{mg}$ Ferric EDTA, $50 \mathrm{mM}$ HEPES, 1 liter distilled water, $\mathrm{pH} 7.2)$ with $0.7 \%(\mathrm{w} / \mathrm{v})$ chitin as the sole nutrient source. Salt tolerance to $1.5 \%(\mathrm{w} / \mathrm{v})$ sodium chloride was tested on $\mathrm{CY}$ agar after incubation for 34 weeks at $30^{\circ} \mathrm{C}$. 

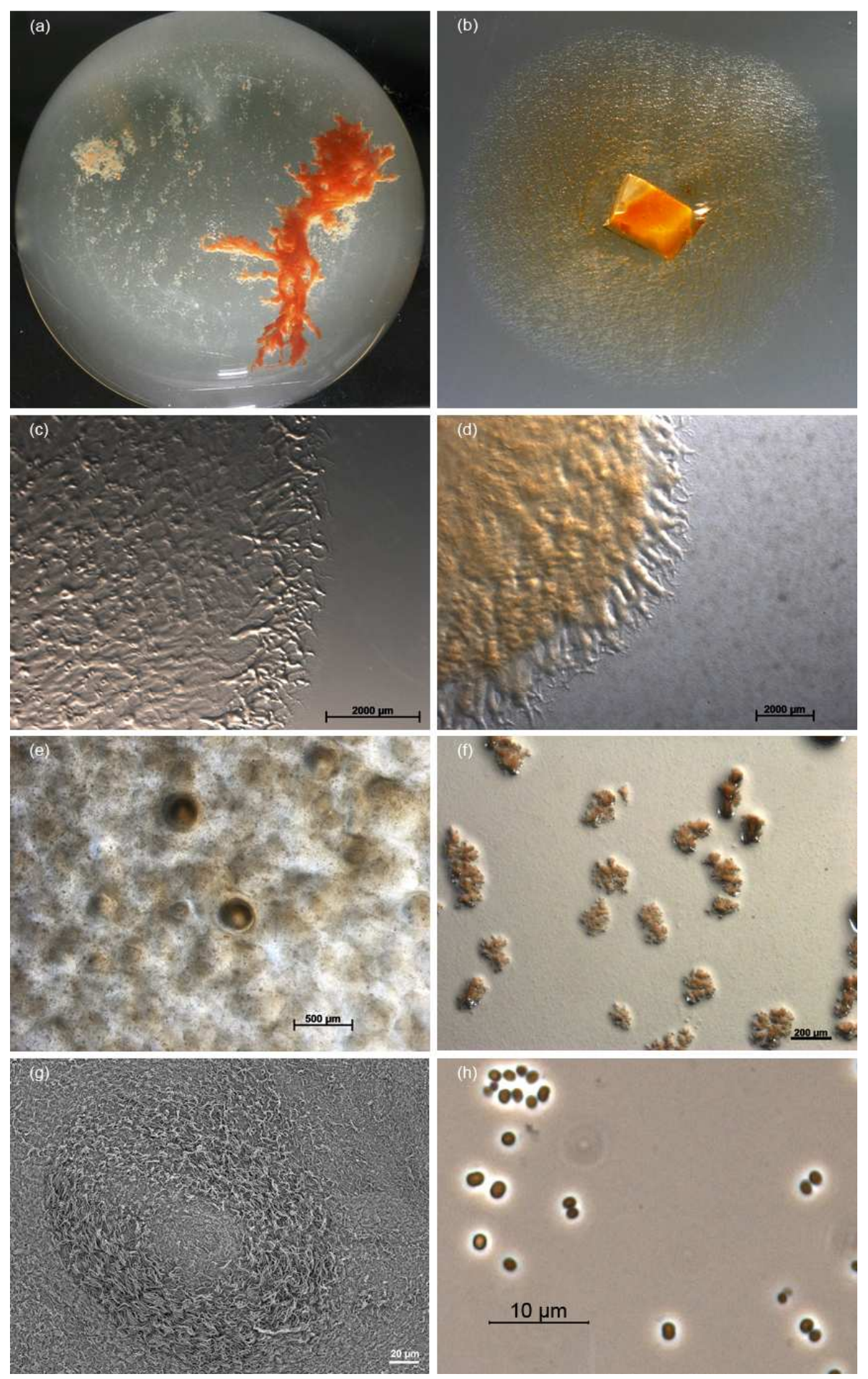

Fig.C1. Photographs showing morphology of strain MCy1366 and MCy10622. (a) Photograph of huge bright orange cell aggregate of $\mathrm{MCy} 1366^{\top}$ in 11 day old culture in $\mathrm{CY}+\mathrm{H}$ broth. (b) Saffron orange coloured 4-week-old swarming colony of MCy1366 ${ }^{\top}$ on CY agar. Stereophotomicrograph of (c) 4-week-old swarm of MCy1366 ${ }^{\top}$ on CY agar (bar, 2000 $\mu \mathrm{m})$, (d) 3 week old swarm of MCy1366 on $P$ agar (bar, $2000 \mu \mathrm{m})$, (e) fruiting body-like aggregates of MCy1366 ${ }^{\top}$ on $P$ agar (bar, $500 \mu \mathrm{m}$ ), (f) mature fruiting bodies of MCy10622 on VY/2 agar (bar, $200 \mu \mathrm{m})$. (g) SEM image showing cell aggregation of MCy1366 ${ }^{\top}$ on agar surface for initiation of fruiting body formation (bar, $\left.20 \mu \mathrm{m}\right)(\mathrm{h})$ Phase contrast image of myxospore-like structures in liquid myxo media (bar, $20 \mu \mathrm{m}$ ) 
The Congo Red reaction was very weak and displayed light pink color (Fig.CS1a) in contrast to strong reactions observed for Corallococcus spp., Pyxidicoccus sp., and some Myxococcus spp. Both the isolates could not degrade cellulose, chitin or agar. No cell growth was observed for MCy $1366^{\top}$ and MCy10622 under $1.5 \% \mathrm{NaCl}$ concentration same as observed for Corallococcus spp. and Melittangium lichenicola while fair to good growth was observed for Pyxidicoccus fallax and all Myxococcus spp. except M. fulvus (Table CS2). The colorless haloes on $\mathrm{P}$ agar plate after staining with Lugol's solution was limited to the size of MCy $1366^{\top}$ and MCy 10622 swarms as opposed to Corallococcus spp. depicting weak starch hydrolysis ability (Fig.CS1c). Ability to degrade starch and salt tolerance are often used as characteristics to differentiate between species of Myxococcus and Corallococcus (Lang and Stackebrandt, 2009).

The reactions on the APIZym strips by $M C y 1366^{\top}$ were reasonably similar to the reactions observed for Corallococcus spp. suggesting close relationship between both (Table CS3). Alkaline phosphatase, esterase lipase, leucine arylamidase and acid phosphatase were positive and B-galactosidase, $\alpha$-mannosidase and $\alpha$ fucosidase were negative for MCy $1366^{\top}$ along with all the other strains used during this study (Table CS1). Trypsin was negative for MCy $1366^{\top}$ along with Corallococcus spp. and M. lichenicola while it was positive for three Myxococcus spp. and P. fallax. All the reactions for MCy $1366^{\top}$ on APIZym strips were same to the reactions from MCy10622 except cysteine arylamidase which was found to be negative for the former and positive for the latter. All these similar reactions observed for all the members of the family Myxococcaceae strengthened the supposition that both new isolates belong to the same family. Detailed results from the APIZym test system for all strains are given in supplementary information (Table CS3).

Cross streaked microbial baits of live bacteria (Paenibacillus polymyxa DSM $36^{\top}$ ), yeasts (Candida albicans DSM 1665, Wickerhamomyces anomalus DSM 6766) and autoclaved E. coli $\mathrm{K} 12$ cells on water agar was used for testing the ability of MCy $1366^{\top}$ and MCy10622 to lyse microorganisms as described by Mohr et al. (2011). E. coli and C. albicans cells were completely lysed by both the strains. $W$. anomalus and $P$. polymyxa supported the growth of $\mathrm{MCy} 1366^{\top}$ on water agar but 
clearing of cells could not be observed, making it difficult to assess the ability of MCy $1366^{\top}$ to lyse the cells of these organisms.

Growth response of MCy $1366^{\top}$ and MCy 10622 to different temperatures was tested at $20^{\circ} \mathrm{C}, 30^{\circ} \mathrm{C}, 37^{\circ} \mathrm{C}$ and $42^{\circ} \mathrm{C}$ on VY/2 agar. The $\mathrm{pH}$ o ptima for both strains were tested between pH 5.0 to 10.0 at intervals of $0.5 \mathrm{pH}$ units in $\mathrm{CY}$ liquid media. Optimum growth temperatures for MCy $1366^{\top}$ and MCy10622 were near $30^{\circ} \mathrm{C}$ like most myxobacteria. Both isolates could not grow at $42^{\circ} \mathrm{C}$. They tolerated wide range of $\mathrm{pH}$ 6.0-10.0 but the maximum growth was seen at $\mathrm{pH}$ 6.5-7.0 (Table CS8). No evidence of growth was found below pH 5.5.

Antibiotic resistance of strains MCy $1366^{\top}$ and MCy10622 was tested along with the other related strains as described by Mohr et al. (2011) against 13 antibiotics. The final concentration was adjusted to $50\left(\mu \mathrm{g} \mathrm{ml}^{-1}\right)$ for most antibiotics except oxytetracycline (10), chloramphenicol (30), ampicillin (100) and hygromycin B (150). MCy $1366^{\top}$ was sensitive to spectinomycin, thiostrepton and chloramphenicol and resistant to cephalosporin $\mathrm{C}$, kanamycin, gentamycin, hygromycin $\mathrm{B}$, polymyxin and bacitracin similar to the Corallococcus spp. used in this study. However, it was sensitive to fusidic acid and ampicillin as opposed to the Corallococcus spp. which showed little growth on fusidic acid but good growth on ampicillin. MCy10622 was found to be sensitive to spectinomycin and thiostrepton whereas resistant to most of the other antibiotics tested. MCy $1366^{\top}$ and MCy 10622 , both grew poorly on trimethoprim. A detailed description of the antibiotic resistance test is given in the supplementary information (Table CS4).

Synthetic liquid medium S containing $0.25 \%(\mathrm{w} / \mathrm{v})$ casitone and supplemented with $0.25 \%(\mathrm{w} / \mathrm{v})$ of various sugars and starch was used for testing the carbon sources favored for growth. Nitrogen requirement was tested on a minimal casitone medium (C) (Mohr et al., 2011) with addition of $0.25 \%(\mathrm{w} / \mathrm{v})$ of some organic and inorganic nitrogen sources. Utilization of various peptones was also tested by addition to synthetic $S$ medium individually at a concentration of $0.25 \%(w / v)$. These experiments were performed in duplicates and all flasks were incubated at $30^{\circ} \mathrm{C}, 200$ rpm for 7 days. Cell pellets were collected and washed with sterile water in order to remove salt contents, dried and the dry weight was noted. 
Table C1. Differential characteristics of strain $M C y 1366^{\top}, M C y 10622$ and their closely related strains

\begin{tabular}{|c|c|c|c|c|c|c|}
\hline Features & Myxococcus spp. & Corallococcus spp. & $\operatorname{MCy} 1366^{T}$ & MCy10622 & Pyxidicoccus fallax & $\begin{array}{c}\text { Melittangium } \\
\text { lichenicola }\end{array}$ \\
\hline No. of strains used for study & 5 & 2 & & & 1 & 1 \\
\hline \multicolumn{7}{|l|}{ Resistance to: } \\
\hline Ampicillin (100ug/ml) & $\mathrm{V}(3)$ & + & - & + & + & - \\
\hline Kanamycin (50ug/ml) & $\mathrm{V}(2)$ & + & + & + & - & + \\
\hline Spectinomycin $(50 \mathrm{ug} / \mathrm{ml})$ & + & - & - & - & + & + \\
\hline Trimethoprim $(50 \mathrm{ug} / \mathrm{ml})$ & $\mathrm{V}(2)$ & + & + & + & + & + \\
\hline Fusidic acid (50ug/ml) & $\mathrm{V}(3)$ & + & - & + & + & - \\
\hline Growth at $1.5 \%$ salt & $\mathrm{V}(4)$ & - & - & - & + & - \\
\hline Starch hydrolysis & Weak positive & Strong positive & Weak positive & Weak positive & Positive & n.i. \\
\hline Congo red reaction & Weak/Strong & Strong & Very weak & Very weak & Strong & Weak \\
\hline \multicolumn{7}{|l|}{ ApiZym Test } \\
\hline Trypsin & $\mathrm{V}(3)$ & - & - & - & + & - \\
\hline \multicolumn{7}{|l|}{ Fatty acid analysis } \\
\hline $\mathrm{C}_{15: 0}$ & $0.0-2.7$ & $0.2-0.8$ & 1.8 & 1.6 & 1.1 & 0 \\
\hline $\mathrm{C}_{15: 1 \text { isomer } 2}$ & $0.0-2.5$ & $0.1-0.4$ & 3.3 & 0 & 0.9 & 0 \\
\hline $\mathrm{C}_{16: 1 \text { isomer } 2}$ & $6.1-14.5$ & $0.2-0.6$ & 1.1 & 0 & 21.0 & 5.5 \\
\hline $\mathrm{C}_{17: 1 \omega 7 \mathrm{cis}}$ & $0.0-1.0$ & $1.5-2.2$ & 0.40 & 0 & 0.2 & 0 \\
\hline iso $\mathrm{C}_{15: 0}$ & $13.5-39.7$ & $17.5-22.3$ & 23.2 & 25.3 & 14.0 & 13.0 \\
\hline iso $\mathrm{C}_{17: 0}$ & $1.3-11.7$ & $4.3-10.1$ & 16.6 & 10.4 & 7.7 & 0.8 \\
\hline iso $\mathrm{C}_{17: 02-\mathrm{OH}}$ & $0.2-12.4$ & $32.9-34.4$ & 26.1 & 14.1 & 9.3 & 0.5 \\
\hline iso $\mathrm{C}_{15: 0 \mathrm{OAG}}$ & $0.0-10.3$ & $3.4-7.2$ & 1.9 & 1.3 & 2.9 & 0 \\
\hline iso $\mathrm{C}_{15: 0 \mathrm{DMA}}$ & $0.0-2.1$ & $1.6-4.2$ & 2.0 & 4.4 & 4.7 & 0 \\
\hline
\end{tabular}


MCy $1366^{\top}$ as well as MCy 10622 could not utilize any of the monosaccharides or disaccharides under the tested conditions (Table CS5). This is also true for most of the members of the family Myxococcaceae (Reichenbach, 2005). However, growth was observed on molasses (Juchem) which could be due to presence of other supplements. They could utilize polysaccharides viz. potato starch, soluble starch and pyruvate. But the two strains differ slightly in their peptone requirements. Strain MCy $1366^{\top}$ yielded high cell densities in neopeptone (Becton Dickinson), phytone peptone (BD) and skimmed milk (Oxoid) whereas MCy10622 grew better in tryptone enzymatic digest from casein (BD). No growth was observed in synthetic media $S$ supplemented with casamino acids (BD). All the organic and inorganic nitrogen sources tested resulted in moderate to fair growth of both the strains (Table CS6).

For fatty acid analysis, all the strains used in the study (Table CS7) were cultivated in $50 \mathrm{ml}$ of CY medium in $300 \mathrm{ml}$ flasks shaken at $160 \mathrm{rpm}$ at $30^{\circ} \mathrm{C}$. Cellular fatty acid extraction, GC-MS analysis and peak identification was done in duplicates using the method described by Garcia et al. (2011). All the strains had substantially high amounts of iso- $\mathrm{C}_{15: 0}$, which is true for most myxobacteria (Garcia et al., 2009). The fatty acid pattern of strains MCy $1366^{\top}$ and MCy 10622 was significantly distinct from all the other strains used in the study. Strain MCy10622 differed from MCy $1366^{\top}$ because of the presence of significant amounts of iso- $\mathrm{C}_{17: 1}(10.9 \%)$ while it was completely absent in the fatty acid profile of the latter. Strain MCy $1366^{\top}$ showed highest percentage of the branched chain fatty acid, iso- $\mathrm{C}_{17: 02}-\mathrm{OH}(26.1 \%)$ followed by iso- $\mathrm{C}_{15: 0}(23.2 \%)$ (Table $\mathrm{C} 1$ ). Indeed, high amounts of iso- $\mathrm{C}_{17: 0} 2-\mathrm{OH}$ has been recommended as a determinative chemotaxonomic marker for Corallococcus spp. in the family Myxococcaceae (Garcia et al., 2011). Strain MCy $1366^{\top}$ possessed a significant amount of iso- $\mathrm{C}_{17: 0}(16.6 \%)$ and higher amounts of $\mathrm{C}_{15: 1}$ isomer2 $(3.3 \%)$ compared to all the other strains. MCy $1366^{\top}$ also differed from Corallococcus spp. because of the lower amounts (1.9\%) of O-alkylglycerol (OAG) FAs. In addition, MCy $1366^{\top}$ and MCy10622 clearly distinguished from M. lichenicola DSM $2275^{\top}$ because of the presence of much higher amounts of $C_{16: 0}(9.8 \%), C_{18: 0}(20.6 \%)$ and unspecified fatty acid alcohol (32.1\%) as well as much lower amounts of iso- $\mathrm{C}_{15: 0}$ $(13.0 \%)$ and iso $-\mathrm{C}_{17: 02}-\mathrm{OH}(0.5 \%)$ in the latter compared to the former two strains. The total amount of SCFAs and BCFAs for strain MCy $1366^{\top}$ was $15.4 \%$ and $84.4 \%$, 
respectively, while MCy 10622 showed $10.0 \%$ and $76.3 \%$ of total SCFAs and BCFAs, respectively (Table CS7).

For 16S rRNA gene amplification, genomic DNA was extracted from actively growing cells of MCy $1366^{\top}$ and MCy 10622 using the protocol for gram-negative bacteria of the Puregene CoreKit A (Qiagen). 16S rRNA gene was amplified by PCR using universal primers (forward 5'-GAGTTTGATCCTGGCTCAGGA-3'; reverse 5'AAGGAGGTGATCCAGCCGCA-3'). The PCR product was purified using Nucleospin Gel and PCR clean-up (Macherey Nagel) following analysis of PCR product by gel electrophoresis using $0.8 \%(\mathrm{w} / \mathrm{v})$ agarose gel at $95 \mathrm{~V}$ for $35 \mathrm{~min}$. The same set of primers along with forward primers F27, F945, F357, F1100 and reverse primers R336, R518, R1078 and R1525 was applied for sequencing of the 16S rRNA gene (Lane, 1991; Turner et al., 1999; Stackebrandt and Liesack, 1993; Weidner et al., 1996). The consensus sequences were produced using the Cap contig assembly function of the BioEdit Sequence Alignment Editor Version 7.1.3.0. and compared to the NCBI-BLAST nucleotide data bank using FASTA search tool and showed highest similarity (MCy1366 ${ }^{\top}, 97.60 \%$, and MCy10622, 97.47\%) to invalidly described taxon, "Stigmatella koreensis"strain KYC-1019 (GenBank accession no. EF_112185).

The complete sequences of MCy $1366^{\top}$ and MCy 10622 were aligned with sequences of their close relatives using ClustalW (Larkin et al., 2007). A phylogenetic analysis with type and representative myxobacterial strains was calculated using two treemaking algorithms; neighbor joining (Saitou and Nei, 1987) and maximum likelihood (Guindon and Gascuel, 2003) methods by using the software package Geneious 7.0.3 version (Biomatters, New Zealand). A sulfate-reducing bacterium, Desulfovibrio desulfuricans DSM $642^{\top}$ (GenBank accession no. NR_036778) was chosen as an out-group to root the phylogenetic tree. Jukes Cantor model (Jukes and Cantor, 1969) was applied to calculate evolutionary distance matrices of the neighbor joining and maximum likelihood method. The topology of the phylogenetic tree was evaluated by bootstrap support based on 1000 resamplings (Felsenstein, 1985).

The tree constructed by maximum likelihood (Fig. C2) method showed that both strains (MCy $1366^{\top}$ and MCy10622), formed a separate cluster within the family Myxococcaceae close to C. exiguus DSM $14696^{\top}$, C. coralloides DSM $2259^{\top}$ and 
Melittangium lichenicola DSM $2275^{\top}$. Their separate branching from the known myxobacterial taxa in the suborder Cystobacterineae was also clear in the phylogenetic tree constructed with the neighbor joining method (Fig.CS2). The delineation of the two isolates from closely related strains and clustering within Myxococcaceae, clearly indicate that they represent a new taxon in the same family.

Desulfovibrio desulfuricans DSM 642 ${ }^{\mathrm{T}}$ (NR_036778)

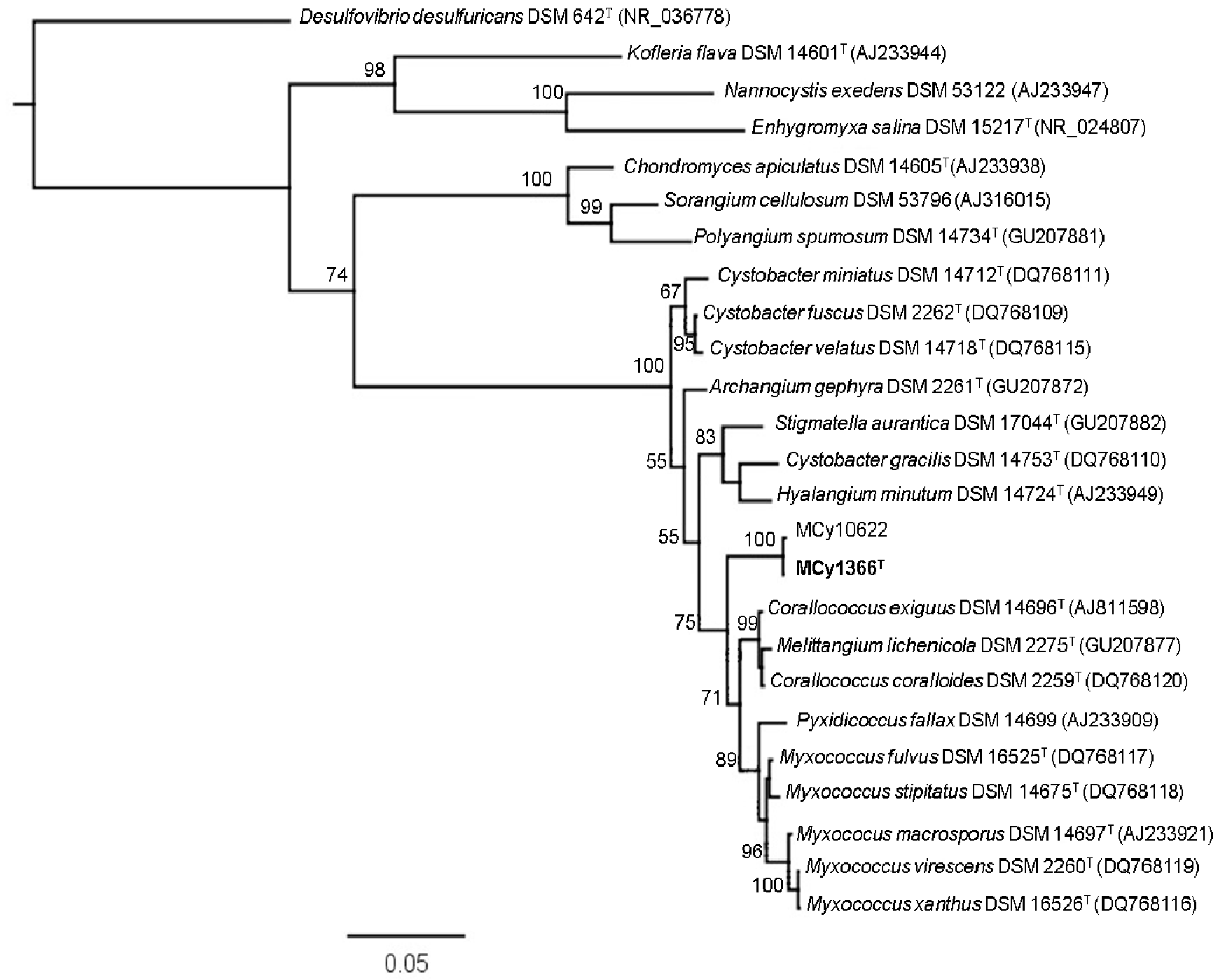

Fig.C2. Maximum likelihood phylogenetic tree (PHYML) based on 16S rRNA gene sequences of strains MCy1366 ${ }^{\top}$ and MCy10622 and related taxa. Numbers at the branch points indicate bootstrap support based on 1000 resamplings. Bar, 0.05 substitutions per nucleotide position. The GenBank accession number of strains used in the tree is shown in parentheses. Desulfovibrio desulfuricans DSM $642^{\top}$ was used as an outgroup.

The two closest relatives of MCy $1366^{\top}$ and MCy10622 according to the 16S rRNA gene sequence-based phylogenetic tree, $C$. exiguus DSM $14696^{\top}$ and $C$. coralloides DSM $2259^{\top}$ were chosen for DNA-DNA hybridization assay and DNA G+C mol\% content analysis. A method adapted from Kieser et al. (2000) but modified and 
optimized especially for myxobacteria was used for isolation of high yields of genomic DNA. $100 \mathrm{ml}$ cultures in myxo media, $\mathrm{CY}+\mathrm{H}$ media and A media $(8 \mathrm{~g}$ starch, $4 \mathrm{~g}$ soymeal, $2 \mathrm{~g}$ yeast, $1 \mathrm{~g} \mathrm{CaCl}_{2}, 1 \mathrm{~g} \mathrm{MgSO}_{4}, 100 \mathrm{mM}$ HEPES, $8 \mathrm{mg}$ Ferric EDTA, $4 \mathrm{ml}$ glycerol, 1 liter distilled water, $\mathrm{pH}$ 7.4), respectively, were harvested by centrifugation at $12000 \mathrm{rpm}$ for $5 \mathrm{~min}$. The cell pellets were re-suspended in $10 \mathrm{ml}$ Tris buffer after discarding the supernatant. The cell aggregates were dispersed and homogenized with an Ultraturrax (Art Moderne Labortechnik). After addition of $200 \mu$ proteinase $\mathrm{K}$ (20 mg ml ${ }^{-1}$ in $50 \mathrm{mM}$ Tris- $\left.\mathrm{HCl}, 1 \mathrm{mM} \mathrm{CaCl}_{2} .2 \mathrm{H}_{2} \mathrm{O}, \mathrm{pH} 7.5\right)$ and $200 \mu \mathrm{l}$ SDS $(20 \%$ $(\mathrm{w} / \mathrm{v})$ solution), the solution was mixed gently and kept in hybridization oven for continuous shaking and incubation at $41{ }^{\circ} \mathrm{C}$ for $30 \mathrm{~min}-2$ hrs until the solution became slightly clear. $3.5 \mathrm{ml}$ of $5 \mathrm{M} \mathrm{NaCl}$ was added to the solution with gentle mixing followed by $4 \mathrm{ml}$ CTAB extraction buffer $(4.1 \%(\mathrm{w} / \mathrm{v}) \mathrm{NaCl}, 10 \%(\mathrm{w} / \mathrm{v})$ Cetyl trimethylammonium bromide, water). The cell solutions were again shaken and incubated at $65^{\circ} \mathrm{C}$ for another $20 \mathrm{~min}$ inside the hyb ridization oven. The cell solution was incubated at room temperature from $1 \mathrm{hr}$ to $12 \mathrm{hrs}$ in an overhead shaker after addition of chloroform up to $35 \mathrm{ml}$. Phase separation of the solution was then achieved by centrifugation at $12000 \mathrm{rpm}$ for $20 \mathrm{~min}$ and the upper phase was carefully transferred into new falcon tubes. The acquired upper phase was mixed with equal volume of isopropanol and mixed gently. The precipitated DNA was aspirated and rinsed with $70 \%(\mathrm{v} / \mathrm{v})$ ethanol twice. DNA was then air dried and dissolved in $2 \mathrm{ml}$ TE buffer.

DNA-DNA hybridizations (DDH) was performed as described by Ziemke et al. (1998), with the modification that for nick translation, $2 \mu \mathrm{g}$ of DNA was labeled during a $3 \mathrm{hr}$ incubation at $15^{\circ} \mathrm{C}$. The $\mathrm{G}+\mathrm{C}$ mol\% was determined using a fluorimetric thermal denaturation temperature determining method described by Gonzalez \& SaizJimenez (2002). Analysis was performed in a total volume of $20 \mu \mathrm{l}$, including $5 \mu \mathrm{g}$ genomic DNA, 0.1X SSC buffer $(0.03 \mathrm{M} \mathrm{NaCl}, 0.03 \mathrm{M}$ sodium citrate), $10 \%(\mathrm{v} / \mathrm{v})$ deionized formamide and 0.25X SYBR Green I (Molecular probes). Thermal denaturation was performed in a CFX384 Touch $^{\text {TM }}$ Real-Time PCR Detection System (BioRad) starting with $15 \mathrm{~min}$ at $25^{\circ} \mathrm{C}$, followed by a ramp from 65 to $98^{\circ} \mathrm{C}$ with an increase of $0.1^{\circ} \mathrm{C}$ cycle $^{-1}$. Each cycle holds for $5 \mathrm{~s}$ including a fluorescence measurement (SYBR channel). Analysis was performed at least in duplicates. Five 
reference strains were used to generate a standard curve of $\mathrm{G}+\mathrm{C}$ mol\% versus melting temperature $(\mathrm{Tm})$. A linear regression analysis was used to calculate the $\mathrm{G}+\mathrm{C}$ mol\%.

The DNA $G+C$ content of strain MCy $1366^{\top}$ was found to be same as Corallococcus coralloides DSM $2259^{\top}$ i.e. $65.6 \mathrm{~mol} \%$ in our analysis. The type strains of $C$. exiguus DSM $14696^{\top}$ and $C$. coralloides DSM $2259^{\top}$ are very closely related species with 99.9\% 16S rRNA gene sequence similarity and sharing 61.5\% DNA-DNA similarity (Stackebrandt et al., 2007). However, these high values did not hold true for the pairs MCy $1366^{\top}$ and DSM $14696^{\top}$ (28\%; with 97\% 16 S rRNA gene sequence similarity) and MCy $1366^{\top}$ and DSM $2259^{\top}$ (35.15\%; with $96.9 \% 16 \mathrm{~S}$ rRNA gene sequence similarity) clearly revealing that strain $\mathrm{MCy} 1366^{\top}$ does not belong to $C$. exiguus or $C$. coralloides (Wayne et al., 1987). MCy $1366^{\top}$ and MCy10622 showed 99.9\% 16S rRNA gene sequence similarity and 100\% DNA-DNA similarity.

Biomass for matrix-assisted laser desorption/ionization time-of-flight mass spectrometry (MALDI-TOF MS) analysis was collected from one week old, $100 \mathrm{ml}$ cultures of MCy1366 ${ }^{\top}, \mathrm{MCy} 10622$ and the reference strains in $\mathrm{CY}+\mathrm{H}$ broth, centrifuged at $12000 \mathrm{rpm}$ for $10 \mathrm{~min}$. Whole-cell protein extracts were analyzed by using a Microflex L20 mass spectrometer (Bruker Daltonics) equipped with a $\mathrm{N}_{2}$ laser. Sample preparation for MALDI-TOF MS protein analysis was carried out according to the ethanol/formic acid extraction protocol recommended by Bruker Daltonics as described in detail by Tóth et al. (2008). The MALDI-TOF mass spectra were analyzed with the BioTyper software (version 3.1, Bruker Daltonics). The dendrogram generated on the basis of MALDI-TOF mass spectra (Fig. C3) confirms the close relationship of the strains MCy $1366^{\top}$ and MCy10622 as revealed by DNADNA hybridization and demonstrates that both strains can be differentiated by MALDI-TOF MS from related type strains of the genera Corallococcus, Myxococcus, Pyxidicoccus and Melittangium.

In addition to the $3 \%$ phylogenetic distance based on 16S rRNA gene sequences and Iow DNA-DNA relatedness to the closest known myxobacterial neighbors ( $C$. exiguus and C. coralloides); strain $\mathrm{MCy} 1366^{\top}$ also delineates into a novel branch in the MALDI-TOF MS dendrogram, show distinct cellular fatty acid profile and biochemical 
characteristics compared to other members of Myxococcaceae. Therefore, we propose strain MCy $1366^{\top}$ as a representative of a new genus Aggregicoccus gen nov., and a new species Aggregicoccus edonensis sp. nov based on these distinguishing characteristics.

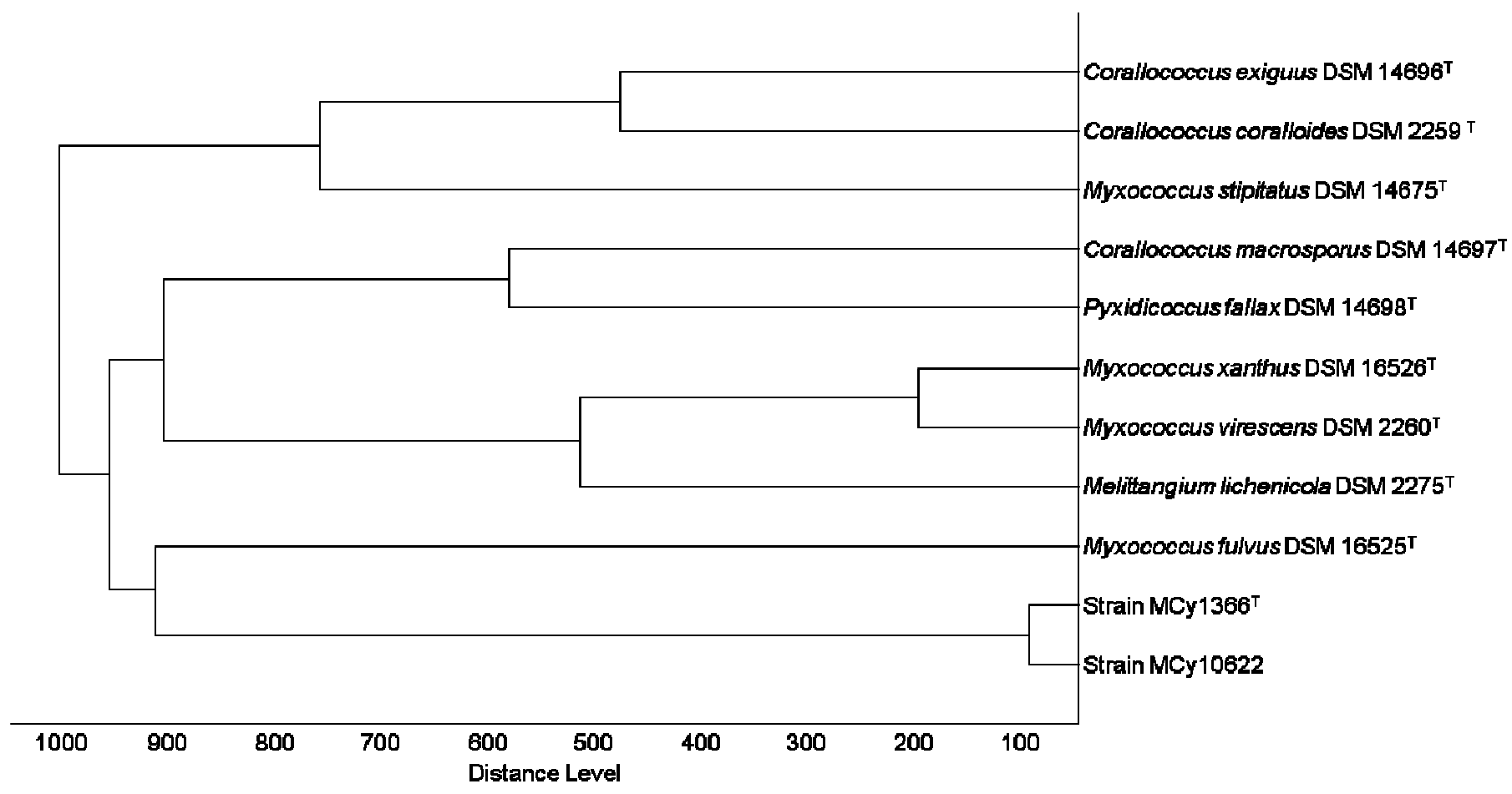

Fig.C3. Score-oriented dendrogram generated by the BioTyper software (version 3.1, Bruker Daltonics) showing the similarity of MALDI-TOF mass spectra of cell extracts of strains MCy1366 ${ }^{\top}$, MCy10622 and type strains of related species within the genera Corallococcus, Myxococcus, Pyxidicoccus and Melittangium.

\section{C.4. Description of Aggregicoccus gen. nov.}

Aggregicoccus gen. nov. (Ag.gre.gi.cocc'us. Lat. v. aggrego, to aggregate, form clumps; N.L. masc. n. coccus (from Gr. masc. n. kokkos, grain, seed, coccus); N.L. masc. n. Aggregicoccus, an aggregating coccus referring to massively aggregating cells in liquid culture)

The vegetative cells are rod-shaped with slight tapering ends (Myxococcaceae type). Transparent swarms on VY/2 yeast agar. Produce wavy, rippling structures with intricate veins on edges on $\mathrm{CY}$ agar. Colonies are very weak positive in Congo Red stain. Fruiting bodies like aggregates and fruiting bodies are spherical to irregularly shaped, cushion like, yellow orange colored, lacking sporangioles and stalks. Myxospores are optically refractive, irregularly spherical. Myxospore-like structures 
are also produced in peptone containing liquid media upon longer incubation. Does not utilize monosaccharides and dissacharides. Bacteria and yeast are lysed. Aerobic, chemoorganotrophic and strictly mesophilic. Hydrolyses starch, but not cellulose, chitin or agar. The $\mathrm{G}+\mathrm{C}$ content is $65.6 \mathrm{~mol} \%$. The phylogenetic position is in the family Myxococcaceae, suborder Cystobacterineae, Order Myxococcales. The type species is Aggregicoccus edonensis.

\section{C.5. Description of Aggregicoccus edonensis sp. nov.}

Aggregicoccus edonensis (e.do.nen'sis. N.L. masc. adj. edonensis, belonging to Edo, former name of Tokyo, where the soil sample was collected from which the type strain was isolated).

In addition to the characteristics of the genus, the vegetative cells are $0.72-0.82 \mu \mathrm{m} \mathrm{x}$ 5.71-10.73 $\mu \mathrm{m}$ in size. The swarm colony varies from yellow orange to almost transparent color depending upon the medium. Myxospore-like structures, 1.3-1.7 $\mu \mathrm{m}$ in size and covered with outer capsule were obtained in liquid media. Cell aggregates are beige to saffron orange in color with extreme branching in peptone or casitone media. Growth optimal temperature is between $30^{\circ} \mathrm{C}$ and $37^{\circ} \mathrm{C}$. pH tolerance is between 6.0-10.0, and optimum at 6.0-7.0. Cannot tolerate high salt concentrations. Best nutritional sources are media with peptones. Can utilize L-asparagine monohydrate, ammonium sulfate, potassium nitrate, urea, L- glutamic acid, glycine, L-lysine monohydrate and L-arginine as nitrogen sources in the presence of casitone. Major fatty acids are $\mathrm{C}_{17: 0}$ 2-OH, iso- $\mathrm{C}_{15: 0}$ and iso- $\mathrm{C}_{17: 0}$. Alkaline phosphatase, esterase lipase, leucine arylamidase and acid phosphatase production was positive while Bgalactosidase, $\alpha$-mannosidase and $\alpha$-fucosidase showed negative reaction in APIZym test system. The type strain is MCy $1366^{\top}$ (=DSM $27872^{\top}$, =NCCB $100468^{\top}$ ), isolated from soil collected in 1981 from a region near Tokyo, Japan.

\section{Acknowledgements}

S.S. is highly indebted to Erasmus Mundus External Cooperation Window for a PhD scholarship and all their support. R.P.A. wishes to acknowledge Deutscher Akademischer Austauschdienst (DAAD) for the PhD fellowship. We thank D. Telkemeyer, S. Schulz and K. Gemperlein for their technical assistance. 


\section{References}

Felsenstein, J. (1985) Confidence limits on phylogenies: An approach using the bootstrap. Evolution $39,783-791$

Fox, G. E., Wisotzkey, J. D. and Jurtshuk, P. (1992) How close is close: 16S rRNA sequence identity may not be sufficient to guarantee species identity, Int. J. Syst. Bacteriol. 42, 166-170

Garcia, R., Gerth, K., Stadler, M., Dogma, I. J. Jr., and Müller, R. (2010) Expanded phylogeny of myxobacteria and evidence for cultivation of the 'unculturables'. Mol. Phylogenet. Evol. 57, 878-887

Garcia, R., Pistorius, D., Stadler, M., and Müller, R. (2011) Fatty acid related phylogeny of myxobacteria as an approach to discover polyunsaturated omega-3/6 fatty acids. J. Bacteriol. 193, 1930-1942

Garcia, R., Reichenbach, H., Ring, M. W. and Müller, R. (2009) Phaselicystis flava gen. nov., sp. nov., an arachidonic acid-containing soil myxobacterium, and the description of Phaselicystidaceae fam. nov. Int. J. Syst. Evol. Microbiol. 59, 1524-1530

Gonzales, J. M. and Saiz-Jimenez, C. (2002) A fluorimetric method for the estimation of $\mathrm{G}+\mathrm{C}$ mol\% content in microorganism by thermal denaturation temperature. Environ. Microbiol. 4, 770-773

Guindon, S. and Gascuel, O. (2003) A simple, fast, and accurate algorithm to estimate large phylogenies by maximum likelihood. Systematic Biology 52, 696-704

Jukes, T. H. and Cantor, C. R. (1969) Evolution of protein molecules. In Mammalian Protein Metabolism, pp. 21-123. Edited by H. N. Munro. New York: Academic Press

Kieser, T., Bibb, M. J., Buttner, M. J., Chater, K. F. and Hopwood, D. A. (2000) Preparation and analysis of genomic and plasmid DNA. Practical Streptomyces Genetics, pp. 161-210. John Innes Foundation Norwich

Lane, D. J. (1991) 16S/23S rDNA sequencing. In Nucleic Acid Techniques in Bacterial Systematics, pp. 115-175. Edited by E. Stackebrandt \& M. Goodfellow. Chichester: Wiley

Lang, E. and Stackebrandt, E. (2009) Emended descriptions of the genera Myxococcus and Corallococcus, typification of the species Myxococcus stipitatus and Myxococcus macrosporus and a proposal that they be represented by neotype strains. Request for an Opinion. Int. J. Syst. Evol. Microbiol. 59, 2122-2128

Larkin, M. A., Blackshields, G., Brown, N. P., Chenna, R., McGettigan, P. A., McWilliam, H., Valentin, F., Wallace, I. M., Wilm, A., and others (2007) Clustal W and clustal X version 2.0. Bioinformatics 23, 2947-2948

McCurdy, H. D. (1969) Studies on taxonomy of the Myxobacterales. I. Record of Canadian isolates and survey of methods. Can. J. Microbiol. 15, 1453-1461

Mohr, K. I., Garcia, R. O., Gerth, K., Irschik, H. and Müller, R. (2011) Sandaracinus amylolyticus gen. nov., sp. nov., a starch degrading soil myxobacterium, and description of Sandaracinaceae fam. nov. Int. J. Syst. Bacterial. 62, 1191-1198

Reichenbach, H. and Dworkin, M. (1992). The myxobacteria. In The Prokaryotes, 2nd edn, pp. 34163487. Edited by A. Balows, H. G. Trüper, M. Dworkin, W. Harder \& K.-H. Schleifer. Berlin: SpringerVerlag 
Reichenbach, H. (2005) Order VIII. Myxococcales Tchan, Pochon and Pre'vot 1948, 398AL. In Bergey's Manual of Systematic Bacteriology, 2nd edn, vol. 2, part C, pp. 1059-1072. Edited by D. J. Brenner, N. R. Krieg, J. T. Staley, \& G. M. Garrity. New York: Springer

Reichenbach, H. (2006) The genus Lysobacter. In The Prokaryotes: A Handbook on the Biology of Bacteria, 3rd edn, vol. 6, pp. 939-957. Edited by M. Dworkin, S. Falkow, E. Rosenberg, K. H. Schleifer \& E. Stackebrandt. New York: Springer

Saitou, N., and Nei, M. (1987) The neighbor-joining method: a new method for reconstructing phylogenetic trees. Mol. Biol. Evol. 4, 406- 425

Schlegel, H. G. (1992) Allgemeine Mikrobiologie, $7^{\text {th }}$ edn. Stuttgart: Georg Thieme Verlag

Shimkets, L. J., Dworkin, M. and Reichenbach, H. (2006) The myxobacteria. In The Prokaryotes: A Handbook on the Biology of Bacteria, $3^{\text {rd }}$ edn, vol. 7, pp. 31-115. Edited by M. Dworkin, S. Falkow, E. Rosenberg, K. H. Schleifer \& E. Stackebrandt, New York: Springer

Stackebrandt, E., and Liesack, W. (1993) Nucleic acids and classification. In Handbook of New Bacterial Systematics, pp. 152-189. Edited by M. Goodfellow \& A.G. O'Donnell. London: Academic Press

Stackebrandt, E., Päuker, O., Steiner, U., Schumann, P., Straubler, B., Heibei, S., and Lang, E. (2007) Taxonomic characterization of members of the genus Corallococcus: Molecular divergence versus phenotypic coherency. Syst. App. Microbiol. 30, 109-118

Tóth, E. M., Schumann, P., Borsodi, A. K., Kéki, Z., Kovács, A. L., and Márialigeti, K. (2008) Wohlfahrtiimonas chitiniclastica gen. nov., sp. nov., a new gammaproteobacterium isolated from Wohlfahrtia magnifica (Diptera: Sarcophagidae). Int. J. Syst. Evol. Microbiol. 58, 976-981.

Turner, S., Pryer, K. M., Miao, V. P. W., and Palmer, J. D. (1999) Investigating deep phylogenetic relationships among cyanobacteria and plastids by small subunit rDNA sequence analysis. J. Eukar. Microbiol. 46, 327-338

Wayne, L. G., Brenner, D. J., Colwell, R. R., Grimont, P. A. D., Kandler, O., Krichevsky, M. I., Moore, L. H., Moore, W. E. C., Murray, R. G. E., and other authors (1987) International Committee on Systematic Bacteriology. Report of the ad hoc committee on reconciliation of approaches to bacterial systematics. Int. J. Syst. Bacteriol. 37, 463-464

Weidner, S., Arnold, W., and Pühler, A. (1996) Diversity of uncultured microorganisms associated with the seagrass Halophila stipulacea estimated by restriction fragment length polymorphism analysis of PCR-amplified 16S rRNA genes. Appl. Env. Microbiol. 62, 766-71

Weissman, K. J., and Müller, R. (2010) Myxobacterial secondary metabolites: bioactivities and modesof-action. Nat. Prod. Rep., 27, 1276-1295

Ziemke, F., Höfle, M. G., Lalucat, J., and Rossello-Mora, R. (1998) Reclassification of Shewanella putrefaciens Owen's genomic group II as Shewanella baltica sp. nov. Int. J. Syst. Bacteriol. 48, 179186 


\section{Supplemental information}

Table CS1. Type and neotype strains used in this study

\begin{tabular}{|c|c|}
\hline Strain name & Strain no. \\
\hline Corallococcus exiguus & DSM $14696^{\mathrm{T}}\left(\mathrm{Cc}\right.$ e $\left.167^{\mathrm{T}}\right)$ \\
\hline Corallococcus coralloides & $\operatorname{DSM} 2259^{\mathrm{T}}\left(\mathrm{M} 2^{\mathrm{T}}\right)$ \\
\hline Myxococcus virescens & $\operatorname{DSM} 2260^{\mathrm{T}}\left(\mathrm{M} 22^{\mathrm{T}}\right)$ \\
\hline Myxococcus fulvus & $\operatorname{DSM} 16525^{\mathrm{T}}\left(\mathrm{M} 17^{\mathrm{T}}\right)$ \\
\hline Myxococcus xanthus & DSM $16526^{\mathrm{T}}$ \\
\hline Myxococcus stipitatus & DSM $14675^{\mathrm{NT}}\left(\mathrm{Mx} \mathrm{s} 8^{\mathrm{NT}}\right)$ \\
\hline Myxococcus macrosporus & $\operatorname{DSM} 14697^{\mathrm{T}}\left(\mathrm{Cc} \mathrm{m} 8^{\mathrm{T}}\right)$ \\
\hline Pyxidococcus fallax & DSM $14698^{\mathrm{T}}\left(\mathrm{Py} \mathrm{f1}^{\mathrm{T}}\right)$ \\
\hline Melittangium lichenicola & $\operatorname{DSM} 2275^{\mathrm{T}}\left(\mathrm{M} 155^{\mathrm{T}}\right)$ \\
\hline
\end{tabular}

Table CS2. Salt tolerance

\begin{tabular}{|lc|}
\hline Strain name & Growth on CY agar with 1.5\% NaCl (w/v) \\
\hline MCy1366 $^{\mathrm{T}}$ & - \\
MCy10622 & - \\
C. ${\text { exiguus DSM } 14696^{\mathrm{T}}}^{\mathrm{T}}$. coralloides DSM $2259^{\mathrm{T}}$ & - \\
M. virescens DSM $2260^{\mathrm{T}}$ & - \\
M. fulvus DSM $16525^{\mathrm{T}}$ & +++ \\
M. xanthus DSM $16526^{\mathrm{T}}$ & - \\
M. stipitatus DSM $14675^{\mathrm{NT}}$ & ++ \\
M. macrosporus DSM $14697^{\mathrm{NT}}$ & + \\
P. fallax DSM $14698^{\mathrm{T}}$ & +++ \\
M. lichenicola DSM $2275^{\mathrm{T}}$ & + \\
\hline
\end{tabular}

*Assessment of growth levels.-, no growth; +, poor growth; ++, moderate; +++, very good growth 
Table CS3. Differential physiological reactions in APIZym tests

\begin{tabular}{|c|c|c|c|c|c|c|c|c|c|c|c|}
\hline Enzyme & $\begin{array}{l}\text { M. stipitatus } \\
\text { DSM } 14675^{\mathrm{NT}}\end{array}$ & $\begin{array}{l}\text { M. virescens } \\
\text { DSM } 2260^{\mathrm{T}}\end{array}$ & $\begin{array}{l}\text { M. xanthus } \\
\text { DSM } 16526^{\mathrm{T}}\end{array}$ & $\begin{array}{c}\text { M. fulvus } \\
\text { DSM } 16525^{\mathrm{T}}\end{array}$ & $\begin{array}{l}\text { M. macrosporus } \\
{\text { DSM } 14697^{\mathrm{T}}}^{\text {M m }}\end{array}$ & ${\operatorname{MCy} 1366^{T}}^{T}$ & MCy10622 & $\begin{array}{l}\text { C. coralloides } \\
\text { DSM } 2259^{\mathrm{T}}\end{array}$ & $\begin{array}{l}\text { C. exiguus } \\
\text { DSM } 14696^{\mathrm{T}}\end{array}$ & $\begin{array}{c}\text { P. fallax } \\
\text { DSM } 14698^{\mathrm{T}}\end{array}$ & $\begin{array}{l}\text { M. lichenicola } \\
\text { DSM } 2275^{\mathrm{T}}\end{array}$ \\
\hline Control & $\mathbf{C}$ & $\mathbf{C}$ & C & $\mathbf{C}$ & $\mathbf{C}$ & C & C & $\mathbf{C}$ & $\mathbf{C}$ & C & $\mathbf{C}$ \\
\hline Esterase(C4) & + & + & + & + & + & $\mathbf{v}$ & + & - & + & + & + \\
\hline Lipase(C14) & - & + & + & - & + & + & + & + & + & + & + \\
\hline Valine arylamidase & + & + & + & + & + & + & + & + & - & - & + \\
\hline Cystine arylamidase & + & + & + & + & - & - & + & + & - & - & + \\
\hline Trypsin & + & - & + & - & + & - & - & - & - & + & - \\
\hline$\alpha$-chymotrypsin & + & - & + & - & - & $\mathbf{V}$ & + & + & - & - & - \\
\hline $\begin{array}{l}\text { Naphthol- AS-BI- } \\
\text { phosphohydrolase }\end{array}$ & - & + & + & + & + & + & + & + & + & + & + \\
\hline$\alpha$-galactosidase & - & - & - & + & - & - & - & - & - & - & - \\
\hline B-glucuronidase & - & - & - & + & - & - & - & - & - & - & - \\
\hline$\alpha$-glucosidase & - & - & - & + & - & - & - & - & - & - & + \\
\hline B-glucosidase & - & - & - & + & - & - & - & - & - & - & - \\
\hline $\begin{array}{l}\text { N-acetyl-B- } \\
\text { glucosaminidase }\end{array}$ & + & - & - & + & - & - & - & - & - & - & + \\
\hline
\end{tabular}

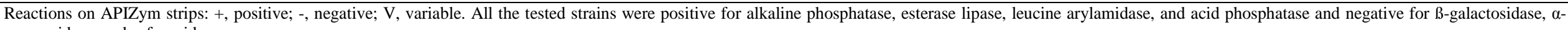
mannosidase, and $\alpha$-fucosidase. 


\section{Table CS4. Antibiotic resistance test for $\mathrm{MCy}^{1366^{\top}}$ and $\mathrm{MCy} 10622$ along with related type and neotype strains}

\begin{tabular}{|c|c|c|c|c|c|c|c|c|c|c|c|}
\hline Antibiotic & $\begin{array}{c}\text { M. stipitatus } \\
\text { DSM } 14675^{\mathrm{NT}}\end{array}$ & $\begin{array}{l}\text { M. virescens } \\
\text { DSM } 2260^{T}\end{array}$ & $\begin{array}{l}\text { M. xanthus } \\
\text { DSM } 16526^{\mathrm{T}}\end{array}$ & $\begin{array}{c}\text { M. fulvus } \\
\text { DSM } 16525^{\mathrm{T}}\end{array}$ & 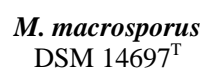 & $\mathrm{MCy} 1366^{\mathrm{T}}$ & MCy10622 & $\begin{array}{c}\text { C. coralloides } \\
\text { DSM } 2259^{\mathrm{T}}\end{array}$ & $\begin{array}{l}\text { C. exiguous } \\
\text { DSM } 14696^{\mathrm{T}}\end{array}$ & $\begin{array}{l}\text { P. } \operatorname{fallax}_{14698^{\mathrm{T}}} \\
14 M \\
\end{array}$ & $\begin{array}{c}\text { M. lichenicola } \\
\text { DSM } 2275^{\mathrm{T}}\end{array}$ \\
\hline $\begin{array}{ll}\begin{array}{l}\text { Control } \\
\text { agar }\end{array} & \text { VY/2 } \\
\end{array}$ & + & + & + & + & + & + & + & + & + & + & + \\
\hline Ampicillin & + & - & + & - & + & - & + & + & + & + & - \\
\hline Kanamycin & + & - & - & + & - & + & + & + & + & - & + \\
\hline Spectinomycin & + & + & + & + & + & - & - & - & - & + & + \\
\hline Trimethoprim & + & - & - & - & + & + & + & + & + & + & + \\
\hline Bacitracin & + & + & + & + & + & + & + & + & + & + & - \\
\hline Oxytetracyclin & - & - & - & - & - & - & n.c. & - & - & - & - \\
\hline Fusidic acid & + & + & + & - & - & - & + & + & + & + & - \\
\hline Thiostreptone & + & - & - & - & - & - & - & - & - & + & - \\
\hline Chloramphenicol & - & + & - & - & - & - & n.c. & - & - & + & - \\
\hline
\end{tabular}

+, Growth; -, Inhibition of growth; n.c., not clear. All the tested strains were resistant to cephalosporin C, gentamycin, hygromycin B and polymyxin. 
Table CS5. Dry weight biomass $(\mathrm{mg})$ of $M C y 1366^{\top}$ and $M C y 10622$ obtained in synthetic $S$ medium with casitone supplemented with various carbon sources.

\begin{tabular}{|c|c|c|}
\hline Carbon sources & Average dry biomasses $\left(\mathrm{MCy} 1366^{\mathrm{T}}\right)$ & Average dry biomasses (MCy10622) \\
\hline 1. Sucrose & 16.05 & 14.25 \\
\hline 2. Fructose & 15.15 & 16.0 \\
\hline 3. Maltose & 14.15 & 16.7 \\
\hline 4. Potato starch & 41.05 & 43.85 \\
\hline 5. Molasses & 29.95 & 29.85 \\
\hline 6. Xylose & 15.05 & 14.4 \\
\hline 7. Soluble starch & 29.6 & 31.35 \\
\hline 8. Cellobiose & 16.1 & 15.2 \\
\hline 9. Lactose & 16.35 & 17.25 \\
\hline 10. Mannose & 14.35 & 15.35 \\
\hline 11. Galactose & 20.5 & 14.75 \\
\hline 12. Glucose & 15.45 & 15.0 \\
\hline 13. Pyruvate & 20.2 & 25.35 \\
\hline 14. Control & 15 & 14.25 \\
\hline
\end{tabular}

Table CS6. Dry weight biomass (mg) of $\mathrm{MCy} 1366^{\top}$ and $\mathrm{MCy} 10622$ in minimal casitone (C) medium with various inorganic nitrogen sources, amino acids or peptones sources.

\begin{tabular}{|l|c|c|}
\hline \multicolumn{1}{|c|}{ Nitrogen sources } & $\begin{array}{c}\text { Average dry biomasses } \\
\left(\mathbf{M C y 1 3 6 6}^{\mathbf{T}}\right)\end{array}$ & $\begin{array}{c}\text { Average dry biomasses } \\
\text { (MCy10622) }\end{array}$ \\
\hline 1. L-asparagine monohydrate & 16.7 & 24.55 \\
2. Urea & 15.6 & 15.55 \\
3. L-arginine & 13.25 & 19 \\
4. $\mathrm{KNO}_{3}$ & 13.25 & 12.5 \\
5. $\left(\mathrm{NH}_{4}\right)_{2} \mathrm{SO}_{4}$ & 11.5 & 14.85 \\
6. L-lysine monohydrate & 14.8 & 14.5 \\
7. Glycine & 12.7 & 12.45 \\
8. L-glutamic acid & 15.3 & 24.35 \\
9. Probion FM 582 & 61.1 & 60.65 \\
10. Tryptone enzymatic digest of casein & 7.9 & 20.35 \\
11. Casitone & 19.75 & 25.75 \\
12. Soytone & 23.4 & 13.9 \\
13. Yeast extract & 13.4 & 21.15 \\
14. Tryptone & 18.95 & 33.05 \\
15. Neopeptone & 9.1 & 4.15 \\
16. Phytone peptone & 10.75 & 3.1 \\
17. Skimmed milk & 16.3 & 7.3 \\
18. Gluten from wheat & 32.85 & 39.6 \\
19. Corn Steep solid & 28.65 & 83.45 \\
20. Meat extract & 15.25 & 14.7 \\
21. Casamino acid & 1.5 & 1.4 \\
22. Control & 1.3 & 1.25 \\
\hline
\end{tabular}


Table CS7. Fatty acid analysis of MCy1366 ${ }^{\top}$, MCy10622 and closely related type strains. Values are represented as percentages of the total fatty acid content.

\begin{tabular}{|c|c|c|c|c|c|c|c|c|c|c|c|}
\hline & $\begin{array}{c}\text { C. exiguus } \\
\text { DSM 14696 }^{\mathrm{T}}\end{array}$ & $\begin{array}{l}\text { C. coralloides } \\
{\text { DSM } 2259^{\mathrm{T}}}^{-}\end{array}$ & ${\operatorname{MCy} 1366^{T}}^{T}$ & МСу10622 & $\begin{array}{l}\text { M. xanthus } \\
\text { DSM 16526 }\end{array}$ & $\begin{array}{c}\text { M. macrosporus } \\
\text { DSM } 14697^{\mathrm{T}}\end{array}$ & $\begin{array}{c}\text { M. fulvus } \\
\text { DSM } 16525^{\mathrm{T}}\end{array}$ & $\begin{array}{l}\text { M. virescens } \\
\text { DSM } 2260^{\mathrm{T}}\end{array}$ & $\begin{array}{l}\text { M. stipitatus } \\
\text { DSM } 14675^{\mathrm{NT}}\end{array}$ & $\begin{array}{c}\text { P. fallax } \\
\text { DSM 14698 }\end{array}$ & $\begin{array}{c}\text { M. lichenicola } \\
\text { DSM 2275 }^{\mathrm{T}}\end{array}$ \\
\hline \multicolumn{12}{|l|}{ SCFAs } \\
\hline $\mathrm{C}_{10: 0}$ & - & - & - & - & 0.2 & 0.3 & - & 0.3 & 0.2 & 0.1 & - \\
\hline $\mathrm{C}_{11: 0}$ & 0.2 & - & - & 0.1 & - & - & - & 0.1 & - & - & - \\
\hline $\mathrm{C}_{12: 0}$ & 0.0 & - & - & - & 0.1 & 0.1 & - & - & - & - & - \\
\hline $\mathrm{C}_{13: 0}$ & 0.1 & - & - & - & - & 0.2 & - & 0.1 & 0.1 & - & - \\
\hline $\mathrm{C}_{14: 0}$ & - & - & 0.1 & - & 5.4 & 6.4 & 0.2 & 3.5 & 2.2 & 0.8 & - \\
\hline $\mathrm{C}_{15: 0}$ & 0.8 & 0.2 & 1.8 & 1.6 & 2.7 & 2.5 & - & 2.5 & 2.7 & 1.1 & - \\
\hline $\mathrm{C}_{16: 0}$ & 1.6 & 1.5 & 2.4 & 0.5 & 4.1 & 4.3 & 8.2 & 4.1 & 4.1 & 6.1 & 9.8 \\
\hline $\mathrm{C}_{17: 0}$ & 0.2 & - & 0.5 & 0.4 & - & - & - & 0.1 & - & 0.3 & - \\
\hline $\mathrm{C}_{18: 0}$ & 3.7 & 3.7 & 4.9 & 0.5 & 5.8 & 4.6 & 14.1 & 1.5 & 5.8 & 4.1 & 20.6 \\
\hline $\mathrm{C}_{14: 1}$ isomer 1 & - & - & - & - & 1.8 & 0.5 & - & 0.5 & - & - & - \\
\hline $\mathrm{C}_{14: 1}$ isomer 2 & - & - & - & - & 0.1 & 0.1 & - & 0.2 & 0.2 & 0.7 & - \\
\hline $\mathrm{C}_{14: 1}$ isomer 3 & - & - & - & - & 0.3 & 0.1 & - & 0.1 & - & - & - \\
\hline $\mathrm{C}_{15: 1}$ isomer 1 & 0.3 & 0.3 & - & 4.3 & 1.9 & 1.1 & - & 1.0 & 0.1 & - & - \\
\hline $\mathrm{C}_{15: 1}$ isomer 2 & 0.4 & 0.1 & 3.3 & - & 2.5 & 1.7 & - & 1.9 & 0.5 & 0.9 & - \\
\hline $\mathrm{C}_{16: 1}$ isomer 1 & - & - & - & 1.6 & 0.5 & 0.8 & 8.6 & 0.6 & 0.4 & - & 3.3 \\
\hline $\mathrm{C}_{16: 1}$ isomer 2 & 0.6 & 0.2 & 2.0 & - & 7.9 & 12.6 & 6.1 & 13.6 & 14.5 & 21.0 & 5.5 \\
\hline $\mathrm{C}_{17: 1}$ isomer 1 & - & - & - & 0.7 & - & - & - & - & - & - & - \\
\hline $\mathrm{C}_{17: 1 \omega 7 \mathrm{cis}}$ & 1.6 & 2.2 & 0.4 & - & - & - & - & 1.0 & - & 0.2 & - \\
\hline $\mathrm{C}_{18: 1}$ & 0.1 & - & - & 0.1 & - & - & - & - & 0.2 & - & - \\
\hline PUFAs & & & & & & & & & & & \\
\hline
\end{tabular}




\begin{tabular}{|c|c|c|c|c|c|c|c|c|c|c|c|}
\hline $\mathrm{C}_{16: 2}$ & - & - & - & - & 3.4 & 3.5 & - & 3.0 & 0.6 & - & - \\
\hline $\mathrm{C}_{18: 3 \mathrm{w} 6, \mathrm{cis} 9,12}$ & - & - & - & 0.2 & - & - & - & - & - & - & - \\
\hline \multicolumn{12}{|l|}{ Hydroxy FAs } \\
\hline $\mathrm{C}_{13: 03-\mathrm{OH}}$ & - & - & - & - & - & - & - & - & - & - & - \\
\hline $\mathrm{C}_{14: 03-\mathrm{OH}}$ & - & - & - & - & 0.4 & 0.7 & - & 0.5 & 0.6 & 0.6 & 0.1 \\
\hline $\mathrm{C}_{15: 03-\mathrm{OH}}$ & - & - & - & - & 0.1 & 0.1 & 0.3 & 0.1 & 0.1 & - & - \\
\hline $\mathrm{C}_{16: 02-\mathrm{OH}}$ & - & - & - & - & 0.2 & 1.1 & - & 0.2 & 0.7 & 1.2 & - \\
\hline $\mathrm{C}_{16: 03-\mathrm{OH}}$ & - & - & - & - & 0.4 & 0.6 & 0.5 & 0.3 & 0.6 & 0.4 & 0.2 \\
\hline $\mathrm{C}_{16: 13-\mathrm{OH}}$ & - & - & - & - & - & - & - & - & - & 0.2 & - \\
\hline $\mathrm{C}_{24: 02-\mathrm{OH}}$ & - & - & - & - & - & - & - & - & - & - & - \\
\hline Total SCFAs & 9.6 & 8.2 & 15.4 & 10.0 & 37.8 & 41.3 & 38.0 & 35.2 & 33.6 & 37.7 & 39.5 \\
\hline \multicolumn{12}{|l|}{ BCFAs } \\
\hline iso- $\mathrm{C}_{13: 0}$ & 1.9 & 0.8 & 0.2 & 1.5 & 0.7 & 0.4 & - & 0.5 & 0.2 & 0.1 & - \\
\hline iso- $\mathrm{C}_{14: 0}$ & 0.7 & 0.3 & - & 0.4 & - & - & - & & 0.1 & - & - \\
\hline iso- $\mathrm{C}_{15: 0}$ & 17.6 & 22.3 & 23.2 & 25.3 & 39.8 & 34.5 & 13.5 & 30.7 & 16.3 & 14.0 & 13.0 \\
\hline iso- $\mathrm{C}_{15: 1}$ & - & - & - & 1.0 & - & - & - & - & - & - & - \\
\hline iso- $\mathrm{C}_{15: 1 \omega 9 \mathrm{cis}}$ & - & 1.1 & - & & 0.8 & - & - & 0.4 & - & - & - \\
\hline iso- $\mathrm{C}_{16: 0}$ & 1.9 & 1.4 & 2.6 & 3.3 & 0.1 & 0.8 & 0.2 & 0.4 & 1.1 & 0.9 & 0.1 \\
\hline iso- $\mathrm{C}_{16: 1}$ & - & 1.1 & - & 0.4 & - & 0.3 & - & 0.1 & - & - & - \\
\hline iso- $\mathrm{C}_{17: 0}$ & 10.1 & 4.3 & 16.6 & 10.4 & 3.3 & 3.2 & 1.4 & 8.1 & 11.8 & 7.7 & 0.8 \\
\hline iso- $\mathrm{C}_{17: 1}$ & - & - & - & 10.9 & - & - & - & - & - & - & - \\
\hline iso- $\mathrm{C}_{17: 105 \mathrm{cis}}$ & 12.8 & 8.2 & 9.5 & - & 1.9 & 1.2 & 7.3 & 2.9 & 2.5 & 1.9 & 6.1 \\
\hline iso- $\mathrm{C}_{17: 1 \omega 11 \mathrm{cis}}$ & - & 2.0 & 0.2 & - & 0.7 & 0.5 & - & - & 0.3 & - & - \\
\hline iso- $\mathrm{C}_{17: 2}$ & - & - & - & 2.3 & - & - & - & - & - & - & - \\
\hline iso- $\mathrm{C}_{17: 2 \omega 5 \text { cis,cis } 11}$ & 1.0 & 3.7 & - & - & 2.4 & 0.9 & - & 1.4 & 0.1 & - & - \\
\hline
\end{tabular}




\begin{tabular}{|c|c|c|c|c|c|c|c|c|c|c|c|}
\hline anteiso- $\mathrm{C}_{15: 0}$ & - & - & 0.3 & 0.3 & - & - & 6.0 & 0.2 & - & - & 0.8 \\
\hline anteiso- $\mathrm{C}_{17: 0}$ & 0.1 & - & 0.4 & - & - & - & - & 0.1 & - & - & - \\
\hline \multicolumn{12}{|l|}{$\begin{array}{l}\text { Branched-chain hydroxy } \\
\text { FAs }\end{array}$} \\
\hline iso- $\mathrm{C}_{16: 02-\mathrm{OH}}$ & 0.1 & 0.2 & 0.1 & - & - & - & - & - & - & - & - \\
\hline iso- $\mathrm{C}_{16: 03-\mathrm{OH}}$ & - & - & - & - & - & - & - & - & - & - & - \\
\hline iso- $\mathrm{C}_{17: 02-\mathrm{OH}}$ & 34.4 & 33.0 & 26.1 & 14.1 & 4.2 & 7.1 & 0.2 & 3.3 & 12.4 & 9.3 & 0.5 \\
\hline iso- $\mathrm{C}_{17: 03-\mathrm{OH}}$ & 0.3 & - & 0.1 & - & 1.2 & 1.3 & 3.7 & 1.2 & 1.1 & 0.4 & 3.2 \\
\hline iso- $\mathrm{C}_{17: 12-\mathrm{OH}}$ & 0.0 & - & - & - & - & - & - & - & - & - & - \\
\hline \multicolumn{12}{|l|}{ Branched chain $O A G$ FAs } \\
\hline $\mathrm{C}_{14: 0}$ & - & - & - & - & - & - & - & 0.1 & 0.3 & 0.4 & - \\
\hline $\mathrm{C}_{15: 0}$ & - & - & - & - & - & - & - & 0.1 & - & 2.9 & - \\
\hline $\mathrm{C}_{16: 0}$ & - & - & - & - & - & - & - & 0.1 & 0.4 & 7.4 & - \\
\hline iso- $\mathrm{C}_{15: 0}$ & 3.4 & 7.2 & 1.9 & 1.3 & 3.0 & 3.9 & - & 10.3 & 10.1 & 10.8 & - \\
\hline $\begin{array}{l}\text { Branched chain DMA } \\
\text { FAs } \\
{\text { iso- } \mathrm{C}_{15: 0}}\end{array}$ & 1.6 & 4.2 & 2.0 & 4.4 & 1.0 & 0.7 & - & 1.7 & 2.1 & 4.7 & - \\
\hline Total BCFAs & 88.7 & 91.4 & 84.4 & 76.3 & 62.2 & 58.1 & 36.7 & 64.5 & 62.3 & 62.4 & 27.2 \\
\hline \multicolumn{12}{|l|}{ Fatty alcohols } \\
\hline iso Pentadecanol & 0.1 & 0.3 & 0.0 & - & - & 0.0 & 0.8 & 0.0 & 0.2 & 0.0 & 0.9 \\
\hline Hexadecanol & - & - & - & - & - & 0.0 & 0.0 & - & - & - & - \\
\hline Unspecified fatty alcohol & - & - & - & - & - & - & 24.4 & - & - & - & 32.1 \\
\hline
\end{tabular}

(Abbreviations: SCFAs, Short chain fatty acids; PUFAs, Polyunsaturated fatty acids; BCFAs, Branched chain fatty acids; OAG Fas, $O$-alkylglycerol fatty acids; DMA Fas, Dimethylacetal fatty acids) *Percentages of major fatty acids in MCy1366 ${ }^{\mathrm{T}}$ and MCy10622 are distinguished in boldface type. 
Table CS8. Dry weight biomass $(\mathrm{mg})$ of MCy $1366^{\top}$ and MCy10622 at different pH.

\begin{tabular}{|l|c|c|}
\hline $\mathbf{p H}$ & Average dry biomasses $\left.^{\left(\mathbf{M C y}_{1366}\right.}{ }^{\mathbf{T}}\right)$ & Average dry biomasses (MCy10622) $\left.^{(}\right)$ \\
\hline 5.0 & 0.10 & 0.25 \\
\hline 5.5 & 0.15 & 0.20 \\
\hline 6.0 & 34.30 & 27.50 \\
\hline 6.5 & 50.15 & 52.00 \\
\hline 7.0 & 41.40 & 38.05 \\
\hline 7.5 & 24.55 & 25.15 \\
\hline 8.0 & 12.35 & 21.30 \\
\hline 8.5 & 12.40 & 15.15 \\
\hline 9.0 & 11.55 & 14.50 \\
\hline 9.5 & 9.55 & 14.35 \\
\hline 10.0 & 9.25 & 14.25 \\
\hline
\end{tabular}

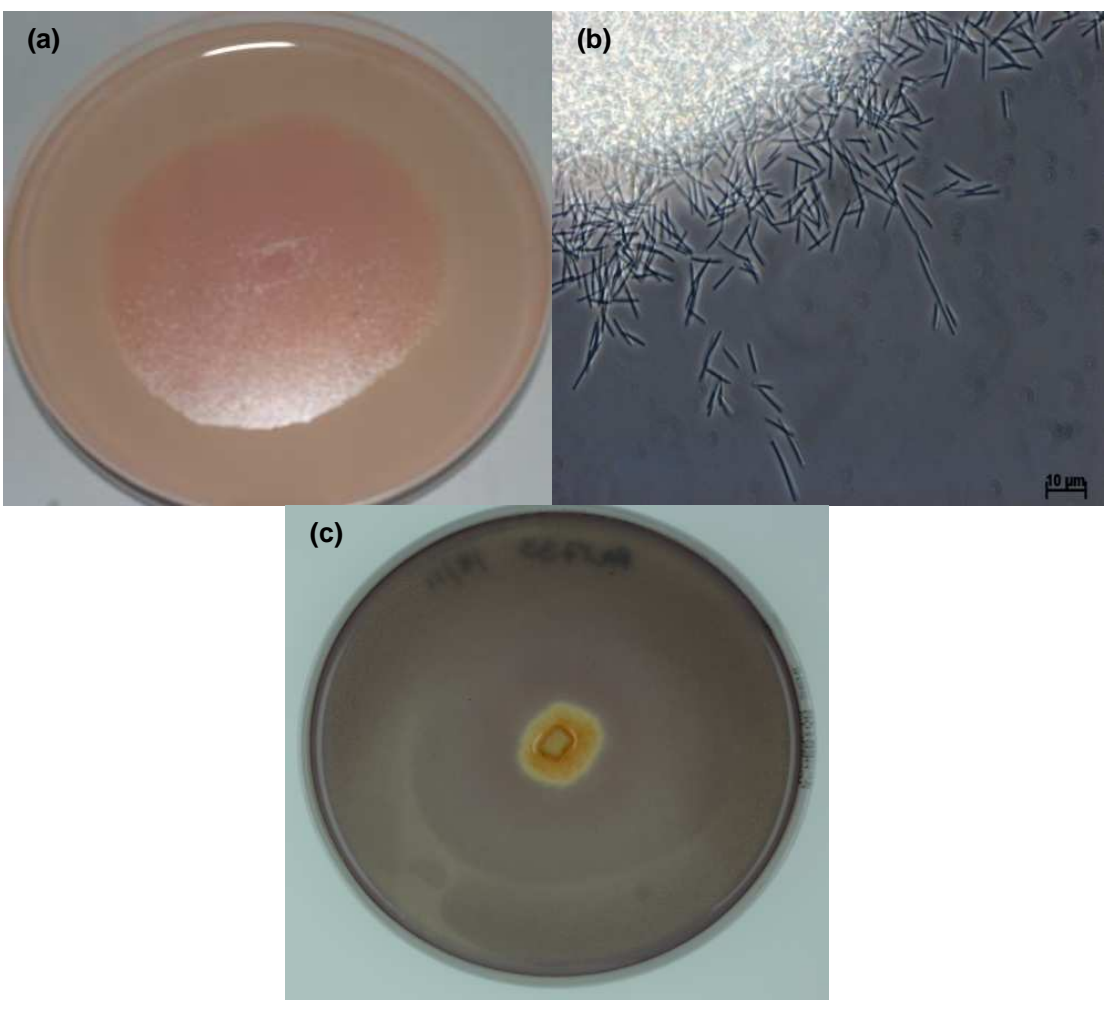

Fig.CS1. (a) Congo Red staining of 3 week old swarm of strain MCy1366 on VY/2 agar displaying a weak positive reaction

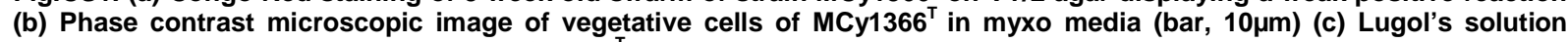
staining of 2 week old swarm of strain $\mathrm{MCy} 1366^{\top}$ on $\mathrm{P}$ agar displaying a weak positive reaction. 


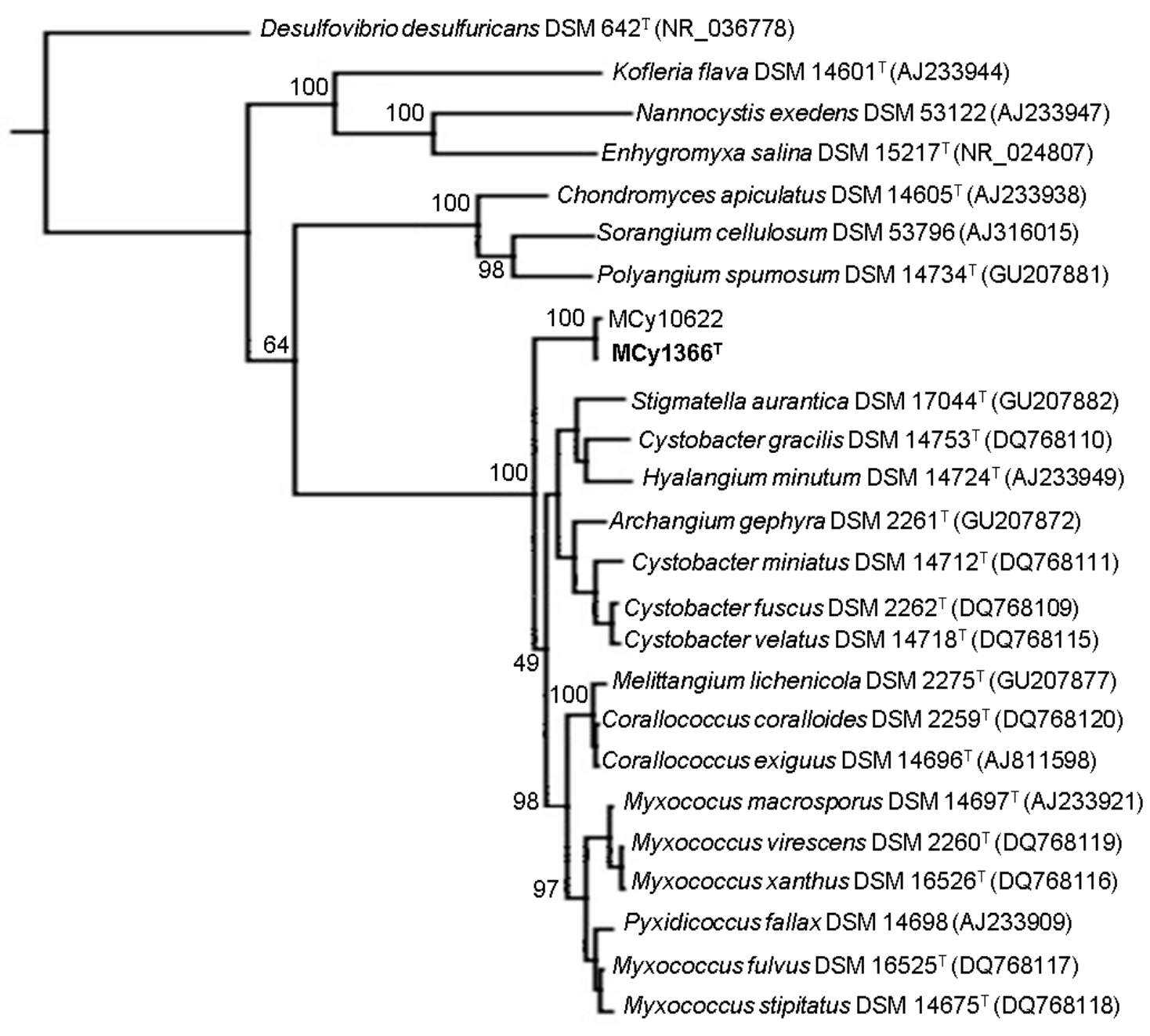

0.05

Fig.CS2. Neighbor-joining tree based on 16S rRNA gene sequence showing the phylogenetic position of MCy1366' and MCy10622. The numbers at branch points indicate bootstrap support based on 1000 resamplings. Bar, 0.05 substitutions per nucleotide position. The GenBank accession number for each strain is shown in parentheses. Desulfovibrio desulfuricans DSM $642^{\top}$ was used as an out group. 
Chapter D

\title{
Pyrronazols, Metabolites from the Myxobacteria
}

\author{
Nannocystis pusilla and N. exedens are Unusual
}

\section{Chlorinated Pyrone-Oxazole-Pyrroles}

Rolf Jansen, Sakshi Sood, Volker Huch, Brigitte Kunze, Marc Stadler and Rolf Müller

Submitted to Journal of Natural Products on October $16^{\text {th }}, 2013$

Accepted on January $24^{\text {th }}, 2014$

(Current status - Published on February 24th, 2014)

\section{Author's contribution to this work}

Performed the experiments: SS, RJ, BK

Analyzed chemical and NMR data: RJ

Analyzed X-Ray data: VH

Wrote the paper: SS, RJ

Provided research facilities: MS, RM

Conceived and designed the experiments: RJ 


\section{D.1. Abstract}

The chlorinated pyrrole-oxazole-pyrones, pyrronazol A (1), pyrronazol A2 (2) and pyrronazol B (3) were isolated from Nannocystis pusilla strain Ari7 as well as two chlorinated pyrrole-oxazole isomers, pyrronazol C1 (4) and C2 (5), from N. pusilla strain $\mathrm{Na}$ a174. HRESIMS, NMR, and X-ray crystallographic analysis was used in the structure elucidation including the absolute configuration of pyrronazol $A(\mathbf{1})$. In addition to pyrronazols, 1,6-phenazine-diol (6) and its glycosyl derivative, 1-hydroxy-phenazine6-yl-a-D-arabinofuranoside (7) were isolated and identified from the culture broth of $N$. pusilla strain Ari7. When tested for biological activity against bacteria, fungi, and yeasts, 1 showed weak antifungal activity against Mucor hiemalis (MIC $33.3 \mu \mathrm{g} / \mathrm{mL}$ ) but no antibacterial activity, while 6 showed weak antibacterial and antifungal activity (MIC 33.3 $\mu \mathrm{g} / \mathrm{mL}$ ) against some of the strains tested. In cell culture experiments 1 showed no significant cytotoxicity while 6 was active against several cell lines, especially the human ovarian carcinoma cells SK-OV-3 $\left(\mathrm{LD}_{50} 2.59 \mu \mathrm{M}\right)$.

\section{D.2. Introduction}

Myxobacteria have been used as a source of new natural products for almost three decades (Bode and Müller, 2007; Wenzel and Müller, 2009). In our quest to find valuable and structurally diverse natural products, we constantly engage in screening strains from our continuously expanding in-house collection of myxobacteria. Pyrronazols were identified from our screening program and isolated as novel secondary metabolites from strain Ari7. The 16S rRNA gene sequence analysis of the producing strain Ari7 showed $99.9 \%$ similarity to Nannocystis pusilla (DSM $14622^{\top}$ ). Previously, N. pusilla strain B150 and $N$. exedens have been reported as producers of phenylnannolones, inhibitors of P-glycoprotein mediated efflux of drugs from eukaryotic cells (Ohelndorf et al., 2008). Further, the siderophores nannochelins (Kunze et al., 1992), steroids (Kohl et al., 1983), germacrane (Reichenbach and Höfle, 2000) and geosmin (Trowitzsch et al., 1981) were reported as Nannocystis metabolites. 
Herein, we report the isolation and structure elucidation of three secondary metabolites, pyrronazol A (1), pyrronazol A2 (2) and pyrronazol B (3) from Nannocystis pusilla, strain Ari7, as well as pyrronazol $\mathrm{C} 1$ (4) and $\mathrm{C} 2$ (5) from N. pusilla strain $\mathrm{Na}$ a174. Extensive HRESIMS, NMR, and X-ray crystallographic analysis was used for the structure elucidation of pyrronazol A (1). In addition to pyrronazols, 1,6-phenazine-diol (6) and its glycosyl derivative, 1-hydroxy-phenazine-6-yl-a-D-arabinofuranoside (7) were isolated and identified from the culture broth of $N$. pusilla strain Ari7.

\section{D.3. Results and Discussion}

For metabolite production N. pusilla, strain Ari7 was inoculated in a liquid medium supplemented with Amberlite XAD 16 resin and fermented in a $10 \mathrm{~L}$ bioreactor for 7 days. The resin was recovered from the culture broth by sieving and the crude extract was eluted from the resin using methanol. The products were isolated from the crude extract using a series of solvent partitioning, silica gel chromatography, preparative RPMPLC and RP-HPLC, and thin layer chromatography.

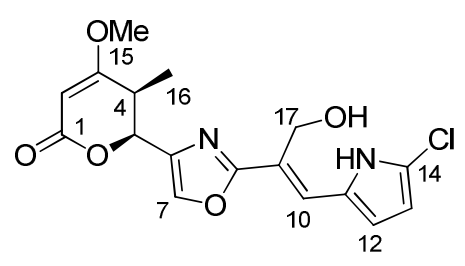

Pyrronazol A (1)

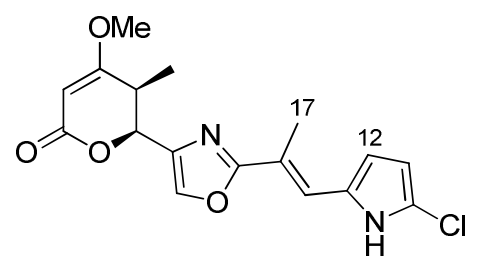

Pyrronazol B (3)

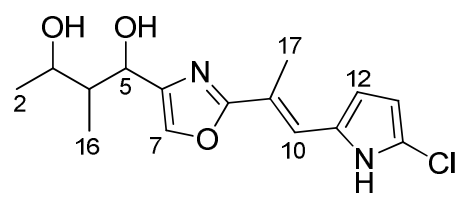

Pyrronazol C1 (4)

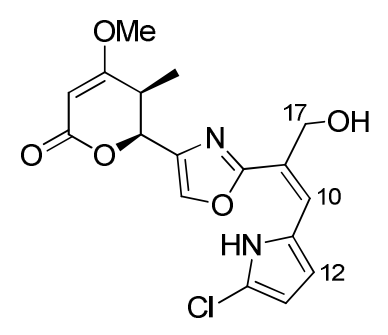

Pyrronazol A2 (2)

Scheme D1. Natural pyrronazol variants 
Pyrronazol A (1) was isolated from both strains as crystals melting under decomposition at $150{ }^{\circ} \mathrm{C}$. HRESIMS presented the molecular ion clus ters for $[\mathrm{M}+\mathrm{H}]^{+}$and $[\mathrm{M}+\mathrm{Na}]^{+}$, and a prominent fragment ion $\left[\mathrm{M}-\mathrm{H}_{2} \mathrm{O}\right]^{+}$in positive mode as well as $[\mathrm{M}-\mathrm{H}]^{-}$in the negative mode, all pointing to the chlorine-containing elemental formula $\mathrm{C}_{17} \mathrm{H}_{17} \mathrm{ClN}_{2} \mathrm{O}_{5}$ with ten double bond equivalents. Accordingly, the UV spectrum displayed two chromophores at 348 and $232 \mathrm{~nm}$. All carbons and protons were visible in the 1D NMR spectra in $\mathrm{CDCl}_{3}$ and those directly connected with each other were correlated by the ${ }^{1} \mathrm{H},{ }^{13} \mathrm{C}$ HMQC spectrum defining the singlets at $\delta_{H}=10.6$ and 4.08 as $\mathrm{NH}$ and $\mathrm{OH}$ signals, respectively. The COSY NMR spectrum revealed only two small structural elements (Figure D1), i.e., methines $\mathrm{H}-4$ and $\mathrm{H}-5$ with methyl group $\mathrm{C}-16$ and methines $\mathrm{H}-12$ and $\mathrm{H}-13$, which showed a long-range correlation to the $\mathrm{NH}$ signal. A further long-range correlation was observed between $\mathrm{H}-5$ and $\mathrm{H}-7$. Thus, the carbon skeleton was derived from the ${ }^{1} \mathrm{H},{ }^{13} \mathrm{C}$ HMBC NMR data (Table D1) as illustrated in Figure D1. The connection of the chlorine atom was required from the elemental formula and the ${ }^{13} \mathrm{C}$ chemical shift of the C-14 atom, while the closure of the 2-pyrone ring was mainly assigned due to the acyl shift of the oxymethine $\mathrm{H}-5$ at $\delta 5.34 \mathrm{ppm}$. The ROESY NMR spectrum offered only a few correlations, although, the proximity of $2-\mathrm{H}$ and the methoxy group $\mathrm{C}-15$ as well as of methines $\mathrm{H}-10$ and $\mathrm{H}-12$ was indicated. The latter revealed the cis relative configuration of the substituted double bond and the pyrrole $\mathrm{H}-12$. A supporting NOE effect was observed between $\mathrm{H}-17 \mathrm{~b}$ and the $\mathrm{NH}$ signal on the opposite side. The absence of NOE effects between methylene C-17 and methine $\mathrm{C}-10$ suggested the trans configuration of the $\Delta^{9,10}$ double bond, whereas the absence of an NOE effect between methine $\mathrm{H}-5$ and methyl $\mathrm{C}-16$ and methine $\mathrm{H}-7$ required their $\mathrm{H}-5 / \mathrm{C}-16$ trans configuration and a $\mathrm{H}-5 / \mathrm{H}-7$ transoidal conformation of the 5,6-dihydro-2 $\mathrm{H}$-pyran-2-one ring, respectively.

Since 1 could be crystalized from methanol, an X-ray crystal analysis was conducted. Fortunately the crystal was of real good quality to allow the determination of the absolute configuration from structure refinement (Flack $x=-0.001$ (22) from 2103 selected quotients (Parsons' method), which indicated the absolute 4S,5S-configuration (Figure D2). The conspicuous inclination of the primary alcohol C-17 towards the pyrrole 
$\mathrm{NH}$ is caused by a hydrogen bond between $17-\mathrm{O}$ and the pyrrole $\mathrm{NH}$. The gross conformation in the crystal is fully compatible with the results of the NMR experiments in solution.

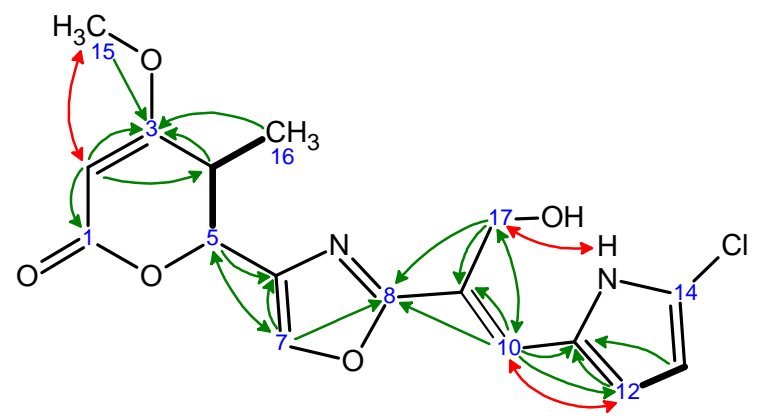

Figure D1. Selected ${ }^{1} \mathrm{H},{ }^{13} \mathrm{C}$ HMBC (green arrows) and ROESY NMR Correlations (red arrows) of Pyrronazol A (1). (bold bonds show vicinal COSY correlations)

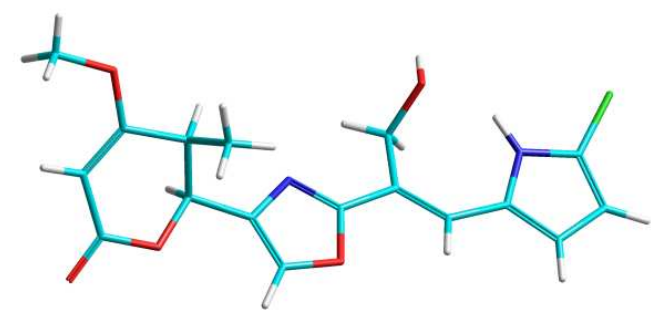

Figure D2. Absolute 4S,5S-Configuration of Pyrronazol A (1) (red: O; blue: N; green: Cl)

Interestingly, as a byproduct from $N$. pusilla strain Ari7, an isomer 2 of $\mathrm{C}_{17} \mathrm{H}_{17} \mathrm{CIN}_{2} \mathrm{O}_{5}$ was isolated showing the same HRESIMS molecular ion clusters as 1. The NMR data (Table D1) of pyrronazole A2 (2) suggested a similar carbon skeleton, though with a cis configuration of the methyl substituted $\Delta^{9,10}$ double bond, that was indicated by a strong ROESY correlation between methylene protons $\mathrm{H}-17$ and $\mathrm{H}-10$. While the correlation between $\mathrm{H}-10$ and $\mathrm{H}-12$ was still present, the ROESY correlation of methylene $\mathrm{H}-17 \mathrm{~b}$ with the pyrrole $\mathrm{NH}$ was lost. As a consequence of the lost fixation by the hydrogen bond the methylene proton signals no longer appeared separated ( $\Delta \delta \sim 0.2 \mathrm{ppm})$ but as a narrow $A, B$ multiplet at $\delta=4.66$ ppm in 2 .

The presence of another pyrronazol 3 was suggested by a more lipophilic peak in the RP-HPLC analyses of strains $N$. pusilla or $N$. exedens exhibiting a related UV spectrum. 
This however, had the elemental formula $\mathrm{C}_{17} \mathrm{H}_{17} \mathrm{ClN}_{2} \mathrm{O}_{4}$ indicated by molecular ion clusters for $[\mathrm{M}+\mathrm{H}]^{+}$and $[\mathrm{M}+\mathrm{Na}]^{+}$, and a conspicuous pyrone fragment ion $[\mathrm{M}-44=\mathrm{M}-$ $\left.\mathrm{CO}_{2}\right]^{+}$in positive mode as well as $[\mathrm{M}-\mathrm{H}]^{-}$in negative mode. The loss of one oxygen atom and the appearance of a new methyl group C-17 in the NMR spectra suggested the absence of the primary alcohol function in pyrronazole B (3) (Table D2). This small difference resulted in a surprising consequence in the solution conformation of $\mathbf{3}$ compared to 1; supported by a weak ROESY correlation between $\mathrm{H}-10$ and the pyrrole $\mathrm{NH}$, the unambiguously strong correlation between methyl group C-17 and the pyrrole $\mathrm{H}-12$ required a 180 degree turn of the pyrrole ring, positioning both in a cisoidal relation (Scheme D1).

Table D1. NMR Data of Pyrronazol A1 (1) and A2 (2)

\begin{tabular}{|c|c|c|c|c|c|c|c|c|c|c|c|c|c|c|}
\hline \multicolumn{8}{|c|}{$\mathbf{1}^{\mathrm{a}}$} & \multicolumn{7}{|c|}{$2^{a}$} \\
\hline Pos. & $\delta \delta_{\mathrm{H}}$ & $\mathrm{m}$ & $J[\mathrm{~Hz}]$ & ROESY & $\delta_{\mathrm{C}}$ & $\mathrm{m}$ & $\mathrm{H}$ in $\mathrm{HMBC}$ & $\overline{\delta_{\mathrm{H}}}$ & $\mathrm{M}$ & $J[\mathrm{~Hz}]$ & ROESY & $\delta_{\mathrm{C}}$ & $\mathrm{m}$ & $\mathrm{H}$ in $\mathrm{HMBC}$ \\
\hline 1 & & & & & 166.1 & $\mathrm{C}$ & 2 & & & & & 165.9 & $\mathrm{C}$ & 2 \\
\hline 2 & 5.07 & $\mathrm{~s}$ & & 15 & 88.9 & $\mathrm{CH}$ & & 5.22 & $\mathrm{~s}$ & & 15 & 89.2 & $\mathrm{CH}$ & 4 \\
\hline 3 & & & & & 178.5 & $\mathrm{C}$ & $16,4,15,2$ & & & & & 178.2 & $\mathrm{C}$ & $16,4,15,2$ \\
\hline 4 & 2.79 & qd & $7.1,3.6$ & 5 & 35.8 & $\mathrm{CH}$ & 16,2 & 2.99 & qd & $7.1,3.7$ & 5 & 36.2 & $\mathrm{CH}$ & 16,2 \\
\hline 5 & 5.34 & dd & $3.6,1.5$ & 4 & 75.0 & $\mathrm{CH}$ & 16 & 5.64 & $\mathrm{~m}$ & & 4,7 & 74.6 & $\mathrm{CH}$ & 16 \\
\hline 6 & & & & & 137.9 & $\mathrm{C}$ & 5,7 & & & & & 137.1 & $\mathrm{C}$ & 5 \\
\hline 7 & 7.66 & d & 1.5 & & 135.9 & $\mathrm{CH}$ & 5 & 7.85 & d & 1.5 & 5 & 135.5 & $\mathrm{CH}$ & 5 \\
\hline 8 & & & & & 163.6 & $\mathrm{C}$ & $17 \mathrm{~b}, 17 \mathrm{a}, 10,7$ & & & & & 162.6 & $\mathrm{C}$ & $17,10,7$ \\
\hline 9 & & & & & 118.3 & $\mathrm{C}$ & $17 \mathrm{~b}, 17 \mathrm{a}, 10$ & & & & & 115.1 & $\mathrm{C}$ & 17,10 \\
\hline 10 & 7.38 & $\mathrm{~s}$ & & 12 & 126.6 & $\mathrm{CH}$ & $17 \mathrm{~b}, 17 \mathrm{a}$ & 6.79 & $\mathrm{~s}$ & & 17 & 126.1 & $\mathrm{CH}$ & 17 \\
\hline 11 & & & & & 128.0 & $\mathrm{C}$ & $13,12,10$ & & & & & 127.7 & $\mathrm{C}$ & $13,12,10$ \\
\hline 12 & 6.45 & $\mathrm{dd}$ & $3.6,2.0$ & 10,13 & 116.9 & $\mathrm{CH}$ & 10 & 6.46 & dd & $3.6,2.3$ & 13 & 117.8 & $\mathrm{CH}$ & 13,10 \\
\hline 13 & 6.16 & dd & $3.8,1.8$ & 12 & 109.1 & $\mathrm{CH}$ & & 6.16 & dd & $3.6,2.5$ & 12 & 108.6 & $\mathrm{CH}$ & 12 \\
\hline 14 & & & & & 120.3 & $\mathrm{C}$ & & & & & & 117.9 & $\mathrm{C}$ & \\
\hline 15 & 3.75 & $\mathrm{~s}$ & & & 56.3 & $\mathrm{CH}_{3}$ & & 3.84 & $\mathrm{~s}$ & & 2 & 56.5 & $\mathrm{CH}_{3}$ & \\
\hline 16 & 0.96 & d & 7.1 & 2,4 & 11.4 & $\mathrm{CH}_{3}$ & 5 & 1.10 & d & 7.3 & 2,5 & 11.8 & $\mathrm{CH}_{3}$ & 4,5 \\
\hline $17 \mathrm{a}$ & 4.93 & d & 13.2 & $17 \mathrm{~b}$ & 58.6 & $\mathrm{CH}_{2}$ & 10 & 4.66 & $\mathrm{~m}$ & & 10 & 65.8 & $\mathrm{CH}_{2}$ & 10 \\
\hline $17 \mathrm{~b}$ & 4.74 & $\mathrm{~d}$ & 13.2 & 17a, NH & & & & & & & & & & \\
\hline $\mathrm{NH}$ & 10.60 & br. s & & $17 b$ & & & & 13.94 & br. s & & & & & \\
\hline $\mathrm{OH}$ & 4.08 & br. s & & & & & & n.o. & & & & & & \\
\hline
\end{tabular}


Table D2. NMR Data of Pyrronazol B (3) in $\mathrm{CDCl}_{3}$

\begin{tabular}{|c|c|c|c|c|c|c|c|}
\hline No. & $\delta_{\mathrm{H}}{ }^{\mathrm{a}}$ & $\mathrm{m}$ & $J[\mathrm{~Hz}]$ & ROESY & $\delta_{\mathrm{C}}$ & $\mathrm{m}^{\mathrm{b}}$ & $\mathrm{H}$ in $\mathrm{HMBC}$ \\
\hline 1 & & & & & 166.45 & $\mathrm{C}$ & 2 \\
\hline 2 & 5.16 & $\mathrm{~s}$ & & 15 & 89.11 & $\mathrm{CH}$ & \\
\hline 3 & & & & & 178.81 & $\mathrm{C}$ & $16,4,15,2$ \\
\hline 4 & 2.91 & $\mathrm{qd}$ & $7.0,3.4$ & 5 & 35.93 & $\mathrm{CH}$ & 16,2 \\
\hline 5 & 5.52 & $\mathrm{dd}$ & $3.4,1.5$ & 4,7 & 75.44 & $\mathrm{CH}$ & 16 \\
\hline 6 & & & & & 138.23 & $\mathrm{C}$ & 5 \\
\hline 7 & 7.71 & $\mathrm{~d}$ & 1.5 & 5 & 135.67 & $\mathrm{CH}$ & 5 \\
\hline 8 & & & & & 164.66 & $\mathrm{C}$ & $17,10,7$ \\
\hline 9 & & & & & 118.47 & $\mathrm{C}$ & 17,10 \\
\hline 10 & 7.21 & $\mathrm{~m}$ & & $\mathrm{NH}$ & 121.11 & $\mathrm{CH}$ & 17 \\
\hline 11 & & & & & 128.74 & $\mathrm{C}$ & 17,12 \\
\hline 12 & 12 & $\mathrm{t}$ & 3.4 & 17 & 113.33 & $\mathrm{CH}$ & 10 \\
\hline 13 & 6.17 & $\mathrm{dd}$ & $3.8,2.6$ & - & 108.77 & $\mathrm{CH}$ & \\
\hline 14 & & & & & 117.11 & $\mathrm{C}$ & \\
\hline 15 & 3.80 & $\mathrm{~s}$ & & $2,16,4$ & 56.36 & $\mathrm{CH}_{3}$ & \\
\hline 16 & 1.01 & $\mathrm{~d}$ & 7.2 & & 11.56 & $\mathrm{CH}_{3}$ & 5 \\
\hline 17 & 2.34 & $\mathrm{~d}$ & 1.1 & 12 & 14.79 & $\mathrm{CH}_{3}$ & 10 \\
\hline $\mathrm{NH}$ & 8.47 & $\mathrm{~s}$ & br. & & & & \\
\hline
\end{tabular}

When N. pusilla strain Na a174 was used for large-scale production of 1, a late eluting fraction from $\mathrm{LH}-20$ chromatography of the extract showed the typical conjugated oxazol-pyrrole chromophore at $340-350 \mathrm{~nm}$ in the UV spectrum for two peaks in the analytical RP-HPLC-HRESIMS at $9.7 \mathrm{~min}$ and $11.8 \mathrm{~min}$ for $\mathbf{4}$ and $\mathbf{5}$, respectively. Both were isomers with the elemental composition $\mathrm{C}_{15} \mathrm{H}_{19} \mathrm{CIN}_{2} \mathrm{O}_{3}$ derived from their molecular ion clusters $[\mathrm{M}+\mathrm{H}]^{+}$at 311.1158 . Their NMR spectra revealed the presence of the pyrrole and oxazol units like pyrronazol B (3) but lacked the 2-pyrone part of the molecule (Table D3). Instead, identical 2-methylbutane-1,3-diol residues were suggested from the COSY NMR spectra of pyrronazol C1 (4) and C2 (5). Suspicious shift differences of $0.7 \mathrm{ppm}$ for $\mathrm{H}-10$ in the ${ }^{1} \mathrm{H}$ NMR spectra and of $6.8 \mathrm{ppm}$ for $\mathrm{C}-17$ in the ${ }^{13} \mathrm{C}$ NMR spectra indicated different configurations of the methyl-substituted $\Delta^{9,10}$ double bond. Actually, 4 was recognized as the $E$ configured pyrronazol $\mathrm{C}$ isomer from NOESY correlations between $\mathrm{CH}_{3}-17$ and $\mathrm{H}-12$ and between $\mathrm{H}-10$ and the $\mathrm{NH}$ proton. Conversely, ROESY correlations were observed between $\mathrm{CH}_{3}-17$ and $\mathrm{H}-10$ and between $\mathrm{H}-10$ and $\mathrm{H}-12$ in the $\mathrm{Z}$ isomer, pyrronazol $\mathrm{C} 2$ (5). 
Table D3. NMR-Data of Pyrronazol C1 (4) and C2 (5) in $\mathrm{CDCl}_{3}{ }^{\mathrm{b}}$

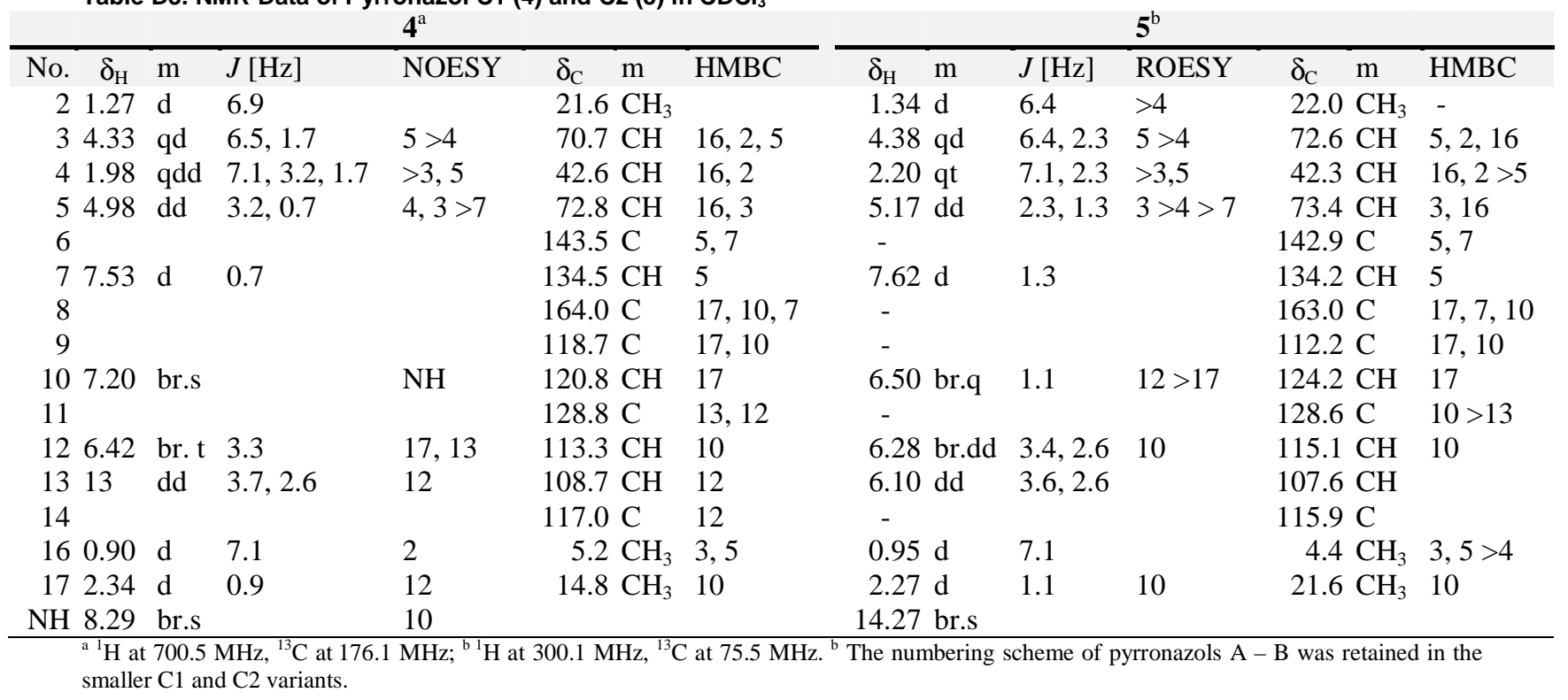

A strongly preferred conformation in solution was expected from the substitution pattern of the 2-methylbutane-1,3-diol residue of the isomers. In the ${ }^{1} \mathrm{H}$ NMR spectra only small coupling constants $J_{3,4}$ and $J_{4,5}$ between 1.7 and $3.2 \mathrm{~Hz}$ were observed for $\mathbf{4}$ and $\mathbf{5}$, together with a strong NOE effect between $\mathrm{H}-3$ and $\mathrm{H}-5$. Assuming the relative position of the substituents on C-4 and C-5 are similar to $\mathbf{1}-\mathbf{3}$, the $4 R, 5 S$ configuration was used to calculate the preferred conformations of the $3 R$ and $3 S$ isomers of pyrronazol C1 (4) using the conformational search module of HyperChem (Ver. 8.0). While none of the $R, R, S$ conformations were compatible with the NMR restrictions, the conformation of the $S, R, S$ configuration of $\mathbf{4}$ shown in Fig. D3 provided calculated coupling constants of 2.7 and $2.3 \mathrm{~Hz}$ for $J_{3,4}$ and $J_{4,5}$, respectively. The strong NOE effects between $\mathrm{H}-3$ and $\mathrm{H}-5$ and the weaker one between $\mathrm{H}-5$ and $\mathrm{H}-7$ were compatible with the atom distances of 2.4 and $3.0 \AA$ in the model. Additionally, the absence of any NOE effect between $\mathrm{H}-5$ and the methyl groups $\mathrm{C}-2$ and $\mathrm{C}-16$ was explained by the conformation of the $3 S, 4 R, 5 S$ isomer $\mathbf{4}$ as shown in Fig. D3. 


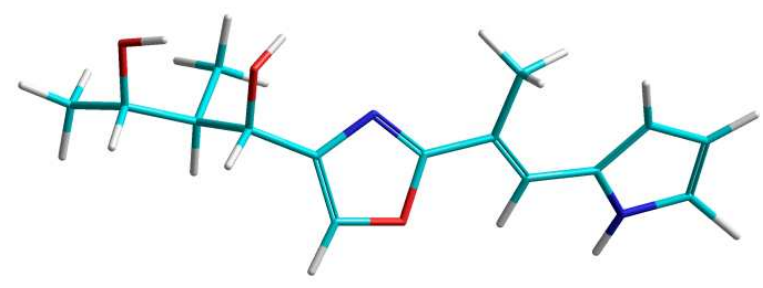

Figure D3. Calculated Solution Conformation of Pyrronazol C1 (4)

(HyperChem Ver. 8.0, Conformational Search (MM+), followed by optimization (pm3))

1,6-Phenazinediol (6) was isolated by Si-flash chromatography of a fraction from Sephadex LH-20 chromatography in dichloromethane/methanol (1:1). 6 was identified by HPLC-HRESI mass spectrometry and ${ }^{1} \mathrm{H}$ and ${ }^{13} \mathrm{C}$ NMR spectroscopy as a metabolite of N. pusilla, strain Ari7 (Breitmaier and Hollstein, 1976; Alonso et al., 2005).<smiles>OCC1OC(Oc2cccc3nc4c(O)cccc4nc23)C(O)[C@@H]1O</smiles>

Scheme D2. 1-Hydroxy-phenazine-6-yl-a-D-arabinofuranoside (7)

The corresponding glycoside 7 (Scheme D2) was identified by HPLC-UV-MS in a Siflash chromatography fraction from its similar UV spectrum and the molecular ion cluster $[\mathrm{M}+\mathrm{H}]^{+}$at $\mathrm{m} / \mathrm{z} 345.1081$ providing the elemental composition $\mathrm{C}_{17} \mathrm{H}_{17} \mathrm{~N}_{2} \mathrm{O}_{6}$. The molecular ion cluster was accompanied by a typical fragment ion $\left[\mathrm{M}+\mathrm{H}-\mathrm{C}_{5} \mathrm{H}_{8} \mathrm{O}_{4}\right]^{+}$at $\mathrm{m} / \mathrm{z}$ 213.0659 indicating the loss of a pentosyl residue. Since the carbon nuclei in furanose sugars are generally less shielded than in related pyranoses and the anomeric configuration can be differentiated by their ${ }^{13} \mathrm{C}$ chemical shifts (Table DS6), the carbohydrate residue was assigned by NMR spectroscopy as an $\alpha$-arabinofuranosyl residue (observed $\delta_{\mathrm{C}} 109.1,83.1,78.9,87.8,63.1$; methyl-a-furanoside $\delta_{\mathrm{C}} 109.3,81.9$, 77.5, 84.9, 62.4) (Agrawal, 1992; Bubb, 2003). The absolute configuration was 
determined to be D-arabinose by GC-MS comparison of the (-)-2-butyl glycoside derivative to authentic standards (Gerwig et al., 1978).

Pyrronazol A (1), 1,6-phenazine-diol (6) and 1-hydroxy-phenazine-6-yl-a-Darabinofuranoside (7) were tested for their biological activity against bacteria, fungi and yeasts. 1 showed weak antifungal activity against Mucor hiemalis with a minimum inhibitory concentration (MIC) of $33 \mu \mathrm{g} / \mathrm{mL}$ but no antibacterial activity, while 6 showed weak antibacterial and antifungal activity with a MIC of $33 \mu \mathrm{g} / \mathrm{mL}$ against some of the strains tested (Table D4). When both the compounds were assessed for cytotoxicity against growing cancer and primary cell lines, 1 showed no significant activity but 6 was active against all cell lines tested with a minimum $\mathrm{LD}_{50}$ value of $2.59 \mu \mathrm{M}$ against SKOV3 cells (Human ovarian carcinoma cells) (Table D5).

Table D4. In-vitro Antibacterial and Antifungal Activity of Pyrronazol A (1), 1,6-Phenazine-diol (6) and 1-Hydroxy-phenazine6-yl- $\alpha$-D-arabinofuranoside (7) (MIC $[\mu \mathrm{g} / \mathrm{mL}])$

\begin{tabular}{lcccc}
\hline Test Organism (DSM No.) & $\mathbf{1}$ & $\mathbf{6}$ & $\mathbf{7}$ & Control \\
\hline Chromobacterium violaceum $(30191)$ & n.i. & 66.7 & n.i. & $2.1^{\mathrm{a}}$ \\
Nocardia sp. $(43069)$ & n.i. & 33.3 & n.i. & $<0.52^{\mathrm{a}}$ \\
Paenibacillus polymyxa (36) & n.i. & 66.7 & n.i. & $6.7^{\mathrm{d}}$ \\
Mycobacterium sp. $(43270)$ & n.i. & 66.7 & & $2.1^{\mathrm{a}}$ \\
Mycobacterium diernhoferi $(43542)$ & n.i. & 33.3 & 66.6 & $<0.52^{\mathrm{a}}$ \\
Mucor hiemalis $(2656)$ & 33.3 & 33.3 & n.i. & $2.1^{\mathrm{b}}$ \\
Trichosporon oleaginosus $(11815)$ & n.i. & n.i. & n.i. & $0.1^{\mathrm{a}}$ \\
Wickerhamomyces anomalus $(6766)$ & n.i. & 33.3 & n.i. & $0.52^{\mathrm{b}}$ \\
Aspergillus flavus $(1959)$ & n.i. & n.i. & n.i. & $1.0^{\mathrm{c}}$ \\
Aspergillus fumigatus $(15966)$ & n.i. & n.i. & 33.3 & $<0.52^{\mathrm{c}}$ \\
\hline \multicolumn{2}{c}{ a Streptomycin sulfate; ${ }^{\mathrm{b}}$ Nystatin dihydrate; n.i. no inhibition; ${ }^{\mathrm{c}}$ Amphotericin B; ${ }^{\mathrm{d}}$ Oxytetracyclin hydrochloride; ${ }^{\mathrm{e}}$ formerly Pichia anomala. }
\end{tabular}

Table D5. Cytotoxicity ( $\left.\mathrm{LD}_{50}[\mu \mathrm{M}]\right)$ of Pyrronazol A (1) and 1,6-Phenazine-diol (6) against growing cell lines.

\begin{tabular}{|c|c|c|c|}
\hline Cell lines & Pyrronazol A (1) & 1,6-Phenazine-diol (6) & Ref. $^{\text {a }}$ \\
\hline L-929 & $>27.41$ & 11.31 & 0.008 \\
\hline KB-3-1 & $>27.41$ & 5.18 & 0.002 \\
\hline HUVEC & $>27.41$ & 3.81 & - \\
\hline SK-OV-3 & $>27.41$ & 2.59 & 0.0026 \\
\hline A-549 & $>27.41$ & 5.65 & 0.0014 \\
\hline
\end{tabular}


With their tricyclic carbon skeleton the pyrronazols $A(\mathbf{1}, \mathbf{2})$ and $B(\mathbf{3})$ represent a novel structural class of secondary metabolites. The minor byproducts pyrronazol C1 (4) and C2 (5) observed with $N$. pusilla strain $\mathrm{Na}$ a174 are probably degradation products, which are sometimes observed to a greater extent after a prolonged cultivation period. As next related natural products (Scheme D3) pyoluteorin (Takeda, 1958), a pyrrole antibiotic from Pseudomonas aeruginosa and $P$. fluorescens with antibacterial, antifungal and herbicidal properties might be seen, or pyrrolomycin B (Kaneda et al., 1981) from Actinosporangium vitaminophilum with antibiotic, antifungal and immunepotentiator properties as well as the phorbazole D variants (Rudi et al., 1994), immunomodulators from the marine sponge Phorbas aff. clathrata. Another antifungal pyrrole antibiotic, the 3-chloro derivative pyrrolnitrin was isolated among others from the myxobacterium Myxococcus fulvus (Gerth et al., 1982).<smiles>Oc1ccc(-c2cnc(-c3[nH]ccc3Cl)o2)cc1</smiles>

Phorbazole D<smiles>O=[N+]([O-])c1c(Cl)cccc1-c1c[nH]cc1Cl</smiles>

Pyrrolnitrin<smiles>O=C(c1cc(Cl)c(Cl)[nH]1)c1c(O)cccc1O</smiles>

Pyoluteorin<smiles>Cc1c(Cc2cc(Cl)cc(Cl)c2O)[nH]c(Cl)c1Cl</smiles>

Pyrrolomycin B

Scheme D3. Pyrrole antibiotics

1,6-Phenazine-diol (6) belongs to a phenazine family of compounds and has been reported previously from of diverse microorganisms such as Brevibacterium iodinum, Microbispora aerata, Streptomyces thioluteus, Pseudomonas iodine and Nocardiopsis dassonvillei(Gerber and Lechevalier, 1965; Podojil and Gerber, 1967; Tsujibo, 1988). The glycosyl derivative, 1-hydroxy-phenazine-6-yl-a-D-arabinofuranoside (7) was isolated from Nannocystis pusilla strain Ari7 for the first time. 
Pyrronazols from Nannocystis

\section{D.4. Experimental Section}

D.4.1. General Experimental Procedures. Melting points were measured on a Büchi510 melting point apparatus; UV data were recorded on a Shimadzu UV/Vis-2450 spectrophotometer in methanol (UVASOL, Merck); IR data were recorded on a Bruker Tensor 27 IR spectrophotometer. ${ }^{1} \mathrm{H}$ NMR and ${ }^{13} \mathrm{C}$ NMR spectra were recorded on Bruker Avance DMX 600 or DPX 300 NMR spectrometers, locked to the deuterium signal of the solvent. Data acquisition, processing and spectral analysis were performed with standard Bruker software and ACD/NMR Spectrus. Chemical shifts are given in parts per million (ppm) and coupling constants in Hertz $(\mathrm{Hz})$. HRESIMS data were recorded on a Maxis ESI TOF mass spectrometer (Bruker Daltonics), molecular formulae were calculated including the isotopic pattern (Smart Formula algorithm). Analytical RP HPLC was carried out with an Agilent 1260 HPLC system equipped with a diode-array UV detector (DAD) and a Corona Ultra detector (Dionex) or a Maxis ESI TOF mass spectrometer (Bruker Daltonics). HPLC conditions: Waters Acquity $\mathrm{C}_{18}$ column $50 \times 2 \mathrm{~mm}, 1.7 \mu \mathrm{m}$, solvent $\mathrm{A}: \mathrm{H}_{2} \mathrm{O}, 0.1 \% \mathrm{HCOOH}$; solvent $\mathrm{B}$ : acetonitrile, $0.1 \%$ $\mathrm{HCOOH}$; gradient system: 5\% B for $1 \mathrm{~min}$, increasing to $95 \% \mathrm{~B}$ in $20 \mathrm{~min}$; flow rate 0.6 $\mathrm{mL} / \mathrm{min} ; 40{ }^{\circ} \mathrm{C}$.

The myxobacterial strain Nannocystis pusilla, strain Ari7 was isolated in 1980 from a soil sample collected on Langeoog island, Germany, in 1977 and strain Na a174 was isolated from soil with plant residues from Rhodos island, Greece in 1999.

\section{D.4.2. Isolation of Pyrronazols A, A2 and B from N. pusilla, strain Ari 7}

Fermentation. The strain was stored at $-80^{\circ} \mathrm{C}$. It was reactivate $\mathrm{d}$ in $20 \mathrm{~mL}$ of liquid media consisting of $0.3 \%$ probion (single cell protein, Hoechst), $0.3 \%$ starch (Cerestar), $0.2 \% \mathrm{MgSO}_{4} \times 7 \mathrm{H}_{2} \mathrm{O}, 0.05 \% \mathrm{CaCl}_{2} \times 2 \mathrm{H}_{2} \mathrm{O}, 50 \mathrm{mM}$ HEPES at pH 7.2. $20 \mu \mathrm{L}$ of vitamin solution was added to the culture. The culture was scaled up to $1 \mathrm{~L}$ and used as inoculum for a fermentation of strain Ari7 that was performed in the same media as above but supplemented with $2 \%$ Amberlite XAD-16 resin in a $10 \mathrm{~L}$ bioreactor. The bioreactor was kept at $30{ }^{\circ} \mathrm{C}$, aerated at 0.05 vvm per minute, $\mathrm{pH}$ regulated at 7.2 , and 
agitated with a flat blade turbine stirrer at $100 \mathrm{rpm}$ for 7 days. At the end of fermentation the XAD resin (181 g) was collected from the culture by sieving.

Extraction and Isolation. The XAD adsorber resin was stored overnight in methanol and extracted three times in a glass column with 3 bed volumes of methanol. The methanol extract was evaporated to an aqueous mixture, diluted with water and extracted with ethyl acetate (three times with $150 \mathrm{~mL}$ ). The combined ethyl acetate was dried with $\mathrm{Na}_{2} \mathrm{SO}_{4}$. It was evaporated to give $1.34 \mathrm{~g}$ of crude extract. A further solventsolvent partitioning was done between methanol and $n$-heptane to eliminate lipophilic compounds. Methanol-n-heptane $(100 \mathrm{~mL})$ partitioning was repeated twice to give 914 $\mathrm{mg}$ of an enriched crude methanol extract. This crude extract was further separated by Sephadex LH-20 chromatography [column $4 \times 84 \mathrm{~cm}$; solvent dichloromethane methanol (1:1); flow rate $3.6 \mathrm{~mL} / \mathrm{min}$, UV detection at $275 \mathrm{~nm}$ ] to obtain two fractions with crude 1,6-phenazinediol (4) $(62 \mathrm{mg})$ and a fraction $2(325 \mathrm{mg})$ after evaporation of the organic solvent.

Crude 4 was dissolved in methanol $(50 \mathrm{~mL})$ and evaporated with silica gel $(11 \mathrm{~g})$. The dried silica gel was used in a solid loader for further purification by silica gel flash chromatography (Reveleris Flash Chromatography System; column 12 g silica $40 \mu$ ), solvent dichloromethane for $10 \mathrm{~min}$; flow rate $36 \mathrm{~mL} / \mathrm{min}$; UV detection at $350 \mathrm{~nm}$ and $270 \mathrm{~nm}$ ) yielding pure 1,6-phenazinediol (4) (17 mg).

The fraction 2 was dissolved in methanol and purified subsequently by RP-MPLC chromatography [column $480 \times 30 \mathrm{~mm}$ (Kronlab), ODS-AQ $\mathrm{C}_{18}$ (YMC), S $16 \mu \mathrm{m}$; solvent A: $\mathrm{H}_{2} \mathrm{O}$-methanol $1 / 1$; solvent B: methanol; gradient: $15 \%$ B to $40 \%$ B in $120 \mathrm{~min}$; flow rate $30 \mathrm{~mL} / \mathrm{min}$; UV detection at $350 \mathrm{~nm}$ ] to give four fractions; fraction $2(58 \mathrm{mg}$ ), fraction $3(13 \mathrm{mg})$, fraction 4 containing pure pyrronazol A2 $(2)(3.5 \mathrm{mg})$, and fraction 5 with pure pyrronazol B (3) (2 mg). Fraction 2 was dissolved in DMSO and ultimately purified by two preparative RP-HPLC runs [column $250 \times 21 \mathrm{~mm}$, Nucleodur 100-10 $\mathrm{C}_{18}$ $\mathrm{EC}, \mathrm{S} 10 \mu \mathrm{m}$; solvent $\mathrm{A}$ : $\mathrm{H}_{2} \mathrm{O}$-methanol 1/1; solvent $\mathrm{B}$ : methanol; gradient: $15 \% \mathrm{~B}$ to $30 \% \mathrm{~B}$ in $60 \mathrm{~min}$; flow rate $20 \mathrm{~mL} / \mathrm{min}$; UV detection at $350 \mathrm{~nm}$ ] yielding pure pyrronazol A (1) (43 mg) and pyrronazol A2 (2) (4.5 mg). 1 was crystalized from methanol at $4{ }^{\circ}$. 
Fraction 3 was purified by preparative TLC [20 × $20 \mathrm{~cm}, 0.25 \mathrm{~mm}$, silica gel 60 F254 nm (Merck), dichloromethane-MeOH (9:1), UV detection at $254 \mathrm{~nm}$ ]. The UV active zone was eluted and to yield $3.2 \mathrm{mg}$ of 1-Hydroxy-phenazine-6-yl-a-D-arabinofuranoside (7).

\section{D.4.3. Isolation of Pyrronazol C1 and C2 from N. pusilla, strain Na a174}

Fermentation. Strain Naa174 was cultivated in $65 \mathrm{~L}$ of a medium consisting of $1 \%$ probion (single cell protein, Hoechst), $0.1 \% \mathrm{MgSO}_{4} \times 7 \mathrm{H}_{2} \mathrm{O}, 0.05 \% \mathrm{CaCl}_{2} \times 2 \mathrm{H}_{2} \mathrm{O}$, and $50 \mathrm{mM}$ HEPES in the presence of $1 \%$ Amberlite XAD-16 in a $100 \mathrm{~L}$ bioreactor. The bioreactor was kept at $30^{\circ} \mathrm{C}$, aerated at $0.05 \mathrm{vvm}$ per minute, $\mathrm{pH}$ regulated at 7.2, and agitated with a flat blade turbine stirrer at $110 \mathrm{rpm}$ for 4 days. At the end of fermentation the XAD resin and cells $(1.6 \mathrm{~kg})$ were collected from the culture by sieving.

Isolation. Amberlite XAD 16 from a fermentation of strain Naa174 was extracted with acetone (three times, $6 \mathrm{~L}$ each) under stirring and filtered through filter paper on a Buchner funnel. The combined extracts were evaporated providing aqueous oil, which was extracted with dichloromethane. After evaporation $22.5 \mathrm{~g}$ of a raw extract remained, that was partitioned between methanol and heptane (1:1, 3 times). After evaporation of the methanol, $8.1 \mathrm{~g}$ of a raw product was obtained and separated by LH-20 column chromatography (column $70 \times 600 \mathrm{~mm}$, dichloromethane-methanol 8:2, flow rate 10 $\mathrm{mL} / \mathrm{min} ; 3$ runs). Five fractions were collected guided by TLC and UV absorption (365 $\mathrm{nm}$ ). Fraction 2 contained pyrronazol A1 (1) (3.1 g with about $0.5 \mathrm{~g}$ of 1). Fraction 5 (82 $\mathrm{mg}$ ) was separated by RP-HPLC [column $22 \times 250 \mathrm{~mm}$, RP-18, solvent gradient 50 to $100 \% \mathrm{MeOH}$ in $30 \mathrm{~min}$, flow $23 \mathrm{~mL} / \mathrm{Min}$; UV detection $350 \mathrm{~nm}$ ) to give fraction 5.1 (5.6 $\mathrm{mg})$ containing enriched pyrronazol $\mathrm{C} 1(4)$ and fraction $5.3(3.4 \mathrm{mg})$ containing enriched pyrronazol C2 (5). Both fractions were again purified by RP-HPLC.

\section{D.4.4. X-Ray Structure Determination of Pyrronazol A (1)}

Crystals suitable for single-crystal $x$-ray analysis were obtained from methanol. Although chlorine is not sufficient normally, fortunately in this case the crystal was of real good quality and allowed the determination of the absolute configuration from structure refinement. The data were collected at $132 \mathrm{~K}$ on a BrukerAXS X8Apex CCD diffractometer operating with graphite-monochromatized Mo Ka radiation. Frames of 
$0.5^{\circ}$ oscillation were exposed; deriving data in the $\theta$ range of 2 to $33^{\circ}$ with a completeness of $\sim 95 \%$. Structure solution and full least-squares refinement with anisotropic thermal parameters of all non-hydrogen atoms and free refinement of the hydrogen were performed using SHELX (Sheldrick, 2008). The final refinement resulted in: $R 1=0.039, w R 2=0.087, S=1.009$ and Flack $=0.00(4)$ for the correct structure and $R 1=0.041, w R 2=0.093, S=1.075$ and Flack $=0.99(6)$ for the opposite configuration.

\section{D.4.5. Structural characteristics of compounds isolated}

Pyrronazol A1 (1) 6-\{2-[(1E)-1-(5-chloro-1H-pyrrol-2-yl)prop-1-en-2-yl]-1,3-oxazol-4-yl\}4-methoxy-5-methyl-5,6-dihydro-2H-pyran-2-one: $\quad \mathrm{C}_{17} \mathrm{H}_{17} \mathrm{ClN}_{2} \mathrm{O}_{5} \mathrm{M}=364.78$; HPLC System A: $R_{\mathrm{t}} 10.2 \mathrm{~min} ; \mathrm{mp} .150{ }^{\circ} \mathrm{C}$ decomp.; [ $\left.\alpha\right]^{22} \mathrm{D}-134.4\left(c=8 \mathrm{mg} / \mathrm{cm}^{-3}, \mathrm{CH}_{3} \mathrm{OH}\right)$; UV (MeOH): $\lambda_{\max }(\log \varepsilon) 232$ (4.229), 346 (4.484) nm; IR (KBr) $v_{\max } 1681$ (s), 1617 (s), $1223(\mathrm{~s}), 781(\mathrm{~m}) \mathrm{cm}^{-1}$; NMR data, see Table D1; HRESIMS m/z $365.0903[\mathrm{M}+\mathrm{H}]^{+}$ (calcd. for $\mathrm{C}_{17} \mathrm{H}_{18} \mathrm{ClN}_{2} \mathrm{O}_{5}, \quad 365.0899$ ), $\mathrm{m} / z \quad 387.0726 \quad[\mathrm{M}+\mathrm{Na}]^{+}$(calcd. for $\mathrm{C}_{17} \mathrm{H}_{17} \mathrm{ClN}_{2} \mathrm{O}_{5} \mathrm{Na}, 387.0718$ ), $\mathrm{m} / 2347.0798\left[\mathrm{M}-\mathrm{H}_{2} \mathrm{O}+\mathrm{H}\right]^{+}$(calcd. for $\mathrm{C}_{17} \mathrm{H}_{16} \mathrm{ClN}_{2} \mathrm{O}_{4}$, 437.0793), $m / z 363.0751$ [M-H]' (calcd. for $\mathrm{C}_{17} \mathrm{H}_{16} \mathrm{ClN}_{2} \mathrm{O}_{5}, 363.0753$ ).

Pyrronazol A2 (2) 6-\{2-[(1Z)-1-(5-chloro-1 H-pyrrol-2-yl)-3-hydroxyprop-1-en-2-yl]-1,3oxazol-4-yl\}-4-methoxy-5-methyl-5,6-dihydro-2H-pyran-2-one): $\mathrm{C}_{17} \mathrm{H}_{17} \mathrm{ClN}_{2} \mathrm{O}_{5} \quad \mathrm{M}=$ 364.78; [ $\alpha]^{22} \mathrm{D}-366\left(c=0.0038 \mathrm{~g} / \mathrm{cm}^{-3}, \mathrm{CH}_{3} \mathrm{OH}\right) ; \mathrm{UV}(\mathrm{MeOH}): \lambda_{\max }(\log \varepsilon) 233$ (4.313), 353 (4.266) nm; NMR data, see Table D1; HRESIMS m/z $365.0900[\mathrm{M}+\mathrm{H}]^{+}$(calcd. for $\mathrm{C}_{17} \mathrm{H}_{18} \mathrm{ClN}_{2} \mathrm{O}_{5}, 365.0899$ ), $\mathrm{m} / 2347.0793\left[\mathrm{M}-\mathrm{H}_{2} \mathrm{O}+\mathrm{H}\right]^{+}$(calcd. for $\mathrm{C}_{17} \mathrm{H}_{16} \mathrm{ClN}_{2} \mathrm{O}_{4}$, 437.0793).

Pyrronazol B (3) (5R,6R)-6-\{2-[(1E)-1-(5-chloro-1H-pyrrol-2-yl)prop-1-en-2-yl]-1,3oxazol-4-yl\}-4-methoxy-5-methyl-5,6-dihydro-2H-pyran-2-one: $\mathrm{C}_{17} \mathrm{H}_{17} \mathrm{CIN}_{2} \mathrm{O}_{4} \quad \mathrm{M}=$ 348.78; HPLC System A: $R_{\mathrm{t}} 11.8 \mathrm{~min}$; m.p. 215-6 ${ }^{\circ}$; $[\alpha]^{22} \mathrm{D}-132.3\left(c=5.3 \mathrm{mg} / \mathrm{cm}^{-3}\right.$, $\mathrm{CH}_{3} \mathrm{OH}$ ); UV (MeOH): $\lambda_{\max }(\log \varepsilon) 231$ (3.852), 338 (4.038) nm; IR (KBr) $v_{\max } 1704$ (s), 1629 (s), 1618 (s), 1379 (s) 1222 (s), 765 (m) cm ${ }^{-1}$; NMR data, see Table D2; HRESIMS $\mathrm{m} / z 349.0954[\mathrm{M}+\mathrm{H}]^{+}$(calcd. for $\mathrm{C}_{17} \mathrm{H}_{18} \mathrm{ClN}_{2} \mathrm{O}_{4}, 349.0950$ ), $\mathrm{m} / z$ 305.1057 $\left[\mathrm{M}+\mathrm{H}-\mathrm{CO}_{2}\right]^{+}$ (calcd. for $\mathrm{C}_{16} \mathrm{H}_{18} \mathrm{CIN}_{2} \mathrm{O}_{2}, 305.1051$ ), $\mathrm{m} / z 371.0756[\mathrm{M}+\mathrm{Na}]^{+}$(calcd. for $\mathrm{C}_{17} \mathrm{H}_{17} \mathrm{ClN}_{2} \mathrm{O}_{4} \mathrm{Na}$, 371.0769), $m / z 347.0801$ [M-H] (calcd. for $\mathrm{C}_{17} \mathrm{H}_{16} \mathrm{ClN}_{2} \mathrm{O}_{4}, 347.0804$ ). 
Pyrronazol C1 (4) 1-\{2-[(1E)-1-(5-chloro-1H-pyrrol-2-yl)prop-1-en-2-yl]-1,3-oxazol-4-yl\}2-methylbutane-1,3-diol: $\mathrm{C}_{15} \mathrm{H}_{19} \mathrm{ClN}_{2} \mathrm{O}_{3} \mathrm{M}=310.78$; HPLC System $\mathrm{A}: R_{\mathrm{t}} 9.7 \mathrm{~min} ; \alpha^{22}{ }_{\mathrm{D}}$ UV (MeOH): $\lambda_{\max }(\log \varepsilon) 341$ (3.381) nm; NMR data, see Table D3; HRESIMS $\mathrm{m} / \mathrm{z}$ $311.1167[\mathrm{M}+\mathrm{H}]^{+}$(calcd. for $\mathrm{C}_{15} \mathrm{H}_{20} \mathrm{ClN}_{2} \mathrm{O}_{3}, 311.1157$ ).

Pyrronazol C2 (5) 1-\{2-[(1Z)-1-(5-chloro-1H-pyrrol-2-yl)prop-1-en-2-yl]-1,3-oxazol-4-yl\}2-methylbutane-1,3-diol: $\mathrm{C}_{15} \mathrm{H}_{19} \mathrm{ClN}_{2} \mathrm{O}_{3} \mathrm{M}=310.78$; HPLC System $\mathrm{A}: R_{\mathrm{t}} 11.85 \mathrm{~min}$; $a^{22}{ }_{D}$ UV (MeOH): $\lambda_{\max }(\log \varepsilon) 349$ (3.851) nm; NMR data, see Table D3; HRESIMS m/z $311.1158[\mathrm{M}+\mathrm{H}]^{+}$(calcd. for $\mathrm{C}_{15} \mathrm{H}_{20} \mathrm{ClN}_{2} \mathrm{O}_{3}, 311.1157$ ).

1,6-Phenazine-diol (6): HPLC System A: $R_{\mathrm{t}} 7.3 \mathrm{~min}$, UV $\lambda_{\max } 271,373,442 \mathrm{~nm} ;{ }^{1} \mathrm{H}$ NMR (400 MHz, DMSO-d $)$ ס $10.48(2 \mathrm{H}$, br. s., OH), $7.76(2 \mathrm{H}, \mathrm{dd}, \mathrm{J}=8.6 \mathrm{~Hz}, \mathrm{~J}=7.1$ $\mathrm{Hz}, \mathrm{CH}), 7.72(2 \mathrm{H}, \mathrm{dd}, \mathrm{J}=8.6 \mathrm{~Hz}, \mathrm{~J}=1.5 \mathrm{~Hz}, \mathrm{CH}), 7.19(2 \mathrm{H}, \mathrm{dd}, \mathrm{J}=6.9 \mathrm{~Hz}, \mathrm{~J}=1.8 \mathrm{~Hz}$, $\mathrm{CH}) ;{ }^{13} \mathrm{C}$ NMR (101 MHz, DMSO- $\left.d_{6}\right) \delta 110.52(\mathrm{CH}), 119.12(\mathrm{CH}), 131.27(\mathrm{CH}), 135.66$, 142.06, 153.37; HRESIMS $\mathrm{m} / \mathrm{z} 213.0662[\mathrm{M}+\mathrm{H}]^{+}$(calcd. for $\mathrm{C}_{12} \mathrm{H}_{8} \mathrm{~N}_{2} \mathrm{O}_{2}$, 213.0659).

1-Hydroxy-phenazine-6-yl- $\alpha$-D-arabinofuranoside (7): $\mathrm{C}_{17} \mathrm{H}_{16} \mathrm{~N}_{2} \mathrm{O}_{6} \quad \mathrm{M}=344.32$; HPLC System A: $R_{\mathrm{t}} 5.47 \mathrm{~min}$; UV (MeOH): $\lambda_{\max }(\log \varepsilon) 270$ (4.698), 371 (3.496), 436 (3.232) nm; NMR data, see Table DS6; HRESIMS $\mathrm{m} / z 345.1081[\mathrm{M}+\mathrm{H}]^{+}$(calcd. for $\mathrm{C}_{17} \mathrm{H}_{17} \mathrm{~N}_{2} \mathrm{O}_{6}, \quad 345.1081$ ), $\mathrm{m} / z \quad 213.0659 \quad\left[\mathrm{M}+\mathrm{H}-\mathrm{C}_{5} \mathrm{H}_{8} \mathrm{O}_{4}\right]^{+}$(calcd. for $\mathrm{C}_{12} \mathrm{H}_{9} \mathrm{~N}_{2} \mathrm{O}_{2}$, 213.0659).

\section{D.4.6. Antimicrobial Testing}

$20 \mu \mathrm{l}$ aliquots (conc. $1 \mathrm{mg} / \mathrm{mL}$ ) of compound 1, 6,7 and reference drugs (streptomycin against bacteria and nystatin against yeast and fungi) were tested against 5 bacteria (Chromobacterium violaceum, Nocardia sp., Paenibacillus polymyxa, Mycobacterium sp., Mycobacterium diernhoferi), fungi (Mucor hiemalis, Aspergillus fumigatus), and two yeasts (Pichia anomala (recently the name $P$. a. was changed to Wickerhamomyces anomalus). The MIC values were determined in 96 well microtitre plates by $1: 1$ serial dilution in EBS medium ( $0.5 \%$ casein peptone, $0.5 \%$ protease peptone, $0.1 \%$ meat extract, $0.1 \%$ yeast extract, $\mathrm{pH} 7.0$ ) for bacteria and MYC medium (1.0\% glucose, 1.0 $\%$ phytone peptone, $50 \mathrm{mM}$ HEPES [11.9 $\mathrm{g} / \mathrm{L}$ ], $\mathrm{pH}$ 7.0) for yeasts and fungi, as 
previously described (Okanya et al., 2011). The test organisms were cultivated at $30^{\circ} \mathrm{C}$ and $160 \mathrm{rpm}$ for 24-48 hrs and the cell concentration adjusted to $\mathrm{OD}_{600} 0.01$ for bacteria and $\mathrm{OD}_{548} 0.1$ for yeasts before the test. The lowest concentration of the drug preventing visible growth of the test organism was taken as the MIC.

\section{D.4.7. Cytotoxicity assay}

In-vitro cytotoxicity $\left(\mathrm{IC}_{50}\right)$ was determined for compound $\mathbf{1}$ and $\mathbf{6}$ against a number of mammalian cell lines including the mouse fibroblast cell line L929, the cervix carcinoma cell line KB-3-1, non-transformed human umbilical vein endothelial cell line HUVEC, human ovarian carcinoma cell line SKOV3, adenocarcinomic human alveolar basal epithelial cell A549. KB-3-1, A549 and L929 were cultured in DMEM (Lonza), HUVEC was cultured in EBM-2 (Lonza) and SKOV3 was cultured in McCoy's (Lonza) media, all supplemented with $10 \%$ of fetal bovine serum (Gibco) and incubated under $10 \% \mathrm{CO} 2$ at $37{ }^{\circ} \mathrm{C}$. The MTT (2-(4,5-dimethylthiazol-2-yl)-2,5-di phenyltetrazolium bromide) method was used for the cytotoxicity assay on 96 well microplates as described previously. Methanol was used as negative control.

\section{Acknowledgements}

S. S. is highly indebted to Erasmus Mundus External Cooperation Window for a PhD scholarship and all their support. We thank C. Kakoschke for measuring the NMR spectra, Dr. M. Nimtz for GC-MS analysis, W. Kessler and his team for large-scale fermentation, and K. Schober, A. Teichmann, D. Telkemeyer, and W. Collisi for technical assistance. 


\section{References}

Agrawal, P. K. (1992) Phytochemistry 31, 3307-3330

Alonso, A. M., Horcajada, R. H., Groombridge, J., Chudasama, R., Motavali, M., Utley, J. H. P., and Wyatt, P. B. ('H NMR) (2005) Org. Biomol. Chem. 3, 2832-2841

Bode, H. B., and Müller, R. (2007) Myxobacteria: Multicellularity and Differentiation; ASM Press:

Washington, DC, 259-282

Bouhired, S. M. (2012) Biosynthesis of Phenylnannolone A, a MDR Reversal Agent from Nannocystis pusilla; Rheinischen Friedrich-Wilhems-Universität Bonn, Bonn, 2012

[hss.ulb.unibonn.de/2013/3127/3127.pdf]

Breitmaier, E., and Hollstein, U. $\left({ }^{13}\right.$ C NMR)(1976) J. Org. Chem. 41, 2104-2108

Bubb, W. A. (2003) Concepts Magn. Reson. A 19, 1-19

Gerber, N. N., and Lechevalier, M. P. (1965) Biochemistry 4, 176-180

Gerth, K., Trowitzsch, W., Wray, V., Höfle, G., Irschik, H., and Reichenbach, H. (1982) J. Antibiot. 35, $1101-1103$

Gerwig, G. J., Kamerling, J. P., and Vliegenthart J.F.G. (1078) Carbohydr. Res. 62, 349-357

Kaneda, M., Akamura, S., Ezaki, N., and litaka, Y. (1981) J. Antibiot. 34, 1366-1368

Kohl, W., Gloe, A., and Reichenbach, H. (1983) J. Gen. Microbiol. 129, 1629-1635

Kunze, B., Trowitzsch-Kinast, W., Höfle, G., and Reichebach, H. (1992) J. Antibiot. 45, 147-150

Ohlendorf, B., Leyers, S., Krick, A., Kehraus, S., Wiese, M., and König, G.M. (2008) ChemBioChem 9, 2997-3003

Okanya, P.W., Mohr, K.I., Gerth, K., Jansen, R., and Müller, R. (2011) J. Nat. Prod. 74, 603-608

Podojil, M., and Gerber, N. N. (1967) Biochemistry 6, 2701-2705

Reichenbach, H., and Höfle, G. in Drug Discovery from Nature (Eds. Grabley, S.; Thierecke, R.), Springer, Heidelberg, 2000, p. 173.

Rudi, A., Stein, Z., Green, S., Goldberg, I., Kashman, Y., Benayahu, Y., and Schleyer, M. (1994) Tetrahedron. Lett. 35, 2589-2592

Sheldrick, G. M. (2008) Acta Cryst. A64, 112-122

Takeda, R. (1958) J. Am. Chem. Soc. 80, 4749-4750

Trowitzsch, W., Witte, L., and Reichenbach, H. (1981) FEMS Microbiol. Lett. 12, 257-260

Tsujibo H., Sato T., Inui M., Yamamoto H., and Inamori Y. (1988) Agric. Biol. Chem. 52, 301-306

Wenzel, S.C., and Müller, R. (2009) Curr. Opin. Drug Discov. \& Devel. 12, 220-230 


\section{Supplemental information}

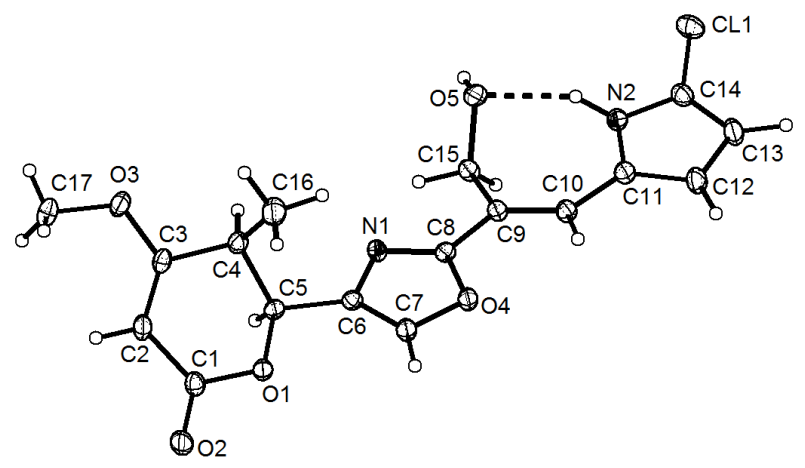

Figure DS1. ORTEP presentation of the X-ray analysis of Pyrronazol A1 (1)

Table DS1. Crystal data and structure refinement for Pyrronazol A1 (1)

\begin{tabular}{|c|c|}
\hline Identification code & $\operatorname{sh} 3288$ \\
\hline Empirical formula & $\mathrm{C} 17 \mathrm{H} 17 \mathrm{Cl}$ N2 O5 \\
\hline Formula weight & 364.78 \\
\hline Temperature & $132(2) \mathrm{K}$ \\
\hline Wavelength & $0.71073 \AA$ \\
\hline Crystal system & Monoclinic \\
\hline Space group & $\mathrm{P} 2(1)$ \\
\hline Unit cell dimensions & $\begin{array}{ll}\mathrm{a}=7.6925(7) \AA & \alpha=90^{\circ} \\
\mathrm{b}=10.9091(8) \AA & \beta=90.238(5)^{\circ} \\
\mathrm{c}=10.2880(8) \AA & \gamma=90^{\circ}\end{array}$ \\
\hline Volume & $863.34(12) \AA^{3}$ \\
\hline $\mathrm{Z}$ & 2 \\
\hline Density (calculated) & $1.403 \mathrm{Mg} / \mathrm{m}^{3}$ \\
\hline Absorption coefficient & $0.252 \mathrm{~mm}^{-1}$ \\
\hline $\mathrm{F}(000)$ & 380 \\
\hline Crystal size & $1.13 \times 0.84 \times 0.32 \mathrm{~mm}^{3}$ \\
\hline Theta range for data collection & 1.98 to $32.92^{\circ}$ \\
\hline Index ranges & $-11<=\mathrm{h}<=6,-16<=\mathrm{k}<=16,-15<=1<=15$ \\
\hline Reflections collected & 9117 \\
\hline Independent reflections & $5584[\mathrm{R}(\mathrm{int})=0.0203]$ \\
\hline Completeness to theta $=32.92^{\circ}$ & $92.9 \%$ \\
\hline Absorption correction & Semi-empirical from equivalents \\
\hline Max. and min. transmission & 0.9229 and 0.7649 \\
\hline Refinement method & Full-matrix least-squares on $\mathrm{F}^{2}$ \\
\hline Data / restraints / parameters & $5584 / 66 / 294$ \\
\hline Goodness-of-fit on $\mathrm{F}^{2}$ & 1.009 \\
\hline Final $R$ indices $[I>2 \operatorname{sigma}(I)]$ & $\mathrm{R} 1=0.0346, \mathrm{wR} 2=0.0841$ \\
\hline $\mathrm{R}$ indices (all data) & $\mathrm{R} 1=0.0393, \mathrm{wR} 2=0.0875$ \\
\hline Absolute structure parameter & $0.00(4)$ \\
\hline Largest diff. peak and hole & 0.438 and -0.412 e. $\AA^{-3}$ \\
\hline
\end{tabular}


Table DS2. Atomic Coordinates $\left(\times 10^{4}\right)$ and Equivalent Isotropic Displacement Parameters $\left(\AA^{2} \times 10^{3}\right)$ for Pyrronazol A1 (1). $\mathrm{U}(\mathrm{eq})$ is defined as one third of the trace of the orthogonalized $\mathrm{U}^{\mathrm{ij}}$ tensor.

\begin{tabular}{|c|c|c|c|c|}
\hline & $x$ & $\mathrm{y}$ & $z$ & U(eq) \\
\hline $\mathrm{Cl}(1)$ & $-294(1)$ & $5373(1)$ & $1719(1)$ & $24(1)$ \\
\hline $\mathrm{O}(1)$ & 13021(1) & $7434(1)$ & $6425(1)$ & $17(1)$ \\
\hline $\mathrm{O}(2)$ & $15685(1)$ & $7783(1)$ & $7123(1)$ & $23(1)$ \\
\hline $\mathrm{O}(3)$ & $12371(2)$ & $4636(1)$ & $9087(1)$ & $22(1)$ \\
\hline $\mathrm{O}(4)$ & $8339(1)$ & $8248(1)$ & $4529(1)$ & $17(1)$ \\
\hline $\mathrm{O}(5)$ & $4504(1)$ & $4925(1)$ & $4266(1)$ & $18(1)$ \\
\hline $\mathrm{N}(1)$ & $8965(2)$ & $6303(1)$ & 4989(1) & $15(1)$ \\
\hline $\mathrm{N}(2)$ & $2599(2)$ & $6376(1)$ & $2658(1)$ & $16(1)$ \\
\hline $\mathrm{C}(1)$ & $14397(2)$ & $7130(1)$ & $7177(1)$ & $18(1)$ \\
\hline $\mathrm{C}(2)$ & $14250(2)$ & $6084(1)$ & $8048(1)$ & $19(1)$ \\
\hline$C(3)$ & $12714(2)$ & $5527(1)$ & $8227(1)$ & $16(1)$ \\
\hline$C(4)$ & $11130(2)$ & $5904(1)$ & $7474(1)$ & $17(1)$ \\
\hline$C(5)$ & $11739(2)$ & $6482(1)$ & $6195(1)$ & $14(1)$ \\
\hline$C(6)$ & $10280(2)$ & $7050(1)$ & $5456(1)$ & $14(1)$ \\
\hline$C(7)$ & $9911(2)$ & $8233(1)$ & $5181(1)$ & $17(1)$ \\
\hline $\mathrm{C}(8)$ & $7854(2)$ & $7053(1)$ & $4451(1)$ & $14(1)$ \\
\hline $\mathrm{C}(9)$ & $6227(2)$ & $6737(1)$ & $3814(1)$ & $14(1)$ \\
\hline$C(10)$ & $5098(2)$ & $7626(1)$ & $3450(1)$ & $16(1)$ \\
\hline $\mathrm{C}(11)$ & $3436(2)$ & $7484(1)$ & $2820(1)$ & $16(1)$ \\
\hline$C(12)$ & $2389(2)$ & $8376(1)$ & $2261(2)$ & $22(1)$ \\
\hline$C(13)$ & $895(2)$ & $7800(1)$ & $1747(2)$ & $22(1)$ \\
\hline $\mathrm{C}(14)$ & $1075(2)$ & $6578(1)$ & $2035(1)$ & $18(1)$ \\
\hline$C(15)$ & $5969(2)$ & $5387(1)$ & $3556(1)$ & $16(1)$ \\
\hline$C(16)$ & $9968(2)$ & $6739(2)$ & $8293(1)$ & $26(1)$ \\
\hline$C(17)$ & $13732(2)$ & $4272(2)$ & $9966(2)$ & $28(1)$ \\
\hline
\end{tabular}

Table DS3. Bond lengths [Å] and angles [ $]$ for Pyrr onazol A1 (1)

\begin{tabular}{lc}
\hline $\mathrm{Cl}(1)-\mathrm{C}(14)$ & $1.7149(14)$ \\
$\mathrm{O}(1)-\mathrm{C}(1)$ & $1.3496(15)$ \\
$\mathrm{O}(1)-\mathrm{C}(5)$ & $1.4516(15)$ \\
$\mathrm{O}(2)-\mathrm{C}(1)$ & $1.2218(17)$ \\
$\mathrm{O}(3)-\mathrm{C}(3)$ & $1.3415(16)$ \\
$\mathrm{O}(3)-\mathrm{C}(17)$ & $1.4357(18)$ \\
$\mathrm{O}(4)-\mathrm{C}(8)$ & $1.3592(15)$ \\
$\mathrm{O}(4)-\mathrm{C}(7)$ & $1.3805(17)$ \\
$\mathrm{O}(5)-\mathrm{C}(15)$ & $1.4363(17)$ \\
$\mathrm{O}(5)-\mathrm{H}(11)$ & $0.79(3)$ \\
$\mathrm{N}(1)-\mathrm{C}(8)$ & $1.3044(16)$ \\
$\mathrm{N}(1)-\mathrm{C}(6)$ & $1.3840(16)$ \\
$\mathrm{N}(2)-\mathrm{C}(14)$ & $1.3524(17)$
\end{tabular}




\begin{tabular}{|c|c|}
\hline $\mathrm{N}(2)-\mathrm{C}(11)$ & $1.3796(17)$ \\
\hline $\mathrm{N}(2)-\mathrm{H}(8)$ & $0.92(2)$ \\
\hline $\mathrm{C}(1)-\mathrm{C}(2)$ & $1.4554(19)$ \\
\hline $\mathrm{C}(2)-\mathrm{C}(3)$ & $1.3425(19)$ \\
\hline $\mathrm{C}(2)-\mathrm{H}(1)$ & $0.945(19)$ \\
\hline$C(3)-C(4)$ & $1.4991(18)$ \\
\hline$C(4)-C(16)$ & $1.531(2)$ \\
\hline $\mathrm{C}(4)-\mathrm{C}(5)$ & $1.5338(18)$ \\
\hline $\mathrm{C}(4)-\mathrm{H}(2)$ & $0.99(2)$ \\
\hline$C(5)-C(6)$ & $1.4891(17)$ \\
\hline $\mathrm{C}(5)-\mathrm{H}(3)$ & $0.928(18)$ \\
\hline$C(6)-C(7)$ & $1.3501(17)$ \\
\hline $\mathrm{C}(7)-\mathrm{H}(4)$ & $0.95(2)$ \\
\hline$C(8)-C(9)$ & $1.4519(18)$ \\
\hline $\mathrm{C}(9)-\mathrm{C}(10)$ & $1.3535(18)$ \\
\hline$C(9)-C(15)$ & $1.5094(18)$ \\
\hline $\mathrm{C}(10)-\mathrm{C}(11)$ & $1.4396(18)$ \\
\hline $\mathrm{C}(10)-\mathrm{H}(5)$ & $0.94(2)$ \\
\hline $\mathrm{C}(11)-\mathrm{C}(12)$ & $1.3858(19)$ \\
\hline $\mathrm{C}(12)-\mathrm{C}(13)$ & $1.410(2)$ \\
\hline $\mathrm{C}(12)-\mathrm{H}(6)$ & $0.95(2)$ \\
\hline $\mathrm{C}(13)-\mathrm{C}(14)$ & $1.373(2)$ \\
\hline $\mathrm{C}(13)-\mathrm{H}(7)$ & $1.01(2)$ \\
\hline $\mathrm{C}(15)-\mathrm{H}(9)$ & $0.983(16)$ \\
\hline $\mathrm{C}(15)-\mathrm{H}(10)$ & $0.981(19)$ \\
\hline $\mathrm{C}(16)-\mathrm{H}(12)$ & $1.00(2)$ \\
\hline $\mathrm{C}(16)-\mathrm{H}(13)$ & $0.90(3)$ \\
\hline $\mathrm{C}(16)-\mathrm{H}(14)$ & $0.97(2)$ \\
\hline $\mathrm{C}(17)-\mathrm{H}(15)$ & $0.92(2)$ \\
\hline $\mathrm{C}(17)-\mathrm{H}(16)$ & $0.86(2)$ \\
\hline $\mathrm{C}(17)-\mathrm{H}(17)$ & $1.00(2)$ \\
\hline $\mathrm{C}(1)-\mathrm{O}(1)-\mathrm{C}(5)$ & $116.60(10)$ \\
\hline $\mathrm{C}(3)-\mathrm{O}(3)-\mathrm{C}(17)$ & $118.08(13)$ \\
\hline $\mathrm{C}(8)-\mathrm{O}(4)-\mathrm{C}(7)$ & $104.84(10)$ \\
\hline $\mathrm{C}(15)-\mathrm{O}(5)-\mathrm{H}(11)$ & $106(2)$ \\
\hline $\mathrm{C}(8)-\mathrm{N}(1)-\mathrm{C}(6)$ & $104.71(10)$ \\
\hline$C(14)-N(2)-C(11)$ & $108.48(11)$ \\
\hline $\mathrm{C}(14)-\mathrm{N}(2)-\mathrm{H}(8)$ & $125.9(14)$ \\
\hline $\mathrm{C}(11)-\mathrm{N}(2)-\mathrm{H}(8)$ & $123.5(14)$ \\
\hline $\mathrm{O}(2)-\mathrm{C}(1)-\mathrm{O}(1)$ & $117.66(12)$ \\
\hline $\mathrm{O}(2)-\mathrm{C}(1)-\mathrm{C}(2)$ & $123.38(12)$ \\
\hline $\mathrm{O}(1)-\mathrm{C}(1)-\mathrm{C}(2)$ & $118.90(12)$ \\
\hline$C(3)-C(2)-C(1)$ & $120.66(12)$ \\
\hline $\mathrm{C}(3)-\mathrm{C}(2)-\mathrm{H}(1)$ & $121.7(13)$ \\
\hline $\mathrm{C}(1)-\mathrm{C}(2)-\mathrm{H}(1)$ & $116.9(13)$ \\
\hline $\mathrm{O}(3)-\mathrm{C}(3)-\mathrm{C}(2)$ & $126.46(12)$ \\
\hline $\mathrm{O}(3)-\mathrm{C}(3)-\mathrm{C}(4)$ & $112.23(12)$ \\
\hline $\mathrm{C}(2)-\mathrm{C}(3)-\mathrm{C}(4)$ & $121.27(12)$ \\
\hline
\end{tabular}




\begin{tabular}{|c|c|}
\hline$C(3)-C(4)-C(16)$ & $110.77(11)$ \\
\hline$C(3)-C(4)-C(5)$ & $107.78(11)$ \\
\hline$C(16)-C(4)-C(5)$ & $114.13(11)$ \\
\hline $\mathrm{C}(3)-\mathrm{C}(4)-\mathrm{H}(2)$ & $107.2(12)$ \\
\hline $\mathrm{C}(16)-\mathrm{C}(4)-\mathrm{H}(2)$ & $112.5(12)$ \\
\hline $\mathrm{C}(5)-\mathrm{C}(4)-\mathrm{H}(2)$ & $104.0(11)$ \\
\hline $\mathrm{O}(1)-\mathrm{C}(5)-\mathrm{C}(6)$ & $107.18(10)$ \\
\hline $\mathrm{O}(1)-\mathrm{C}(5)-\mathrm{C}(4)$ & $111.36(10)$ \\
\hline$C(6)-C(5)-C(4)$ & $112.16(11)$ \\
\hline $\mathrm{O}(1)-\mathrm{C}(5)-\mathrm{H}(3)$ & $107.6(12)$ \\
\hline $\mathrm{C}(6)-\mathrm{C}(5)-\mathrm{H}(3)$ & $109.1(11)$ \\
\hline $\mathrm{C}(4)-\mathrm{C}(5)-\mathrm{H}(3)$ & $109.2(11)$ \\
\hline $\mathrm{C}(7)-\mathrm{C}(6)-\mathrm{N}(1)$ & $109.75(11)$ \\
\hline$C(7)-C(6)-C(5)$ & $131.46(12)$ \\
\hline $\mathrm{N}(1)-\mathrm{C}(6)-\mathrm{C}(5)$ & $118.70(10)$ \\
\hline $\mathrm{C}(6)-\mathrm{C}(7)-\mathrm{O}(4)$ & $107.25(11)$ \\
\hline $\mathrm{C}(6)-\mathrm{C}(7)-\mathrm{H}(4)$ & $139.8(12)$ \\
\hline $\mathrm{O}(4)-\mathrm{C}(7)-\mathrm{H}(4)$ & $112.9(12)$ \\
\hline $\mathrm{N}(1)-\mathrm{C}(8)-\mathrm{O}(4)$ & $113.45(11)$ \\
\hline $\mathrm{N}(1)-\mathrm{C}(8)-\mathrm{C}(9)$ & $127.19(11)$ \\
\hline $\mathrm{O}(4)-\mathrm{C}(8)-\mathrm{C}(9)$ & $119.36(11)$ \\
\hline $\mathrm{C}(10)-\mathrm{C}(9)-\mathrm{C}(8)$ & $120.40(11)$ \\
\hline$C(10)-C(9)-C(15)$ & $124.49(11)$ \\
\hline $\mathrm{C}(8)-\mathrm{C}(9)-\mathrm{C}(15)$ & $115.06(10)$ \\
\hline$C(9)-C(10)-C(11)$ & $128.01(12)$ \\
\hline $\mathrm{C}(9)-\mathrm{C}(10)-\mathrm{H}(5)$ & $116.9(12)$ \\
\hline $\mathrm{C}(11)-\mathrm{C}(10)-\mathrm{H}(5)$ & $115.1(12)$ \\
\hline $\mathrm{N}(2)-\mathrm{C}(11)-\mathrm{C}(12)$ & $107.19(12)$ \\
\hline $\mathrm{N}(2)-\mathrm{C}(11)-\mathrm{C}(10)$ & $124.12(12)$ \\
\hline$C(12)-C(11)-C(10)$ & $128.69(13)$ \\
\hline $\mathrm{C}(11)-\mathrm{C}(12)-\mathrm{C}(13)$ & $108.31(13)$ \\
\hline $\mathrm{C}(11)-\mathrm{C}(12)-\mathrm{H}(6)$ & $125.2(13)$ \\
\hline $\mathrm{C}(13)-\mathrm{C}(12)-\mathrm{H}(6)$ & $126.5(13)$ \\
\hline $\mathrm{C}(14)-\mathrm{C}(13)-\mathrm{C}(12)$ & $105.70(12)$ \\
\hline $\mathrm{C}(14)-\mathrm{C}(13)-\mathrm{H}(7)$ & $122.8(12)$ \\
\hline $\mathrm{C}(12)-\mathrm{C}(13)-\mathrm{H}(7)$ & $131.3(12)$ \\
\hline $\mathrm{N}(2)-\mathrm{C}(14)-\mathrm{C}(13)$ & $110.30(12)$ \\
\hline $\mathrm{N}(2)-\mathrm{C}(14)-\mathrm{Cl}(1)$ & $119.69(10)$ \\
\hline $\mathrm{C}(13)-\mathrm{C}(14)-\mathrm{Cl}(1)$ & $130.01(11)$ \\
\hline $\mathrm{O}(5)-\mathrm{C}(15)-\mathrm{C}(9)$ & $110.80(11)$ \\
\hline $\mathrm{O}(5)-\mathrm{C}(15)-\mathrm{H}(9)$ & $110.2(11)$ \\
\hline $\mathrm{C}(9)-\mathrm{C}(15)-\mathrm{H}(9)$ & $108.2(12)$ \\
\hline $\mathrm{O}(5)-\mathrm{C}(15)-\mathrm{H}(10)$ & $109.3(11)$ \\
\hline $\mathrm{C}(9)-\mathrm{C}(15)-\mathrm{H}(10)$ & $108.8(11)$ \\
\hline $\mathrm{H}(9)-\mathrm{C}(15)-\mathrm{H}(10)$ & $109.4(15)$ \\
\hline $\mathrm{C}(4)-\mathrm{C}(16)-\mathrm{H}(12)$ & $111.3(14)$ \\
\hline $\mathrm{C}(4)-\mathrm{C}(16)-\mathrm{H}(13)$ & 110.1(19) \\
\hline $\mathrm{H}(12)-\mathrm{C}(16)-\mathrm{H}(13)$ & $107(2)$ \\
\hline
\end{tabular}




\begin{tabular}{lc}
$\mathrm{C}(4)-\mathrm{C}(16)-\mathrm{H}(14)$ & $108.5(15)$ \\
$\mathrm{H}(12)-\mathrm{C}(16)-\mathrm{H}(14)$ & $111(2)$ \\
$\mathrm{H}(13)-\mathrm{C}(16)-\mathrm{H}(14)$ & $109(2)$ \\
$\mathrm{O}(3)-\mathrm{C}(17)-\mathrm{H}(15)$ & $112.6(11)$ \\
$\mathrm{O}(3)-\mathrm{C}(17)-\mathrm{H}(16)$ & $105.3(13)$ \\
$\mathrm{H}(15)-\mathrm{C}(17)-\mathrm{H}(16)$ & $111.8(19)$ \\
$\mathrm{O}(3)-\mathrm{C}(17)-\mathrm{H}(17)$ & $111.4(12)$ \\
$\mathrm{H}(15)-\mathrm{C}(17)-\mathrm{H}(17)$ & $110.1(17)$ \\
$\mathrm{H}(16)-\mathrm{C}(17)-\mathrm{H}(17)$ & $105.3(17)$ \\
\hline
\end{tabular}

Table DS4. Anisotropic displacement parameters $\left(\AA^{2} \times 10^{3}\right)$ for Pyrronazol A1 (1). The anisotropic displacement factor exponent takes the form: $-2 \pi^{2}\left[h^{2} a^{\star 2} U^{11}+\ldots+2 h k a^{\star} b^{\star} U^{12}\right.$

\begin{tabular}{lcccccc}
\hline & $\mathrm{U}^{11}$ & $\mathrm{U}^{22}$ & $\mathrm{U}^{33}$ & $\mathrm{U}^{23}$ & $\mathrm{U}^{13}$ & $\mathrm{U}^{12}$ \\
\hline $\mathrm{Cl}(1)$ & $19(1)$ & $27(1)$ & $25(1)$ & $-3(1)$ & $-1(1)$ & $-7(1)$ \\
$\mathrm{O}(1)$ & $15(1)$ & $13(1)$ & $24(1)$ & $3(1)$ & $-5(1)$ & $-2(1)$ \\
$\mathrm{O}(2)$ & $18(1)$ & $18(1)$ & $34(1)$ & $4(1)$ & $-6(1)$ & $-4(1)$ \\
$\mathrm{O}(3)$ & $24(1)$ & $20(1)$ & $24(1)$ & $9(1)$ & $-5(1)$ & $-1(1)$ \\
$\mathrm{O}(4)$ & $16(1)$ & $11(1)$ & $24(1)$ & $1(1)$ & $-5(1)$ & $-1(1)$ \\
$\mathrm{O}(5)$ & $19(1)$ & $11(1)$ & $26(1)$ & $1(1)$ & $2(1)$ & $-1(1)$ \\
$\mathrm{N}(1)$ & $14(1)$ & $11(1)$ & $18(1)$ & $-1(1)$ & $-3(1)$ & $0(1)$ \\
$\mathrm{N}(2)$ & $14(1)$ & $15(1)$ & $21(1)$ & $0(1)$ & $-2(1)$ & $0(1)$ \\
$\mathrm{C}(1)$ & $16(1)$ & $14(1)$ & $22(1)$ & $0(1)$ & $-5(1)$ & $1(1)$ \\
$\mathrm{C}(2)$ & $18(1)$ & $16(1)$ & $22(1)$ & $2(1)$ & $-6(1)$ & $0(1)$ \\
$\mathrm{C}(3)$ & $20(1)$ & $12(1)$ & $18(1)$ & $1(1)$ & $-4(1)$ & $1(1)$ \\
$\mathrm{C}(4)$ & $17(1)$ & $15(1)$ & $18(1)$ & $2(1)$ & $-4(1)$ & $-1(1)$ \\
$\mathrm{C}(5)$ & $14(1)$ & $11(1)$ & $18(1)$ & $0(1)$ & $-2(1)$ & $-1(1)$ \\
$\mathrm{C}(6)$ & $14(1)$ & $12(1)$ & $16(1)$ & $-1(1)$ & $-1(1)$ & $0(1)$ \\
$\mathrm{C}(7)$ & $15(1)$ & $12(1)$ & $23(1)$ & $1(1)$ & $-4(1)$ & $-1(1)$ \\
$\mathrm{C}(8)$ & $14(1)$ & $9(1)$ & $18(1)$ & $-1(1)$ & $0(1)$ & $0(1)$ \\
$\mathrm{C}(9)$ & $13(1)$ & $12(1)$ & $18(1)$ & $-1(1)$ & $-2(1)$ & $0(1)$ \\
$\mathrm{C}(10)$ & $16(1)$ & $13(1)$ & $21(1)$ & $0(1)$ & $-2(1)$ & $1(1)$ \\
$\mathrm{C}(11)$ & $15(1)$ & $13(1)$ & $20(1)$ & $-1(1)$ & $-2(1)$ & $0(1)$ \\
$\mathrm{C}(12)$ & $18(1)$ & $17(1)$ & $30(1)$ & $2(1)$ & $-4(1)$ & $3(1)$ \\
$\mathrm{C}(13)$ & $16(1)$ & $23(1)$ & $26(1)$ & $2(1)$ & $-6(1)$ & $4(1)$ \\
$\mathrm{C}(14)$ & $14(1)$ & $21(1)$ & $18(1)$ & $-1(1)$ & $-2(1)$ & $-1(1)$ \\
$\mathrm{C}(15)$ & $13(1)$ & $12(1)$ & $23(1)$ & $-2(1)$ & $0(1)$ & $0(1)$ \\
$\mathrm{C}(16)$ & $25(1)$ & $33(1)$ & $20(1)$ & $3(1)$ & $3(1)$ & $9(1)$ \\
$\mathrm{C}(17)$ & $29(1)$ & $29(1)$ & $24(1)$ & $11(1)$ & $-5(1)$ & $4(1)$ \\
\hline & & & & & \\
\hline
\end{tabular}


Table DS5. Hydrogen coordinates $\left(\times 10^{4}\right)$ and isotropic displacement parameters $\left(\AA^{2} \times 10^{3}\right)$ for Pyrronazol A1 (1)

\begin{tabular}{lrrrr}
\hline & $\mathrm{x}$ & $\mathrm{y}$ & $\mathrm{z}$ & $\mathrm{U}(\mathrm{eq})$ \\
\hline $\mathrm{H}(1)$ & $15230(30)$ & $5902(18)$ & $8573(18)$ & $23(5)$ \\
$\mathrm{H}(2)$ & $10530(30)$ & $5140(20)$ & $7199(18)$ & $27(5)$ \\
$\mathrm{H}(3)$ & $12260(30)$ & $5884(16)$ & $5685(16)$ & $16(4)$ \\
$\mathrm{H}(4)$ & $10420(30)$ & $9020(20)$ & $5261(18)$ & $23(5)$ \\
$\mathrm{H}(5)$ & $5420(30)$ & $8441(19)$ & $3637(18)$ & $19(4)$ \\
$\mathrm{H}(6)$ & $2660(30)$ & $9230(20)$ & $2220(20)$ & $33(5)$ \\
$\mathrm{H}(7)$ & $-90(30)$ & $8130(19)$ & $1200(20)$ & $27(5)$ \\
$\mathrm{H}(8)$ & $2900(30)$ & $5680(20)$ & $3110(20)$ & $36(6)$ \\
$\mathrm{H}(9)$ & $5780(20)$ & $5275(18)$ & $2617(16)$ & $16(4)$ \\
$\mathrm{H}(10)$ & $7020(30)$ & $4944(17)$ & $3825(17)$ & $19(4)$ \\
$\mathrm{H}(11)$ & $4360(30)$ & $4240(20)$ & $4030(30)$ & $47(7)$ \\
$\mathrm{H}(12)$ & $8860(30)$ & $6930(20)$ & $7830(20)$ & $38(6)$ \\
$\mathrm{H}(13)$ & $10510(40)$ & $7450(30)$ & $8450(20)$ & $52(8)$ \\
$\mathrm{H}(14)$ & $9740(30)$ & $6330(20)$ & $9120(20)$ & $35(5)$ \\
$\mathrm{H}(15)$ & $14650(30)$ & $3912(19)$ & $9548(17)$ & $21(5)$ \\
$\mathrm{H}(16)$ & $13250(30)$ & $3780(18)$ & $10506(18)$ & $18(4)$ \\
$\mathrm{H}(17)$ & $14150(30)$ & $4980(19)$ & $10501(19)$ & $27(5)$ \\
\hline
\end{tabular}

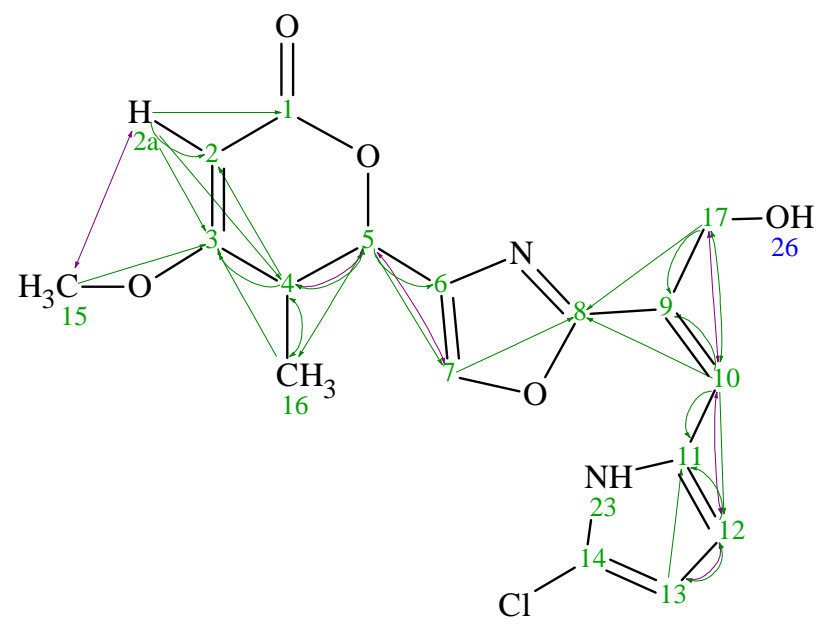

Figure DS2. HMBC-correlations of Pyrronazol A2 (2) 


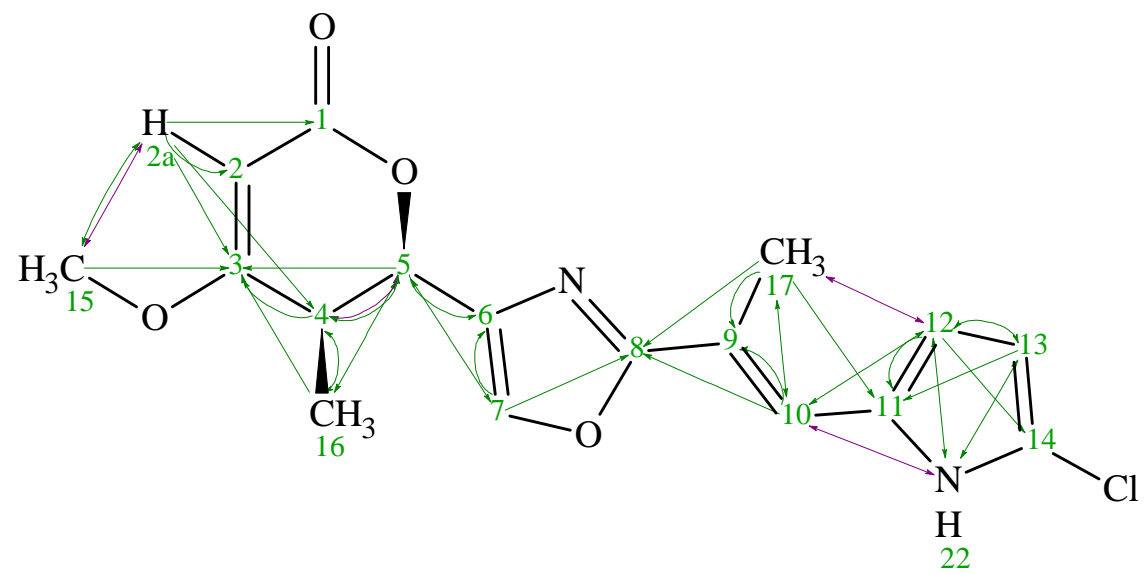

Figure DS3. HMBC-correlations of Pyrronazol B (3)

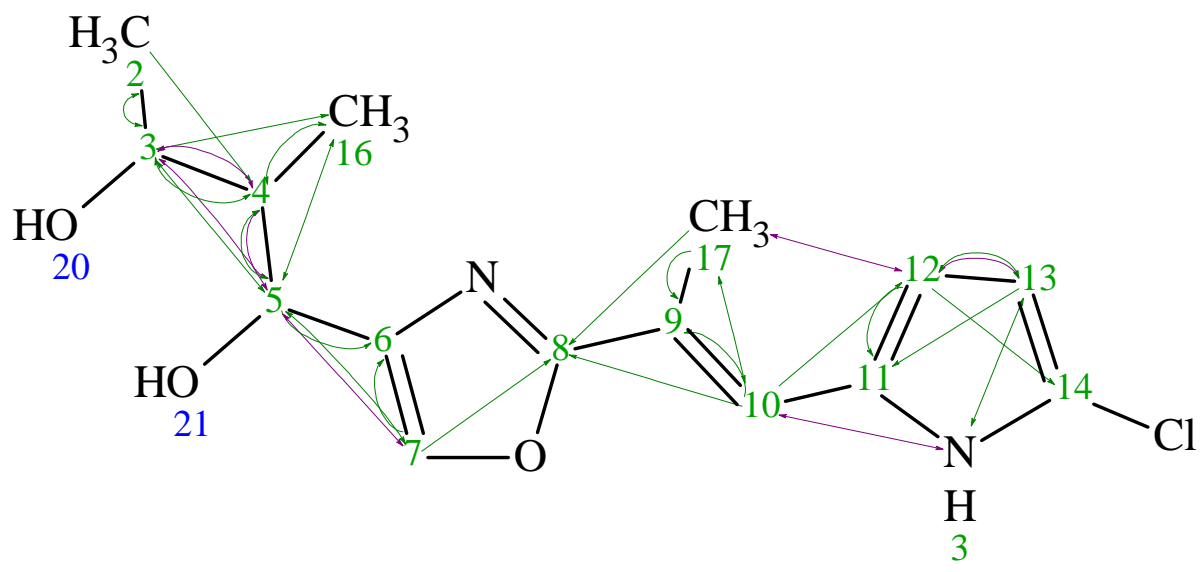

Figure DS4. HMBC-correlations of Pyrronazol C1 (4)

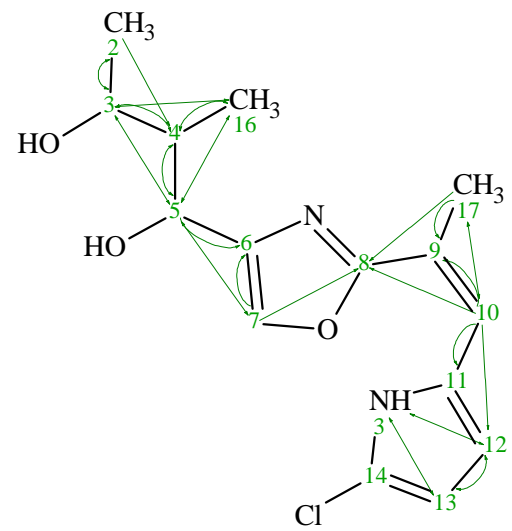

Figure DS5. HMBC-correlations of Pyrronazol C2 (5) 


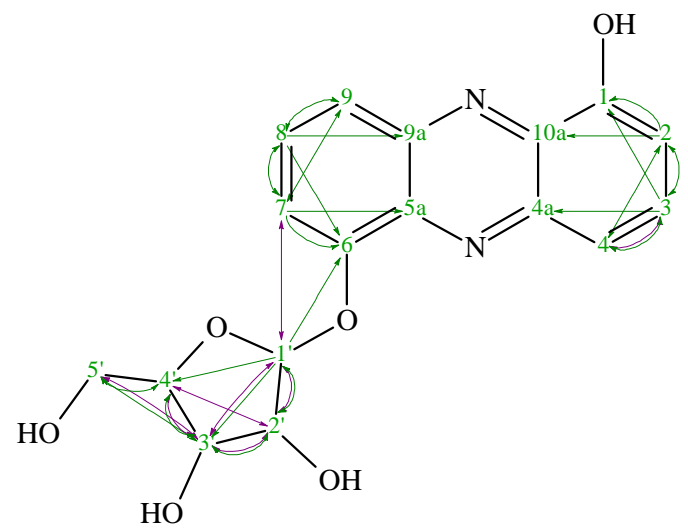

Figure DS6. HMBC- (green) and ROESY (violet) correlations of 1,6-Phenazine-diol- $\alpha$-D-arabinofuranoside (7)

Table DS6. NMR Data of 1,6-Phenazine-diol-a-D-arabinofuranoside (7) in $\mathrm{CD}_{3} \mathrm{OD}\left[{ }^{1} \mathrm{H} 600 \mathrm{MHz}\right.$; $\left.{ }^{13} \mathrm{C} 100 \mathrm{MHz}\right]$

\begin{tabular}{|c|c|c|c|c|c|c|c|}
\hline Pos. & $\delta_{\mathrm{H}}$ & $\mathrm{H}$ & $J[\mathrm{~Hz}]$ & ROESY & $\delta_{\mathrm{C}}$ & $\mathrm{m}$ & $\mathrm{H}$ in $\mathrm{HMBC}$ \\
\hline 1 & & & & & 154.73 & $\mathrm{C}$ & 2,3 \\
\hline $10 a$ & & & & & 137.45 & $\mathrm{C}$ & 2 \\
\hline 2 & 7.22 & br. d & 6.2 & & 111.69 & $\mathrm{CH}$ & \\
\hline 3 & 7.80 & $\mathrm{~m}$ & & 4 & 133.51 & $\mathrm{CH}$ & \\
\hline 4 & 7.78 & $\mathrm{~m}$ & & 3 & 120.10 & $\mathrm{CH}$ & 2 \\
\hline $4 a$ & & & & & 144.14 & $\mathrm{C}$ & 3 \\
\hline $5 a$ & & & & & 138.48 & $\mathrm{C}$ & 7 \\
\hline 6 & & & & & 152.94 & $\mathrm{C}$ & $1^{\prime}, 7,8$ \\
\hline 7 & 7.57 & br. d & 7.3 & 1 ' & 115.07 & $\mathrm{CH}$ & 9 \\
\hline 8 & 7.82 & $\mathrm{~m}$ & & & 131.60 & $\mathrm{CH}$ & \\
\hline 9 & 8.01 & br. d & 7.7 & & 124.10 & $\mathrm{CH}$ & 7 \\
\hline $9 a$ & & & & & 143.91 & $\mathrm{C}$ & 8 \\
\hline $1^{\prime}$ & 5.95 & br. s & & $3^{\prime}, 2^{\prime}, 7$ & 109.09 & $\mathrm{CH}$ & \\
\hline $2^{\prime}$ & 4.65 & dd & $3.3,1.1$ & $3^{\prime}, 4^{\prime}, 1^{\prime}$ & 83.09 & $\mathrm{CH}$ & 3 ' \\
\hline $3^{\prime}$ & 4.08 & dd & $5.5,3.3$ & $5^{\prime} \mathrm{ab}, 4^{\prime}, 1^{\prime}, 2^{\prime}$ & 78.90 & $\mathrm{CH}$ & $5^{\prime} \mathrm{ab}, 4^{\prime}, 2^{\prime}, 1^{\prime}$ \\
\hline $4^{\prime}$ & 4.18 & $\mathrm{td}$ & $5.2,3.5$ & $3^{\prime}, 2^{\prime}$ & 87.84 & $\mathrm{CH}$ & $5^{\prime} \mathrm{b}, 1^{\prime}$ \\
\hline $5^{\prime} \mathrm{a}$ & 3.78 & dd & $12.1,3.3$ & $5^{\prime} \mathrm{b}, 3^{\prime}$ & & & 3 \\
\hline $5 ' b$ & 3.70 & dd & $12.1,5.5$ & $5^{\prime} \mathrm{a}, 3^{\prime}$ & 63.05 & $\mathrm{CH}_{2}$ & $3^{\prime}$ \\
\hline
\end{tabular}




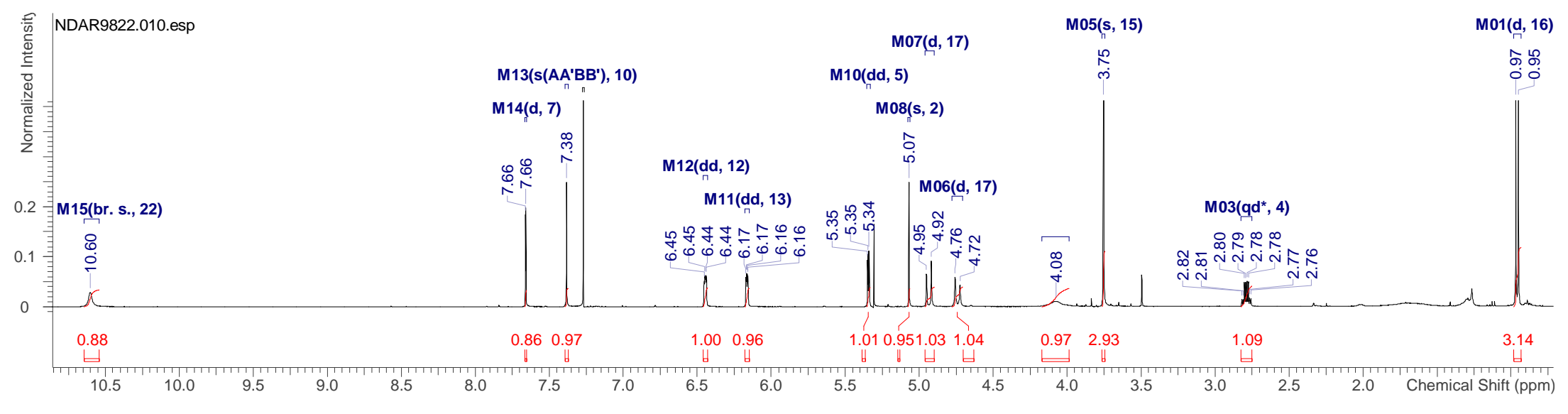

Figure DS7. ${ }^{1} \mathrm{H}$ NMR spectrum of Pyrronazol A (1) in $\mathrm{CDCl}_{3}(400 \mathrm{MHz})$

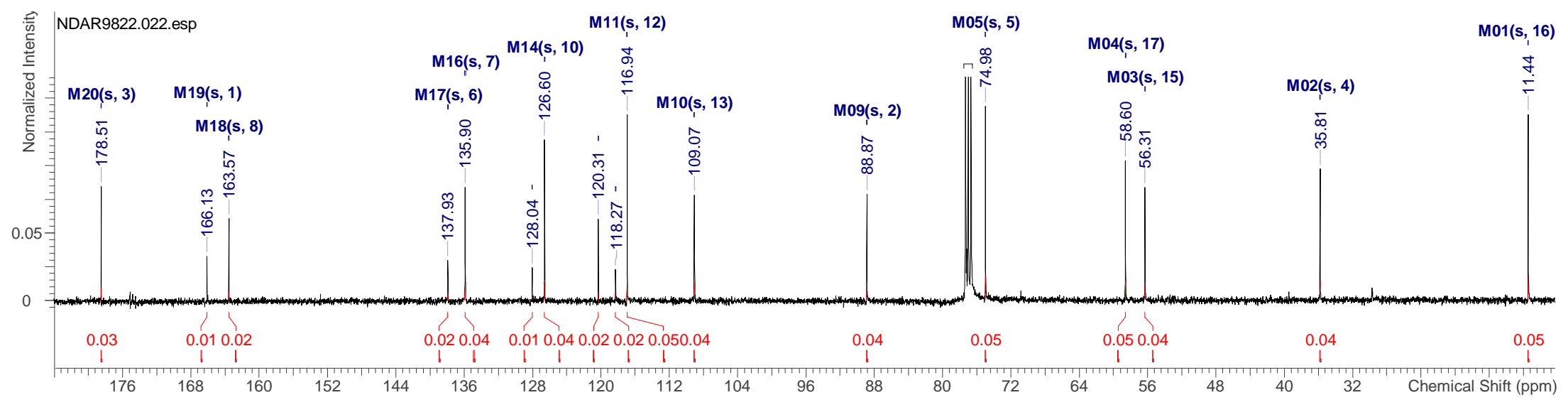

Figure DS8. ${ }^{13} \mathrm{C}$ NMR spectrum of Pyrronazol A (1) in $\mathrm{CDCl}_{3}(100.6 \mathrm{MHz})$ 


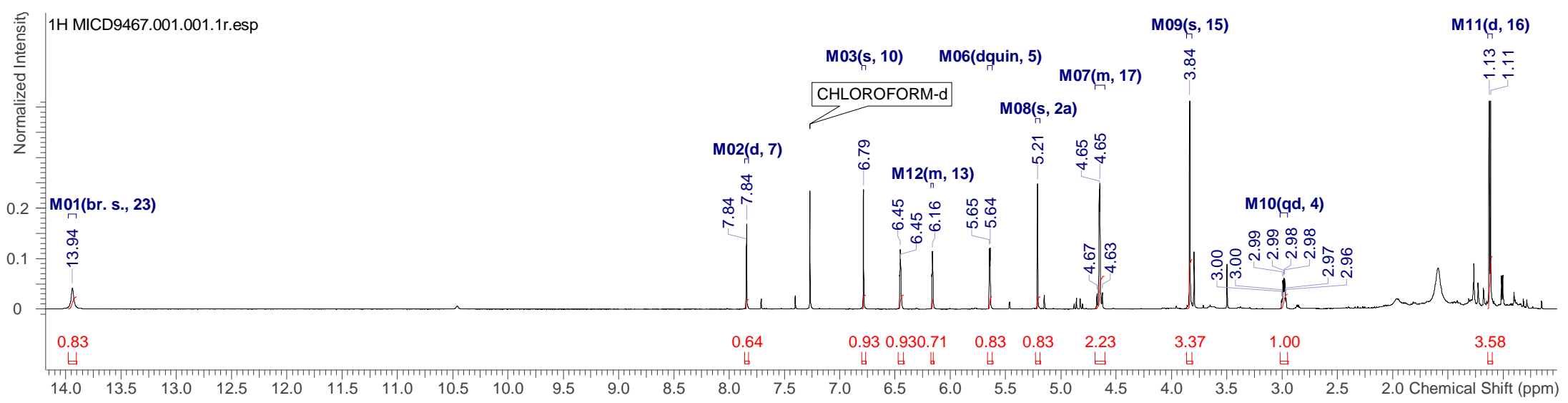

Figure DS9. ${ }^{1} \mathrm{H}$ NMR spectrum of Pyrronazol A2 (2) in $\mathrm{CDCl}_{3}(600 \mathrm{MHz})$

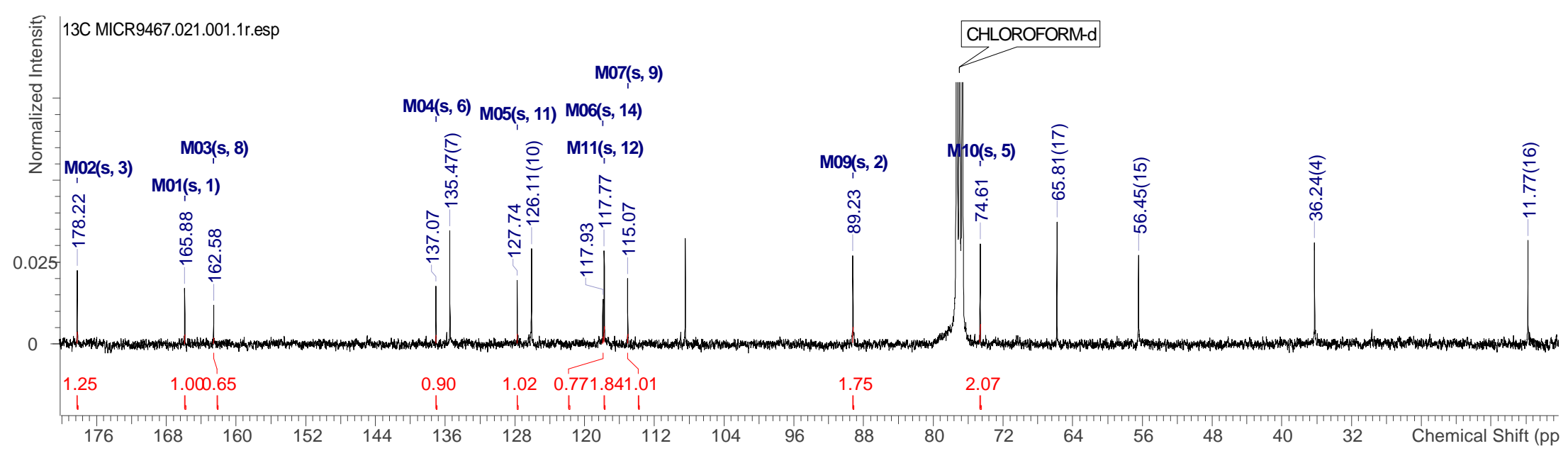

Figure DS10. ${ }^{13} \mathrm{C}$ NMR spectrum of Pyrronazol A2 (2) in $\mathrm{CDCl}_{3}(100.6 \mathrm{MHz})$ 


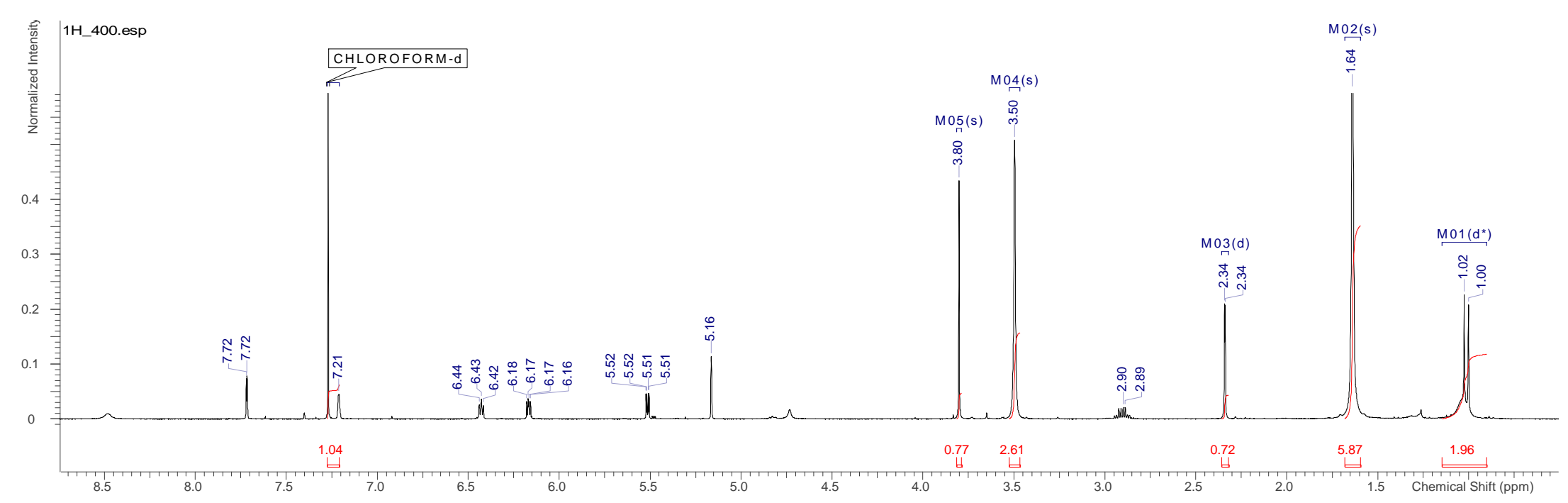

Figure DS11. ${ }^{1} \mathrm{H}$ NMR spectrum of Pyrronazol B (3) in $\mathrm{CDCl}_{3}(400 \mathrm{MHz})$

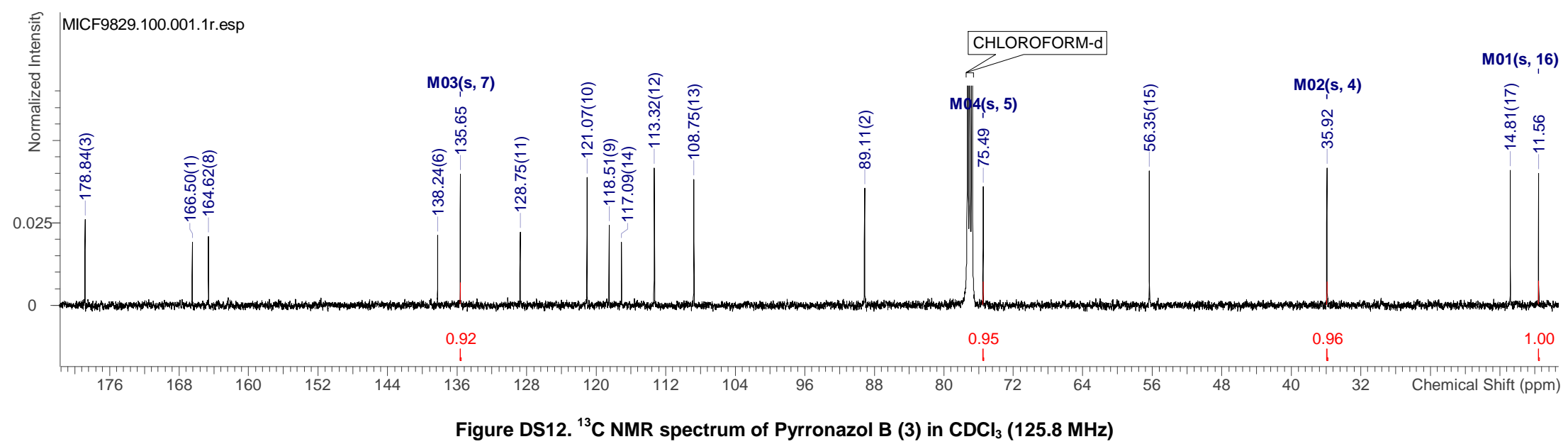




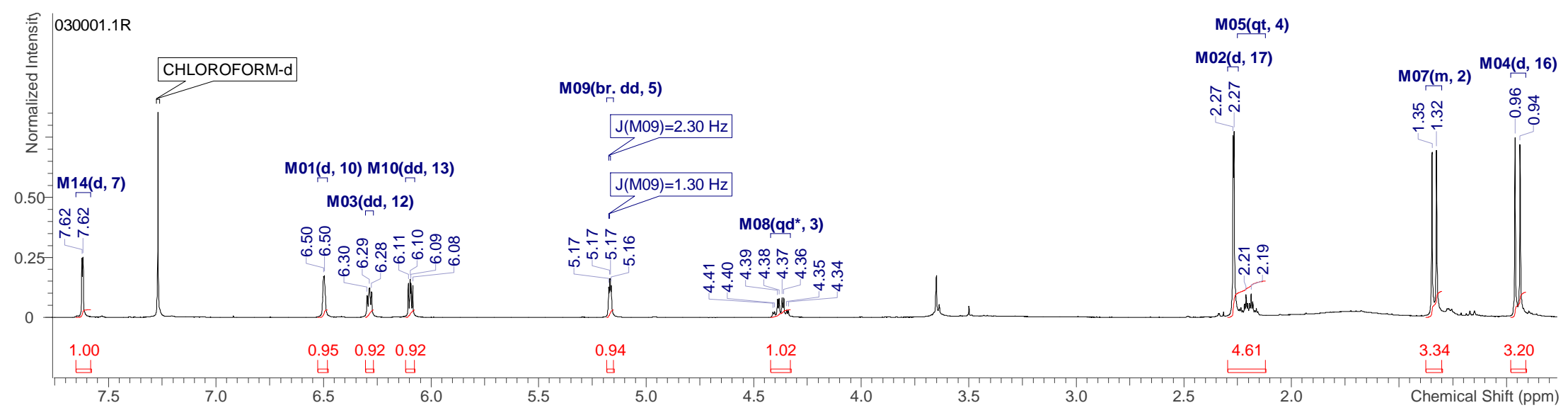

Figure DS13. ${ }^{1} \mathrm{H}$ NMR spectrum of Pyrronazol C2 (5) in $\mathrm{CDCl}_{3}(300 \mathrm{MHz}$ ) (Broad singlet at $14.27 \mathrm{ppm}$ not shown)

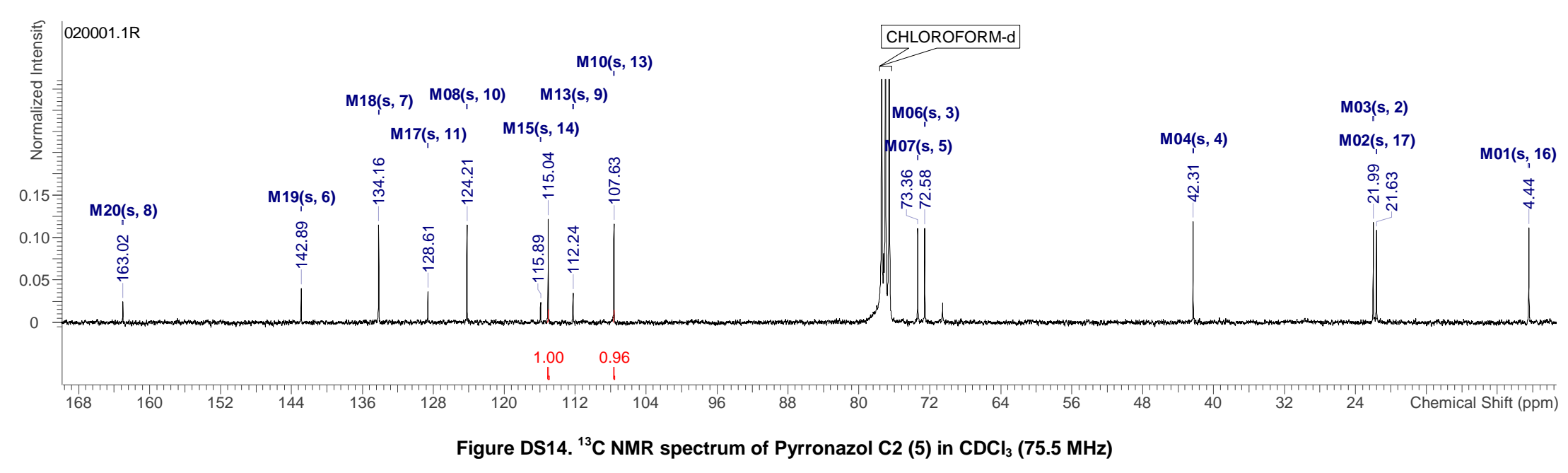




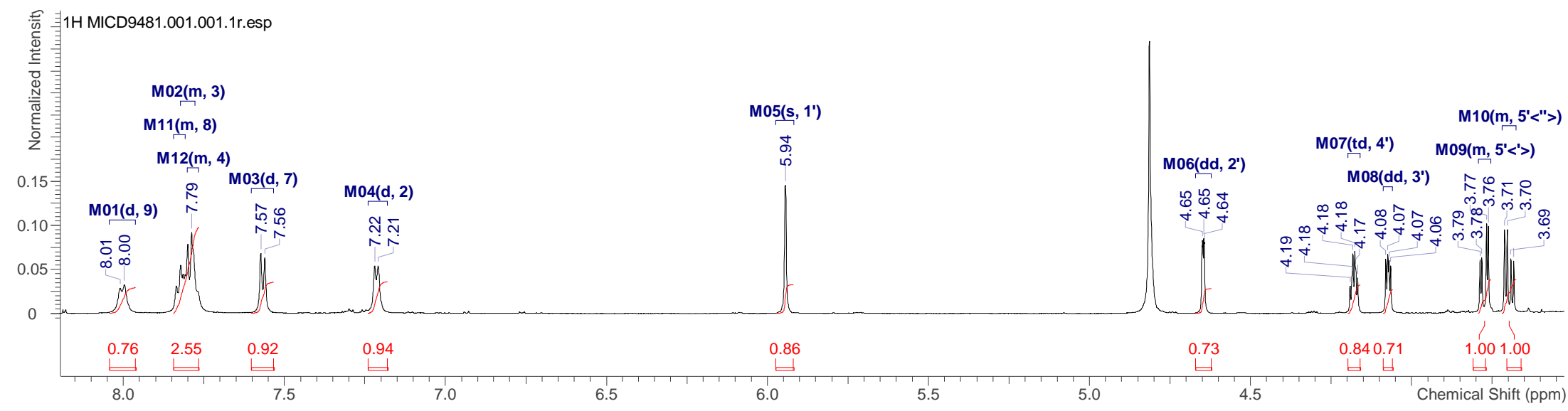

Figure DS15. ${ }^{1} \mathrm{H}$ NMR spectrum of 1,6-Phenazine-diol- $\alpha-\mathrm{D}-$ arabinofuranoside $(7)$ in $\mathrm{CD}_{3} \mathrm{OD}(600 \mathrm{MHz})$

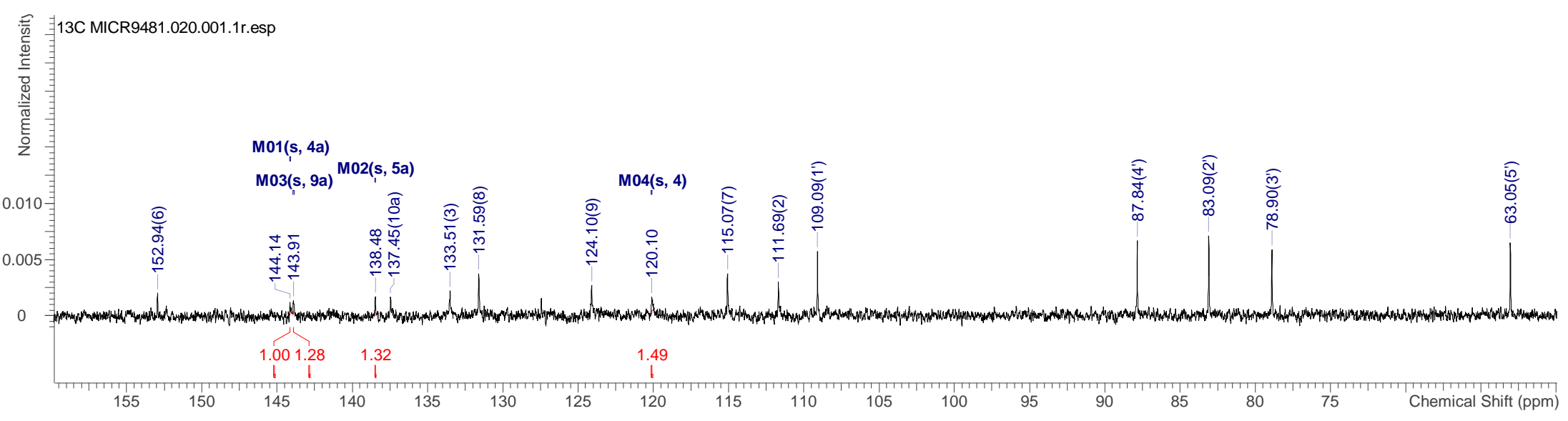

Figure DS16. ${ }^{13} \mathrm{C}$ NMR spectrum of 1,6-Phenazine-diol- $\alpha-\mathrm{D}$-arabinofuranoside (7) in $\mathrm{CD}_{3} \mathrm{OD}(100.65 \mathrm{MHz})$ 


\section{Chapter E}

\section{Discussion}

It is evident that microbes are accountable for plethora of human and animal ailments but the fact that most drugs currently in clinical application have been derived from microorganisms is also undeniable (Newman and Cragg, 2012). While fungi and actinobacteria have long established themselves as two of the most renowned sources of microbial drugs, other groups like Bacillus, cyanobacteria and myxobacteria are slowly emerging as the future potential sources for microbial drugs (Berdy, 2012). New technologies based on genome mining, high throughput screening and modern purification methods complement the age old culture based methods of drug discovery and aid to explore the metabolic diversity of the microbial world. This study mainly focused on discovery of novel microbial natural products and myxobacterial taxons and the outcome and future prospects of the study are discussed in this chapter.

\section{E.1. Paenilarvins, antifungal peptides from honey bee pathogen, Paenibacillus larvae}

Paenibacillus larvae has been the subject of studies since many decades to unravel the virulence factors and the strategies it employs during infection of the host i.e. honey bee larvae. The partial genome sequences available and the proteomics studies have helped to determine some important virulence factors and their role in pathogenesis including toxins, proteases, and S-layer protein (Fünfhaus et al., 2009; Antunez et al., 2010). It is also evident from the results that both prominent genotypes of $P$. larvae, ERIC I and II adapt different approaches for infection (Poppinga et al., 2012; Fünfhaus et al., 2013).

Complete genome sequencing and annotation of $P$. larvae ERIC I and II in the group of Prof. Rolf Daniel, University of Göttingen, brought into light an astounding arsenal of virulence factors that could possibly allow the pathogen to conquer various sites in the host throughout the course of infection (Djukic et al., unpublished). One of the 
most interesting sequences confirmed from this study with respect to pathogenicity were the NRPS and NRPS/PKS hybrid biosynthetic gene clusters which putatively coded for some secondary metabolites (Fünfhaus et al., 2009).

With the aim of finding the bioactive products of these biosynthetic gene clusters,

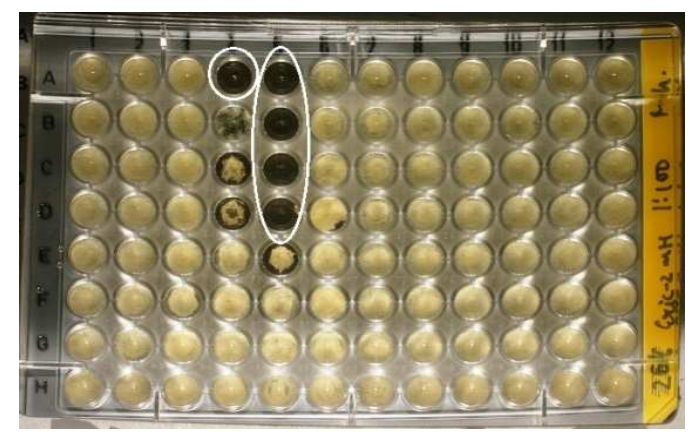

Fig.E1. Antifungal activity of crude methanol extract of $P$. larvae ERIC II (DSM 25430) against Mucor hiemalis after HPLC fractionation methanol extracts from $P$. larvae ERIC I and ERIC II were screened for antimicrobial activity and exhibited antifungal activity. Bioactivity guided HPLC and LC-MS data analysis of $P$. larvae ERIC II extracts indicated production of a group of lipopeptides with masses ranging from 1069 to $1112 \mathrm{Da}$. Characterization of the pure compounds based on molecular

formulae and UV spectra revealed their affiliation to iturin family compounds including iturins, mycosubtilin and bacillomycin which are known to be produced by most Bacillus species (Ongena and Jacques, 2008). This family of compounds along with other Bacillus lipopeptides plays an important role in control of fungal phytopathogens in their natural environments (Romero et al., 2007) establishing their producers as versatile biocontrol agents (Zeriouh et al., 2011).

The complete structure elucidation of some of the lipopeptides produced by $P$. larvae using NMR spectroscopy and MS-MS fragmentation firmly established the resemblance of these lipopeptides to Mojavensin A, produced by Bacillus mojavensis B0621A (Ma et al., 2012) except the length of the $\beta$-Aa side chain in one of the compounds and replacement of asparagine by aspartic acid in another. All the other compounds obtained were found to be derivatives of these two major classes with the difference in the length of the $\beta$-Aa side chain.

These lipopeptides were named paenilarvins and the major products were paenilarvins $A-C$. The antifungal activity observed for paenilarvins against certain fungi was significantly higher than reported for Anteiso-C15 mojavensin A (1) against some soil-borne phytopathogens like Valsa mali, Fusarium oxysporum f. $\mathrm{sp}$. cucumerinum, and Fusarium verticillioides (Ma et al., 2012). However, P. larvae can never be utilized for phytopathogen control because of its lethal effects on Apis mellifera whereas in fact the simultaneous production of many lipopeptides like 
surfactins, fengycins and iturins, with good biological activity by the marine- derived bacterium Bacillus mojavensis B0621A makes it a potential biocontrol agent (Ma et al., 2012).

Paenilarvins exhibited no antibacterial activity but some cytotoxic activity against mouse fibroblast cell line L929. Further experiments using different concentrations of compounds on honey bee larvae can help to determine their larval toxicity. Paenilarvins could be directly insecticidal to the bee larvae like bassianolide, an insecticidal cyclodepsipeptide produced by the fungus, Beauveria bassiana and Verticillium lecanii (currently known as Lecanicillium lecanii), which elicits atonic symptoms in silkworm larvae (Kanoaka et al., 1977) or they could indirectly assist in disease progression.

Production of secondary metabolites with antibiotic activity by a pathogen is very common in order to eliminate other potential pathogens of the same host (Axelrood et al., 1988). Many infectious agents like parasites, mites, fungi and viruses apart from $P$. larvae pose a serious threat to honey bee larvae (Murray and Aronstein, 2008; Puerta et al., 1999) and production of paenilarvins could help the producer to establish its dominance over other pathogens. They might also give a growth advantage to the pathogen in the competitive environment of larval gut microflora.

It has been proven that antibiotics can act at much lower concentrations than their lethal dose in natural environments and target and regulate different genes including virulence genes (Aminov, 2009). A polypeptide encoded by a NRPS in the citrus pathogen Alternaria alternata, can regulate siderophore and melanin production, iron uptake under low iron conditions, oxidative stress resistance, conidia formation and virulence (Chen et al., 2013).

Thus, it can be speculated that paenilarvins aid the pathogen during infection using any of the above mentioned or any other mechanism but their exact role in disease progression still needs to be thoroughly investigated. Construction of $P$. larvae mutants lacking expression of NRPS/PKS gene cluster responsible for paenilarvin production can help to ascertain their role as virulence factors. An insight into the biosynthesis of paenilarvins in $P$. larvae and their precise molecular mechanism of action inside the bee larvae is also essential. Another main objective for future should 
be identification, purification and characterization of the products of other NRPS/PKS gene clusters in the $P$. larvae genome and to establish their role in pathogenesis.

\section{E.2. Aggregicoccus edoensis gen. nov., sp. nov., a soil myxobacterium with characteristic aggregation}

Myxococcaceae include four genera of myxobacteria, namely, Myxococcus, Corallococcus, Pyxidicoccus and Anaeromyxobacter. No new genus has been added to the family since the description of facultative anaerobic Anaeromyxobacter dehalogenans in 2002 (Sanford et al., 2002). Hereby we describe a novel genus in the Myxococcaceae, Aggregicoccus represented by two strains of the novel species A. edoensis, MCy $1366^{\top}\left(\right.$ Ar1733 $^{\top}$ ) and MCy10622 (SBCy015) which were isolated from soil samples from different locations (Japan, Switzerland resp.) and at different times (1980, 2013 resp.) at $\mathrm{HZI}$ in our continuing efforts to isolate new myxobacteria.

The 16S rRNA gene sequence of strain MCy $1366^{\top}$ was analyzed together with other 50 myxobacterial strains selected from our in house myxobacterial strain collection. It exhibited only $97.56 \% 16 \mathrm{~S}$ rRNA gene sequence similarity to Stigmatella koreensis strain KYC-1019 (no valid description available, accession no. EF112185) in BLAST $\mathrm{N}$ analysis and branched out notably from all other known genera of myxobacteria in the phylogenetic tree. Hence, it was chosen for further study as a novel taxon.

Strain MCy10622 was isolated by Ram Awal Prasad, Helmholtz Institute for Pharmaceutical Research, Saarbrücken and characterized as strain belonging to Myxococcaceae. It was upon comparison of the 16S rRNA gene sequence of MCy $1366^{\top}$ with MCy $1366^{\top}$ that they were found to be $99.9 \%$ similar and hence, representing the same taxon. The morphological characteristics like swarming pattern and shape and size of fruiting body like structures, vegetative cells and myxospore like structures indicated that the two strains belong to the family Myxococcaceae.

A polyphasic approach including genotypic, phenotypic and chemotypic features was followed to investigate the reliable taxonomic status of MCy $1366^{\top}$ and MCy10622 because of their close relation to Corallococcus species (97\%) on the basis of $16 \mathrm{~S}$ rRNA gene sequences and similar $G+C$ content (65.6\%). The $3 \%$ sequence 
divergence suggested the two novel strains to represent a new species but in depth analysis was needed to confirm the results.

The two isolates under study were checked for their physiological characteristics like antibiotic resistance, carbon and nitrogen source requirements, optimum temperature and $\mathrm{pH}$ for growth, starch, chitin and cellulose degradation, Congo Red reaction, salt tolerance, microbial predation and APIZym assay for enzyme production. Most of the results from the physiological studies like positive Congo Red reaction, inability to degrade monosaccharides, disaccharides, chitin and cellulose definitely placed them in the family Myxococcaceae but could not provide any clear delineation from the already known genera in the family.

Fatty acid content including FA types, FA ratio and major FA markers have been successfully used to determine the chemo-phylogenetic relationship within the order Myxococcales (Garcia et al., 2011). Around 34 FAs have been reported in members of the family Myxococcaceae (Garcia et al., 2011), but only 26 could be detected in MCy $1366^{\top}$ and 27 in MCy10622, some of which were present in very minute quantities. The close divergence of MCy $1366^{\top}$ and MCy10622 from Corallococcus exiguus and $C$. coralloides was reflected in their SCFAs to BCFAs ratio. An extensive analytical study of FA profiles of MCy $1366^{\top}$ and MCy 10622 along with other closely related strains in comparison to the FA profiles of other myxobacteria already illustrated in literature supported the taxonomic placement of the new isolate into a new taxon.

DNA-DNA hybridization is based on comparison between whole genomes of two bacterial strains and has been applied as one of the most important tools for bacterial systematics since almost 50 years (Goris et al., 2007). A group of bacteria showing $70 \%$ or more DNA-DNA relatedness is often regarded as belonging to same species (Prakash et al., 2007). So, DNA-DNA hybridization was employed to ascertain the status of MCy $1366^{\top}$ and MCy 10622 as a new genus or a new species. $28-35 \%$ DNADNA relatedness of MCy $1366^{\top}$ with Corallococcus spp. and $100 \%$ DNA-DNA relatedness of MCy $1366^{\top}$ with MCy 10622 clearly advocated their description as two isolates of one species in a new genus. 
Matrix assisted laser desorption ionization time-of-flight (MALDI-TOF) mass spectrometric analysis has become an important tool in chemotaxonomic classification of bacteria using some proteins as biomarkers or the comparison of the proteomics spectra of a group of related bacteria (Lay, 2000). MALDI-TOF MS has been successfully used for classification up to genus, species and subspecies level (Murray, 2010). The ability of this technique to differentiate between methicillin sensitive and methicillin-resistant Staphylococcus aureus projects its true potential in bacterial strain typing as well (Edwards-Jones et al., 2000). When MALDI-TOF MS was used to study the chemotaxonomic relations between MCy $1366^{\top}$ with MCy 10622 and the other members of the family Myxococcaceae, the dendrogram obtained after data analysis showed clear delineation of the new isolates from Corallococcus Myxococcus and Pyxidicoccus spp.

Based on the polyphasic analysis, especially 16S rRNA gene sequences, DNA-DNA hybridization and MALDI-TOF data, it could be determined that novel strains, MCy $1366^{\top}$ and MCy10622 represent a new genus (Aggregicoccus) and species (Aggregicoccus edoensis).

As exemplified in section 5.1, screening of novel taxa for secondary metabolites is a promising approach towards discovery of novel natural products. This suggests that screening of the novel isolates, MCy $1366^{\top}$ and MCy10622 under optimum growth conditions and methodical analysis of its metabolome can lead to detection of yet unexplored products.

\section{E.3. Pyrronazols and phenazines from Nannocystis pusilla}

Bacteria of the genus Nannocystis represent the family Nannocystaceae within Myxococcales and are closely related to marine myxobacteria like Enhygromyxa, Pseudenhygromyxa and Plesiocystis. The secondary metabolite potential of Nannocystis spp. has not been thoroughly exploited. They have been reported to produce only few compounds like phenylnannolones (Ohlendorf et al., 2008), germacran (Reichenbach and Höfle, 2000), geosmin (Trowitzsch et al., 1981) and the siderophores called nannochelins (Kunze et al., 1992). This could be due to the description and availability of only two species in this genus, $N$. exedens and $N$. pusilla till date. 
Nannocystis pusilla, strain Ari7 was selected from the 50 myxobacterial strains which were screened when it showed some antifungal activity in the course of preliminary screening. During HPLC-UV-HRESIMS data analysis, it was found to produce pyrronazols, which had been identified previously in another Nannocystis strain but remained unpublished. Pyrronazols represent a novel structural class of secondary metabolites constituting chlorinated pyrrole-oxazole-pyrones showing very weak activity against the filamentous fungi, Mucor hiemalis. Three pyrronazol variants, pyrronazol A, A2 and B were isolated and characterized from strain Ari7. The other known derivatives of pyrronazol, pyrronazol $\mathrm{C} 1$ and pyrrronazol $\mathrm{C} 2$ had been isolated from $N$. pusilla, strain Na 174. Pyrronazols were detected in extracts from both species of Nannocystis, $N$. pusilla and $N$. exedens but not from any other myxobacteria screened during our screening program, which leads us to speculate that pyrronazols production is limited to this genus only and thus has the potential to be used as a chemotaxonomic biomarker in future.

N. pusilla strains Ari7 and $\mathrm{Na}$ a174 were isolated from Langeoog Island in Germany and Rhodos Island in Greece, respectively, which suggests their close association with the marine environment. In this perspective, it is very fascinating to note the resemblance in the molecular structures of pyrronazols and phorbazoles, which have been isolated from the marine sponge, Phorbas aff. clathrata (Rudi et al., 1994) and the marine mollusk, Aldisa andersoni (Nuzzo et al., 2012). The detection of phorbazoles in $A$. andersoni extracts can be mostly accredited to their feeding on Phorbas sponges. Phorbazoles are chlorinated phenyl-pyrrolyl-oxazoles which differ in the number and position of the chlorine atoms.

The two phorbazole derivatives, 9-chloro-phorbazole $\mathrm{D}$ and N1-methyl-phorbazole $\mathrm{A}$ exhibited good inhibitory activity against many human cancer cell lines (Nuzzo et al., 2012) while pyrronazol A failed to show any significant activity against the cell lines tested. The similarity between the structures for both these classes of compounds suggests that chemical modification of pyrronazols might help to enhance their biological activity.

Three other natural compounds closely related to pyrronazols are pyoluteorin (Takeda, 1958), pyrrolomycin B (Kaneda et al., 1981) and pyrrolnitrin (Arima et al., 
1964). Pyrrolnitrin and its derivatives were long known to be produced by Pseudomonas species but were discovered for the first time from a myxobacterial strain of Myxococcus fulvus (Gerth et al., 1982). Pyrrolnitrin was later detected in many other myxobacteria from the suborder Cystobacterineae including Corallococcus and Cystobacter (Gerth et al., 1982).

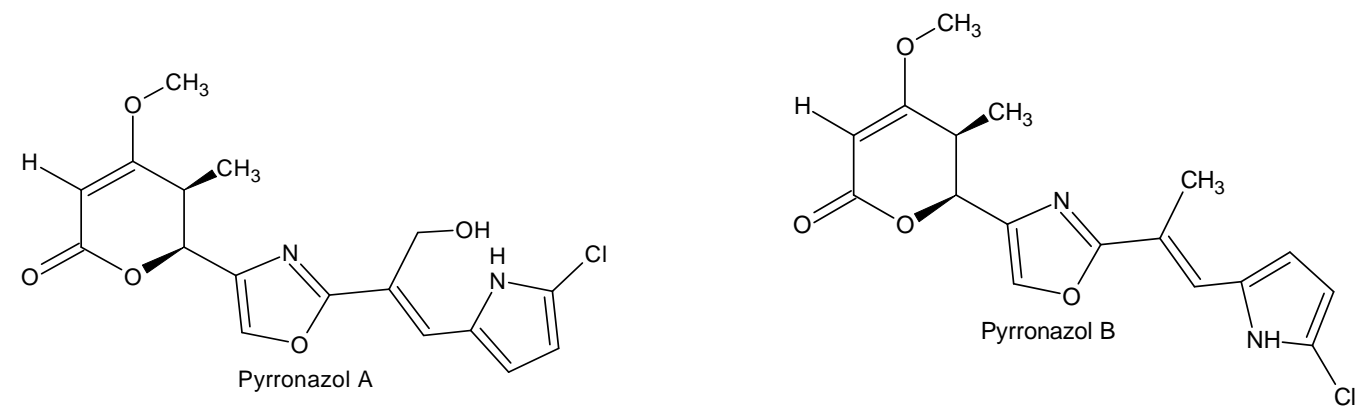<smiles>Oc1ccc(-c2oc(-c3[nH]cc(Cl)c3Cl)nc2Cl)cc1</smiles><smiles>Oc1ccc(-c2cnc(-c3[nH]cc(Cl)c3Cl)o2)cc1</smiles><smiles>Oc1ccc(-c2cnc(-c3[nH]ccc3Cl)o2)cc1</smiles><smiles>Oc1ccc(-c2oc(-c3[nH]ccc3Cl)nc2Cl)cc1</smiles><smiles>Cn1cc(Cl)c(Cl)c1-c1nc(Cl)c(-c2ccc(O)cc2)o1</smiles>

N1-methyl-phorbazole A

Fig.E2. Structures of pyrronazols and phorbazoles

Natural products containing heterocyclic rings can also be found from other sources like fungi and plants besides bacteria and marine organisms (Gribble, 1996). The fungus Auxarthron umbrinum along with other members of order Onygenales are known to produce a pyrrolylpolyene called rumbrin (Yamagishi et al., 1993). Rumbrin structurally resembles pyrronazol with the presence of a pyrrole and a pyrone ring, here completely unsaturated. Rumbrin was found to possess potent cytoprotective (Yamagishi et al., 1993) and calcium-accumulation inhibitory activities (Yamagishi and Shindo, 1993). An isomer of rumbrin, 12E-isorumbrin also showed potent anticancer activity (Clark et al., 2006). It can be speculated that pyrronazols may also 
exhibit such distinct biological activities if tested in some exclusive screening program.

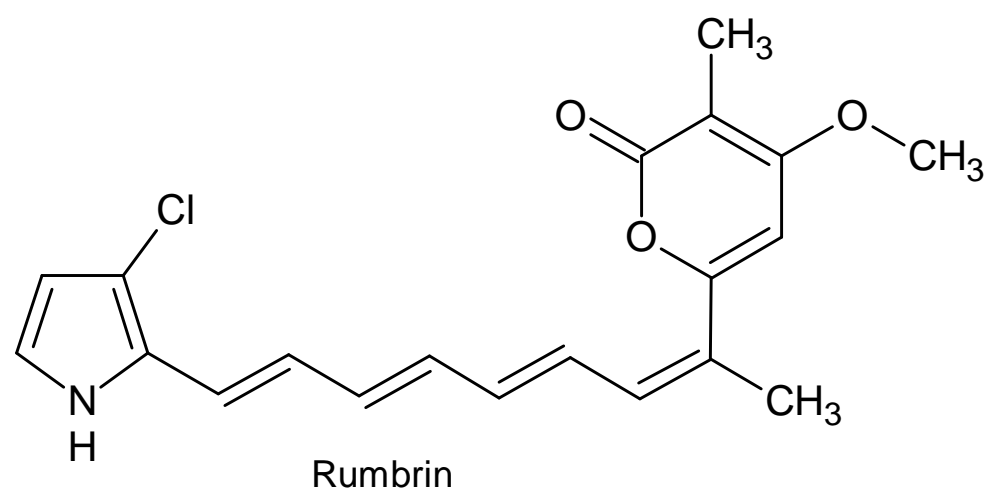

Fig. E3. Structure of Rumbrin

N. pusilla, strain Ari7 also produced two phenazine compounds, 1,6-phenazinediol and 1-hydroxy-phenazine-6-yl-a-D-arabinofuranoside in addition to pyrronazols. Phenazines have been reported from a wide variety of bacteria like Nocardia, Brevibacterium, Burkholderia, Pseudomonas and Streptomyces (Dwivedi and Johri, 2003$,$) . The phenazine antibiotic, myxin was first isolated from Sorangium s p$. and reported to exhibit potent antimicrobial activity (Peterson et al., 1966). 1,6phenazinediol was first reported from Streptomyces thioluteus (Akabori and Nakamura, 1959).

Though phenazines are versatile natural compounds and more than 100 structural derivatives have been identified from numerous bacteria, phenazine glycosides are rarely encountered as natural products (Abdelfattah et al., 2011). Izuminosides (Abdelfattah et al., 2011), phenazoviridine (Kato et al., 1993), aestivopheonins (ShinYa et al., 1995) and L-quinovose esters of saphenic acid (Pathirana et al., 1992) are amongst the few phenazine glycosides which have been primarily known to be produced by actinomycetes. This is the first report of the production of a phenazine glycoside from myxobacteria.

Pseudomonads are known to suppress the growth and survival of competitive microbes by production of many secondary metabolites including pyrroles and phenazines (Dwivedi and Johri, 2003) and the occurrence of both these classes of compounds from a single myxobacterial strain suggest that the biosynthetic gene 
clusters or biosynthetic pathways for these two classes of compounds could be linked in some way. It also explains the antifungal effects of crude methanol extract of strain Ari7 and implicates the possibility of use of these compounds by the producer for its competitive fitness in its natural environment. 


\section{References}

Abdelfattah, M.S., Toume, K., and Ishibashi, M. (2011) Isolation and structure elucidation of izuminosides A-C: a rare phenazine glycosides from Streptomyces sp. IFM 11260. J. Antibiot. 64, 271-275

Akabori, H., and Nakamura, M. (1959) 1,6-Dihyrodxyphenazine, an antibiotic produced by Streptomyces thioluteus. J. Antibiot.12, 17-20

Aminov, R. I. (2009) The role of antibiotics and antibiotic resistance in nature. Environ. Microbiol. 11(12), 2970-2988

Antunez , K., Anido, M., Evans, J. D., and Zunino, P. (2010) Secreted and immunogenic proteins produced by the honeybee bacterial pathogen, Paenibacillus larvae. Vet. microbiol. 141, 385-389

Arima, K., Imanaka, H., Kausaka, M., Fukuda, A., and Tameera, C. (1964) Pyrrolnitrin, a new antibiotic substance, produced by Pseudomonas. Agric. Biol. Chem. 28, 575-576

Axelrood, P.E.,Rella, M. and Schroth, M.N. (1988) Role of antibiosis in competition of Erwinia strains in potato infection courts. Applied and Environmental microbiology, 54(5), 1222-1229

Berdy, J. (2012) Thoughts and facts about antibiotics: Where we are now and where we are heading. J. Antibiot. 65, 385-395

Chen, L., Lin, C., and Chung, K. (2013) A nonribosomal peptide synthetase mediates siderophore production and virulence in the citrus fungal pathogen Alternaria alternate. Molecular Plant Pathology. 14(5), 497-505

Clark, B. R., Capon, R. J., Lacey, E., Tennant, S., and Gill, J. H. (2006) Polyenylpyrroles and Polyenylfurans from an Australian Isolate of the Soil Ascomycete Gymnoascus reessii. Org. Lett., 8, 701-704

Dwivedi, D., and Johri, B.N. (2003) Antifungals from fluorescent pseudomonads: Biosynthesis and regulation. Current Science. 85(12), 1693-1703

Edwards-Jones, V., Claydon, M., Evason, D., Walker, J., Fox, A. J., and Gordon, D. B. (2000) Rapid discrimination between methicillin-sensitive and methicillin-resistant Staphylococcus aureus by intact cell mass spectrometry. J. Med. Microbiol. 49, 295-300

Fünfhaus, A., Ashiralieva, A., Borriss, R. and Genersch, E. (2009) Use of suppression subtractive hybridization to identify genetic differences between differentially virulent genotypes of Paenibacillus larvae, the etiological agent of American Foulbrood of honeybees. Environ. Microbiol. Rep. 1, 240-250

Fünfhaus, A., Poppinga, L., and Genersch, E. (2013) Identification and characterization of two novel toxins expressed by the lethal honey bee pathogen Paenibacillus larvae, the causative agent of American foulbrood. Environ. Microbiol. doi:10.1111/1462-2920.12229

Garcia, R., Pistorius, D., Stadler, M. \& Müller, R. (2011) Fatty acid related phylogeny of myxobacteria as an approach to discover polyunsaturated omega-3/6 fatty acids. J. Bacteriol. 193, 1930-1942

Genoveffa Nuzzo, G., Ciavatta, M. L., Kiss, R., Mathieu, V., Leclercqz, H., Manzo, E., Villani, G., Mollo, E., Lefranc, F., D'Souza, L., Gavagnin, M., and Cimino, G. (2012) Chemistry of the Nudibranch Aldisa andersoni: Structure and Biological Activity of Phorbazole Metabolites. Mar. Drugs10, 1799-1811 
Gerth, K., Trowitzsch, W., Wray, V., Höfle, G., Irschik, H., and Reichenbach, H. (1982) Pyrrolnitrin from Myxococcus fulvus. J. Antibiot. 35, 1101-1103

Goris, J., Konstantinidis, K. T., Klappenbach, J. A., Coenye, T., Vandamme, P., and Tiedje, J. M. (2007) DNA-DNA hybridization values and their relationship to whole-genome sequence similarities. Intern. J. Syst. Evol. Microb. 57, 81-91

Gribble, G. W. (1996) Pyrroles and their Benzo Derivatives: Applications. Reference Module in Chemistry, Molecular Sciences and Chemical Engineering-Comprehensive Heterocyclic Chemistry II. Pages 207-257

Kaneda, M., Akamura, S., Ezaki, N., and litaka, Y. (1981) Structure of Pyrrolmycin B, a chlorinated nitro-pyrrole antibiotic. J. Antibiot. 34, 1366-1368

Kanoaka, M., Isogai, A., Murakoshi, S., Ichjnoe, M., Suzuki, A. and Tamura, S. (1977) Bassianolide, a new insecticidal cyclodepsipeptide from Beauveria bassiana and Verticillium lecanii. Agric. Biol. Chem., 42(3), 629-635

Kato, S., Shindo, K., Yamagishi, Y., Matsuoka, M., Kawai, H., and Mochizuki, J. (1993) Phenazoviridin, a novel free radical scavenger from Streptomyces sp. J. Antibiot. 46, 1485-1493

Kunze, B.,Trowitzsch-Kinast, W., Höfle, G. and Reichebach, H. (1992) Nannocheline A,B and C, new iron chelating compounds from Nannocystis exedens (Myxobacteria). J. Antibiot. 45, 147-150

Lay, J. O. (2000) MALDI-TOF mass spectrometry and bacterial taxonomy. Trends in analytical chemistry.19, 8

Ma, Z., Wang, N., Hu, J., and Wang, S. (2012) Isolation and characterization of a new iturinic lipopeptide, mojavensin A produced by a marine-derived bacterium Bacillus mojavensis B0621A. J. Antib. 00, 1-6

Murray, K. D., Aronstein, K. A. (2008) Transformation of the Gram-positive honey bee pathogen, Paenibacillus larvae, by electroporation. J. Microbiol. Meth. 75, 325-328

Murray, P.R. (2010) Matrix-assisted laser desorption ionization time-of-flight mass spectrometry: usefulness for taxonomy and epidemiology. Clin. Microbiol. Infect. 16, 1626-1630

Newman, D.J., and Cragg, G.M. (2012) Natural products as sources of new drugs over the 30 years from 1981 to 2010. J. Nat. Prod. 75, 311-335

Ohlendorf, B., Leyers, S., Krick, A., Kehraus, S., Wiese, M., and König, G. M. (2008) Phenylnannolones A-C: Biosynthesis of New Secondary Metabolites from the Myxobacterium Nannocystis exedens. ChemBioChem. 9, $2997-3003$

Ongena, M., and Jacques, P. (2008) Bacillus lipopeptides: versatile weapons for plant disease biocontrol. Trends Microbio. 16, 115-125

Pathirana, C., Jensen, P. R., Dwight, R., and Fenical, W. (1992) Rare phenazine L-quinovose esters from a marine actinomycete. J. Org. Chem. 57, 740-742

Peterson, E. A., Gillespie, D. C., and Cook, F. D. (1966) A wide spectrum antibiotic produced by a species of Sorangium. Can. J. Microbiol. 12, 221-230

Poppinga, L., Janesch, B., Fünfhaus, A., Sekot, G., Garcia-Gonzalez, E., et al. (2012) Identification and Functional Analysis of the S-Layer Protein SpIA of Paenibacillus larvae, the Causative Agent of American Foulbrood of Honey Bees. PLoS Pathog. 8(5): e1002716. doi:10.1371/journal.ppat.1002716 
Prakash, O., Verma, M., Sharma, P., Kumar, M., Kumari, K., Singh, A., Kumari, H., Jit, S., Gupta, S.K., Khanna, M., and Lal, R. (2007) Polyphasic approach of bacterial classification - An overview of recent advances. Indian J. Microbiol. 47:98-108

Puerta, F., Flores, J. M., Ruiz, J. A., Ruz J. M. and Centro, C. (1999) Fungal diseases of the honeybee (Apis mellifera L.). In: Colin M.E. (ed.), Ball B.V. (ed.), Kilani M. (ed.). Bee disease diagnosis. Zaragoza : CIHEAM, 61-68

Reichenbach, H., and Höfle, G.(2000) in Drug Discovery from Nature (Eds. Grabley, S.; Thierecke, R.), Springer, Heidelberg, p. 173

Romero, D., de Vicente, A., Rakotoaly, R. H., Dufour, S. E., Veening, J. W., Arrebola, E., Cazorla, F. M., Kuipers, O. P., Paquot, M., and Pérez-García, A. (2007) The iturin and fengycin families of lipopeptides are key factors in antagonism of Bacillus subtilis toward Podosphaera fusca. Mol. Plant Microbe Interac. 20, 430-440

Rudi, A., Stein, Z., Green, S., Goldberg, I., Kashman, Y., Benayahu, Y., and Schleyer, M. (1994) Phorbazoles A-D, Novel Chlorinated Phenylpyrrolyloxazoles from the Marine Sponge Phorbas aff. clathrata. Tetrahedron. Lett. 35, 2589-2592

Sanford, R. A., Cole, J. R., and Tiedje, J. M. (2002) Characterization and Description of Anaeromyxobacter dehalogenans gen. nov., sp. nov., an Aryl-Halorespiring Facultative Anaerobic Myxobacterium. App. Env. Microb. 893-900

Shin-Ya, K. Shimizu, S., Kunigami, T., Furihata, K., Hayakawa, Y., and Seto, H. (1995) Novel neuronal cell protecting substances, aestivophoenins A and B, produced by Streptomyces purpeofuscus. J. Antibiot. 48, 1378-1381

Takeda, R. (1958) Structure of new antibiotic, Pyoluteorin. J. Am. Chem. Soc. 80, 4749-4750

Trowitzsch, W., Witte, L., and Reichenbach, H. (1981) Geosmin from earthy smelling cultures of Nannocystis exedens (Myxobacterales). FEMS Microbiol. Lett. 12, 257-260

Yamagishi, J., and Shindo, K. (1993) Japanese Patent 5039288-A

Yamagishi, Y., Matsuoka, M., Odagawa, A., Kato, S., Shindo, K., and Mochizuki, J. (1993) Rumbrin, a new cytoprotective substance produced by Auxarthron umbrinum. J. Antibiot. 46 (6), 884-887

Zeriouh, H., Romero, D., García-Gutiérrez, L., Cazorla, F. M., de Vicente, A. and Pérez-García, A. (2011) The Iturin-like lipopeptides are essential components in the biological control arsenal of Bacillus subtilis against bacterial diseases of Cucurbits. Mol. Plant Microbe Interac. 24, 12, 1540-1552 


\section{Summary}

With the advent of new pathogens and upsurge in the number of antibiotic resistant microbes, concerted efforts need to be made by pharmaceutical, biotechnological and academic communities to pace up the antibiotic discovery programs and combat these deadly pathogens to ensure progress in health sector. Natural products continue to be a plenteous source of new chemical entities with distinct biological activities in extended screening programs. Microbe derived natural products and analogues have found applications in wide range of fields from pharmaceuticals to agriculture.

The present thesis mainly focused on natural products isolation and characterization from myxobacteria and Paenibacillus larvae and identification and description of a novel myxobacterial taxon, Aggregicoccus edoensis. In order to find new compounds, 50 myxobacterial strains from our in house myxobacterial collection and two genotypes (ERIC I and ERIC II) of Paenibacillus larvae were cultivated and screened by biological assays, HPLC and HPLC-HRESIMS analysis. The compounds recognized as new metabolites were subsequently purified and characterized followed by structure elucidation.

Pyrronazols and phenazine derivatives purified from Nannocystis pusilla, strain Ari7 give an insight of yet unexhausted metabolic diversity of microbes, specifically, of myxobacteria. Furthermore, description of paenilarvins from $P$. larvae is the first report of purification of secondary metabolites from this deadly honey bee pathogen. It is known that novel microbial taxa have a huge potency to detect new secondary metabolites. Hence, with an aim to identify novel myxobacterial taxa amongst the group of myxobacteria screened for natural products, their 16S rRNA genes were analyzed and compared to representative strains of the validly published taxa to determine their position in the myxobacterial phylogeny. One strain which delineated from other myxobacterial strains during phylogenetic studies was compared to the type strains of closely related genera for proteomics, fatty acid content and antibiotic resistance and described as a representative of a new genus, Aggregicoccus edoensis. Comprehensive screening of this novel taxon can possibly grant access to new myxobacterial metabolites. 


\section{List of Figures}

Figure A1. Structure of Polymyxin B isolated from B. subtilis $\quad 5$

Figure A2. Systematic description of myxobacteria within order Myxococcales 10

Figure A3. Natural compounds from myxobacteria with cytotoxic, antifungal and antibacterial activity 12

Figure B1. Structures of paenilarvins A (1), B (2), and C (3) 32

Figure B2. Key HMBC and ROESY correlations of paenilarvin A (1) 35

Figure BS1. ${ }^{1} \mathrm{H}$ NMR of 1 in $\mathrm{CD}_{3} \mathrm{OH}, 700 \mathrm{MHz} \quad 48$

Figure BS2. ${ }^{13} \mathrm{C}$ NMR of 1 in $\mathrm{CD}_{3} \mathrm{OH}, 176 \mathrm{MHz}$

Figure BS3. ${ }^{1} \mathrm{H}-{ }^{1} \mathrm{H}$ COSY NMR of 1 in $\mathrm{CD}_{3} \mathrm{OH}$, selected area $\quad 49$

Figure BS4. ${ }^{1} \mathrm{H}-{ }^{1} \mathrm{H}$ COSY NMR of 1 in $\mathrm{CD}_{3} \mathrm{OH}$, selected area $\quad 50$

Figure BS5. HSQC NMR of 1 in $\mathrm{CD}_{3} \mathrm{OH}$, selected area $\quad 50$

Figure BS6. $\mathrm{HMBC}$ NMR of 1 in $\mathrm{CD}_{3} \mathrm{OH}$, selected area $\quad 51$

Figure BS7. $\mathrm{HMBC}$ NMR of 1 in $\mathrm{CD}_{3} \mathrm{OH}$, selected area 51

Figure BS8. TOCSY NMR of 1 in $\mathrm{CD}_{3} \mathrm{OH}$, selected area $\quad 52$

Figure BS9. TOCSY NMR of 1 in $\mathrm{CD}_{3} \mathrm{OH}$, selected area $\quad 52$

Figure BS10. ROESY NMR of 1 in $\mathrm{CD}_{3} \mathrm{OH}$, selected area 53

Figure BS11. ROESY NMR of 1 in $\mathrm{CD}_{3} \mathrm{OH}$, selected area 53

Figure BS12: ESI HRMS of paenilarvin A (1) 54

Figure BS13. MS/MS spectra of (1) 54

Figure BS14. ${ }^{1} \mathrm{H}$ NMR of 2 in $\mathrm{CD}_{3} \mathrm{OH}+5 \mu \mathrm{L} \mathrm{HCOOH}, 700 \mathrm{MHz}$

Figure BS15. ${ }^{13} \mathrm{C}$ NMR DEPT of 2 in $\mathrm{CD}_{3} \mathrm{OH}+5 \mu \mathrm{L} \mathrm{HCOOH}, 176 \mathrm{MHz}$, selected area 56

Figure BS16. ${ }^{12} \mathrm{C}$ NMR of 2 in $\mathrm{CD}_{3} \mathrm{OH}+5 \mu \mathrm{L} \mathrm{HCOOH}, 176 \mathrm{MHz}$, selected area $\quad 57$

Figure BS17. ${ }^{1} \mathrm{H}-{ }^{1} \mathrm{H}$ COSY NMR of 2 in $\mathrm{CD}_{3} \mathrm{OH}+5 \mu \mathrm{L} \mathrm{HCOOH}, 700 \mathrm{MHz}$, selected area $\quad 57$

Figure BS18. ${ }^{1} \mathrm{H}-{ }^{1} \mathrm{H}$ COSY NMR of 2 in $\mathrm{CD}_{3} \mathrm{OH}+5 \mu \mathrm{L} \mathrm{HCOOH}, 700 \mathrm{MHz}$, selected area 58

Figure BS19. HSQC NMR of 2 in $\mathrm{CD}_{3} \mathrm{OH}+5 \mu \mathrm{L} \mathrm{HCOOH}, 700 \mathrm{MHz}$, selected area 58

Figure BS20. $\mathrm{HMBC} \mathrm{NMR}$ of 2 in $\mathrm{CD}_{3} \mathrm{OH}+5 \mu \mathrm{L} \mathrm{HCOOH}, 700 \mathrm{MHz}$, selected area 59

Figure BS21. $\mathrm{HMBC} \mathrm{NMR}$ of 2 in $\mathrm{CD}_{3} \mathrm{OH}+5 \mu \mathrm{L} \mathrm{HCOOH}, 700 \mathrm{MHz}$, selected area 59

Figure BS22. TOCSY NMR of 2 in $\mathrm{CD}_{3} \mathrm{OH}+5 \mu \mathrm{L} \mathrm{HCOOH}, 700 \mathrm{MHz}$, selected area 60

Figure BS23. TOCSY NMR of 2 in $\mathrm{CD}_{3} \mathrm{OH}+5 \mu \mathrm{L} \mathrm{HCOOH}, 700 \mathrm{MHz}$, selected area 60

Figure BS24. ROESY NMR of 2 in $\mathrm{CD}_{3} \mathrm{OH}+5 \mu \mathrm{L} \mathrm{HCOOH}, 700 \mathrm{MHz}$, selected area 61

$\begin{array}{ll}\text { Figure BS25. ESI HRMS of paenilarvin B (2) } & 61\end{array}$

Figure BS26: 1H NMR of 3 in DMSO-d6, $700 \mathrm{MHz} \quad 62$ 
Figure BS27. 13C NMR of 3 in DMSO-d6, $176 \mathrm{MHz} \quad 62$

Figure BS28. $1 \mathrm{H}-1 \mathrm{H}$ COSY NMR of 3 in DMSO-d6, selected area 63

Figure BS29. 1H-1H COSY NMR of 3 in DMSO-d6, selected area 63

Figure BS30. HSQC NMR of 3 in DMSO-d6 +5 $\mu \mathrm{L} \mathrm{HCOOH,} 700 \mathrm{MHz}$, selected area 64

Figure BS31. HMBC NMR of 3 in DMSO-d6, $700 \mathrm{MHz}$, selected area 64

Figure BS32. HMBC NMR of 3 in DMSO-d6, $700 \mathrm{MHz}$, selected area 65

Figure BS33. HMBC NMR of 3 in DMSO-d6, $700 \mathrm{MHz}$, selected area $\quad 65$

Figure BS34. HMBC NMR of 3 in DMSO-d6, $700 \mathrm{MHz}$, selected area 66

Figure BS35. TOCSY NMR of 3 in DMSO-d6, $700 \mathrm{MHz}$, selected area 66

Figure BS36. TOCSY NMR of 3 in DMSO-d6, $700 \mathrm{MHz}$, selected area $\quad 67$

Figure BS37. ROESY NMR of 3 in DMSO-d6, $700 \mathrm{MHz}$, selected area $\quad 67$

Figure BS38. ROESY NMR of 3 in DMSO-d6, $700 \mathrm{MHz}$, selected area 68

$\begin{array}{ll}\text { Figure BS39. ESI HRMS of paenilarvin C (3) } & 68\end{array}$

Figure C1. Photographs showing morphology of strain MCy1366T and MCy10622 74

Figure C2. Maximum likelihood phylogenetic tree (PHYML) based on 16S rRNA gene sequences 80

Figure C3. Score-oriented dendrogram showing the similarity of MALDI-TOF mass spectra of cell extracts

Figure CS1. (a) Congo Red staining of 3 week old swarm of strain MCy1366T on VY/2 agar displaying a weak positive reaction (b) Phase contrast microscopic image of vegetative cells of MCy1366T in myxo media (bar, 10 $\mu \mathrm{m}$ ) (c) Lugol's solution staining of 2 week old swarm of strain MCy1366T on $\mathrm{P}$ agar displaying a weak positive reaction

Figure CS2. Neighbor-joining tree based on 16S rRNA gene sequence 95

$\begin{array}{ll}\text { Scheme D1. Natural pyrronazol variants } & 98\end{array}$

Scheme D2. 1-Hydroxy-phenazine-6-yl-a-d-arabinofuranoside (7) 104

$\begin{array}{ll}\text { Scheme D3. Pyrrole antibiotics } & 106\end{array}$

Figure D1. Selected 1H, 13C HMBC (green arrows) and ROESY NMR Correlations (red arrows) of Pyrronazol A (1)

Figure D2. Absolute 4S,5S-Configuration of Pyrronazol A (1) 100

Figure D3. Calculated Solution Conformation of Pyrronazol C1 (4) 104

Figure DS1. ORTEP presentation of the X-ray analysis of Pyrronazol A1 (1) 114

Figure DS2. HMBC-correlations of Pyrronazol A2 (2) 119

$\begin{array}{lr}\text { Figure DS3. HMBC-correlations of Pyrronazol B (3) } & 120\end{array}$

Figure DS4. HMBC-correlations of Pyrronazol C1 (4) 120 
$\begin{array}{ll}\text { Figure DS5. HMBC-correlations of Pyrronazol C2 (5) } & 120\end{array}$

Figure DS6. HMBC- and ROESY correlations of 1-hydroxy-phenazine-6-yl- $\alpha$-d-arabinofuranoside (7) 121

Figure DS7. 1H NMR spectrum of Pyrronazol A (1) in $\mathrm{CDCl}_{3}(400 \mathrm{MHz}) \quad 122$

Figure DS8. 13C NMR spectrum of Pyrronazol A (1) in $\mathrm{CDCl}_{3}(100.6 \mathrm{MHz}) \quad 122$

Figure DS9. 1H NMR spectrum of Pyrronazol A2 (2) in $\mathrm{CDCl}_{3}(600 \mathrm{MHz}) \quad 123$

Figure DS10. 13C NMR spectrum of Pyrronazol A2 (2) in $\mathrm{CDCl}_{3}(100.6 \mathrm{MHz}) \quad 123$

Figure DS11. 1H NMR spectrum of Pyrronazol B (3) in $\mathrm{CDCl}_{3}(400 \mathrm{MHz}) \quad 124$

Figure DS12. 13C NMR spectrum of Pyrronazol B (3) in $\mathrm{CDCl}_{3}(125.8 \mathrm{MHz}) \quad 124$

Figure DS13. 1H NMR spectrum of Pyrronazol C2 (5) in $\mathrm{CDCl}_{3}(300 \mathrm{MHz}) \quad 125$

Figure DS14. 13C NMR spectrum of Pyrronazol C2 (5) in $\mathrm{CDCl}_{3}(75.5 \mathrm{MHz}) \quad 125$

Figure DS15. 1H NMR spectrum of 1-hydroxy-phenazine-6-yl- $\alpha$-d-arabinofuranoside (7) in $\mathrm{CD}_{3} \mathrm{OD} \quad 126$

Figure DS16. 13C NMR spectrum of 1-hydroxy-phenazine-6-yl-a-d-arabinofuranoside (7) in $\mathrm{CD}_{3} \mathrm{OD} \quad 126$

Figure E1. Antifungal activity of crude methanol extract of $P$. larvae ERIC II (DSM 25430) against Mucor hiemalis after HPLC fractionation

Figure E2. Structures of pyrronazols and phorbazoles 134

Figure E3. Structure of Rumbrin 135 


\section{List of Tables}

Table B1. ${ }^{1} \mathrm{H}(700 \mathrm{MHZ})$ and ${ }^{13} \mathrm{C}(175 \mathrm{MHz}) \mathrm{NMR}$ data of paenilarvin $\mathrm{A}(1)$ in $\mathrm{CD}_{3} \mathrm{OH}$

Table B2. Minimum inhibitory concentration (MIC) in $\mu \mathrm{g} / \mathrm{mL}$ of paenilarvin A (1) and B (2) 37

Table C1. Differential characteristics of strain MCy1366T, MCy10622 and their closely related strains

$\begin{array}{ll}\text { Table CS1. Type and neotype strains used in this study } & 87\end{array}$

$\begin{array}{ll}\text { Table CS2. Salt tolerance } & 87\end{array}$

Table CS3. Differential physiological reactions in APIZym tests 88

Table CS4. Antibiotic resistance test for MCy1366T and MCy10622 along with related type $\begin{array}{ll}\text { and neotype strains } & 89\end{array}$

Table CS5. Dry weight biomass $(\mathrm{mg})$ of MCy1366T and MCy10622 obtained in synthetic $\begin{array}{ll}S \text { medium with casitone supplemented with various carbon sources } & 90\end{array}$

Table CS6. Dry weight biomass (mg) of MCy1366T and MCy10622 in minimal casitone (C) medium with various inorganic nitrogen sources, amino acids or peptones sources

Table CS7. Fatty acid analysis of MCy1366T, MCy10622 and closely related type strains $\quad 91$

Table CS8. Dry weight biomass (mg) of MCy1366T and MCy10622 at different pH 94

Table D1. NMR Data of Pyrronazol A1 (1) and A2 (2) 101

Table D2. NMR Data of Pyrronazol B (3) in CDCl3 102

Table D3. NMR-Data of Pyrronazol C1 (4) and C2 (5) in CDCl3b 103

Table D4. In-vitro Antibacterial and Antifungal Activity of Pyrronazol A (1), 1,6-Phenazine-diol (6)

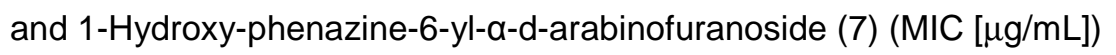

Table D5. Cytotoxicity (LD50 [ $\mu \mathrm{M}]$ ) of Pyrronazol A (1) and 1,6-Phenazine-diol (6) against growing cell lines

Table DS1. Crystal data and structure refinement for Pyrronazol A1 (1)

Table DS2. Atomic Coordinates and Equivalent Isotropic Displacement Parameters for Pyrronazol A1 (1)

Table DS3. Bond lengths $[\AA ̊]$ and angles [ 9 for Pyrr onazol A1 (1)

Table DS4. Anisotropic displacement parameters (Å2×103) for Pyrronazol A1 (1)

Table DS5. Hydrogen coordinates $(\times 104)$ and isotropic displacement parameters (Å2×10 3) for Pyrronazol A1 (1) 


\section{Acknowledgements}

"Feeling gratitude and not expressing it, is like wrapping a gift and not giving it"

William Arthur Ward

It is impossible for any work to come to a conclusion without adding a warm note of thanks to all those special people who have been kind enough to encourage me throughout and to help me in completing this dissertation.

I am deeply indebted to my doctoral advisors, Prof. Dr. Rolf Müller and Prof. Dr. Rolf Daniel for giving me the opportunity to work under their guidance. I am also really thankful to Prof. Dr. Marc Stadler for his stimulating suggestions and encouragement which helped me at all times. I am grateful to them for their continuous support through my tough times and taking out time from their busy schedules for proof reading of my manuscripts and thesis. Their critical questioning, remarks and suggestions proved to be a helpful motivating force which made me think all the time and progress in the right direction.

I would also like to express my gratitude to Dr. Kathrin I. Mohr for immense personal attention, dedication, relentless energy, and optimism which enabled me to bring this dissertation to fruition. I am really thankful for her overwhelming care and affection and I will forever cherish my graduate experience working with her.

I also take this opportunity to express my heartfelt thanks to Dr. Joachim Wink, Dr. Rolf Jansen and Heinrich Steinmetz for giving me a deeper insight into subjects which were new to me like chemistry and taxonomy. Their doors were always open for attending and answering all my naïve queries on various subjects. I am also thankful to them for carefully reading and commenting on various versions of manuscripts and thesis.

I wish to reckon my gratefulness to all the members of Microbial Drugs for their unconditional support and help. I appreciate the support of Diana Telkemeyer, Wera Collisi, Klaus Conrad, Stephanie Schulz and Birte Trunkwalter in all the biological work. Special thanks to Dr. Enge Sudarman, Kerstin Schober, Sabrina Wollpers, Silke Reinecke and Aileen Teichmann for all their help in chemistry lab which was a completely new field for me. I tastefully acknowledge their unparalleled enthusiasm 
demonstrated by the readiness to share the workspace under any circumstances and care and affection, which made research a pleasant experience. I would also like to acknowledge the fermentation team, the mycology team and the G2L team in Göttingen, especially Wolfgang Kessler, Steffen Bernecker, Marvin Djukic, John Vollmers, Sandra Wiegand for always helping me out in lab and administrative procedures.

This acknowledgment is incomplete without acknowledging my friends in HZI, Vinay Pawar, Smita Bhuyan, Abhinay Sharma, Pratibha Gaur with whom research even during the stressful conditions was a pleasant learning experience. I thank them all for providing resourceful suggestions to many aspects during the preparation of the thesis.

Most importantly, I am thankful to my family in India, particularly my parents for their unconditional love, encouragement and unending patience. I would also like to express my heartfelt appreciation to Sriharsha Puranik for his constant belief in me and for being there with me at every step of the way.

Finally, I acknowledge Erasmus Mundus External Cooperation Window for providing great opportunity in the form of Eurlndia fellowships for my PhD. 


\section{Promovierenden-Erklärung der Georg-August-Universität Göttingen}

Name: Sood, Sakshi

Anschrift: Jüdelstraße 13, 38126 Braunschweig

Ich beabsichtige, eine Dissertation zum Thema „Natural products from Myxococcales and Bacillales \& Description of a new myxobacterial taxon" an der Georg-AugustUniversität Göttingen anzufertigen. Dabei werde ich von Herrn Prof. Rolf Daniel und Prof. Rolf Müller betreut.

Ich gebe folgende Erklärung ab:

1. Die Gelegenheit zum vorliegenden Promotionsvorhaben ist mir nicht kommerziell vermittelt worden. Insbesondere habe ich keine Organisation eingeschaltet, die gegen Entgelt Betreuerinnen und Betreuer für die Anfertigung von Dissertationen sucht oder die mir obliegenden Pflichten hinsichtlich der Prüfungsleistungen für mich ganz oder teilweise erledigt.

2. Hilfe Dritter wurde bis jetzt und wird auch künftig nur in wissenschaftlich vertretbarem und prüfungsrechtlich zulässigem Ausmaß in Anspruch genommen. Insbesondere werden alle Teile der Dissertation selbst angefertigt; unzulässige fremde Hilfe habe ich dazu weder unentgeltlich noch entgeltlich entgegengenommen und werde dies auch zukünftig so halten.

3. Die Richtlinien zur Sicherung der guten wissenschaftlichen Praxis an der Universität Göttingen werden von mir beachtet.

4. Eine entsprechende Promotion wurde an keiner anderen Hochschule im In- oder Ausland beantragt; die eingereichte Dissertation oder Teile von ihr wurden nicht für ein anderes Promotionsvorhaben verwendet.

Mir ist bekannt, dass unrichtige Angaben die Zulassung zur Promotion ausschließen bzw. später zum Verfahrensabbruch oder zur Rücknahme des erlangten Grades führen.

Göttingen, 


\section{Curriculum Vitae}

Name: Sakshi Sood

Nationality: Indian

Birth Date: $2^{\text {nd }}$ March, 1987

Email: Sakshi.sood@helmholtz-hzi.de

Sakshisood87@gmail.com

Since 08/2010

08/2009-05/2010

08/2008-05/2010

07/2005-05/2008

$03 / 2008$

\section{Doctorate studies}

Department of Microbial Drugs, Helmholtz Centre for infection Research, Braunschweig, Germany

Department of Genomic and Applied Microbiology \& Göttingen Genomics Laboratory, Institute of Microbiology and Genetics, Georg-August University of Göttingen, Germany

\section{Masters thesis}

"Isolation and characterization of an antibacterial small molecule from a soil bacterium"

Department of Biotechnology, Indian Institute of Technology Roorkee, India

\section{M.Sc. Biotechnology}

Department of Biotechnology, Indian Institute of Technology Roorkee, India

\section{B.Sc. (Hons.) Microbiology}

Department of Microbiology, Institute of Home Economics, University of Delhi, India

\section{High School}

St. Luke's Sen. Sec. School, Solan, India 